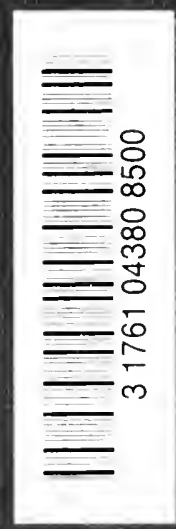

N. 


Digitized by the Internet Archive in 2007 with funding from Microsoft Corporation 
INFANT MORTALITY 

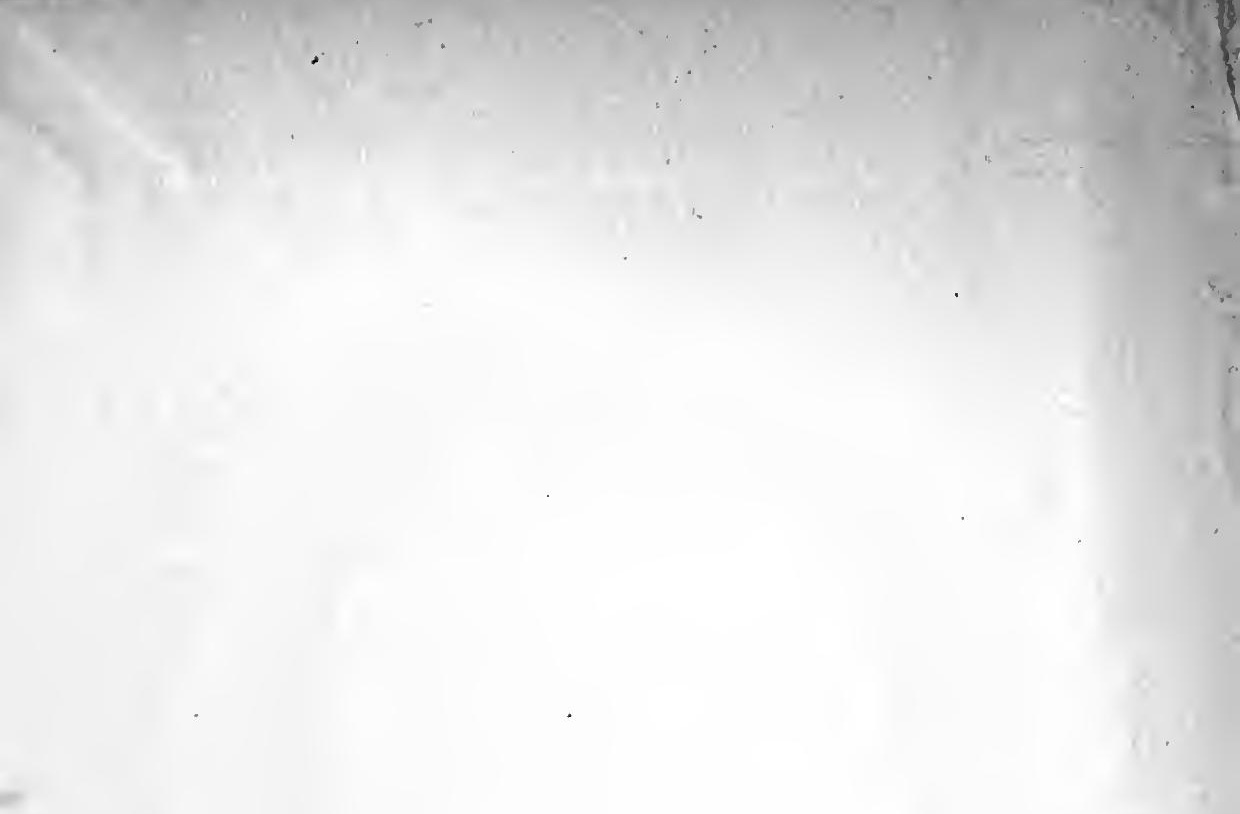

.




\section{INFANT MORTALITY}

\section{A SOCIAL PROBLEM}

BY

(Sir) GEORGE NEW M A N

M.D., D.P.H., F.R.S.E.

IECTURER ON PUBLIC HEALTH AT ST. BARTHOLONEW'S HOSPITAL, LONDON ;

MEDICAL OFFICER OF HEALTH OF METROPOLITAN BOROUGH OF FINSBURY

WITH SIXTEEN DIAGRAMS

NEW YORK

E. P. DUTTON AND COMPANY

3I West TWRnty-thiRd Street

1907

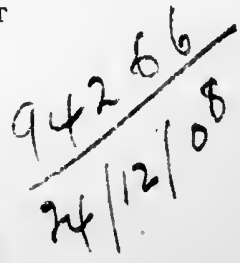





\section{PREFACE}

URING the last five years my work in Finsbury has necessitated a careful study of the problem of infant mortality. This book is part of the outcome. It is an attempt to state in a plain way the chief facts concerning a question which is not without national importance.

The young of all animals are more susceptible than the adult to the influence of environment and the approach of death. Hence, it is inevitable that, even under the most favourable circumstances, the deaths of infants will furnish a large contribution to the bills of mortality. As civilisation advances, however, this should become less. That it does not, in fact, become substantially less is surely a matter calling for consideration, for at the present time there is an annual loss to England and Wales of 120,000 lives by the death of infants. In past years there has been a similar drain upon the national resources of life. But it should not be forgotten that a rapidly declining birth-rate means that this loss of life is now operating in conjunction with a diminished income.

Nor is this all. For it cannot be too distinctly recognised, as Sir John Simon pointed out, that a high infant mortality rate almost necessarily denotes a prevalence of those causes and con- 
ditions which in the long run determine a degeneration of race; and further, that a high death-rate of infants is an indication of the existence of evil conditions in the homes of the people-which are, after all, the vitals of the nation. Poverty is not alone responsible, for in many poor communities the infant mortality is low. Housing and external environment alone do not cause it, for under some of the worst external conditions in the world the evil is absent. It is difficult to escape the conclusion that this loss of infant life is in some way intimately related to the social life of the people.

It only remains for me to add a word of sincere gratitude and appreciation to those who have advised me or furnished me with facts not otherwise obtainable. The reader will soon discover how numerous are those to whom I am indebted, but I must particularly mention my obligations to Dr. Tatham, of the Registrar-General's Office; Dr. Newsholme, of Brighton ; Professor Budin, of Paris ; Dr. Niven, of Manchester; Dr. Robertson, of Birmingham; Dr. Leslie Mackenzie, Medical Member of the Local Government Board for Scotland; and Sir Shirley Murphy, the Medical Officer of Health of the Administrative County of London. It will be understood that the book is of an elementary character only, and it is hoped that it may serve as an introduction to the intricate problem with which it is concerned.

G. $\mathbf{N}$.

LONDON, 1906 


\section{CONTENTS}

CHAPTER PAGE

I. PRESENT POSITION AND INCIDENCE OF INFANT MORTALITY . . . . . . . . I

11. Distribution OF Infant Mortality in Great BRITAIN . . 20

11I. The Fatal Diseases of Infancy . . . 43

IV. ANTE-Natal Influences ON INfant Mortality - 6I

V. The Occupation of Women and Infant Mortality 90

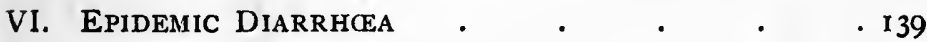

ViI. The Influence of Domestic and Social ConDITIONS . $\quad . \quad$. $\quad . \quad$. 177

VIII. INFANT FeEding and Management . . . $22 \mathrm{I}$

IX. Preventive Methods: (1.) The Mother . . 257

X. Preventive Methods: (II.) The Child . . 278

XI. Preventive Methods : (III.) The Environment · 316

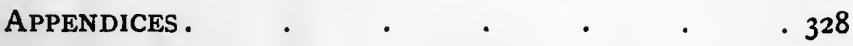

INDEX $\quad \cdot \quad \cdot \quad \cdot \quad \cdot \quad \cdot \quad \cdot \quad \cdot \quad \cdot 352$ 


\section{LIST OF DIAGRAMS}

England and Wales, Showing Infant Mortality in Counties, I845-I854; I87I-I880 ; I 88I-I890; 189I-I900; I90I-I905 . 22

Scotland, Showing Infant MoRTality in Counties $\quad$ • 30

INFANT MORTALITY IN COUNTY OF Bedford • • . . 34

Rise and Fall of Diarrheea Deaths in Three Selected Towns AND Counties, I889-I89I . . . . . . . 4I

ENGLAND AND WALES, $1903 \quad . \quad . \quad . \quad . \quad . \quad . \quad . \quad 46$

FINSBURY, I9O4 $\quad$ •

Infant Deaths From Epidemic DiaRrhasa in PaRis, I898 286

Infant Deaths from Epidemic Diarrhcea in Paris, 1899, 1900

AND IgOI .

Chart A.-Cases I, 2 and 3 . $30 . \quad$. 306

Chart B.-Cases 7 and 8 .

Chart C.-Cases 9 and to $. \quad . \quad . \quad . \quad . \quad . \quad . \quad . \quad 308$

ChaRT D.-CASES II, I2, I3, I4 AND I5 . . . . 312 


\section{INFANT MORTALITY}

\section{PRESENT POSITION AND INCIDENCE OF INFANT MORTALITY}

THE death of infants in relation to a community is 1 gauged by a form of death rate known as the infantile mortality rate. Infants are children under twelve months of age, and the infant mortality rate is the proportion which the deaths of such infants bears to every thousand births. An ordinary death rate is the proportion which the total deaths of a community bears to a thousand of the population in such a community. But it is clear that a more accurate death rate for infants is obtained if we compare the total number of infant deaths not to a thousand of the general population but to a thousand births in the same year. In some places this is a low rate such as 80 per 1,000 births, which means, of course, that for every thousand children born in a year 80 die before they are twelve months old. In other places it is found that this infant mortality rate is high, say 200 or 250 per 1,000 . A low rate, other things being equal, indicates a healthy community, a high rate the reverse. As communal life becomes more healthy and civilised it 
is observed that the ordinary death rate steadily declines, and also the death rate of the more preventable diseases; and acting on that principle it seems reasonable to expect that the infant death rate will follow a similar course.

The first broad fact of importance with regard to this problem, indeed the fact which creates the problem, is that though the general death rate is decreasing the infant mortality rate is not declining. This means that whilst during the last half-century, a time of marvellous growth of science and of preventive medicine, human life has been saved and prolonged, and death made more remote for the general population, infants still die every year much as they did in former times. Indeed, in many places it appears that they die in greater numbers, and more readily than in the past. But a nation grows out of its children ; and if its children die in thousands in infancy it means that the sources of a nation's population are being sapped, and further that the conditions which kill such a large proportion of infants injure many of those which survive. Last year (1905) there was a loss to the nation of 120,000 dead infants in England and Wales alone, a figure which is almost exactly one quarter of all the deaths in England and Wales in that year. That is to say, that one quarter of the total deaths every year is of children under the age of twelve months. And this enormous sacrifice of human life is being repeated year by year, and is not growing less. ${ }^{\mathrm{I}}$

In the following table will be seen the decennial death rates for the whole population and for infants, both in England and Wales and in London. For convenience

I In I903 in England there were 514,628 deaths, of which 124,718 , or 24 per cent., were infants under twelve months of age ; in London there were $70,28 \mathrm{I}$ deaths, of which 24 per cent. were infants. In I904 there were 549,784 deaths, of which 137,392 , or 25 per cent., were infants. 
the number of births per I,000 of the population (the birth rates) are included :-

\begin{tabular}{|c|c|c|c|c|c|c|}
\hline & \multicolumn{3}{|c|}{ ENGLAND AND WaLES. } & \multicolumn{3}{|c|}{ LONDON. } \\
\hline & $\begin{array}{l}\text { Birtb Rate } \\
\text { per I,000 of } \\
\text { Population. }\end{array}$ & $\begin{array}{l}\text { Death Rate } \\
\text { per I,Ooo of } \\
\text { Population. }\end{array}$ & $\begin{array}{c}\text { Infant } \\
\text { Mortality } \\
\text { Rate per } \\
\text { I,ooo of } \\
\text { Population. }\end{array}$ & $\begin{array}{l}\text { Birth Rate } \\
\text { per I,Ooo of } \\
\text { Population. }\end{array}$ & $\begin{array}{l}\text { Death Rate } \\
\text { per } 1,000 \text { of } \\
\text { Population. }\end{array}$ & $\begin{array}{c}\text { Infant } \\
\text { Mortality } \\
\text { Rate per } \\
\text { I,ooo of } \\
\text { Popuiation. }\end{array}$ \\
\hline $\begin{array}{l}185 \mathrm{I}-60 . . \\
1861-70 . . \\
187 \mathrm{I}-80 . . \\
188 \mathrm{I}-90 . . \\
189 \mathrm{I}-1900 \\
190 \mathrm{I}-1905\end{array}$ & $\begin{array}{l}34^{\circ} 1 \\
35^{\circ} 2 \\
35^{\circ} 4 \\
32^{\circ} 5 \\
29^{\circ} 9 \\
28^{\circ} \cdot 4\end{array}$ & $\begin{array}{l}22 \cdot 2 \\
22 \cdot 5 \\
21 \cdot 4 \\
19 \cdot 1 \\
18 \cdot 2 \\
16 \cdot 0\end{array}$ & $\begin{array}{l}\text { I54 } \\
\text { I54 } \\
\text { I49 } \\
\text { I42 } \\
\text { I54 } \\
\text { I38 }\end{array}$ & $\begin{array}{l}33^{\circ} 6 \\
35^{\circ} 4 \\
35^{\circ} 4 \\
33^{\circ} \cdot 2 \\
30^{\circ} \cdot 2 \\
28^{\circ} \cdot 4\end{array}$ & $\begin{array}{l}23 \cdot 7^{2} \\
24 \cdot 4 \\
22 \cdot 5 \\
20 \cdot 5 \\
19 \cdot 6 \\
16.5\end{array}$ & $\begin{array}{l}155 \\
162 \\
158 \\
152 \\
160 \\
141\end{array}$ \\
\hline
\end{tabular}

Now, if we take the present population of England and Wales at 34,000,000 persons we shall realise something of the meaning of this table. A simple calculation gives us nearly a million births every year, more than half a million deaths every year, and out of that half million deaths at least I 20,000 dead infants-a vast army of small human beings that lived but a handful of days. And this series of events, so difficult to make real to the mind, recurs annually.

So much for the actual facts of life and death which the figures, as rates, represent. But the table has other lessons to teach. First, the birth rate is decreasing; for proportionately to the population there were four births less in every thousand persons in 1905 than there were for the same number of persons in $185 \mathrm{I}$. If the birth rate were the same to-day as it was in the middle of last

I From 1832-50 the average infant mortality in England and Wales ivas 153 .

2 From 184I-50 the death rate was 24.8 and the infant mortality rate 157 . 
century there would be every year more than 60,000 additional infants born. ${ }^{\mathrm{I}}$

Secondly, the general death rate is declining, there being 4 deaths per 1,000 less than half a century ago; therefore, whether the whole country be taken or only London, there has been a marked saving of life. Dr. Newsholme expresses it as follows :-

"The general death rate at all ages has declined 14 per cent. among males and 19 per cent. among females between the decennial period $185 \mathrm{I}$ to 1860 , and the quinquennial period 1896 to 1900 , while the infantile mortality has remained stationary. The following table is of interest as showing the portions of life which have enjoyed the greatest decline of death-rate in the two periods under comparison (I851-1860 and I896-1900) :-

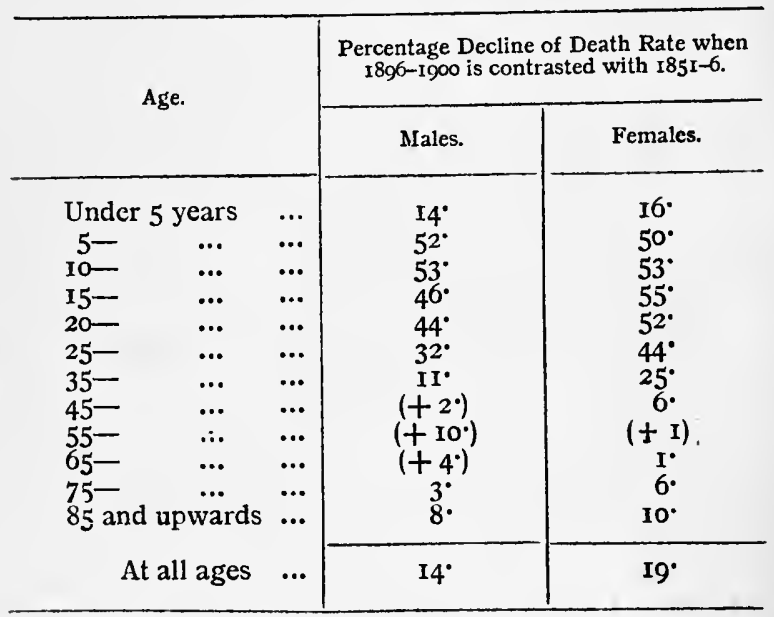

- The Registrar-General states that approximately 70 per cent. of the decrease in the birth rate during the last thirty-five years results from the decreased fertility of married women, which is due in part to changes in their age constitution; that about Io per cent. may be ascribed to the decrease of illegitimacy (which has fallen since $1870-72$ by about 28 per cent.); and that the remaining 20 per cent. is due to the decrease in the 
"Thus, with the exception of ages 45 to 75 among men, and 45 to 55 among women, there has been a great reduction in the death rate from all causes in the aggregate. The greatest reduction of death rate in both sexes has been at ages 5 to 25 , at which ages the average reduction is not far from 50 per cent. At ages 35 to 45 , it is still very considerable, and there is evidence of considerable improvement so far as women over 65 and men over 75 years of age are concerned. At ages under 5 an improvement of 14 to 16 per cent. is shown. As the death rate of infants has not improved, it follows that in children, between $I$ and 5 years of age, the prospects of survival have improved even more than is indicated by the above percentage reductions. The causes of increased death rate in men from 45 to 75 years of age are not far to seek. They are doubtless connected with the increased preponderance of urban life and of indoor occupations, without corresponding sanitary precautions. It is satisfactory to find that when 1871 to 1880 is compared with 1896 to 1900 , there has been a considerable decline of the death rate at these, as well as at other ages, showing that improved conditions of life are being made to overcome, at these ages, the evils associated with increased

proportion of married women in the female population of conceptive ages. Apart from the variations in the physiological, social, and economic conditions of the people, and the greater use of artificial means to secure a restricted fertility, the principal factors that exert an influence on the birth rate are $(a)$ variations in the proportion of women of conceptive ages in the population, $(b)$ variations in the marriage rate, and (c) variations in the age-constitution of married women. Although the number of women of conceptive ages in proportion to the total population has increased in the two last decennia, the proportion of married women aged 15-45 years to the total female population has not materially altered. On the other hand, the marriage rate has fallen continuously since 1871 , and the marriage age has been postponed, thus curtailing the period within which children can be born. During the last thirty years the actual rate of reproduction in the towns was some 15 to 18 per cent. greater than the rate in country districts, but the relative fertility of women living in the country was about ro per cent. greater than that of women residing in towns. (See Sixty-Seventh Ann. Rep. of RegistrarGeneral, 1904, pp. xviii.-xxv.). 
aggregation of communities in towns. But in infancy it is otherwise. The infantile population has not shared in the general improvement at other ages." I

The third fact is that which has already been stated. There has been no change in the infant death rate. In England and Wales it is stationary, and this notwithstanding the fact that there has been an enormous improvement in sanitation and in the standard of comfort of the people. Such improvements have had a direct influence on the total death rate. Further, they have also exerted, as we shall see, a direct and favourable effect on some of the diseases of infants. Yet the deaths of infants still continue at the old high rate, one in six dying before it is twelve months of age.

\begin{tabular}{|c|c|c|c|c|c|c|c|c|}
\hline & & \multicolumn{2}{|c|}{ BIRTH RATE. } & \multicolumn{2}{|c|}{ Death Rate. } & \multicolumn{3}{|c|}{ INFANT MORTALITY RATE. } \\
\hline & & $1883-92$. & $1893-02$. & $1883-92$ & 1893-02. & $1883-92$. & $1893-02$. & 1903. \\
\hline \multicolumn{2}{|c|}{ England \& Wales } & $3 \mathrm{I} \cdot 9$ & $29 \cdot 3$ & $18 \cdot 9$ & $17 \cdot 6$ & I44 & 152 & 132 \\
\hline Scotland & ... & $3 \mathrm{r} \cdot 8$ & 29.9 & $19 \cdot 2$ & r $8 \cdot 0$ & 120 & 127 & - \\
\hline Denmark & $\ldots$ & $3 I \cdot 6$ & $29^{\circ} 9$ & I $8 \cdot 7$ & $16 \cdot 5$ & I35 & I33 & - \\
\hline Russia ... & ... & $48 \cdot 4$ & $48 \cdot 8^{2}$ & $34 \cdot 6$ & $32 \cdot 9^{2}$ & 270 & $272^{3}$ & - \\
\hline Germany & $\ldots$ & $36 \cdot 6$ & $35^{\circ} 9$ & 2477 & $2 \mathrm{I} \cdot 5$ & - & $195^{4}$ & - \\
\hline Prussia ... & ... & $37 \cdot 2$ & $36 \cdot 5$ & $24^{\circ} 2$ & $2 I \cdot 2$ & $207^{8}$ & 199 & I94 \\
\hline Austria ... & ... & $37 \cdot 7$ & $37 \cdot 2$ & $29^{\circ} \mathrm{I}$ & $25^{\circ} 9$ & - & $227^{5}$ & - \\
\hline Hungary & $\ldots$ & $45^{\circ} 5$ & 39.9 & $32 \cdot 3$ & $26 \cdot 3$ & - & 224 & 212 \\
\hline Netherlands & $\ldots$ & 33.7 & $32 \cdot 3$ & $20 \% 9$ & $18 \cdot 5$ & 176 & 152 & $\mathrm{r} 35$ \\
\hline Belgium... & ... & $29 \cdot 8$ & 28.9 & $20 \% 7$ & $18 \cdot 3$ & $161^{9}$ & 157 & 155 \\
\hline France ... & ... & 23.4 & $22 \cdot 0$ & $22 \cdot 2$ & $20 \cdot 8$ & 167 & $x$ & - \\
\hline Spain ... & ... & $36: 0$ & $34 \cdot 7$ & $3 x \cdot 9$ & $28 \cdot 7$ & - & $190^{6}$ & - \\
\hline Switzerland & ... & $27 \cdot 8$ & $28 \cdot 2$ & $20 \cdot 3$ & $18 \cdot 5$ & $160^{10}$ & 145 & I33 \\
\hline Italy $\quad \ldots$ & ... & $37 \cdot 5$ & $34 \cdot 2$ & 26.9 & $23 \cdot 3$ & $209^{11}$ & I73 & - \\
\hline Chili & ... & $35^{\circ} 7$ & 35.5 & $32 \cdot 7$ & 29.8 & $297^{7}$ & 333 & $35^{2}$ \\
\hline
\end{tabular}

In making comparison of infant mortality rates in various countries it is necessary to remember the varying significance of still-born infants.

I Practitioner, Oct., I905, pp. 489-509.

2 1893-99.

3 1890-99. From $1867-78$ Russian infant mortality was 266 (Bertillon).

5 I895-1900. From $1866-83$
6 I900-2. (Bertillon).

8 It was the same figure $1874-82$ (Bertillon).

9 In Belgium from $1867-83$ it was 148 (Bertillon).

so From $1869-80$ it was 195 .

7 I885-92.

I I872-8.2 
Nor is England alone. We have not the same complete statistical return in other countries as we have for the United Kingdom. But such returns as are available (see preceding page) tell the same story. (See Appendix, p. 328 , for returns for 1904.)

The birth rate is declining in civilised nations with few exceptions ; the same may be said of the death rate. But the infant mortality rate, as a rule, is stationary or even increasing. In the Australian Commonwealth, New Zealand, Ireland, Norway and Sweden, the Netherlands, Switzerland and Denmark it shows signs of decreasing, and in several of these last-named countries the death rate of infants falls to a comparatively low figure. In Ireland it is 96, in Norway 94, and in New Zealand it stands at the proud figure of $8 \mathrm{I}$. But these are the exceptions. In foreign countries as a rule, the infant mortality rate is higher than in Great Britain, and in some countries, as Austria, Russia, and Chili, it reaches extremely high figures. ${ }^{x}$

I The following figures enable a comparison to be made between the infant mortality of several European countries for each sex :-

\begin{tabular}{|c|c|c|c|c|c|c|c|c|}
\hline \multirow{4}{*}{ COUNTRY. } & & \multicolumn{3}{|c|}{ FROM RETURNS. } & \multicolumn{4}{|c|}{ FROM LIFE TABLES. } \\
\hline & & \multirow{2}{*}{\multicolumn{2}{|c|}{$\begin{array}{l}\text { In } r, 000 \text { Births, } \\
\text { Deaths in first } \\
\text { Year. }\end{array}$}} & \multirow{3}{*}{$\begin{array}{c}\begin{array}{c}\text { Boys } \\
\text { born } \\
\text { Alive, } \\
\text { per 1,000 } \\
\text { Girls. }\end{array} \\
\text { I894. }\end{array}$} & \multirow{2}{*}{\multicolumn{2}{|c|}{$\begin{array}{c}\begin{array}{c}\text { Annual Deaths } \\
\text { per } 1,000 .\end{array} \\
\text { Under I Year. }\end{array}$}} & \multirow{2}{*}{\multicolumn{2}{|c|}{$\begin{array}{c}\text { Mean After-life } \\
\text { in Years. }\end{array}$}} \\
\hline & & & & & & & & \\
\hline & & $1874-83$. & I884-93. & & Boys. & Girls. & M. & F. \\
\hline Sweden ... & ... & 128 & 107 & 1,050 & $I_{4} \mathrm{I}$ & II9 & $45 \cdot 3$ & $48 \cdot 6$ \\
\hline Norway ... & ... & 104 & 96 & $1,05^{8}$ & II3 & 96 & 474 & $49^{\circ} 9$ \\
\hline Denmark & ... & I4I & I36 & 1,048 & 147 & 124 & $45^{\circ} 6$ & $47^{\circ} 4$ \\
\hline England ... & ... & I44 & I 46 & I,039 & x6I & $13 \mathrm{I}$ & 437 & $47^{\prime} 2$ \\
\hline Holland ... & $\ldots$ & 204 & I74 & 1,055 & I97 & 165 & 42.5 & $45^{\circ} \mathrm{O}$ \\
\hline France ... & $\ldots$ & I65 & 168 & 1,046 & 198 & 167 & 40.8 & 43.4 \\
\hline Italy $\quad \ldots$ & ... & 208 & I90 & $1,05^{8}$ & 213 & I93 & $35^{\circ} \mathrm{I}$ & 35.4 \\
\hline Prussia ... & $\ldots$ & 216 & 207 & 1,052 & 221 & 189 & $39^{\circ} 0$ & $42 \cdot 2$ \\
\hline Saxony ... & $\ldots$ & 284 & 282 & 1,050 & 303 & $25^{8}$ & $34^{.6}$ & $38 \cdot 5$ \\
\hline
\end{tabular}

It may be added that in the tropics infant mortality rates are, as a rule, 
We may consider in more detail the Australian Com-

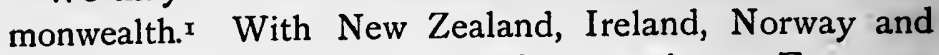
Sweden, it affords the grand exception. For convenience these countries may be tabulated together as follows :-

\begin{tabular}{|c|c|c|c|c|c|c|c|c|}
\hline & & \multicolumn{2}{|c|}{ BIRTH RATES. } & \multicolumn{2}{|c|}{ DEATH Rates. } & \multicolumn{3}{|c|}{ INFANT MORTALITY. } \\
\hline & & $1883-92$ & 1893-02. & $1883-92$. & $1893-02$. & $1883-92$. & $1893-02$. & 1903. \\
\hline \multicolumn{2}{|c|}{$\begin{array}{l}\text { AUSTRALIAN COM- } \\
\text { MONWEALTH- }\end{array}$} & & & & & & & \\
\hline N. S. Wales & $\ldots$ & $36 \cdot 4$ & $29^{\circ} 0$ & I4.2 & $12^{\circ} \mathrm{O}$ & 117 & III & I Io \\
\hline Victoria & $\ldots$ & $32 \cdot 2$ & $27^{\circ} 0$ & $15 \cdot 3$ & 13.5 & 122 & 109 & 106 \\
\hline Queensland & $\ldots$ & $36 \cdot 9$ & 300 & $16 \cdot 2$ & $12^{\circ} \mathrm{O}$ & 123 & 103 & 120 \\
\hline S: Australia & $\ldots$ & $35 \cdot 6$ & $27 \cdot 8$ & I3. I & II'9 & $103^{2}$ & 106 & 97 \\
\hline W. Australia & $\ldots$ & 35.5 & $28 \cdot 8$ & I $7 \cdot I$ & $15^{\circ} 0$ & $125^{3}$ & 146 & $14 \mathrm{I}$ \\
\hline Tasmania & $\cdots$ & $34^{\circ} 6$ & $29 \cdot 5$ & $15 \cdot 3$ & I $2 \cdot I$ & 104 & 93 & $\overline{0}$ \\
\hline New Zealand & $\ldots$ & $3 \mathrm{I} \cdot 9$ & $26 \cdot 2$ & $10 \cdot 2$ & $9 \cdot 8$ & 87 & 82 & $8 I^{4}$ \\
\hline Norway ... & $\cdots$ & 30.6 & $30^{\circ} \mathrm{I}$ & $160^{\circ}$ & $15^{\circ} 6$ & 97 & 94 & - \\
\hline Sweden ... & ... & $28 \cdot 7$ & $26 \cdot 9$ & I6.9 & I6.0 & 108 & 99 & 二 \\
\hline Ireland $\ldots$ & $\cdots$ & $23^{\circ} 0$ & $23^{\circ} I$ & I8. & I8*o & 96 & 104 & 96 \\
\hline
\end{tabular}

The birth rate and the infant mortality rate were, with few exceptions, slightly higher throughout from $1871-83$.

\section{If we compare the figures of the infant mortality rate in} the above table with similar returns for New South Wales

higher than in temperate climates. In India they vary enormously, being in few districts as low as 200 , and in some regions rising to 400 per 1,000 births. In the Malay States the infant mortality is usually about one-third of the total births. In . Fiji and Sierra Leone it is somewhat higher. In British Guiana the still-births are usually above ro per cent. for the whole colony, and higher in Georgetown. The infant mortality is rarely below 200. A marked rise in mortality usually occurs about the ninth day of life, due to trisnuts neonatorum. Sometimes as much as 9 or 10 per cent. of all children born alive die within twenty-four hours. Prematurity, dietetic diseases, pulmonary conditions, and malarial diseases are the chief causes of infant mortality in the tropics. Owing to absence of accurate statistics it is impossible to compare the mortality of infants in the tropics with the United Kingdom. (See Trans. of Epidem. Society of London, I902, vol. xxi. p. 90. Daniels.)

I See also Appendix, p. 328.

2 I885-92. From I88I-85 it was 134 , and in the decennium $187 \mathrm{I}-80,149$.

3 I886-92.

4 In 1904 the rate was 71 , to which it had fallen from 107 in $1871-75$. 
and Victoria and with the chief town in each Colony, we obtain the following result :-

\begin{tabular}{c|c|c|c|c|c|c}
\hline & $\begin{array}{c}\text { New } \\
\text { Zealand. }\end{array}$ & Wellington. & $\begin{array}{c}\text { New South } \\
\text { Wales. }\end{array}$ & Sydney. & Victoria. & M elbourne. \\
\hline 1899 & $95 \cdot 9$ & $117 \cdot 9$ & $118 \cdot 7$ & $120 \cdot 4$ & $110 \cdot 9$ & $124 \cdot 8$ \\
1900 & $75 \cdot 2$ & $73 \cdot 2$ & $103 \cdot 3$ & $109 \cdot 0$ & $95 \cdot 3$ & $113 \cdot 0$ \\
1901 & $76 \cdot 3$ & $100 \cdot 3$ & $103 \cdot 7$ & $120 \cdot 4$ & $102 \cdot 9$ & $124 \cdot 1$ \\
1902 & $82 \cdot 9$ & $130 \cdot 2$ & $109 \cdot 7$ & $112 \cdot 1$ & $108 \cdot 6$ & $127 \cdot 2$ \\
1903 & $81 \cdot 1$ & $92 \cdot 8$ & $110 \cdot 4$ & $116 \cdot 3$ & $106 \cdot 4$ & $124 \cdot 3$ \\
\hline Mean & $82 \cdot 3$ & $102 \cdot 9$ & $109 \cdot 2$ & $115 \cdot 6$ & $104 \cdot 8$ & $122 \cdot 7$ \\
\hline
\end{tabular}

Thus it appears that even in communities where the infant mortality rate is comparatively low it is, with few exceptions, stationary, and tends to rise in urban districts. It will be necessary to consider this latter point subsequently.

\section{NEW ZEALAND.}

Deaths of Infants under One Year, and Proportion to Births.

\begin{tabular}{|c|c|c|c|c|c|c|c|c|c|}
\hline & \multirow[b]{2}{*}{ Year. } & \multirow[b]{2}{*}{, } & \multicolumn{5}{|c|}{$\begin{array}{c}\text { Deaths of Infants under I Year of Age. } \\
\text { (Totals for each Year, and Means of Io Years.) }\end{array}$} & \multirow{2}{*}{$\begin{array}{c}\text { Total } \\
\text { Births } \\
\text { registered } \\
\text { in each } \\
\text { Year, and } \\
\text { Mean of } \\
\text { Io Years. }\end{array}$} & \multirow{2}{*}{$\begin{array}{l}\text { Proportion } \\
\text { of Deaths } \\
\text { of Infants } \\
\text { under } \\
\text { I Year to } \\
\text { every } \\
\text { I,ooo } \\
\text { Births. }\end{array}$} \\
\hline & & & 总意 & 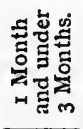 & 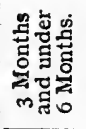 & 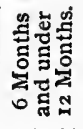 & 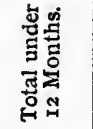 & & \\
\hline 1895 & ... & ... & 575 & 333 & 329 & 400 & 1,637 & 18,546 & $88 \cdot 3$ \\
\hline $\mathbf{I}$ & ... & ... & 566 & 229 & 304 & 340 & 1,439 & 18,612 & $77 \cdot 3$ \\
\hline 1897 & $\ldots$ & $\ldots$ & 512 & 240 & 269 & 333 & $\mathrm{I}, 354$ & $\mathbf{1 8 , 7 3 7}$ & $72 \cdot 3$ \\
\hline 1898 & ... & ... & 573 & 289 & 306 & 342 & 1,510 & 18,955 & 79.7 \\
\hline 1899 & ... & $\ldots$ & 619 & 389 & 378 & 420 & 1,806 & 18,835 & $95 \% 9$ \\
\hline 1900 & $\ldots$ & $\ldots$ & 607 & 288 & 293 & $28 I$ & 1,469 & 19,546 & $75 \cdot 2$ \\
\hline 1901 & ... & ... & 6ro & 272 & 392 & 289 & 1,563 & 20,49 I & $76 \cdot 3$ \\
\hline 1902 & $\ldots$ & $\ldots$ & 665 & 344 & 313 & 390 & 1,712 & 20,655 & 82.9 \\
\hline 1903 & $\ldots$ & $\ldots$ & 692 & 346 & 367 & 365 & 1,770 & $2 \mathrm{I}, 829$ & $8 \mathrm{I} \cdot \mathrm{I}$ \\
\hline 1904 & ... & ... & 669 & 260 & 356 & 321 & I,6 16 & 22,766 & $7 x \cdot 0$ \\
\hline \multicolumn{3}{|c|}{ Means of ten years } & 609 & 299 & $33 \mathrm{I}$ & 349 & 1,588 & I9,897 & $80^{\circ} 0$ \\
\hline
\end{tabular}

Note.-The total number of deaths of infants for the period included in the table is 15,876 . 
New Zealand furnishes the lowest national infant mortality rate, and it will be convenient to look somewhat more closely at its return. In the Fifth Annual Report of Dr. Malcolm Mason, the Chief Health Officer of the Colony, for 1904, it is pointed out that 79 out of every 1,000 male children born and 62 of every 1,000 female children are found to have died before attaining the age of twelve months. The mortality is thus one in thirteen for boys and one in sixteen for girls, and the total infant mortality during the last decennium (1895I904) is 80 per I,000 births. In 1904 it fell to the almost ideal figure of $7 \mathrm{I}$. The infant deaths since 1895 may be set out as in table at foot of p. 9.

The above table is interesting not only as exhibiting a low and declining infant mortality rate, but for the revelation it yields as to the age incidence of death within the twelve months of infancy. If the number of deaths in each trimester, or three-month period, be turned into percentages on total infant deaths, it will become clear that not only is there a marked incidence of death on infants but on infants within the first months of life:-

NEW ZEALAND.

\begin{tabular}{cc|c|c|c|c} 
& & \multicolumn{4}{|c}{$\begin{array}{c}\text { Deaths of Infants in Months. } \\
\text { Yercentage on Total Infant Deaths. }\end{array}$} \\
\cline { 3 - 6 } & & $0-1$ & $0-3$ & $3-6$ & $6-12$ \\
\hline 1895 & $\ldots$ & 35 & 55 & 20 & 25 \\
1896 & $\ldots$ & 38 & 53 & 21 & 26 \\
1897 & $\ldots$ & 37 & 54 & 19 & 27 \\
1898 & $\ldots$ & 37 & 56 & 20 & 24 \\
1899 & $\ldots$ & 34 & 55 & 20 & 25 \\
1900 & $\ldots$ & 41 & 60 & 19 & 21 \\
1901 & $\ldots$ & 39 & 56 & 25 & 19 \\
1902 & $\ldots$ & 39 & 59 & 19 & 22 \\
1903 & $\ldots$ & 39 & 58 & 20 & 22 \\
1904 & $\ldots$ & 41 & 57 & 22 & 21 \\
\hline
\end{tabular}


This is a very interesting but in no way exceptional result. In England and Wales in 1904, the latest available figures, there were 137,392 deaths of infants, of whom $67,02 \mathrm{I}$ died in the first trimester, 28,478 in the second, and $4 \mathrm{I}, 893$ in the last six months. This yields a percentage in the first trimester of 49 , in the second $2 \mathrm{I}$, and in the last two trimesters 30 . In London in the same year the percentages were 47 in the first trimester, 21 in the second, and 32 in the last six months. ${ }^{x}$

If now we go a step further and take the first month of the twelve-let us say for New Zealand-it will be seen that a higher percentage of infants die in that month than in any other month, or indeed in any trimester of the twelve, excluding the first month. And the same has been shown to be the case in this country for many years past. Dr. Farr pointed this out in 1864 in the following table of the Annual Rate Mortality per cent. at each month in first year ${ }^{2}:-$

\begin{tabular}{|c|c|c|c|}
\hline Age in Months. & Boys. & Girls. & Total. \\
\hline $0-1$ & $64 \cdot 50$ & $49 \cdot 45$ & $57 \cdot 13$ \\
\hline I- & 24.09 & 19.50 & $2 I \cdot 83$ \\
\hline $2-$ & $17 \cdot 18$ & I 4 . I9 & 1571 \\
\hline $3^{-}$ & $14^{\circ} 42$ & II'9I & $13 \cdot 18$ \\
\hline $4-$ & I3.86 & II'30 & $12 \cdot 60$ \\
\hline 5 & I3.29 & 10.76 & 12.05 \\
\hline 6 & 1271 & 10.27 & II.50 \\
\hline $7-$ & I2. II & 9.84 & $10 \% 99$ \\
\hline $8-$ & II' 50 & 9.48 & 10.50 \\
\hline $9-$ & 10.86 & $9 \cdot 18$ & 10.03 \\
\hline Io- & 10.22 & $8 \cdot 93$ & $9 \cdot 5^{8}$ \\
\hline I I- & $9 \cdot 56$ & $8 \cdot 75$ & $9 \cdot 16$ \\
\hline
\end{tabular}

These figures are to all intent and purpose "a lifetable." It will be observed that the rate of mortality

I Sixty-seventh Annual Report of the Registrar-General, I904, pp. 142-I43 and $160-161$.

${ }^{2}$ Decennial Supplement of Registrar-General, I85I-60, p. vii. 
rapidly declines from month to month, and that the mortality of boys in every month exceeds that of girls, so that at the end of the first year the number of boys does not greatly exceed the number of girls. In France the mortality of infants was such that in 1856 the rate was I 54 per cent. per annum (on children born) in the first seven days of life, I20 in the second week, and 54 in the sixteen days following.

In the report of the decenniad following a further table was issued revealing a similar condition of things, except that children under 5 years of age were grouped together and compared with the rest of the population. It was there shown that over a period of 34 years (1838-1871) the male children under 5 had a percentage mortality of $7 \cdot 26$, and the female children $6 \cdot 27$ compared with an average percentage mortality of 2.3 and 2.1 respectively at all ages. Nor were these figures of $7 \cdot 2$ and $6 \cdot 2$ respectively approached again until age periods beyond 75 years. ${ }^{x}$

If, bearing this incidence in mind, we make comparisons between the present time and the past, we shall find not only that the fatal incidence falls upon the first months, but that it falls there in ever-increasing proportion. This point is clearly brought out by Dr. Sykes of St. Pancras, where he has compared the infant mortality rates of 1876 with those of I90I at each of the four trimesters in the first year of life. ${ }^{2}$ The results are as follows :-

\begin{tabular}{c|c|c|c|c}
\hline Year. & $0-3$ & $3-6$ & $6-9$ & $9-12$ \\
\hline 1876 & $68 \cdot 1$ & $32 \cdot 2$ & $25 \cdot 3$ & $26 \cdot 8$ \\
1901 & $76 \cdot 5$ & $33 \cdot 1$ & $24 \cdot 3$ & $20 \cdot 8$ \\
\hline Total & +8.4 & +0.9 & $-1 \cdot 0$ & $-6 \cdot 0$ \\
\hline
\end{tabular}

Decennial Supplement of Registrar-General, 186i-70, p. xxvi.

2 Special Report on Infantile Mortality, 1904, p. 8. 
This, however, is only for one year. But since 1888 the Registrar-General has furnished returns of infant deaths in three periods of the first and second three months and the last six months of the first year, which, as Dr. Sykes points out, yield a like return. ${ }^{x}$

\begin{tabular}{|c|c|c|c|c|c|c|c|c|}
\hline \multicolumn{5}{|c|}{ ENGLaNd aNd WaLES. } & \multicolumn{4}{|c|}{ LONDON. } \\
\hline Years. & $0-3$ & $3-6$ & $6-12$ & One Year. & $0-3$ & $3-6$ & $6-12$ & One Year \\
\hline $1888-1892$ & $70 \cdot 5$ & $29 \cdot 5$ & $45^{\circ} 4$ & $145^{\circ} 4$ & $69^{\circ} I$ & $3 I \cdot 6$ & $50 \% 7$ & $\mathrm{I}_{5} \mathrm{I}_{4} 4$ \\
\hline $1893-1897$ & 7377 & $32 \cdot 0$ & 47.7 & 153.4 & $73 \cdot 5$ & $33 \cdot 8$ & $5 I \cdot 3$ & $158 \cdot 7$ \\
\hline I898-I90I & $75{ }^{\prime} 3$ & $3 I \cdot 2$ & $48 \cdot 0$ & $154 \cdot 5$ & 74.5 & $34^{\circ} 9$ & $5 I^{\prime} 6$ & $16 I \cdot 0$ \\
\hline
\end{tabular}

- Similar returns are available for Manchester and Glasgow. In the former city there has been a steady though not a marked increase of infant deaths in the first three months. In 189542 per cent. of all the infant deaths occurred in the first trimester, but in 190445 per cent., and in 190549 per cent. In Glasgow the infant mortality rate for $1870-72$ and I900-2 in the first trimester are the same, namely, 72, but there has been a marked decline in the second trimester and the last six months of the first year of life. The comparative figures, which are full of interest, are as follows :-

\section{GLASGOW.}

Infant MoRtality Rate at Several Monthly Periods, I870-1902.

\begin{tabular}{|c|c|c|c|c|c|c|c|}
\hline \multicolumn{4}{|c|}{ Period. } & \multirow{2}{*}{$\begin{array}{c}\begin{array}{c}0-3 \\
\text { Months. }\end{array} \\
72 \\
65 \\
70 \\
72\end{array}$} & \multirow{2}{*}{$\begin{array}{c}\begin{array}{c}3-6 \\
\text { Months. }\end{array} \\
31 \\
25 \\
25 \\
26\end{array}$} & \multirow{2}{*}{$\begin{array}{c}\begin{array}{c}6-12 \\
\text { Months. }\end{array} \\
67 \\
5^{8} \\
54 \\
47\end{array}$} & \multirow{2}{*}{$\begin{array}{l}\text { Total. } \\
\text { I70 } \\
148 \\
149 \\
145\end{array}$} \\
\hline $\begin{array}{l}1870-72 \\
1880-82 \\
1890-92 \\
1900-02\end{array}$ & $\begin{array}{l}\ldots \\
\ldots . \\
\cdots \\
\cdots\end{array}$ & $\begin{array}{l}\ldots \\
\ldots \\
\cdots \\
\ldots\end{array}$ & $\begin{array}{l}\ldots \\
\ldots \\
\ldots \\
\ldots\end{array}$ & & & & \\
\hline \multicolumn{4}{|c|}{$\begin{array}{r}\text { Percentage reduction, } \\
1870-72 \text { and } 1900-2\end{array}$} & - & -16 & -30 & -15 \\
\hline
\end{tabular}

Thus a reduction of 15 per cent. in the total infant mortality resolves itself into a reduction of 30 per cent. in the last six months, 16 per cent. in the second three months, and an almost stationary rate in the first three months of life. (Public Health, Ig06, vol. xviii., No. 7, p. 423.) 
These comparisons have the disadvantage that they do not take us far enough back.

The following table of infant mortality rates per 1,000 births has been drawn up for London :-

\begin{tabular}{|c|c|c|c|c|c|c|c|}
\hline Years. & $\begin{array}{l}\text { No. of } \\
\text { Deaths. } \\
0-3\end{array}$ & $\begin{array}{l}\text { Infant } \\
\text { Death } \\
\text { Rate. }\end{array}$ & $\begin{array}{c}\text { No. of } \\
\text { Deaths. } \\
3^{-6}\end{array}$ & $\begin{array}{l}\text { Infant } \\
\text { Death } \\
\text { Rate. }\end{array}$ & $\begin{array}{c}\text { No. of } \\
\text { Deaths. } \\
6-12\end{array}$ & $\begin{array}{l}\text { Infant } \\
\text { Death } \\
\text { Rate. }\end{array}$ & $\begin{array}{c}\text { Total } \\
\text { Infant } \\
\text { Death } \\
\text { Rate. }\end{array}$ \\
\hline I839-44 & 24,354 & 68 & 12,507 & 35 & 20,940 & 59 & 162 \\
\hline I898-I903 & 56,963 & 72 & 25,457 & 32 & 38,306 & 48 & 152 \\
\hline $\begin{array}{c}\text { Per- } \\
\text { centage } \\
\text { Increase } \\
\text { or } \\
\text { Decrease }\end{array}$ & & $+5 \cdot 5$ & & $-8 \cdot 5$ & & -16.9 & \\
\hline
\end{tabular}

This furnishes a comparison across sixty years for the whole of London. In I 839-44 the infants' deaths contributed 20 per centage of the deaths of all persons. Sixty years later that ratio had increased to 25 per cent., which was in itself an increase of 25 per cent. on the 1839-44 returns. Further, the infant mortality rate under three months of age at the end of the sixty years show a 5 per cent. increase over the former period, even on a lower total rate. Nothing could show more clearly the broad changes which have been taking place than these figures.

The general deductions to be drawn from all these figures are clear. In the first place the chief fatality of the first year is not uniformly distributed, but falls in the first three months. Secondly, the change that has been taking place and which is so well illustrated in the comparative figures in the above tables, is that there has been an increase in the deaths in the first trimester, accompanied by a 
decrease, or at least an almost stationary position, in the last two trimesters of the first year of life. The St. Pancras figures show a fall in the last quarter of 6 per 1,000 , and a rise in the first quarter of 8.4 per 1,000 . In the returns for England and Wales and for London we see that the total infant mortality has increased on the whole twelve months, but more so in the first half than the second, and more so in the first trimester than in the second. The returns for London (1839-1903) and for Manchester and Glasgow speak for themselves of the increased incidence on the first three months, or the decrease in the later months. Thirdly, when the returns of the first quarter and of the first month are examined it will be found that within the first quarter the rise has been almost wholly in the first month and within the first month almost wholly in the first week. These changes indicate what Dr. Sykes calls "an inçreased immaturity of infants at birth." The connotation of which phrase means that infants die more from immaturity (premature birth) at the present time than formerly, and therefore more of the survivors start life handicapped by immaturity than formerly. In other words, infants are dying earlier and earlier, and therefore the cause of death whatever it be is operating on the survivors at the commencement of life, which renders them more susceptible to unfavourable influences in later years. What those causes and conditions are it will be necessary to consider subsequently.

One further purely statistical point remains. It has relation to the infant mortality rate of legitimate as compared with illegitimate infants, or children born out of wedlock. Dr. Tatham has drawn up tables for the year 1902 to show the facts in regard to this matter, $\mathrm{I}$ and brief

- Report of Interdepart. Com. on Physical Deterioration, I904, vol. i. pp. $133-136$. 
reference must now be made to his summary of infant deaths per 1,000 births at the several age periods under one year. For comparative purposes he selected London as an example of urban environment (with not less than I 30,000 births) and certain counties of England as rural environment I (with not less than 100,000 births).

\begin{tabular}{|c|c|c|c|c|c|c|c|c|}
\hline & \multicolumn{4}{|c|}{ LoNDON. } & \multicolumn{4}{|c|}{ RURAL COUNTIES. } \\
\hline & \multicolumn{2}{|c|}{ Males. } & \multicolumn{2}{|c|}{ Females. } & \multicolumn{2}{|c|}{ Males. } & \multicolumn{2}{|c|}{ Females. } \\
\hline & $\begin{array}{l}\text { Legiti- } \\
\text { mate. }\end{array}$ & $\begin{array}{l}\text { Illegiti- } \\
\text { mate. }\end{array}$ & $\begin{array}{l}\text { Legiti- } \\
\text { mate. }\end{array}$ & $\begin{array}{l}\text { Illegiti- } \\
\text { mate. }\end{array}$ & $\begin{array}{l}\text { Legiti- } \\
\text { mate. }\end{array}$ & $\begin{array}{l}\text { Illegiti- } \\
\text { mate. }\end{array}$ & $\begin{array}{l}\text { Legiti- } \\
\text { mate. }\end{array}$ & $\begin{array}{l}\text { Illegiti- } \\
\text { mate. }\end{array}$ \\
\hline $\begin{array}{ll}\text { Under I week } & \ldots \\
\text { I-2 weeks } & \ldots \\
2-3 \text { weeks } & \ldots \\
3-4 \text { weeks } & \ldots\end{array}$ & $\begin{array}{r}27 \cdot 8 \\
7 \cdot 1 \\
6 \cdot 8 \\
5 \cdot 0\end{array}$ & $\begin{array}{l}4 I \cdot 9 \\
\text { IO } \cdot 9 \\
\text { II } \cdot 8 \\
\text { II } \cdot 3\end{array}$ & $\begin{array}{r}\text { I8.8 } \\
5 \cdot I \\
5 \cdot 3 \\
5 \cdot 0\end{array}$ & $\begin{array}{r}42 \cdot 8 \\
12 \cdot I \\
8 \cdot 6 \\
5 \cdot 6\end{array}$ & $\begin{array}{r}29 \cdot 1 \\
6 \cdot 4 \\
5 \cdot 7 \\
4 \cdot 6\end{array}$ & $\begin{array}{r}39 \cdot 6 \\
13 \cdot 4 \\
9 \cdot 2 \\
7 \cdot 4\end{array}$ & $\begin{array}{r}21 \cdot 5 \\
4 \cdot 7 \\
5 \cdot 2 \\
3 \cdot 3\end{array}$ & $\begin{array}{l}3 I \cdot 8 \\
8 \cdot 4 \\
9 \cdot I \\
4 \cdot 0\end{array}$ \\
\hline $\begin{array}{l}\text { Total under I mth. } \\
\text { I-2 months } \\
2-3 \text { months }\end{array}$ & $\begin{array}{l}46 \cdot 7 \\
\text { I } 6 \cdot 0 \\
\text { II } 9\end{array}$ & $\begin{array}{l}75^{\circ} 9 \\
43^{\circ} 2 \\
36^{\circ} 9\end{array}$ & $\begin{array}{r}34 \cdot 2 \\
12 \cdot 3 \\
9 \cdot 6\end{array}$ & $\begin{array}{l}69^{\circ} \cdot 1 \\
37^{\circ} \cdot \\
27^{\circ} \cdot 6\end{array}$ & $\begin{array}{l}45^{\cdot} \cdot 8 \\
14 \cdot 1 \\
10 \cdot 7\end{array}$ & $\begin{array}{l}69 \cdot 6 \\
25 \cdot 8 \\
18 \cdot 7\end{array}$ & $\begin{aligned} 34.7 \\
\text { II. } \\
8 \cdot 4\end{aligned}$ & $\begin{array}{l}53 \cdot 3 \\
20 \cdot 8 \\
14 \cdot 2\end{array}$ \\
\hline $\begin{array}{cc}\text { Total in Ist tri- } \\
\text { mester ... }\end{array}$ & $\begin{array}{l}73^{\circ} 6 \\
29 \cdot 1 \\
25 \cdot 8 \\
21 \cdot 7\end{array}$ & $\begin{array}{r}156 \cdot 0 \\
65 \cdot 4 \\
41 \cdot 5 \\
26 \cdot 4\end{array}$ & $\begin{array}{l}56 \cdot 1 \\
22 \cdot 7 \\
20 \cdot 3 \\
19 \cdot 6\end{array}$ & $\begin{array}{r}\mathrm{I} 33 \cdot 8 \\
55 \cdot 2 \\
42 \cdot 3 \\
32 \cdot 8\end{array}$ & $\begin{array}{l}70 \cdot 6 \\
23 \cdot 2 \\
17 \cdot 8 \\
14 \cdot 0\end{array}$ & $\begin{array}{r}\text { II } 4^{\circ} \mathrm{I} \\
36 \cdot 5 \\
24^{\circ} \cdot 0 \\
\text { I5.6 }\end{array}$ & $\begin{array}{l}54^{\circ} 5 \\
17 \cdot 6 \\
14.0 \\
12 \cdot 7\end{array}$ & $\begin{array}{l}88 \cdot 3 \\
34^{\circ} 8 \\
24^{\circ} 0 \\
19 \cdot 0\end{array}$ \\
\hline Total under I year & $15 I \cdot 2$ & $289 \cdot 3$ & II $8 \cdot 7$ & $264^{\circ} I$ & $125 \cdot 6$ & $190^{\circ} 2$ & $98 \cdot 8$ & $I 66 \cdot I$ \\
\hline
\end{tabular}

We may conveniently read this summarised table commencing with the totals at the foot. From these totals the first fact becomes evident, namely, that infant mortality rate for males and fermales in London or in rural counties is enormously greater among illegitimate infants than among legitimate. In 1902 there were in London 690 deaths out of 2,385 illegitimate male infants (yielding the

I Bucks, Cambridge, Cornwall, Hereford, Hunts, Lincoln, North Wales, Norfolk, Oxford, Rutland, Somerset, Salop, South Wales (less Glamorgan), Suffolk, Westmoreland, and Wilts. Estimated population in Ig02, $4,279,175$. 
exceptional death rate of $289^{\circ} 3$, as compared with $I_{5} I^{\prime} \cdot 2$ ) and 612 out of 2,317 illegitimate female infants (infant mortality rate, $264^{\circ} \mathrm{I}$ ). In the rural counties under consideration the same comparison holds good, though in less degree.

The next fact which becomes clear is that the incidence of fatality becomes much more marked, without exception, in the first three months period, and of that period most marked in the first month, and of that first month most marked in the first week. It is precisely the same finding as before, but is, in all cases, of illegitimates more marked than in legitimates. The diseases which carry off illegitimate children at such an increased rate over legitimate children will be considered at a later stage. Here it is only necessary to observe $(a)$ that the mortality of illegitimate infants is much greater than the mortality of legitimate infants; $(b)$ that the illegitimate mortality of London is greater than that of the rural counties; $(c)$ that the illegitimate mortality in London is twice as great as the legitimate mortality; and (d) that in all cases the mortality of illegitimate infants is proportionately greater earlier in life than that of legitimate infants. It should be added that there is reason to believe that this excessive mortality among illegitimate infants in London is understated, for it is a known fact that many unmarried women who reside outside London are admitted to London hospitals at the time of confinement and the births are registered in London. But most of the mothers return again to the country, and any deaths of their children a few weeks after birth are, in all probability, registered outside London.

\section{SUMMARY.}

We have seen that the general death rate from all causes in this country and most other civilised countries 
is slowly but surely declining. That is a favourable sign, which means that fewer persons per 1,000 are dying within an annual period and more persons are living for a longer span of life. It does not necessarily mean that men are living a healthier physical life, though in all probability that also is involved. The birth rate is declining in most civilised states, which is an unfavourable sign.

The infant mortality rate, on the other hand, is not declining, and this is the broad fact which constitutes the problem to be considered. Children under twelve months of age die in England to-day, in spite of all our boasted progress and in spite of an immense improvement in the social and physical life of the people, as greatly as they did seventy years ago. Nor is England alone. Over all the continent of Europe there are but four States with a lower infant mortality rate than that of the British Islands. To find healthy rates elsewhere we must take the wings of the morning to the new lands of the Australian Commonwealth and the island of New Zealand. But even so we shall not wholly escape our problem.

Further, we have seen that the incidence of death in infancy is not equally or uniformly distributed, but falls in exceptional measure on the first weeks and months of life, having a tendency to fall earlier rather than later, and carrying off more boys than girls. That there is here something in operation outside the laws of nature becomes certain when we find that infant mortality is enormously increased in illegitimately born infants as compared with legitimate.

These are the ground facts of the problem. It is experience of them which makes it true to say that in England and Wales out of 100,000 infants born 17,139 will not live to their first birthday, and nearly 25,000 will succumb 
before their $f\left(f^{\prime},^{\mathrm{I}}\right.$ and that the nation is suffering a dead loss every year of not less than 120,000 lives under twelve months of age.

Subsequently we shall see how greatly increased those figures become in certain towns. 
THE DISTRIBUTION OF INFANT MORTALITY IN GREAT BRITAIN

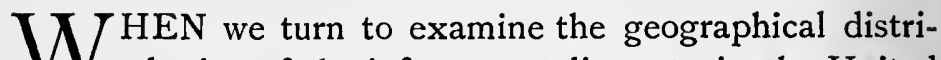
bution of the infant mortality rate in the United Kingdom for any year we find at once that it is not uniform. Some parts of the country show a high rate, others a low rate. So greatly, in fact, does the infant mortality vary that it is impossible to form any reliable opinion except on broad lines. Such broad measurements must be taken in two directions. First it is necessary to judge by periods of five or ten years rather than by single years, and next it is necessary to take counties and, where possible, even broader areas as a basis of observation.

The official returns of dead infants for England and Wales are not available in infant mortality form before I871. By the kindness, however, of Dr. Tatham, of the Registrar-General's Office, I am able to furnish a decennial infant mortality rate for the years $1845-54$ to compare with the three decennial periods I87I-80, I88I-90, I89II900, and with the last quinquenniad 1901-1905. By means of these figures we are able to inquire into the incidence of infant mortality over a period of sixty years. For convenience and graphic illustration these returns have been charted on five maps of England. The actual table of returns is as follows:- 
INFANTILE MORTALITY.

RATES For ENgland and Wales.

\begin{tabular}{|c|c|c|c|c|c|c|c|c|}
\hline \multicolumn{4}{|c|}{ County. } & \multirow{2}{*}{$\frac{1845-54 .}{145}$} & \multirow{2}{*}{$\frac{1871-80}{149}$} & \multirow{2}{*}{$\frac{1881-90 .}{142}$} & \multirow{2}{*}{$\frac{1891-1900}{153}$} & \multirow{2}{*}{$\frac{1901-05 .}{138}$} \\
\hline England and $W a$ & les & ... & $\cdots$ & & & & & \\
\hline Leicestershire & ... & $\cdots$ & ... & I73 & 176 & I64 & I64 & I44 \\
\hline Lancashire... & $\ldots$ & $\cdots$ & $\cdots$ & 193 & 172 & 166 & 179 & 163 \\
\hline Nottinghamshire & ... & $\ldots$ & ... & I74 & 164 & I54 & 164 & 156 \\
\hline East Riding & ... & $\ldots$ & $\cdots$ & 182 & 162 & 149 & 166 & I52 \\
\hline Durham ... & $\cdots$ & $\cdots$ & $\cdots$ & I59 & 166 & 152 & 167 & I 57 \\
\hline West Riding & $\cdots$ & $\cdots$ & $\cdots$ & I74 & 166 & 156 & 164 & I54 \\
\hline Staffordshire & ... & $\ldots$ & $\cdots$ & 180 & I 59 & I 56 & 172 & I 5 I \\
\hline Warwickshire & $\cdots$ & $\cdots$ & $\cdots$ & I74 & I59 & I50 & 169 & I52 \\
\hline Northumberland & $\cdots$ & $\cdots$ & $\cdots$ & I47 & 152 & I 42 & I6I & I53 \\
\hline London $\quad \ldots$ & $\cdots$ & $\cdots$ & $\cdots$ & I57 & $15^{8}$ & 152 & I60 & I39 \\
\hline Cheshire ... & $\cdots$ & $\cdots$ & $\cdots$ & 174 & 144 & 142 & 156 & I43 \\
\hline Norfolk .... & $\cdots$ & $\cdots$ & $\cdots$ & I65 & I49 & I34 & I42 & I28 \\
\hline Derbyshire & $\cdots$ & $\cdots$ & $\cdots$ & 153 & I4I & I34 & I46 & I36 \\
\hline North Riding & $\cdots$ & $\cdots$ & $\cdots$ & 123 & 140 & I35 & 146 & I44 \\
\hline Cornwall ... & ... & $\cdots$ & $\cdots$ & I2I & 145 & I37 & I4 I & II7 \\
\hline Northamptonshir & & $\cdots$ & $\cdots$ & . I 59 & 146 & 132 & 133 & II 5 \\
\hline Bedfordshire & $\ldots$ & $\cdots$ & $\cdots$ & I59 & 147 & I3I & I26 & 106 \\
\hline South Wales & $\cdots$ & $\ldots$ & $\cdots$ & 127 & 132 & 140 & 163 & 148 \\
\hline Monmouth... & $\cdots$ & $\cdots$ & $\cdots$ & 154 & 135 & I40 & I52 & I44 \\
\hline Lincolnshire & $\cdots$ & .. & $\cdots$ & 156 & 137 & I32 & 142 & 138 \\
\hline Middlesex ...: & $\cdots$ & $\cdots$ & $\cdots$ & I39 & 133 & 128 & I39 & I2I \\
\hline Worcestershire & $\cdots$ & $\ldots$ & ... & I53 & I39 & I34 & I4I & 124 \\
\hline Cambridgeshire & .. & ... & ... & I70 & I35 & I2I & 124 & 107 \\
\hline Gloucestershire & $\cdots$ & $\cdots$ & $\cdots$ & 147 & I35 & I 24 & I28 & II4 \\
\hline Cumberland & $\cdots$ & $\cdots$ & $\cdots$ & I33 & 136 & I23 & I30 & I32 \\
\hline Essex $\quad \ldots$ & $\cdots$ & $\cdots$ & ... & 138 & 126 & 126 & I4I & 127 \\
\hline Kent $\quad \ldots$ & ... & ... & $\ldots$ & I32 & 124 & I I6 & I 29 & II9 \\
\hline Devonshire & $\cdots$ & $\cdots$ & $\cdots$ & I I9 & 125 & 120 & I3I & 118 \\
\hline North Wales & ... & $\cdots$ & $\cdots$ & II7 & 125 & I 18 & 135 & 133 \\
\hline Suffolk , ... & ... & $\cdots$ & $\cdots$ & I4I & 125 & II 4 & I2I & II I \\
\hline Buckinghamshire & & $\ldots$ & $\cdots$ & 140 & 129 & I 16 & I I3 & 98 \\
\hline Oxfordshire & $\cdots$ & $\cdots$ & $\cdots$ & I45 & 128 & I 12 & II3 & 98 \\
\hline Huntingdonshire & $\ldots$ & ... & $\cdots$ & I57 & 124 & I07 & I 18 & 95 \\
\hline Somersetshire & ... & ... & ... & I28 & I2 I & IIO & II 4 & 95 \\
\hline Salop $\quad \ldots$ & ... & $\cdots$ & $\cdots$ & I4I & 125 & I I7 & II4 & 105 \\
\hline Hertfordshire & ... & $\cdots$ & $\cdots$ & 135 & I2I & 108 & IIO & 92 \\
\hline Rutlandshire & ... & $\cdots$ & $\ldots$ & 126 & I2I & I I I & I IO & I IO \\
\hline Surrey , ... & ... & $\cdots$ & .. & II6 & 115 & IIO & 122 & 105 \\
\hline Hampshire & ... & $\cdots$ & $\cdots$ & 123 & I 16 & II2 & 127 & IIO \\
\hline Sussex $\quad \ldots$ & ... & $\cdots$ & $\cdots$ & I2I & II 5 & 109 & 118 & IOI \\
\hline Berkshire ... & ... & ... & ... & I 28 & II 8 & 105 & II 4 & Ior \\
\hline Wiltshire ... & ... & $\cdots$ & $\cdots$ & 128 & IIo & 103 & 102 & 9I \\
\hline Herefordshire & ... & $\cdots$ & $\cdots$ & I27 & II5 & 109 & 112 & 100 \\
\hline Dorsetshire & ... & $\ldots$ & $\cdots$ & I23 & 108 & 96 & 102 & 92 \\
\hline Westmoreland & $\cdots$ & $\cdots$ & $\cdots$ & 102 & 106 & 100 & 107 & 97 \\
\hline
\end{tabular}


On examining this table and these maps certain characteristics present themselves :-

1. There is a general similarity of incidence in all five periods.-The actual averages may be stated for convenience thus:-

$$
\begin{array}{lllll}
\mathrm{I} 845-\mathrm{I} 854 & \ldots & \ldots & \ldots & \mathrm{I} 45 \\
\mathrm{I} 87 \mathrm{I}-\mathrm{I} 880 & \ldots & \ldots & \ldots & \mathrm{I} 49 \\
\mathrm{I} 882-\mathrm{I} 890 & \ldots & \ldots & \ldots & \mathrm{I} 42 \\
\mathrm{I} 89 \mathrm{I}-\mathrm{I} 900 & \ldots & \ldots & \ldots & \mathrm{I} 54 \\
\mathrm{I} 90 \mathrm{I}-\mathrm{I} 905 & \ldots & \ldots & \ldots & \mathrm{I} 38
\end{array}
$$

There is therefore, to begin with, no wide divergence of mortality. It rose in the decennial period I87I-I880 above the first period for which we have figures, but in the succeeding decennium it fell again almost to the former figure. In I89I-I900, however, it rose to the highest figure of which we have record, falling again in the next quinquenniad, the lowest figure of which we have record.

2. There is a general similarity of distribution.-The chief mortality occurs in the North and North-Midland districts, and the lowest mortality in the counties below a line drawn from the Wash to the mouth of the Severn. Each decennium shows some minor variation, but practically it may be said that during the whole of last century this was in the main the general distribution. The degrees of severity differ, the distribution remains about the same, and it will be seen that it follows with some measure of accuracy the chief coal-fields; or in other words, the imaginary line that divides the high infant mortality districts from the low, is the line which now divides the 


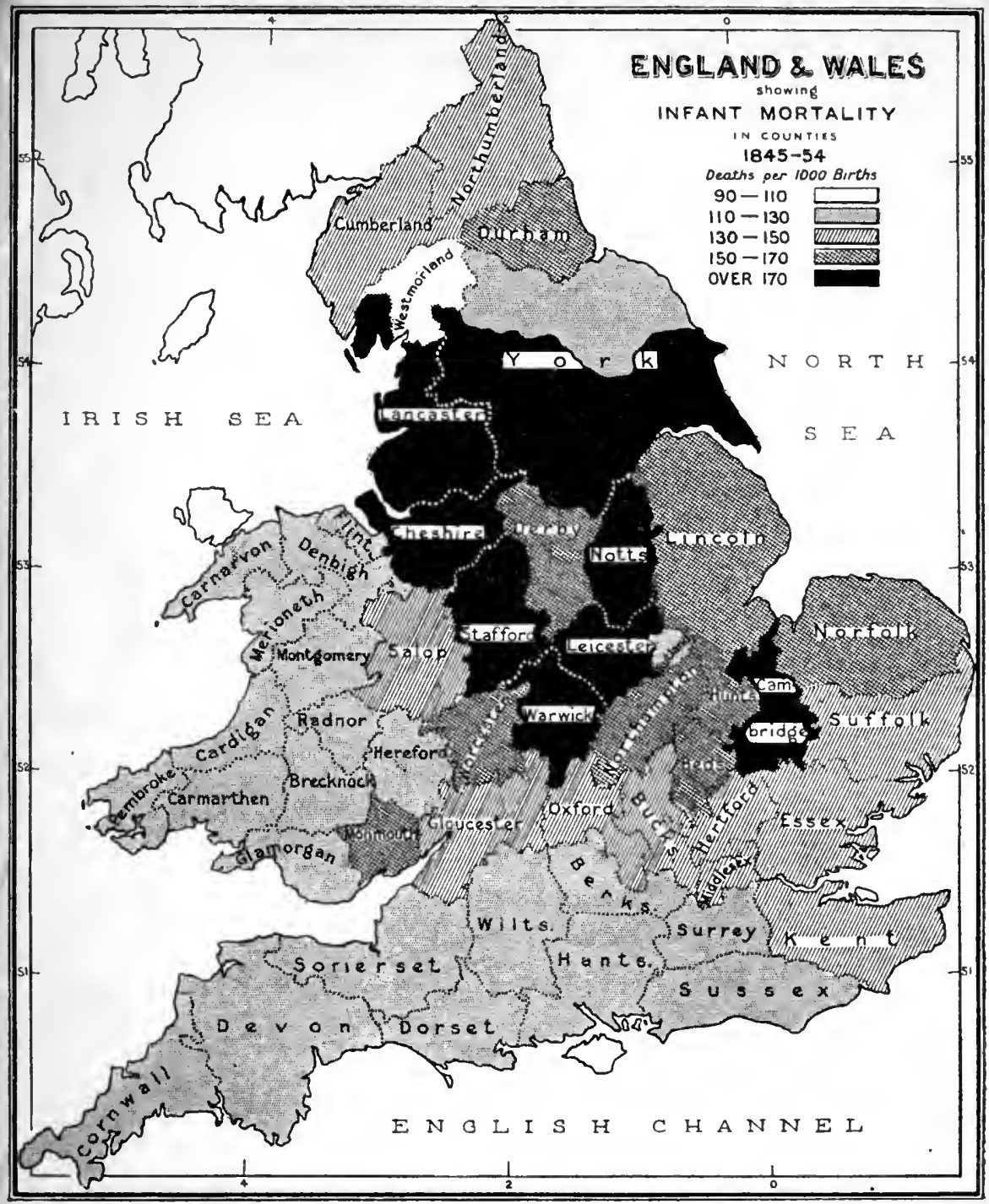




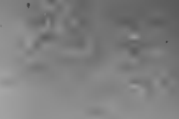

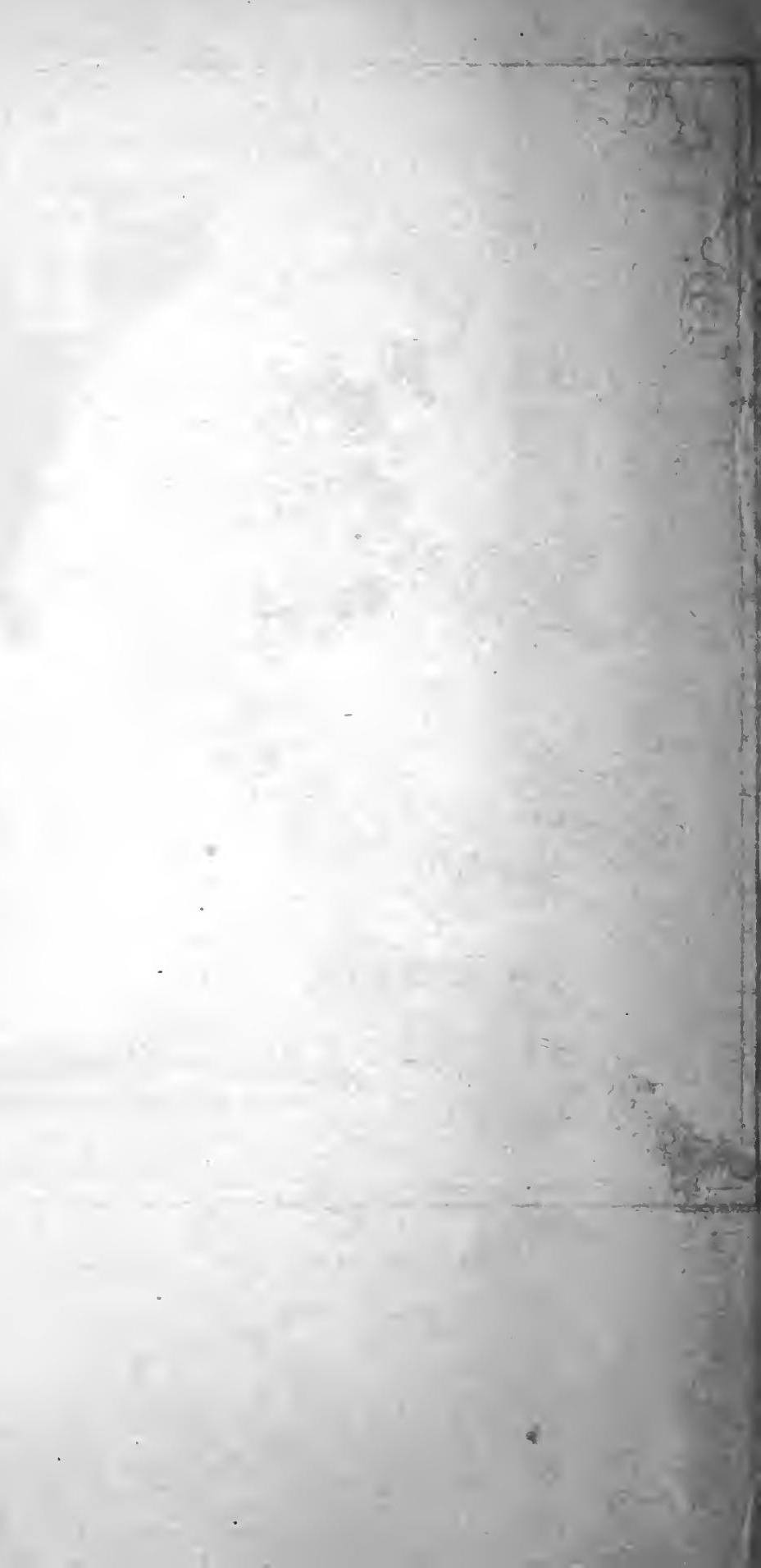




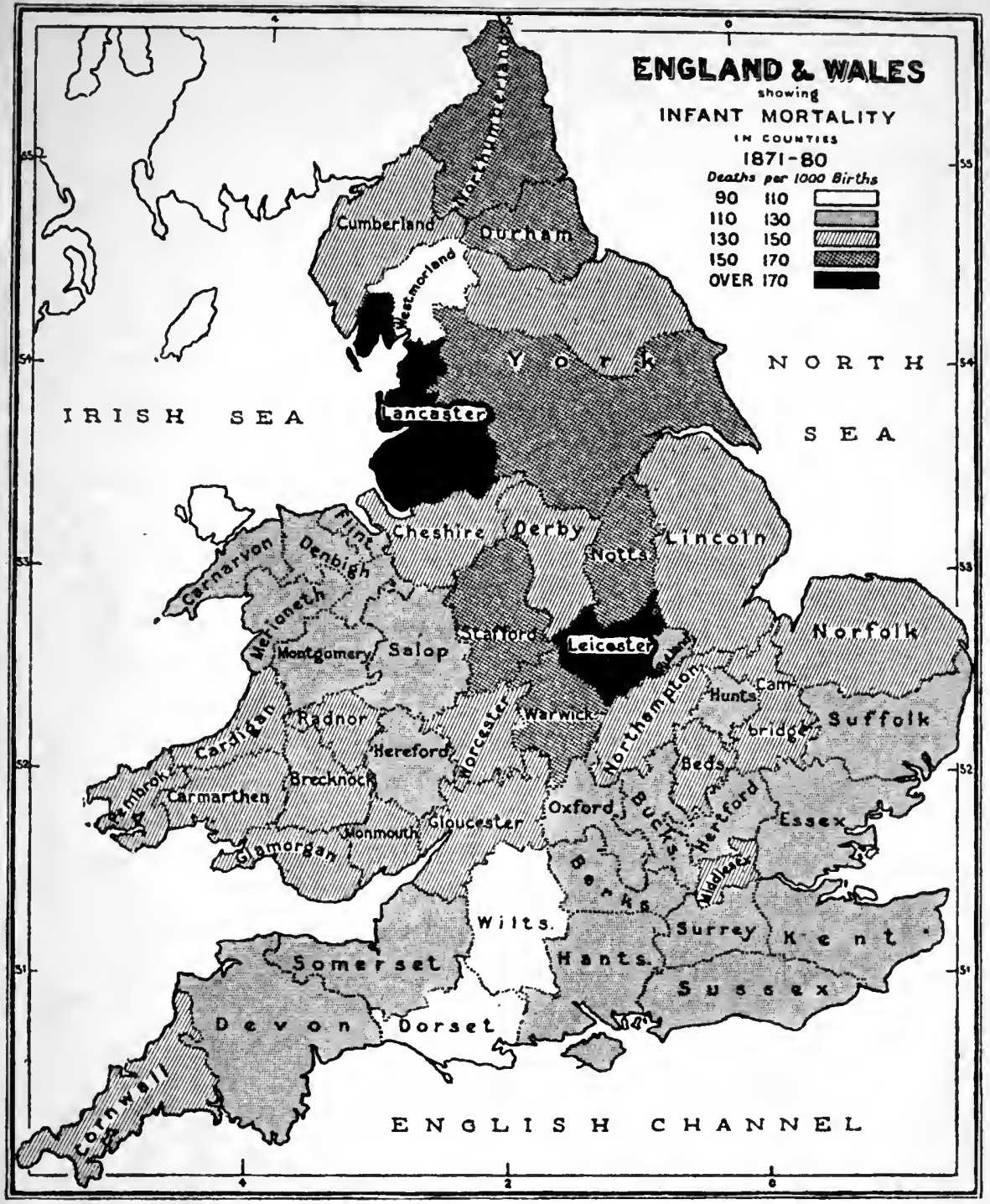




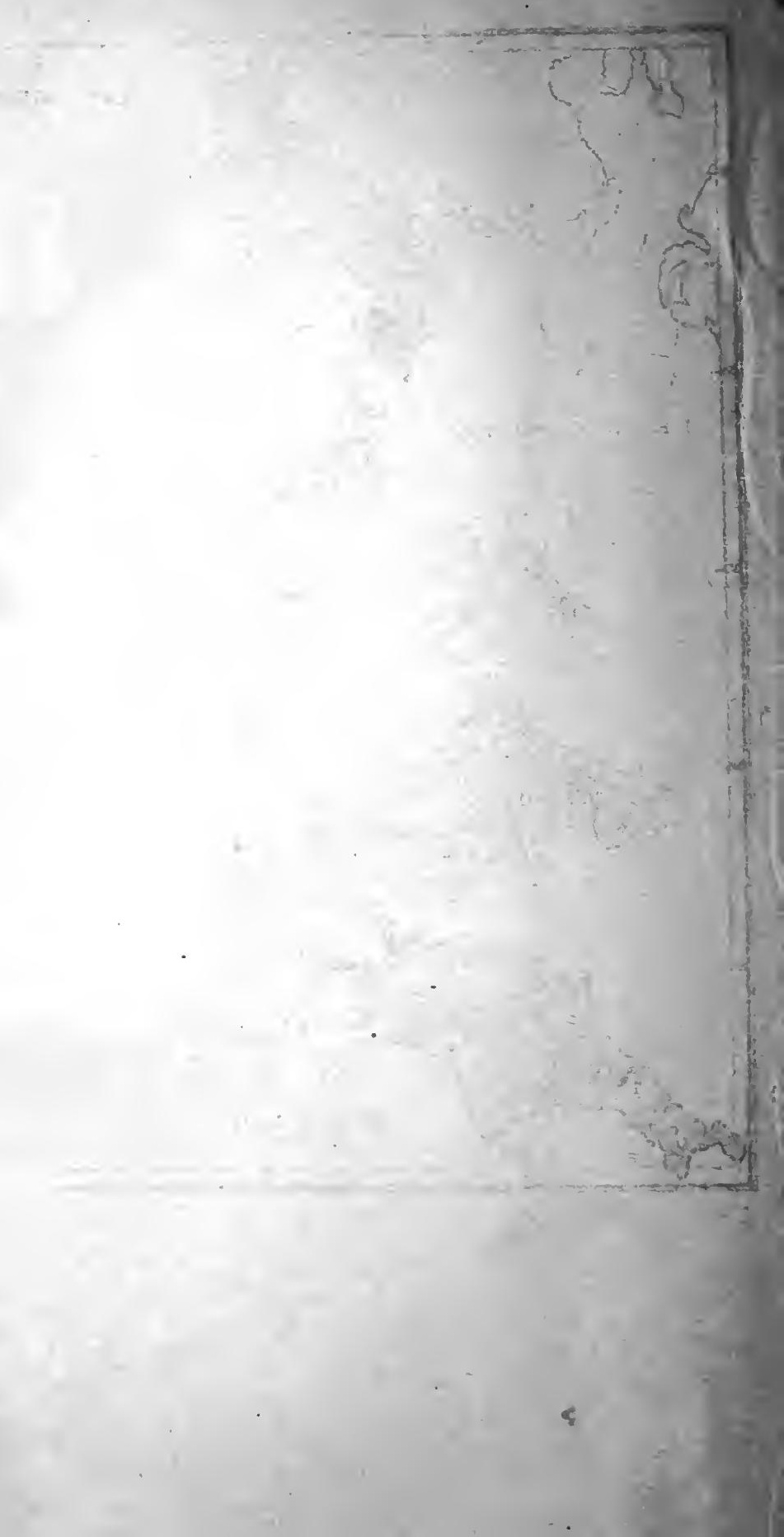


agricultural from the industrial, particularly the mining and textile, portions of the community.

3. Certain counties are characterised throughout by a high or a lowe infant mortality.-Among the high-mortality counties are Northumberland, Durham, the East and West Ridings of Yorkshire, Lancashire, Cheshire, Staffordshire, Nottingham, Leicester, and Warwick. Among the lowmortality counties are Westmoreland, Wiltshire, and Dorset. Other counties share the credit of a low mortality in certain decennial periods, but the three named have almost without exception maintained a remarkably low infant death rate. It will be remembered that before the middle of the eighteenth century the distribution of industries in England was not circumscribed by coalfields, and was much more located in Somerset, Gloucester, Wilts, Oxford, Bucks, Northampton, Worcester, and Warwick, than in Stafford, Nottingham, Cheshire, the East and West Ridings, Durham, and Northumberland. And it is possible that if we could produce an infant mortality map of England from 17381747-that is to say, before the modern industrial revolution occurred-we should find considerable alteration in distribution.

Now it will be noticed that the counties characterised by a high or low infant mortality in the last decennium I 89I-1900 are the same with few exceptions as those so characterised in the first decennium. The incidence remains high or low year after year. And the question naturally arises, Why should certain counties always be characterised by a high infant mortality? Before attempting to consider that question we shall do well to note the exceptions. Examples of increase are mainly two, Northumberland and South Wales. In the first decennial period neither of these districts was much affected. In the last decennial period both are marked districts, though Cum- 
berland and Herefordshire, immediately adjoining them, remain with low infant mortality. Of examples of decrease there are eight or ten counties, but chiefly perhaps Cambridge, Huntingdon, and Cheshire. It is noteworthy, however, that Lancashire and Yorkshire have also shown some measure of decrease.

4. There is a fourth point of much interest and of some obscurity, concerning which a table will be found in the Appendix (see p. 333), in which will be seen the distribution of infant deaths in counties in trimester periods. The figures are percentages of infant deaths at each of the three periods on total infant deaths for the year in each county. The average is $5^{\circ} 4$ in the first trimester of life, $19^{\circ} 9$ in the second, and 28.7 in the third. Subsequently we shall see that the causes of death in the first trimester of life are in the main a group of diseases concerned with immaturity (premature birth, early atrophy, congenital defects, \&c.) ; the chief cause in the second trimester is epidemic diarrhœa; and in the third trimester there are a variety of diseases, particularly of the lungs, and epidemic diarrhœa again. Now when we examine the figures in this table we find the counties with the highest percentage of deaths in the first trimester are as follows (the infant mortality figure for $1901-05$ is inserted in brackets): Bedford (I06), Wiltshire (9I), Dorset (92), Oxford (98), Cornwall (II7), and Westmoreland (97)-that is to say, agricultural counties with exceptionally low infant mortality rates. Whereas the counties with the lowest percentage of deaths in the first trimester are as follows: Lancashire (163), East Riding (152), Leicester (144), West Riding (I54), and Cheshire (I43) - that is to say, manufacturing counties with exceptionally high infant mortality rates. That this is not wholly a question of deaths from immaturity becomes clear when we 
study the accompanying table (in the Appendix, p. 329) as to causes of death in the English counties. From this table it will be seen that the counties with a high percentage of deaths in the first trimester (Bedford, Wilts, \&c.) have not an excessively high death rate from wasting disease which in this table is synonymous with immaturity. Cornwall alone is above the average. The others are either at, or just below, the average. On the other hand Lancashire, East Riding, \&c., are, with the exception of Cheshire, slightly above the average death rate of wasting diseases. ${ }^{\mathrm{I}}$ A partial explanation of these interesting figures is to be found in the relative incidence of diarrhœa, convulsions, and respiratory diseases. But making all allowance, it is clear that the counties having a high percentage of deaths in the first trimester are characterised by a relative excess of deaths from immaturity.

Returning now to the general distribution of infant mortality in counties, it may at once be said that it is evident that no mere physical or geological conditions are operating in assisting to bring about the very characteristic distribution revealed by these maps. Geological strata, soil, and climate are not exerting the main influence in a distribution of death such as this. The climate of Lancashire, its temperature and its rainfall, is not greatly different from that of Cumberland, or that

It is singular that the counties which in recent years have shown high infant death rates from "wasting diseases," that is immaturity, are Norfolk, Suffolk, Nottinghamshire, Warwickshire, Worcestershire, and Durham. The first three counties are characterised by a high illegitimate birth rate, the second three by a low illegitimate birth rate. The whole problem of the distribution of illegitimacy and mortality from immaturity in English counties is somewhat obscure. It might be expected that exceptionally high illegitimate birth rates would lead to (a) high infant mortality ; (b) high mortality from immaturity; (c) a high mortality from infant diarrhoea and diseases due to neglect; or $(d)$ a high mortality from all three. No doubt this is often the case. But that it is not invariably so is evident from the experience of Herefordshire, Shropshire, and Cumberland, which have a high degree of illegitimacy but low infant mortality rates. (See also Appendix, p. 33I.) 
of Shropshire from Staffordshire, or that of Herefordshire from Warwickshire, and yet these districts are pole-wide asunder in regard to infant mortality. Nor is the difference due to outward physical conditions of topography. Lancashire is flat and low, the West Riding of Yorkshire mountainous. Both are affected with a high infant mortality. Nor is it a question, broadly, of the environment of different populations. In so small a country as England, habits and customs have, like the climate, much in common. People are housed much the same, live on the same diet, adopt the same habits, clothe themselves similarly, and on the whole even treat their infants the same. Nor is it a question of pauperism per se. Pauperism has greatly declined in England, for whereas in 1848-49 the mean number of paupers was $\frac{1}{16}$ th of the population, it was in $1902-03$ only ${ }_{4}^{1} 0$ th of the population. ${ }^{I}$ But we can be more precise, for whilst the average ratio per 1,000 of paupers in 1904 in union counties was $26^{\circ}$, it was $34^{\circ} 9$ in Wiltshire, $40^{\circ} 4$ in Dorset, and $4 \mathrm{r}^{\circ} \mathrm{O}$ in Herefordshire (three counties characterised by the lowest infant mortality rates), the highest in the whole country. Yet in the West Riding it was 18.2 , in Northumberland $19^{\circ} 7$, and in Lancashire $21^{\circ} \mathrm{O}$ per 1,000 of the estimated population. Poverty is not satisfactorily measured by pauperism, but if such be taken as a standard - and it is an accepted standard-the counties having least official pauperism, so to speak, are the counties having the highest rates of infant mortality. ${ }^{2}$

There are two features, however, which appear to be common to the high infant mortality districts, namely, a high density of population, and a considerable degree of

Report of Local Government Board, I902-03, p. 1xvii.

2 There is, of course, a distinction between pauperism and poverty. The following table gives the proportion which the highest and lowest pauperism of several Union Counties in England bore to the estimated 
manufacturing industry. The former will be considered here, the latter in another chapter. It is true that mere density of population is not one of the chief conditions giving rise to infant mortality-for if that were so the metropolis itself would have the highest rate-yet it cannot be denied that density of population to the acre

population on January I, 1905 (Thirty-fourth Ann. Rep. of Local Government Board, I904-05, p. 437) :-

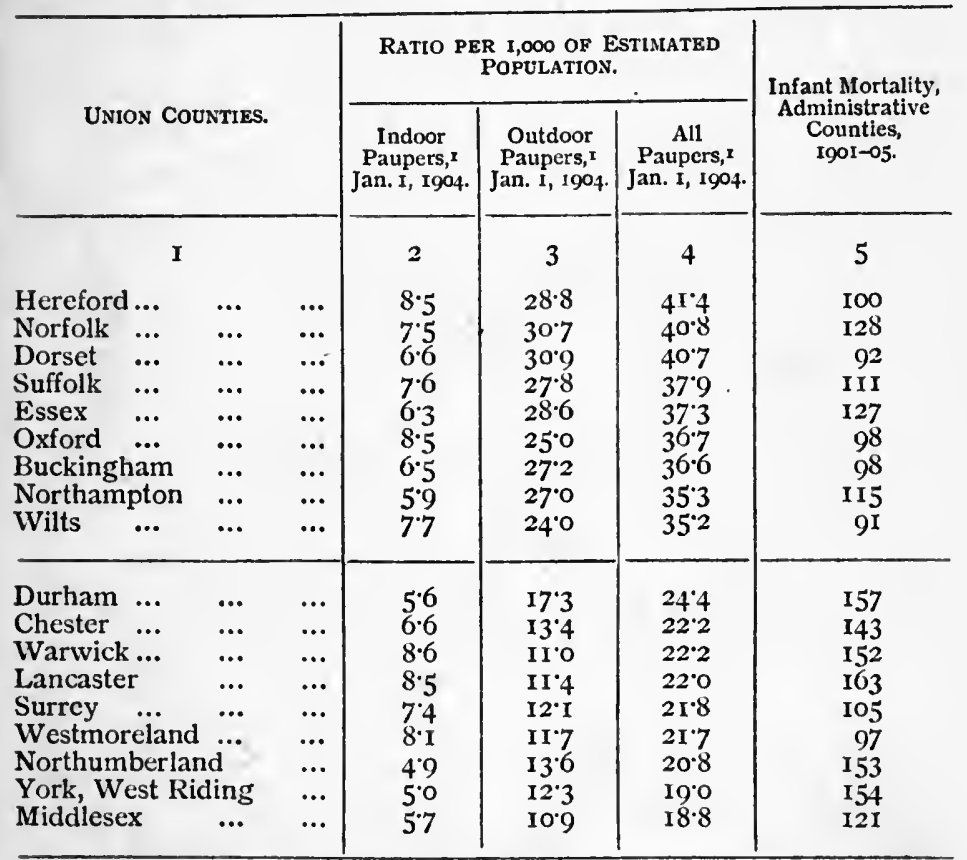

I Including Vagrants. Lunatics in County and Borough Asylums, \&c., are included in col. 4 only.

The figures as to indoor paupers are merely inserted for comparative purposes. Differences of administration and accommodation are so considerable that indoor pauperism is no indication of district poverty. Probably, indeed, the only figures serving as an index of district poverty are those in col. 3 , as col. 4 includes lunatics. We shall subsequently find that the relation of domestic poverty to infant mortality is much more intimate than official pauperism. 
appears at first sight to bear some relation to the death rate. If the 44 counties $I$ be classified according to their infant mortality rates, and the density of the population (acres per person) be added as recorded in the decennial reports of the Registrar-General for $187 \mathrm{I}-80$ and $188 \mathrm{I}-90$, it will be found that there is frequently some apparent relation between infant mortality and density. But this does not by any means always obtain. The apparent general result, however, becomes more obvious if the counties are grouped in four divisions according to their infant mortality : first, those above 160 infant deaths per I,000 births; secondly, those between I40-160; thirdly, those between I20-140; and lastly, those below I2O. And if the densities of population are similarly grouped we obtain the following table:-

\begin{tabular}{c|c|c|c|c|c|c}
\hline & \multicolumn{3}{|c|}{$1871-1880}$. & \multicolumn{3}{|c}{$1881-1890}$. \\
\hline $\begin{array}{c}\text { Scale of In- } \\
\text { fant Mortality. }\end{array}$ & $\begin{array}{c}\text { No. of } \\
\text { Countics in } \\
\text { each Scale. }\end{array}$ & $\begin{array}{c}\text { Averagc } \\
\text { Infant Mor- } \\
\text { tality Rate }\end{array}$ & $\begin{array}{c}\text { Acres per } \\
\text { Person. }\end{array}$ & $\begin{array}{c}\text { No. of } \\
\text { Counties in } \\
\text { each Scale. }\end{array}$ & $\begin{array}{c}\text { Average } \\
\text { Infant Mor- } \\
\text { tality Rate }\end{array}$ & $\begin{array}{c}\text { Acres per } \\
\text { Person. }\end{array}$ \\
\hline $160+$ & 6 & 167 & 1.09 & 2 & 165 & 0.95 \\
$140-160$ & 10 & 148 & 2.05 & 10 & 148 & 1.43 \\
$120-140$ & 20 & 128 & 2.65 & 14 & 129 & 2.24 \\
$100-120$ & 8 & 112 & 4.01 & 18 & 109 & 3.14 \\
\hline
\end{tabular}

It has long been recognised that density of population bears some relation to death rates. Dr. Farr was so convinced of the fact that within certain limits a definite relation subsisted between density of population and mortality that he devised a formula by which this relation in the decennary of $1861-70$ could be approximately each. 
shown. And though the relation is now too complex to admit of being expressed by any such formula, the broad fact remains, and the four decennial reports of the RegistrarGeneral contain abundant evidence in support of it. On the whole, Urban England, or the more densely populated districts, suffers a higher death rate from all causes and a higher infant mortality rate than Rural England, or the less densely populated districts. ${ }^{\mathrm{I}}$

Scotland, as we have seen, enjoys a much lower infant death rate than England, though it has a higher general death rate. If we tabulate the infant mortality for the counties of Scotland in the same way as we have done in the English counties, we shall, by reason of the figures which are available, carry the argument a step further. In the official returns contained in the Annual Reports of the Local Government Board for Scotland, 1899-1904, will be found the figures from which the following table has been constructed. Here we have two infant mortalities in each district, one for the rural county (termed landward) as such, one for the burghs, an urban or burghal rate. These have been taken out for a six-year period, 1899-1904. Opposite to these figures have been placed the persons per acre at the last census (190I), both county or landward,

I "It must not be supposed," wrote Dr. Ogle, "that the higher death rates, which go hand-in-hand with increased density of population, are simply the direct results of such aggregation. Doubtlessly where people are crowded together certain injurious conditions are produced which directly affect the mortality; the air, the soil, and often the water are liable to be fouled; and infectious diseases, having a shorter average distance to travel from individual to individual, are more readily spread abroad. But these direct consequences of close aggregation are probably as nothing in comparison with its indirect consequences or concomitants. The more crowded a community the greater, speaking generally, is the amount of abject want, of filth, of crime, of drunkenness, and of other excesses, the more keen is the competition, and the more feverish and exhausting the conditions of life. It is not so much aggregation itself, as these other factors which are associated with aggregation, that produce the high mortality of our great towns or other thickly populated areas." (Supplement to the Forty-fifth Ann. Rep. of the Registrar-General, 1885, p. $x x i$.) 
and urban or burghal. The following is the interesting table which results:-

\begin{tabular}{|c|c|c|c|c|c|c|c|c|c|c|}
\hline & \multicolumn{3}{|c|}{$\begin{array}{c}\text { Average } \\
\text { Infant } \\
\text { Mortality Rate } \\
\text { per } \\
\text { I,000 Births, } \\
\text { I899-1904. }\end{array}$} & \multicolumn{2}{|c|}{$\begin{array}{l}\text { Persons } \\
\text { per Acre, } \\
\text { 1904. }\end{array}$} & & \multicolumn{2}{|c|}{\begin{tabular}{|c|} 
Average \\
Infant \\
Mortality Rate \\
per \\
1,000 Births, \\
I899-1904.
\end{tabular}} & \multicolumn{2}{|c|}{$\begin{array}{l}\text { Persons } \\
\text { per Acre, } \\
\text { rgo4. }\end{array}$} \\
\hline & & 宛 & 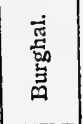 & 悹 & 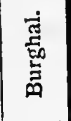 & & 空 & $\begin{array}{l}\text { 㺃 } \\
\text { 总 } \\
\text { 点 }\end{array}$ & 产 & 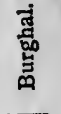 \\
\hline Aberdeen & & $82 \cdot 3$ & $142 \cdot 2$ & $\cdot 098$ & 19.6 & Kinross ... & $88 \cdot 8$ & $84: 2$ & 093 & $12 \cdot 1$ \\
\hline Argyll ... & ... & $60 \%$ & IIO.I & 025 & $7 \cdot 2$ & Kirkcudbright .. & $75^{\circ} 6$ & 113.4 & 040 & 47 \\
\hline Ayr $\quad \ldots$ & $\cdots$ & $104^{\circ}$ & 115.5 & $\cdot 182$ & 12.5 & Lanark ... & $123^{\circ} 9$ & $143 \cdot 3$ & 504 & $5^{2 \cdot 6}$ \\
\hline Banff ... & .. & 86.4 & $129^{\circ}$ & .087 & $8 \cdot 0$ & Linlithgow & 112.8 & 125.3 & 540 & 14.9 \\
\hline Berwick... & ... & $94 \cdot 8$ & $97 \cdot 6$ & $.08 \mathrm{I}$ & $8 \cdot 4$ & Nairn $\quad .$. & $98 \cdot 9$ & 140.2 & .046 & $10 \% 4$ \\
\hline Bute $\quad \ldots$ & ... & 749 & 103.6 & .057 & $3 \cdot 4$ & Orkney ... & $70^{\circ}$ & $66 \cdot 0$ & $\cdot 093$ & $7^{\circ} 0$ \\
\hline Caithness & .. & 733 & $149^{\circ} 2$ & 049 & 609 & Peebles ... & 78.9 & 947 & .036 & $9^{\circ} 0$ \\
\hline Clackmannon & $\ldots$ & $100^{\circ} 5$ & $100 \cdot 3$ & 331 & $15^{\circ} 8$ & Perth $\quad .$. & $68 \cdot 3$ & $112^{\circ} 4$ & .042 & IIOO \\
\hline Dumbarton & .. & 103.0 & $130 \% 3$ & $35 \mathrm{I}$ & if.I & Renfrew $\quad$. & 94 & $129^{\circ} 4$ & 404 & $23 \cdot 7$ \\
\hline Dumfries & ... & $96 \cdot 4$ & $115 \%$ & .065 & ir.2 & Ross \& Cromarty & $79^{\circ} 6$ & $1180^{\circ}$ & 033 & $6 \cdot I$ \\
\hline Edinburyh & .. & ror 9 & $132 \cdot 3$ & 318 & $3 \mathrm{I} \cdot 8$ & Roxburgh $\quad$. & $83^{\circ} 1$ & 122.4 & .051 & 10'0 \\
\hline Elgin $\quad \ldots$ & .. & 98.9 & II 8.3 & 077 & $7 \cdot 5$ & Selkirk ... & 934 & $109^{\circ} 8$ & 025 & $16 \cdot 3$ \\
\hline Fife $\quad \ldots$ & & $107 \cdot 6$ & III'3 & $\cdot 275$ & II. 6 & Stirling ... & .. 107.5 & 122.5 & 250 & 15.4 \\
\hline Forfar $\ldots$ & ... & $78 \cdot 5$ & $150 \% 3$ & .084 & $23 \cdot 3$ & Sutherland & .. $86^{\circ} 4$ & $120^{\circ}$ & .016 & 0.5 \\
\hline Haddington & ... & ror 3 & 122.5 & $\cdot 129$ & II $\cdot 3$ & Wigtown & $87 \cdot \mathrm{I}$ & 1159 & .069 & 34 \\
\hline Inverness & & $8 \mathrm{r} \cdot 5$ & $130^{\circ} 9$ & 024 & $10 \cdot 1$ & Zetland ... & $6 \mathrm{I} \cdot 2$ & $37^{\circ} 9$ & | 068 & $21 \cdot 7$ \\
\hline Kincardine & & $88^{\circ} 0$ & $95^{-8}$ & $\cdot 093$ & $5 \cdot 3$ & All Scotland & \begin{tabular}{l|l}
... $99^{\circ} 4$ \\
na
\end{tabular} & $134^{\circ} 9$ & . 082 & 20.9 \\
\hline
\end{tabular}

From these figures we may judge and compare density per acre with infant mortality in both rural and urban districts. The most rural county, if judged by sparseness of population, is Sutherlandshire, which supports upon each acre the small fraction of a person denoted by the figures 0.016. The infant mortality, however, is 86 , and there are a dozen counties with a smaller rate. Banff also has an infant mortality of 86 , though its density per acre is five times greater than Sutherland. In short, we find as we found in England, only more so because of the greater scarcity of population, that the density per acre in the counties has no correspondence with infant mortality, 


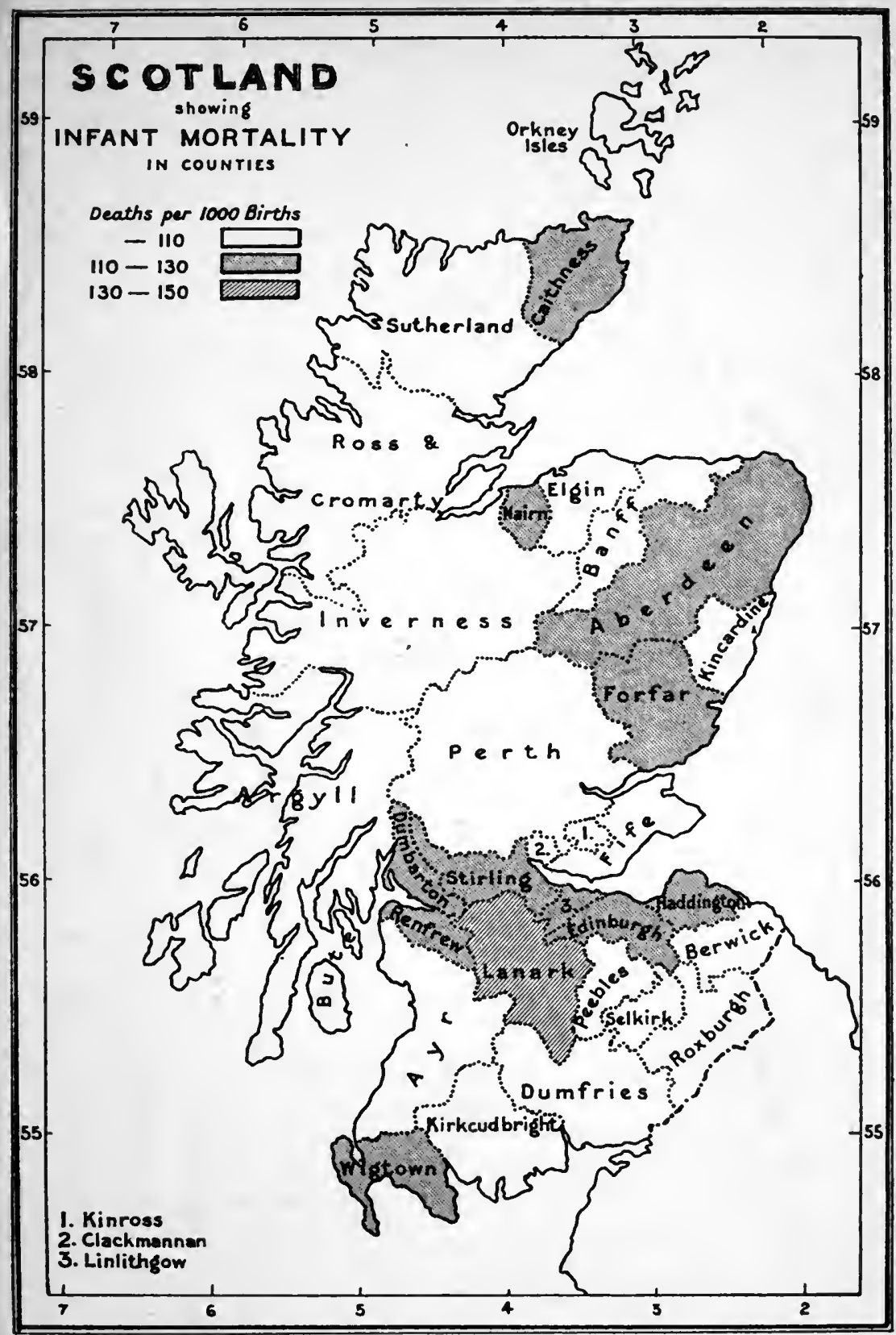



except where the county is almost wholly urban. When, however, we turn to the towns themselves-and the advantage of this table is that we can compare towns with the counties-we find a fairly close correspondence. The five burghal districts having the highest density per acre, namely, Lanark, Edinburgh, Renfrew, Forfar, and Aberdeen, are characterised by five of the highest infant mortalities, and an average of I 39 as compared with 123 for all Scotland.

From a study of these facts it is becoming evident that whatever may be the relation existing between density of persons per acre and the infant death rate in counties, it is an effect of the torens. . Very small towns do not appear to make much difference in the relationship, whatever it be. If we could, so to speak, analyse each county, as we have roughly differentiated England and Scotland, into areas of high and areas of low infant mortality, we might obtain further evidence, for each county would then become a microcosm of the conditions as we see them in England and Scotland as a whole. Such an examination of the statistical records of each county for a period of years is,

I In a general way this applies to the 76 large towns and the 142 smaller towns, but it is noticeable that in recent years (rgor-05) there has been in the country as a whole a decline in the infant mortality rate which has been shared in by the largest towns but not always by the smaller towns. To set out this change adequately would require many pages, for which we have not space. In the last decennium (I89I-I900) the infant mortality increased in the whole country and fell in the large towns, but in the smaller towns, in new towns, and in rural districts, it tended to rise, and in this way the gain of the previous decennium was lost. Hence it is not by any means always true to say that urban infant mortality is higher than rural. It may be so, and generally is so. But, on the other hand, some of the lowest mortalities are occurring in urban districts. And it must not be forgotten that in the largest towns there has been definite decline of infant mortality in the last twenty-five years. To what is that due? It may be due to extension of boundaries which have absorbed healthy suburbs (in 1905 the infant mortality rate of Manchester was 159 , but excluding the newly amalgamated districts it was 164), or it may be due to sanitary improvement, either in the direction of housing, or the abolition of privy-middens, or merely of an immense advance in general sanitation. The decreasing birth rate in these towns must also not be forgotten. 
however, impossible. The figures are not available, and there is the further difficulty that did they exist they would be largely unreliable because the boundaries of the urban and rural districts vary, from time to time, being extended or reduced, or even whole districts absorbed. Hence comparable statistics for a period longer than one year are unobtainable. I am able, however, to supply two instances of such local differentiation of infant mortalities within counties, one a fairly typical urban and rural county, Bedfordshire, the other wholly an urban county, the administrative county of London, and we may briefly examine these. ${ }^{\mathrm{I}}$

The county of Bedford has an acreage of 303,500 . There are thirteen local government districts, seven urban and six rural. The population in I90I was 172,569 , of whom 95,248 lived in urban districts and 77,321 in rural. The latter districts are declining in population. The infant mortality in I $845-54$ for the whole county was 159 per 1,000 births; in $1871-80$ it had declined to 147 , and in the latest decennium (189I-1900) it had further fallen to 126 , and 106 in $1901-05$. This shows a steady and

I For the reasons stated above it is only possible to quote returns for London since the formation of the boroughs in 1900. Taking the last five years, 190I-05, the average infant mortality for London is 138 . The return for each borough is as follows :-

$\begin{array}{ll}\text { Paddington, 129 } & \text { Stoke Newington, Ir7 } \\ \text { Kensington, 150 } & \text { Hackney, 129 } \\ \text { Hammersmith, I48 } & \text { Holborn, ro9 } \\ \text { Fulham, r45 } & \text { Finsbury, 139 } \\ \text { Chelsea, 139 } & \text { City of London, 138 } \\ \text { Westminster, 127 } & \text { Shoreditch, I79 } \\ \text { Marylebone, 99 } & \text { Bethnal Green, I51 } \\ \text { Hampstead, 97 } & \text { Stepney, 149 } \\ \text { St. Pancras, I44 } & \text { Poplar, I56 } \\ \text { Islington, 131 } & \text { Southwark, 161 }\end{array}$

Bermondsey, I6I

Lambeth, 129

Battersea, 140

Wandsworth, 122

Camberwell, 134

Deptford, 137

Greenwich, I3I

Lewisham, II2

Woolwich, I 20

It will be seen at once, as we shall mention subsequently, that the central districts are characterised by a higher infant death rate than the outside areas. The more urban the district of the county the higher the death rate of children. But this is not due to mere density, but to social and industrial conditions and to domestic insanitation. 
marked improvement to which we shall again refer. The infant mortality rates for each of the thirteen districts for the last five years, which owing to adjustment of boundaries are the only figures available, were as follows:-

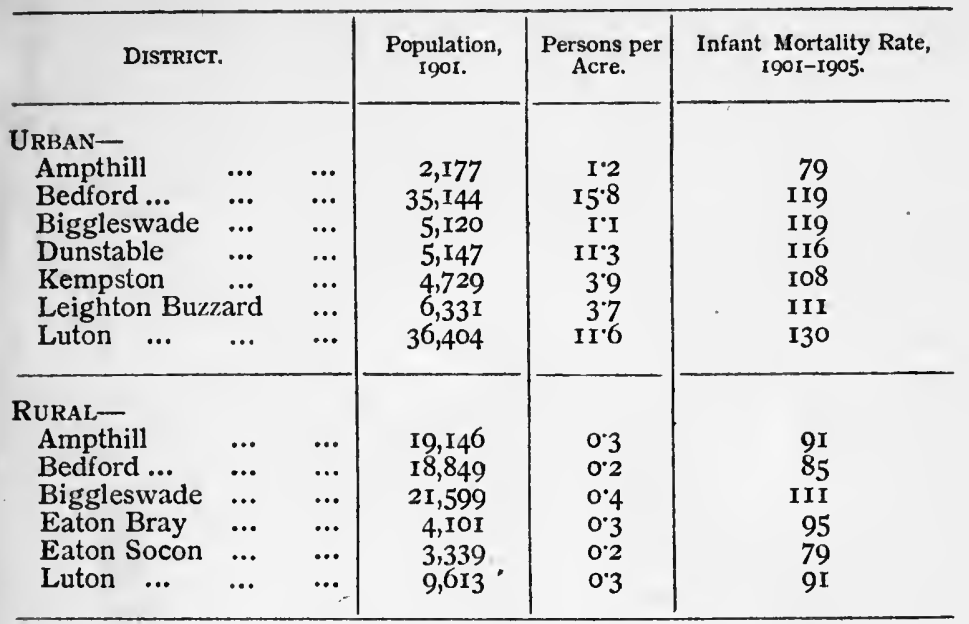

The density of population per acre has also been added for comparative purposes, and we at once see how a decennial return of infant mortality such as 106 per I,000 births becomes distributed. The urban districts (population density 6.9) are approximately (for the quinquenniad) I 12 , and the rural districts (population density $0.28)$ 92. So far the distribution of rate appears to be following density of population. But wren we come to examine each district we find that infant mortality bears no relation to density of population. In the middle of the county is a large rural district, that of Ampthill, with some three acres of land to each person, and an infant mortality rate of $9 \mathrm{r}$; whilst the little town of Ampthill, with one acre to each person, has a mortality of 79 . Bedford, the county town, has 15 persons to the acre and an infant mortality rate of I I 9 , but Luton, a town of almost exactly 
the same size with many physical advantages over Bedford, and having only I I persons to the acre, has an infant mortality of 130 per 1,000 , by far the highest in the county. The Biggleswade rural district, too, does not behave itself as might be expected. There also there are, roughly, three acres to each person, as in the neighbouring district of Ampthill, but the infant mortality is I I I, 20 per I,Ooo above Ampthill, and precisely the same figure as Leighton Buzzard with its three people to each acre.

The fact is, when we come to examine the matter of person's per acre, density per se has very little to do with the causation of infant mortality, as Dr. Newsholme pointed out in I89I when he showed that in good-class model dwellings, though the density of persons per acre was high, the infant mortality rate was low. ${ }^{x}$ The relation indeed obtaining between density per acre and infant mortality is little more than a preliminary guidance to the investigator to direct his attention to the torons. Let us look at the microcosm of the problem as observable in Bedfordshire. A glance at the chart will show five towns, in their order of infant mortality, as follows : Luton (I 30), Bedford (I I9), Biggleswade (I I9), Dunstable (I I6), and Leighton Buzzard (I I I). Bedford and Luton are approximately of equal population and much larger places than the other towns named. The infant mortality rate for Luton was 175 per $\mathrm{I}, 000$ for $\mathrm{I} 88 \mathrm{I}-90$, in the next decenniad it fell to $I 58$. It is now approximately I30 (190I-05). The infant death rate for Bedford has been low for many years. What is the difference between the two towns in relation to this question? It is threefold.

r. A difference of age incidence of population.

2. A difference of social life and poverty.

3. A difference of occupation.

- Vital Statistics of Peabody Buildings, \&c., I89I, p. Io. 


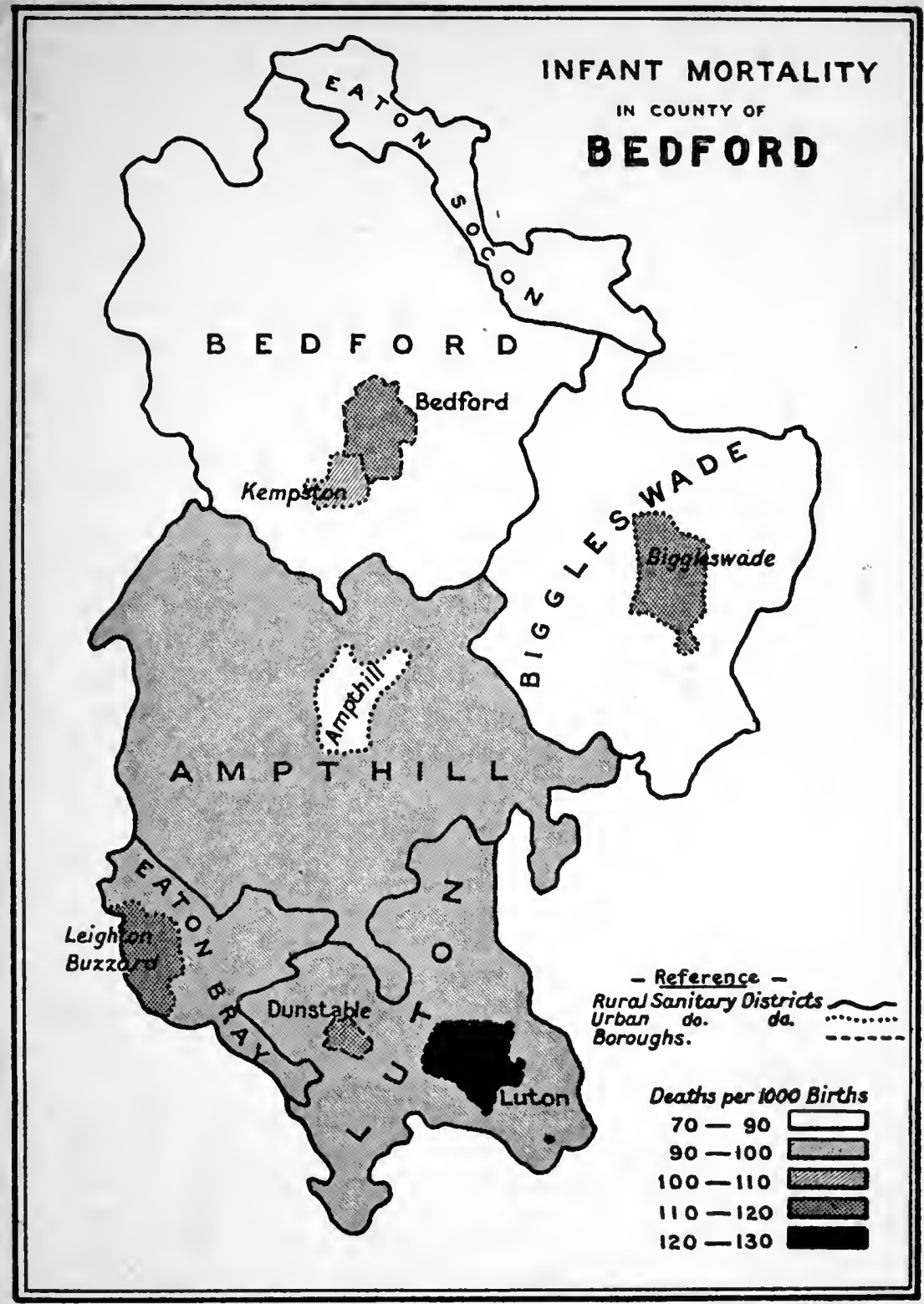





\section{DISTRIBUTION OF INFANT MORTALITY}

Bedford is a centre of school education, and has an exceptionally large population of young people, and therefore a very low birth rate. There is a more leisured social life, and a small degree of "primary" poverty. Lastly, it is not an industrial or manufacturing town. Luton, on the other hand, though a town of equal size, is composed of a less selected population as regards age incidence. There is a good deal of poverty, some of which is "primary," and, generally speaking, the town is a manufacturing one, with all that such a condition involves.

We shall discover subsequently how intimately these social conditions are connected with infant mortality, but we have already found that the distribution of this particular death rate in England and Scotland leads us to believe that there may be, broadly, a line of cleavage between urban and rural conditions, a study of which may throw some light on to the causes of infant mortality. Before discussing the point we shall do well to widen our ground, and thereby make the more certain of it. We may take Wiltshire. In 1845-54 the infant mortality rate of Wilt-

INFANT MORTALITY RATES IN WILTSHIRE AND ENGLAND AND WALES, I900-r904.

\begin{tabular}{|c|c|c|c|c|c|}
\hline Districts. & 1900. & rgor. & I902. & 1903. & I904. \\
\hline County of Wiltshire $\quad \ldots$ & $94^{\circ} \mathrm{O}$ & 9377 & $97: 23$ & $85 \cdot 63$ & 95.99 \\
\hline Urban Districts (Wilts) ... & $95 \cdot 6$ & $106 \cdot 8$ & $93 \cdot 63$ & $89 \cdot 27$ & $100 \cdot 32$ \\
\hline Rural Districts (Wilts) & 1157 & 83.8 & $99 \cdot 89$ & $82 \cdot 76$ & $92^{\circ} 52$ \\
\hline England and Wales & $154^{\circ} \mathrm{O}$ & I5 r.o & $133^{\circ} \mathrm{O}$ & $132^{\circ} \mathrm{O}$ & $145^{\circ} \mathrm{O}$ \\
\hline Large towns in England... & I72. & $168{ }^{\circ} 0$ & $145^{\circ} \mathrm{O}$ & $144^{\circ} \mathrm{O}$ & $160^{\circ} 0$ \\
\hline Rural England and Wales & 138.0 & $137^{\circ} 0$ & $135^{\circ} \mathrm{O}$ & Ir8*0 & $125^{\circ} 0$ \\
\hline
\end{tabular}


shire was 128. In $187 \mathrm{I}-80$ it had fallen to 110 , and in the last decennial period to IO2. It is a county without any large towns, and may be suitably contrasted with England and Wales and with the large towns. The result is shown in the table on the previous page.

This forms a proud record, and it is but a part of a similar record running back over many years. The whole county of Wiltshire is characterised by a lower infant mortality rate even than rural England, but it will be noticed that whilst the rural infant death rate in Wiltshire is always low, it is not always below the urban; yet it is always below the rates for England and Wales. The order of sequence from the worst districts to the best in regard of infant mortality is : Large Towns, Large Towns and Rural Districts, Rural Districts. ${ }^{I}$ It is ever the same as we travel outwards from the centres of our largest towns. In the centre the high rates, on the circumference the middle rates, in the rural district outside the lowest rates. If the metropolitan boroughs in the heart of London be compared with those on the circumference, however rapid their growth, ${ }^{2}$

I Compare the following table of a similar character for Lancashire, one of the worst counties in England in respect of infant mortality :-

\begin{tabular}{|c|c|c|c|c|c|c|c|c|c|c|c|}
\hline \multirow{2}{*}{ DISTRICTS. } & \multicolumn{11}{|c|}{ DEATHS OF CHILDREN UNDER I YEAR TO I,000 BIRTHS. } \\
\hline & 1904. & I903. & 1902. & Igor. & 1900. & I899. & 1898. & I897. & 1896. & 1895 . & 1894. \\
\hline $\begin{array}{l}\text { Administrative } \\
\text { County }\end{array}$ & 157 & 140 & 139 & I6I & 162 & 175 & 168 & 169 & 155 & I7I & 134 \\
\hline Urban Districts & 162 & 143 & 143 & 167 & 167 & I 81 & 173 & 174 & I6I & 178 & 138 \\
\hline Rural Districts & I24 & $\mathrm{II}_{4}$ & II 6 & II 8 & I23 & I34 & $13^{\circ}$ & 138 & $12 \mathrm{I}$ & 127 & 109 \\
\hline $\begin{array}{l}\text { England and } \\
\text { Wales }\end{array}$ & 145 & 132 & I33 & I5I & 154 & 163 & 160 & $15^{6}$ & 148 & $16 \mathrm{I}$ & 137 \\
\hline
\end{tabular}

${ }^{2}$ It has been alleged that rapid increase of population affects infant mortality rates. The most marked increases in town populations in the 
it will be found that the central districts have the highest rates :-

Metropolitan Districts' Infant MORTALITy Raty, Ig0I-05.

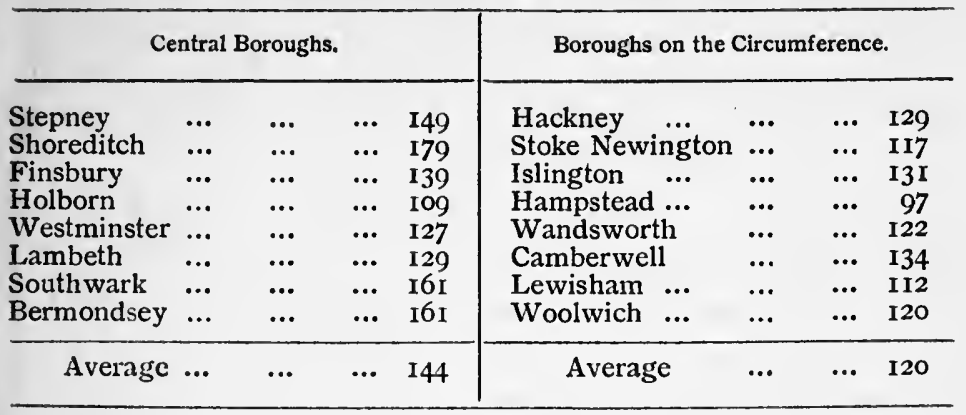

If instead of the metropolitan boroughs, some of which though forming the boundary of London in one part contribute to its centre in another, the really suburban districts be taken the difference between the averages would be greater still. ${ }^{\prime}$ Or if we take Manchester we obtain a similar result. In Manchester township, the central districts of the city, the infant mortality rate in 1904 was 208 -for legitimate infants 196, for illegitimate children 445 per I,000 births. But in North Manchester the figures fell respectively to

inter-census period of $189 \mathrm{I}-\mathrm{I} 90 \mathrm{I}$ were as follows : East Ham increased by 193 per cent. $(32,712$ in 1891 to 96,018 in 1901$)$. The infant mortality in 1905 was 125. Walthamstow increased by 105 per cent. (infant mortality rate 1905, 106). Wiltesden increased by 87 per cent. (infant mortality rate 1905, I 12). Hornsey increased 6I per cent. (infant mortality rate 1905, 66). Leyton increased 56 per cent. (infant mortality rate 1905, 94). Nor are the London outgrowths alone. Two very opposite suburbs of Birmingham may be cited as typical. King's Norton increased from 28,300 in I891 to 57,122 in I9OI, an increase of Ior per cent. The infant mortality for 1905 was 89 . Sinethwick increased by 56 per cent., and even its infant mortality rate is only 137 for 1905 .

x Taking the infant mortality rate for 1905 in Croydon, Willesden, Hornsey, Tottenham, West Ham, East Ham, Leyton, and Walthamstoweight districts actually on the circumference of London and comprising a total population of $1,135,316$, we get an average infant mortality rate of 108 per I,000 births. 
I66, I 59, and 408, and in the country districts north of Manchester the infant mortality was 124 per 1,000 births. All these facts and figures point to one conclusion, namely, that there is a relation existing between conditions arising out of urban life which are unfavourable to the life of infancy, and there are conditions existing in rural districts which are on the whole favourable to infancy.

We must therefore examine more closely into the facts relating to urban and rural counties. Fortunately this has been made possible by the returns provided by the Registrar-General, and in particular in his report for 1891 . In that year the infant mortality rate for England and Wales was 149 , which was higher than the average of the decennial period immediately preceding. The rates, however, for the several counties followed the ordinary distribution, "the general rule being," as the RegistrarGeneral expresses it, "that the rate is lowest in the purely agricultural and highest in the mining counties and those with textile industries." Particularly is it high in the towns in the latter, of which Preston, Blackburn, and Leicester are fairly typical. In order to compare infant mortalities of urban and rural districts the RegistrarGeneral selected the two extremes, namely, three agricultural counties, in which, as we have seen, the mortality of infants is low, and the three towns above named. For comparative purposes five mining and manufacturing counties were selected as lying between the two, being neither purely industrial and yet containing a considerable intermixture of rural elements. These five districts were Staffordshire, Leicestershire, Lancashire, the West Riding of Yorkshire, and Durham.

The infantile deaths in these three groups of districts in I889-9I were as follows :- 


\begin{tabular}{|c|c|c|c|c|c|c|}
\hline \multirow{2}{*}{ AGE. } & \multicolumn{3}{|c|}{$\begin{array}{l}\text { OF 100,000 Infants BORN, THE NuMBER } \\
\text { SURVIVING AT EACH AGE. }\end{array}$} & \multicolumn{3}{|c|}{$\begin{array}{l}\text { ANNUAL DEATH RATES } \\
\text { PER I,OOO LIVIMG IN } \\
\text { EACH SUCCESSIVE } \\
\text { INTERVAL OE AGE. }\end{array}$} \\
\hline & $\begin{array}{l}\text { Three Rural } \\
\text { Counties : } \\
\text { Herts, Wilts, } \\
\text { Dorset. }\end{array}$ & $\begin{array}{c}\text { Five Mining } \\
\text { and Manufac- } \\
\text { turing Counties: } \\
\text { Staffs, Leic., } \\
\text { Lancs, W. R. } \\
\text { Yorks, Durham. }\end{array}$ & $\begin{array}{l}\text { Three Selected } \\
\text { Towns : Pres- } \\
\text { ton, Blackburn, } \\
\text { Leicester. }\end{array}$ & 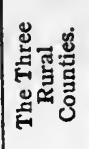 & 总骂总 & $\begin{array}{l}\text { The } \\
\text { Three } \\
\text { Towns. }\end{array}$ \\
\hline At birth & 100,000 & 100,000 & 100,000 & $2 \mathrm{I} 3$ & $33 I$ & 382 \\
\hline 3 months & 94,820 & $92,05 \mathrm{r}$ & 90,874 & 75 & I54 & 240 \\
\hline 6 months & 93,068 & 88,574 & 85,574 & $6 \mathrm{I}$ & I28 & 180 \\
\hline I 2 months & 90,283 & $83,08 \mathrm{I}$ & 78,197 & - & - & - \\
\hline
\end{tabular}

From this table it is evident that in the three years under consideration that of 100,000 infants born in the agricultural counties 5,180 had died within the first three months, in the mining districts 7,949 had died, and in the three selected towns 9,126 had died. These differences are sufficiently distinct to emphasise the fact that infant life survives in much greater measure in agricultural districts. But for reasons which will appear subsequently the first three months of life are likely to witness less change in incidence of death in such groups as these three than later months in the first year of life. And this becomes evident when we observe that at the end of the first twelve months there have died in the rural counties, in round numbers, 10,000 infants, in the manufacturing counties 17,000 , and in the manufacturing towns 22,000 , or more than double the total of the agricultural districts. The annual death rates tell the same story.

That further light might be thrown upon the interesting record revealed in this table, the Registrar-General furnished full particulars with regard to the actual cause of death and the exact period in the first year at which death 
took place in the case of the infants dying in the agricultural counties and in the three selected towns. The broad facts which they teach may be mentioned here. Taking the three rural counties and the three selected towns the following features are common to both groups:-

(a) The infant mortality is highest in the first day of life in both groups. Out of 100,000 infants born I,002 died on the first day in the counties and I, 198 in the towns.

(b) The mortality, though remaining high, then declines through the remaining days of the first week, falling from 296 on the second day to 80 on the seventh in the counties and from 485 to Iog in the towns.

(c) The mortality is at its maximum in the first week, falls enormously in the second week, remains at much the same level through the third week, and falls again in the fourth. In the towns the mortality rose in the third week.

(d) Passing from weeks to months the mortality falls enormously in the second month, by 2,493 deaths in the counties and $2,8 \mathrm{I} 7$ in the towns. Then it continues very slowly to fall during the remainder of the year, showing, both in the three counties and the three towns, the least fall between the seventh and eighth months.

So much for the characteristics which are common to both the agricultural group and the town group. In both the mortality is so high in the first week that were it maintained without diminution every infant of 100,000 would die without nearly completing one year of existence. These common features, presented alike by low infant mortality of rural counties and the high infant mortality of certain towns, must, as the Registrar-General points out, be accepted as distinguishing infant mortality generally. 


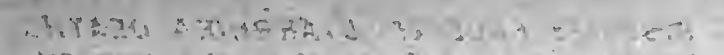

(1)

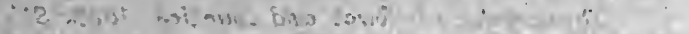

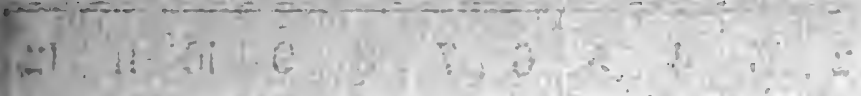

if

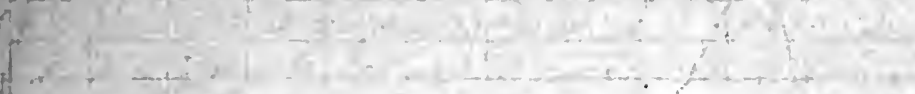

$\sqrt{3}$

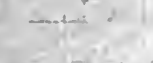

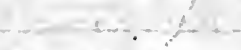

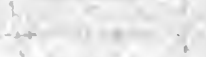

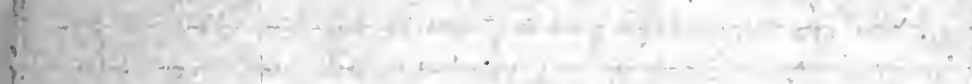

i.

6
$\vdots$
$\vdots$

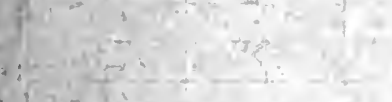

ir.

that ari,

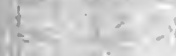

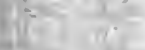

?

$5 i=$

is

$-2$

$1-x^{2}=$

$=-2+1+9$

$\therefore i=1$

$1+1,1=0+3$

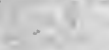

$18=$

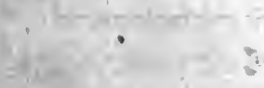

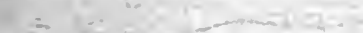

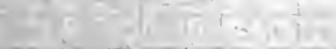

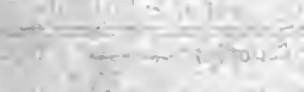

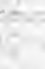

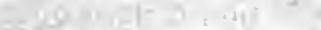

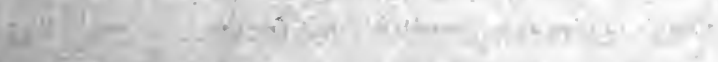

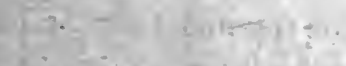




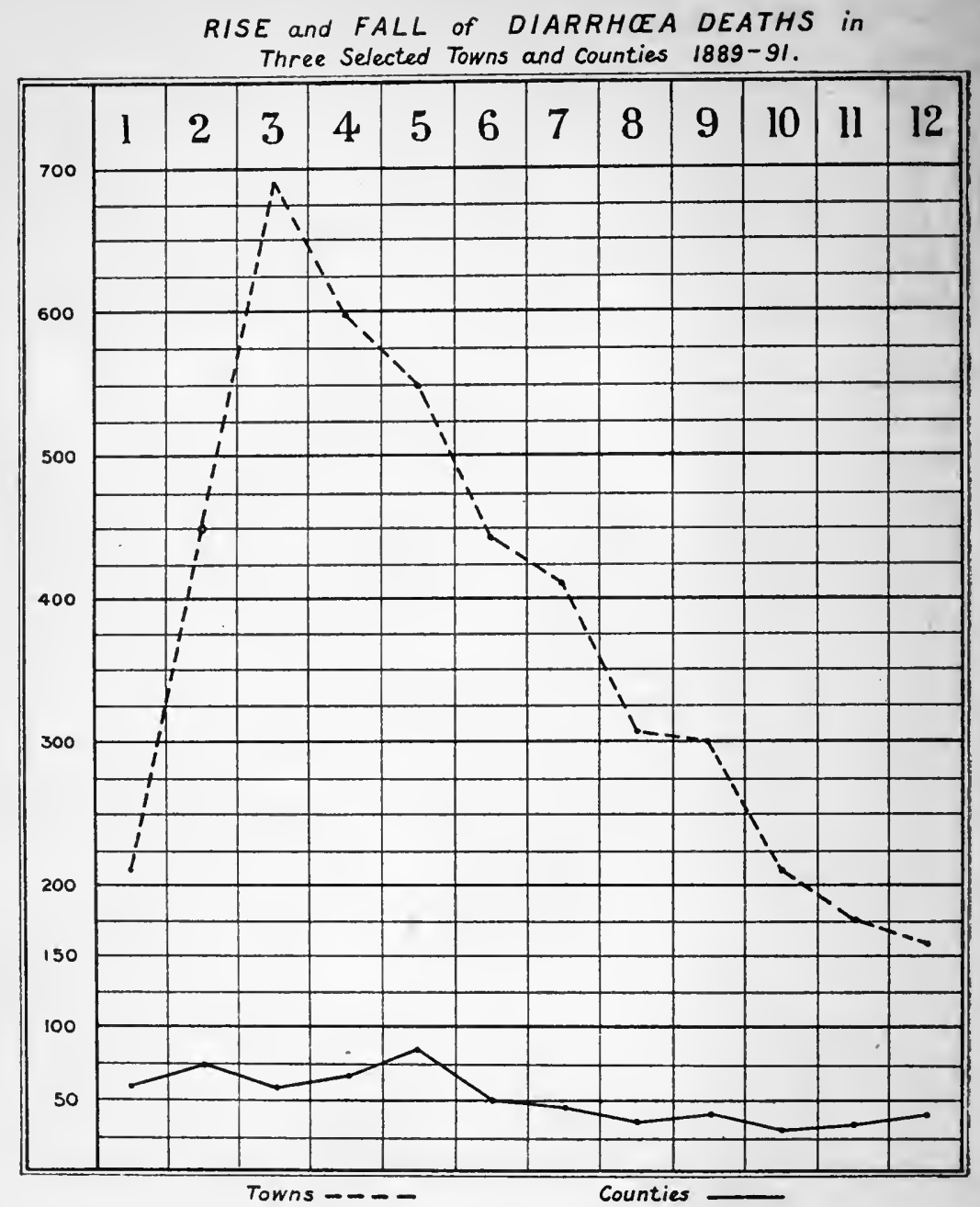

Deaths per 100,000 infants born alive stated for each month of first year 
The differences must now be named.

(a) The aggregate mortality in the three towns is twice as high as it is in the three counties. There are, in fact, 21,803 deaths in the towns as compared with 9,717 in the counties.

(b) The town rate is throughout the twelve months higher than the rural rate except on the fifth day of the first week.

(c) The town rates are most in excess of the rural rates in the later months of the year. In the first week of life the town rate exceeds the rural by 23 per cent., in the second by 64 , in the third by 83 , and in the fourth by 97 , showing a progressive increase in the deleterious effects of town conditions on infant life. And the same is true of the months; until in the sixth month it amounts to no less than 273 per cent. The conditions of Preston, Leicester, and Blackburn therefore destroyed infants in 1889,1890 , and 1891 throughout the first year of life, but more so in the later weeks of the year than in the earlier, and they were especially destructive after the second month.

When we turn to the table of causes some explanation of these remarkable rates is obtainable. First, in both groups premature birth, congenital defects, atrophy, and immaturity have their maximum in the first weeks, causing more than four-fifths of all the deaths in the first month. Secondly, the next wave of disease begins about the second month, and consists of respiratory diseases and diarrhœa; the former runs through the rest of the year, the latter reaches its zenith about the third and fourth months, after which it slowly declines (see Chart). Thirdly, infectious diseases, such as whooping-cough and measles begin, the former in the second month and the latter somewhat later, reaping their harvest of death later in the year.

The chief causes of death in the counties are, in order, immaturity, respiratory diseases, and nervous diseases, including convulsions; in the towns the chief causes are 
immaturity, diarrhœe, nervous diseases, including convulsions, and respiratory diseases. Infectious diseases, "overlaying," and syphilis are more frequent as causes of death in the towns than in the counties. Thus the salient features may be expressed in two sentences-

All diseases of infancy are heavier in the towns than the counties; but immaturity is twice as fatal and epidemic diarrheea seven times as fatal in the towns.

In conclusion, then, it may be said that the distribution of infant mortality in Great Britain follows mainly in the wake of urbanisation - that is, high density of population in towns-combined with industrial and social conditions. It becomes in its most acute form a problem of town life. Rural life, as found in agricultural counties, appears to be favourable to infancy, probably owing to social conditions and domestic habits. But in those counties which are largely composed of towns, or in the towns themselves, the infant mortality is in excess of that of rural districts, particularly in the later months of the first year. Immaturity exacts its toll of deaths in both urban and rural communities, though most heavily in the towns. Epidemic diarrhoea, on the other hand, is in the main an urban disease. It is now necessary, therefore, to consider the diseases which chiefly bring about high infant mortality. 


\section{III}

\section{THE FATAL DISEASES OF INFANCY}

“

I N no year, from the extinction of the plague (in I679) 1 until the last decennium of the eighteenth century, do the bills of the parish clerks show an excess of baptisms over burials, and in most years they show a greater shortcoming of births than the somewhat negligent registration of baptisms could account for. On the other hand, there were many years of the earlier period, in the intervals between the greater explosions of plague, when the baptisms exceeded the burials by various fractions up to 25 per cent. But whereas in the plague period the high mortalities were largely of adults, there is reason to think that afterwards they fell more upon the age of infancy." I

The sacrifice of infant life in London from the Restoration until late in the eighteenth century was enormous, the deaths under the age of two amounting in some years to two-fifths of the deaths at all ages, and to more than half the births. One great cause, in Dr. Creighton's opinion, of this high mortality among infants was the same Summer Diarrhœa that cuts off so many infants in the manufacturing and industrial towns at the present time. "In each of the three successive hot summers and autumns in London, 1669-71, that malady added some 2,000 to the bill [of mortality] for the year in the course of some eight or ten

' Dr. Charles Creighton in Traill's Social England (1903), vol. iv. p. 645. 
weeks. An epidemic of measles in 1674 , the first severe one that is recorded, brought up the deaths by its direct and indirect effects to a much higher average for the first six months of the year than a severe epidemic of smallpox did in the last six. In certain unhealthy seasons, such as those of $1669-71,1678-80,1685-86$, and 1688-89, there were many market towns and country parishes whose registers showed an excess of burials over christenings, the special occasional causes having been widely prevailing fevers, epidemic agues, with influenzas and smallpox."I

London, in the seventeenth and eighteenth centuries, was even more urban than it is now, and within its walls there was more overcrowding of the houses as they then existed, and less ventilation and light. Of sanitation and prevention, as we understand the terms, there was none. Little wonder that epidemic disease wrought havoc, and that every summer brought, with a regularity and certainty that impressed the mind of Sydenham, the very malady which even yet kills in such large numbers the infants of towns. Nor can there be much doubt but that the Fire of London was one of the greatest sanitary events of the seventeenth century. And yet after the rebuilding of London many of the old diseases returned, though probably in less prevalent degree. Though Summer Diarrhœa is periodically still with us in epidemic form, some changes have occurred. Measles is probably less fatal, and smallpox, compared with its ravages before the time of Jenner, has almost vanished. Epidemic ague has likewise been driven out. What, then, has been left that our infant mortality rate remains high?

The diseases from which infants die are various. But for obvious reasons they are less diverse than those causing death in adults. The influences surrounding the life of an infant are less numerous and on the whole less complex.

× Dr. Charles Creighton in Traill's Social England (1903), vol. iv. p. 646. 
Its environment is not only smaller in compass and sphere but more uniform throughout than that of the adult. It is less exposed to weather, to cold, to a changing diet, to the dangers and exigencies of occupation, and so forth. On this account it is possible to delimit the main causes of death in infancy with some exactitude.

In the Appendix will be found two tables ${ }^{\mathrm{I}}$ in which are classified the chief causes of death among male and female infants in England and Wales, and in London in 1903, the latest year for which statistics are available. ${ }^{2}$ For England and Wales the diseases causing most infant deaths are charted on the attached diagram. The total number of deaths of children under twelve months of age in England

Appendix pp. 334, 335 .

2 Since this chapter was in type the Registrar-General's Report for Ig04 has been issued, in which the following interesting table appears, giving the Infant Mortality Rate for England and Wales in 1904 (Tatham) under the chief causes:-

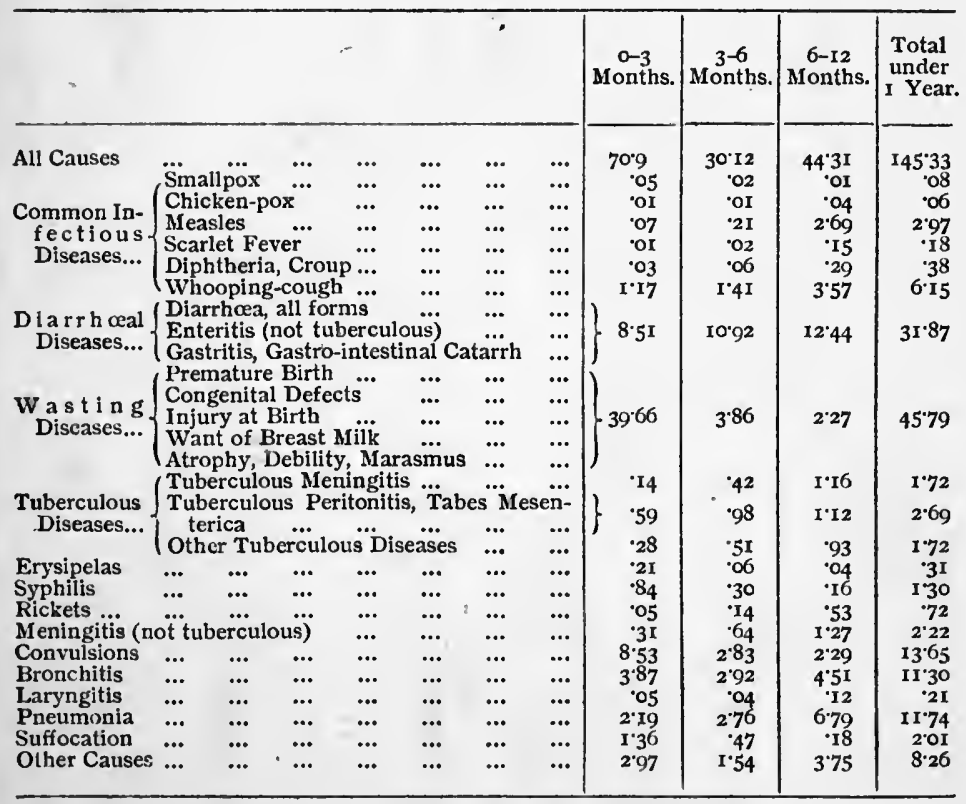


and Wales in 1903 was 124,718 . The following diseases caused 84 per cent. of this total, as follows :-

\begin{tabular}{|c|c|c|c|c|c|c|}
\hline & & & & & $\begin{array}{l}\text { No. of Infant } \\
\text { Deaths. }\end{array}$ & $\begin{array}{l}\text { Percentage of Total } \\
\text { Infant Deaths. }\end{array}$ \\
\hline \multicolumn{5}{|c|}{ Prematurity and Congenital Conditions... } & 23,886 & r9:I \\
\hline Diarrhoea and En & ateritis & ... & ... & ... & 17,387 & 13.9 \\
\hline Atrophy and Deb & ility & $\ldots$ & $\cdots$ & $\ldots$ & 16,588 & 1322 \\
\hline Convulsions ... & ... & ... & ... & ... & 13,283 & 10.7 \\
\hline Pneumonia $\ldots$ & ... & ... & ... & ... & I0,84I & $8 \cdot 7$ \\
\hline Bronchitis $\quad \ldots$ & ... & $\ldots$ & ... & ... & 10,792 & $8 \cdot 7$ \\
\hline All Tuberculous I & Diseases & ... & ... & $\ldots$ & 5,701 & $4^{\circ} 6$ \\
\hline Whooping-cough & $\ldots$ & $\ldots$ & $\ldots$ & $\ldots$ & 4,773 & $3 \cdot 8$ \\
\hline Measles $\quad \ldots$ & $\ldots$ & $\ldots$ & $\ldots$ & $\ldots$ & $2,14 I$ & $1 \cdot 7$ \\
\hline All other causes & $\ldots$ & ... & ... & ... & 19,326 & $15^{\circ} 6$ \\
\hline Total ... & ... & $\ldots$ & $\cdots$ & ... & 124,718 & $100 \cdot 00$ \\
\hline
\end{tabular}

It will be seen that Prematurity and Atrophy together constitute more than 30 per cent. of the total deaths. The death rate from these diseases is, as a rule, approximately the same in London and in large towns, namely, 45 per 1,000 , as compared with 42 in the country districts. Dr. Farr used to say that 7 per cent. of all births were premature. In Finsbury during the last five years the deaths of infants from conditions to be classified under this term were as follows :-

INFANT DEATHS FROM IMMATURITY IN FINSBURY, CENTRAL LONDON, I9OI-05.

\begin{tabular}{|c|c|c|c|c|c|c|}
\hline & IgOI & 1902 & I903 & 1904 & 1905 & Totals. \\
\hline $\begin{array}{l}\text { I. Premature Birth } \\
\text { II. Congenital Conditions (in- } \\
\text { cluding Atrophy, Debility } \\
\left.\begin{array}{lll}\text { Atelectasis and } & \text { Wasting } \\
\text { Disease) } & \ldots & \ldots\end{array}\right\}\end{array}$ & 97 & 79 & 86 & 63 & 65 & 342 \\
\hline Total Deaths from Immaturity & 162 & 169 & 156 & 152 & 132 & 771 \\
\hline $\left.\begin{array}{c}\text { Total Infant Deaths ... } \\
\text { Percentage of Immaturity } \\
\text { Deaths on } \\
\text { Deaths ... } \\
\text { Total Infant }\end{array}\right\}$ & $\begin{array}{r}533 \\
30.4\end{array}$ & $\begin{array}{r}558 \\
30 \cdot 3\end{array}$ & $\begin{array}{r}503 \\
31 \cdot 0\end{array}$ & $\begin{array}{r}522 \\
29 \cdot I\end{array}$ & $\begin{array}{r}429 \\
30 \cdot 7\end{array}$ & $\begin{array}{r}2,545 \\
30 \cdot 3\end{array}$ \\
\hline
\end{tabular}


ENGLAND \& WALES 1903.

Thirteen principal causes of Deaths of Infants.

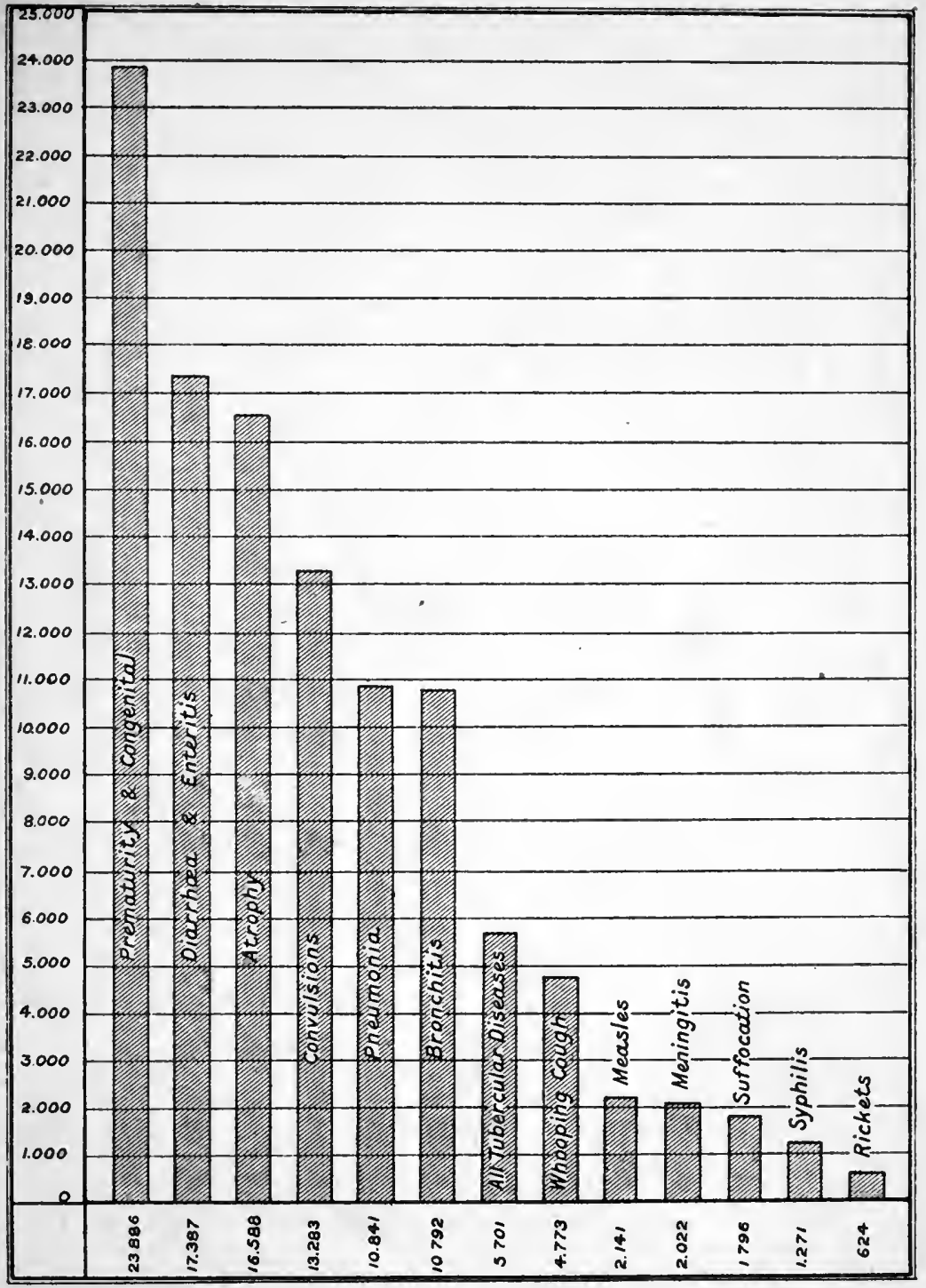



In Glasgow (1903-04) the figure was 32.2 ; in Manchester (1904) 30.8; in Liverpool (1904) 29.7; and in Brighton (1905) $39^{\circ} 0$ per cent. of the total infant deaths. The distribution of these deaths in Glasgow are printed in a table in the Appendix. The distribution in Manchester for the last five years (1900-04) are as follows :-

CITY OF MANCHESTER.

DEATH RATES UNCER I YEAR PER I,OOO BIRTHS.

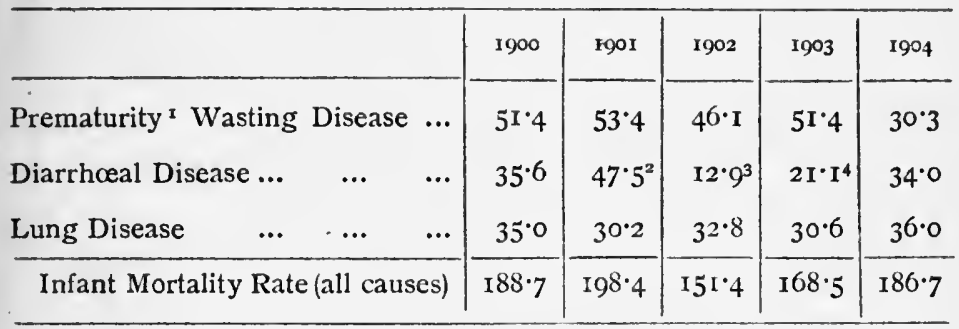

It will be noted that atrophy and debility are grouped with prematurity as belonging really to the same genus of diseases, which with congenital defects form a large group of conditions having, in many cases, an ante-natal origin. These children are simply born in such poor physical condition that they are unfit to live, and find a few hours or days of extra-uterine life too much for them. They are not so. much diseased as merely unfit, and either not ready or not equipped for a separate existence. In Manchester in 1891 wasting diseases and prematurity caused 20.5 per cent. of the total infant deaths; in 1905 these conditions caused $29^{\circ} 6$ per cent.

These include premature birth, atrophy, marasmus, debility, inanition, \&c.

2 The mean temperature of third quarter in I90I was $6 I^{\circ} 9$ as against mean of $59^{\circ}$ for 15 years. The rainfall was 6.5 in. as against 9.4 mean for 15 years.

3 The mean temperature of the third quarter in 1902 was $57^{\circ} 6^{\circ}$ as against $59^{\circ} 0^{\circ}$. The rainfall was $5^{\prime} 9$ in.

4 Mean temperature of third quarter $57.8^{\circ}$ as against mean of $59^{\circ}$. The rainfall was $12 \cdot 3$ in. 
Epidemic Diarrheea is, as we shall see in a later chapter, a specific and fairly definite disease. It is the most destructive of all diseases attacking children under the age of five years. Diarrhœal diseases are ordinarily very much more fatal in urban districts than rural, are more dangerous to boys than to girls, and cause the greatest havoc among children in the first year of life, bringing about on an average one-fifth of the total mortality of infants. In the table on p. 46 it will be seen that the disease was responsible in 1903 for 13.9 per cent. of the infant deaths in England and Wales. This figure only concerns zymotic diarrhœa and does not include gastric catarrh or gastritis. All these diseases, as we shall subsequently see, are aggravated by bad housing conditions, poverty, artificial feeding, and domestic insanitation. It has been shown that in poor homes diarrhœa alone may cause an infant mortality rate of 30 or 40 per 1,000 births, whereas under better circumstances it may contribute only Io or 12 per 1,000 to the infant mortality rate.

Convulsions is a word designating a symptom rather than a disease. But it has come to be used, unfortunately, as synonymous with disease. The condition may be idiopathic and allied to epilepsy. Possibly ro per cent. of the cases of epilepsy begin specifically as convulsions. More commonly the condition is symptomatic of other disease. (I) It may be the indication of brain disease, such as meningitis or intracranial tumour, or even a fall on the head ; (2) it may be of the nature of a rigor and indicate the onset of an acute fever, such as scarlet fever or pneumonia; (3) reflex irritation may cause it due to unwise diet, or colic, or teething, or the presence of parasitic worms in the intestine; (4) lastly, convulsions may be caused by toxic conditions of the blood, such as uræmia and some cases of epidemic diarrhœa. These four conditions do not exhaust the etiology of this symptom, 
which is always aggravated, if not in part caused, by constitutional disease such as rickets and possibly syphilis. But be it caused how it may, "convulsions" kills upwards of 13,000 infants in England and Wales every year, and proves to be most fatal in the first weeks of life.

Pneumonia is a disease which affects all classes and at all ages. It is not in any special sense a disease of infancy, and yet more than 10,000 infants succumb to it annually, and another 10,000 to bronchitis in England and Wales alone. The urban rates are usually some 80 per cent. in excess of the rural, and males suffer more than females. It is in childhood and old age that pneumonia is most destructive to life. No doubt it is caused in part by careless exposure of infants to cold. Infancy is a time of very fine physical susceptibility, and in no respect more so than in bodily temperature.

One further preliminary matter remains to be considered, namely, the distribution of the chief fatal diseases of infancy as regards urban and rural districts in England. The returns for the latest available quinquenniad are set out on the next page.

From these figures will be seen the influence of urban life upon infant death rates distributed as to disease. Each of the chief diseases is more fatal in urban counties than in rural, but particularly is this so in diarrhœal diseases. In Dundee, a typically urban district with all its evils, the three common causes of infant mortality are immaturity, respiratory diseases, and gastric conditions. The first is probably due to pre-natal influences, the second to exposure, and the third is "associated with the predominance of married women's labour." I

In passing it may be noted that in France the chief

I Dundee Social Union Report on Housing and Industrial Conditions in Dundee, I905, pp. 68, 69 .

E 
cause of infant mortality appears to be epidemic diarrhœe. Balaestra and Gilletta have shown that of a thousand dead infants 385 succumbed to diarrhœa, 177 to congenital defects, 147 to pulmonary affections, and 50 to contagious diseases. In the urban districts of Pas-deCalais it was found that even a higher proportion of infants died from diarrhœa. ${ }^{I}$

INFANTILE MORTALITY.-DEATHS UNDER ONE YEAR OF AGE PER I,OOO BIRTHS.

AVERAGES, I898-IgO2.

\begin{tabular}{|c|c|c|c|c|c|c|c|c|c|c|c|}
\hline & & & 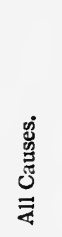 & 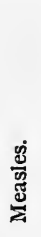 & 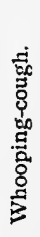 & 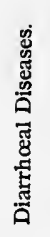 & 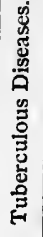 & 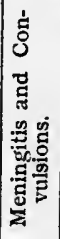 & $\begin{array}{l}\text { 芯 } \\
\text { : } \\
\text { : } \\
\text { : }\end{array}$ & 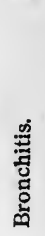 & 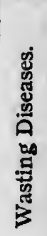 \\
\hline \multirow{3}{*}{$\begin{array}{r}\text { Both } \\
\text { Sexes. }\end{array}$} & (England \& Wales & $\cdots$ & 152 & 3 & 5 & 32 & 7 & I9 & II & 14 & 45 \\
\hline & Urban Counties... & $\cdots$ & 165 & 3 & 5 & 37 & 7 & $2 I$ & 12 & 15 & 45 \\
\hline & (Rural Counties ... & $\cdots$ & 126 & 2 & 5 & I9 & 5 & I8 & 8 & II & 43 \\
\hline \multirow{3}{*}{ Boys. } & (England \& Wales & ... & 167 & 3 & 5 & 35 & 7 & $2 \mathrm{I}$ & 12 & 15 & 50 \\
\hline & Urban Counties... & $\cdots$ & I80 & 4 & 5 & 39 & 8 & 23 & 14 & 16 & 50 \\
\hline & (Rural Counties ... & $\cdots$ & I39 & 2 & 5 & $2 I$ & 5 & 20 & 9 & 12 & 48 \\
\hline \multirow{3}{*}{ Girls. } & (England \& Wales & $\cdots$ & 137 & 3 & 6 & 30 & 6 & I7 & 9 & 12 & 40 \\
\hline & Urban Counties... & $\ldots$ & I49 & 3 & 6 & 35 & 7 & I8 & II & I3 & 40 \\
\hline & (Rural Counties ... & $\cdots$ & III & 2 & 6 & I6 & 4 & I5 & 7 & IO & 38 \\
\hline
\end{tabular}

An examination of these various returns seems at first sight a formidable task. Yet if we take a broad view of the matter we shall find that there are at the present time

' Revue d'Hygiène et de Mèdicine Infantiles, I902 (Budin), pp. 398-9. 
five main pathological conditions, to which we can reduce these tables, which prove more fatal than any other diseases within the first twelve months of life. These five conditions are as follows :-

I. Epidemic diarrhœa.

2. Respiratory disease (including bronchitis and pneumonia).

3. Prematurity and congenital defects.

4. Atrophy and debility.

5. Meningitis and convulsions.

After these five diseases there is a long gap in fatality until we come to tuberculous diseases, whooping-cough, measles, and diseases of the stomach and liver. The above-named diseases have been stated in order of occurrence in male and female infants and for urban communities. For rural districts there would be some alteration in order of importance, but not otherwise. For example, in rural districts prematurity and congenital defects would stand first, and would be followed by atrophy, which in its turn would be closely followed by the other three conditions named. But the five conditions would remain as by far the greatest contributors to the death of infants. Moreover, if we go back a quarter of a century and examine the bills of mortality of that period we shall find precisely these same five diseases playing havoc with infant life. But the chief of the five will be general conditions, such as atrophy and bronchitis, and prematurity and diarrhœa will be at the bottom of the list. In addition to the decline which has taken place in bronchitis, in atrophy, debility and inanition, and in meningitis and convulsions, there has also been a marked decline in some of those diseases which make a smaller contribution to the fatality of infants, such as tuberculosis, syphilis, smallpox, and other infective diseases. 
AVERAGE RATE OF INFANT MORTALITY UNDER ONE YEAR PER I,000 BIRTHS AMONG MALE AND FEMALE INFANTS -SEVERALLY-IN A GROUP OF URBAN AND A GROUP OF RURAL COUNTIES, IN THE OPENING AND CLOSING QUINQUENNIA RESPECTIVELY OF THE LAST QUARTER OF A CENTURY.

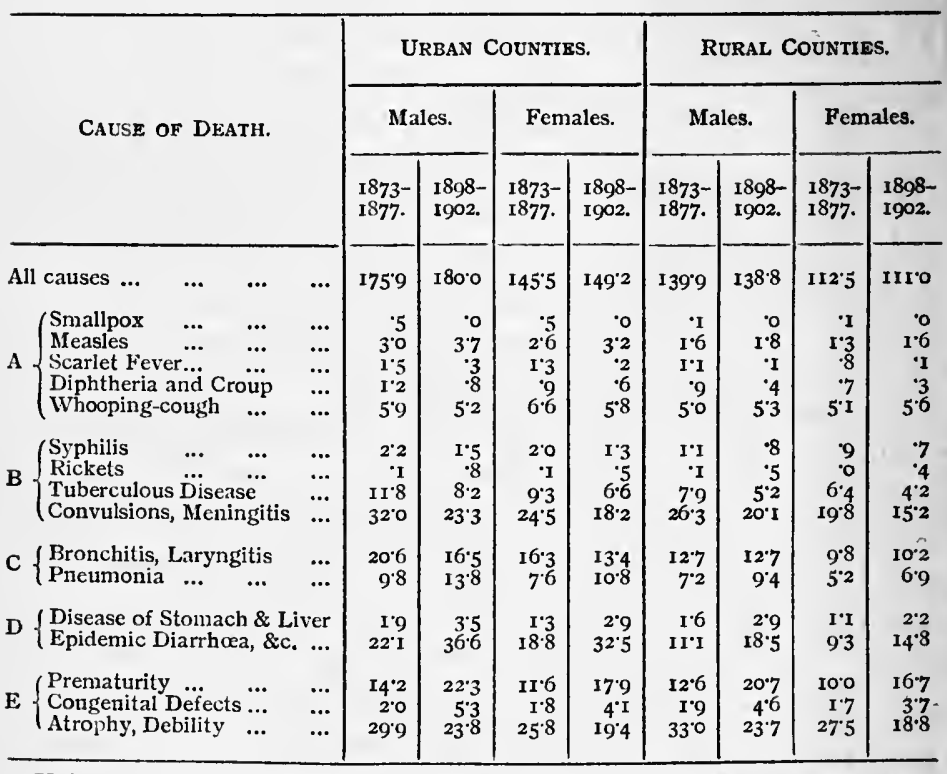

Urban Counties.-Glamorgan, Lancaster, London, Middlesex, Monmouth, Northumberland, Nottingham, Stafford, Warwick, East Riding, West Riding (York). Estimated urban population (I902), I7,818,667.

Rural Countics.-Buckingham, Cambridge, Cornwall, Hereford, Huntingdon, Lincoln, North Wales, Norfolk, Oxford, Rutland, Salop, Somerset, South Wales (less Glamorgan), Suffolk, Westmoreland, Wilts. Estimated urban population (1902), 4,279, 175.

There has been, then, a heavy decline in some of the infant diseases which were most fatal twenty-five years ago, and yet the total infant mortality has not declined. It therefore seems probable that some fatal conditions have increased. Now, when we examine the accompanying table, modified from Dr. Tatham ${ }^{\mathbf{}}$ we shall find

Report of Interdepartmental Committee on Physical Deterioration, vol. i. p. I32. 
that the causes which have contributed to maintain the total infant mortality at about its former level appear to have been epidemic diarrhoea, pneumonia, and prematurity, including congenital defects.

"The increase of pneumonia mortality," writes Dr. Tatham, "is coincident with an increased fatality of that disease in the general population, and although this increase between the two quinquennia [1873-77 and 1898-1902] is proportionally large, it counts but little against the decrease from the other causes just mentioned. With diarrhoeal diseases and with premature birth and congenital defects the case is far different, the increased mortality from these causes being very marked. Taking together diarrhœal diseases and diseases of the stomach and liver, the recent five years show an increase of more than 70 per cent. in the urban and of nearly 70 per cent. in the rural counties. From premature birth and congenital defects the increase, though numerically smaller, was proportionally even greater than that from diarrhœal diseases. Among males in the urban counties the rate had increased by 70 per cent., and among females by 64 per cent., while in the rural counties it had increased by 74 per cent. in each sex." Dr. Tatham states that "the increased mortality from diarrhœal diseases is probably attributable in great part to the prevalence of artificial infant feeding, and this view appears to be consistent with the fact that the increase has been greater in the urban than in the rural counties." $\mathrm{x}$

It should be added that Whooping-cough showed a decrease of more than ro per cent. in the urban counties but an increase of nearly the same amount in the rural counties, while Measles showed an increased fatality among children of each sex and in both groups of counties.

Report of Interdepartmental Committee on Physical Deterioration, vol. i. p. 30 . 
Much the same broad conclusions must be arrived at if we take England and Wales as a whole instead of selected areas. The following table sets out the annual death rates at all ages in England and Wales from measles, whooping-cough, diarrhœa, and prematurity from 1866 to the last decennium. I

\begin{tabular}{|c|c|c|c|c|}
\hline \multirow{2}{*}{ Years. } & \multicolumn{4}{|c|}{$\begin{array}{l}\text { ANNUAL DEATH RATES IN ENGLAND AND WALeS } \\
\text { FROM CERTAIN DISEASES OF INFANCY PER } \\
\text { MILLION PERSONS LIVING. }\end{array}$} \\
\hline & Measles. & $\begin{array}{l}\text { Whooping- } \\
\text { cough. }\end{array}$ & Diarrhœa. & $\begin{array}{l}\text { Prematurity } \\
\text { and Congenita } \\
\text { Defects. }\end{array}$ \\
\hline $1866-70$ & 428 & 545 & $I, 235^{2}$ & $47 \mathrm{I}$ \\
\hline I87I-75 & 373 & 498 & $I, 03 I^{2}$ & $5^{12}$ \\
\hline I $876-80$ & 384 & 527 & $85^{2^{2}}$ & 557 \\
\hline I $88 \mathrm{I}-85$ & $4 \mathrm{I} 3$ & $45^{8}$ & 672 & 560 \\
\hline I 886-9o & 468 & 443 & $68 I$ & $5^{88}$ \\
\hline I89r-95 & 407 & 397 & $65 I$ & 646 \\
\hline I896-I900 & $42 \mathrm{I}$ & $35^{8}$ & 817 & 659 \\
\hline
\end{tabular}

These figures, of course, have the disadvantage for the present purpose of dealing with deaths at all ages, but with the exception of diarrhœa the diseases are almost wholly of children only. The result is fairly clear-measles has declined less than whooping-cough; diarrhœa, if cholera be deducted, is steadily increasing; and fatality from prematurity and congenital defects have increased by 40 per cent. since r $866-70$. The returns for London since $185 \mathrm{I}-60$ show almost precisely the same changes, except that whooping-cough shows a more marked decline. But it is important to follow the changes of diarrhœa, pre-

I Sixty-sixth Annual Report of Registrar-General (1903), p. ciii.

2 Including cholera. 
maturity, and respiratory diseases in London with more precision. For this purpose the following table has been drawn up from the Registrar-General's reports in the two periods quoted :-

\section{LONDON.}

DEATHS UNDER I YEAR.

Percentage on Total Infant Deaths.

\begin{tabular}{|c|c|c|c|}
\hline DiSEASE. & $\begin{array}{r}1845^{-1849} \\
\text { (inclusive). }\end{array}$ & $\begin{array}{c}1899^{-1} 1903 \\
\text { (inclusive). }\end{array}$ & $\begin{array}{l}\text { Percentage } \\
\text { Increase. }\end{array}$ \\
\hline Epidemic Diarrhœa ... $\quad$... & $10 \cdot 7$ & $15 \cdot 1$ & $4 I \cdot I$ \\
\hline Pneumonia and Bronchitis ... & $16 \cdot 3$ & $18 \cdot 8$ & $15 \cdot 3$ \\
\hline $\begin{array}{l}\text { Prematurity (including Congenital } \\
\text { Defects, Atrophy, Debility) }\end{array}$ & $17 \cdot 2$ & $29 \cdot 5$ & $7 I \cdot 5$ \\
\hline
\end{tabular}

Here we have returns for infants only, covering a period of about sixty years. The changes which have occurred in the relative importance of death from these three causes are emphatic. Diarrhœe, which formerly caused the death of only ro per cent. of dead infants, has increased in half a century to 15 per cent.; respiratory diseases have risen from 16 to 18 per cent.; and prematurity from 17 to 29 per cent.I These figures may be accepted as representative of the changes which have been proceeding with all the more confidence in that the returns which Dr. Tatham furnished ${ }^{2}$ for urban counties, 1873-77 compared with 1898-1902, occupy an intermediate position in percentage on total infant deaths between the returns in the above table for 1845-49 and 1899-1903. The changes here represented, then, had been going on more or less through the whole period, and, allowing for variations

I In Liverpool the number of deaths from prematurity per I,000 in 1903 was more than double the number per 1,000 births in 1873 .

Report of Interdepartmental Committee on Physical Deterioration, I904, vol. i. p. I3I. 
in nomenclature and improved medical diagnosis, the percentage increase is so marked that it cannot be doubted.

Nor is England alone, for the changes which have been taking place here, an old country, during the last half century, have begun to take place in the Australian Colonies, a new country, within the last ten years. In New South Wales there has been a decline in infant deaths due to certain zymotic diseases, to convulsions and to debility, but an increase in the number due to diarrhœa and prematurity. Comparing 1902 with 1893 , diarrhoa and enteritis has undergone an increase of 30 per cent. and prematurity an increase of 26 per cent. $\mathrm{I}$

These facts leave us in no doubt as to the total increase which has taken place in some of the chief fatal diseases of infancy - to wit, prematurity and congenital conditions, epidemic diarrhœa, and respiratory diseases.

Other children's diseases are vanishing or have vanished. There has been a vast improvement in the general environment surrounding their lives. But the problem of infantile mortality still remains because of the increase in these diseases-prematurity, pneumonia, and diarrhœa.

We have now to consider the age incidence of these diseases, and some particulars as to occurrence and fatality. And first as to age incidence. To obtain light upon this point it is necessary to bear in mind the age incidence of death in infants, which, as we have already seen, falls mainly upon the first trimester of the first year of life, and becomes less in each succeeding quarter. The table on the opposite page will serve to emphasise this fact again (see also p. I4) :-

From these figures it is evident that whatever differences in circumstances and conditions obtain in these six towns,

I See Appendix, p. 338. Much the same change has taken place in other Australian States. 


\begin{tabular}{|c|c|c|c|c|c|c|c|}
\hline+ & 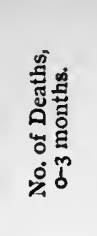 & 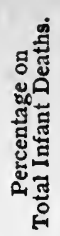 & 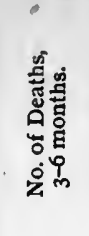 & 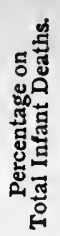 & 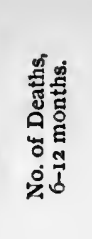 & 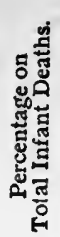 & 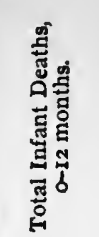 \\
\hline Manchester, I904... & 1,464 & $45^{\circ} \mathrm{I}$ & 729 & $22 \cdot 5$ & I,047 & $32 \cdot 3$ & 3,240 \\
\hline Blackburn, I904 ... & 266 & 447 & 142 & $23^{\circ} 8$ & I87 & 314 & 595 \\
\hline Oldham, $1904 \quad \ldots$ & 262 & $48 \cdot 7$ & I 16 & $2 I \cdot 6$ & I59 & $29 \cdot 6$ & 537 \\
\hline Finsbury, $1905 \quad \ldots$ & 206 & $4^{8} \cdot 0$ & 87 & $20 \cdot 2$ & 136 & $3 I^{\prime} 7$ & 429 \\
\hline Brighton, 1905 $\quad .$. & 164 & $55 \cdot 2$ & 59 & I9.8 & 74 & 249 & 297 \\
\hline Glasgow, I904 $\quad \ldots$ & 1,736 & $48 \cdot 5$ & 675 & & I, I64 & $32 \cdot 5$ & 3,575 \\
\hline $\begin{array}{l}\text { England and } \\
\text { Wales, } 1904\end{array}$ & 67,021 & $4^{8 \cdot 7}$ & 28,478 & $20 \% 7$ & $4 I, 893$ & $30^{\circ} 4$ & 137,392 \\
\hline
\end{tabular}

they all yield the same result, namely, that about 45 per cent. of all infant deaths occur in the first trimester. In England and Wales the percentage is 48 . If this first trimester were further subdivided into one-month periods, it would be found that the majority of deaths occur in the first month, next in the second, and so on (see p. I I). Now if we take the three diseases which are increasingly responsible for infant mortality, we shall find that for these same towns the percentages are as follows :-

PERCENTAGES OF INFANT DEATHS FROM CERTAIN CAUSES ON TOTAL INFANT DEATHS.

\begin{tabular}{|c|c|c|c|c|c|c|c|c|c|c|}
\hline \multirow[t]{2}{*}{1904.} & \multicolumn{3}{|c|}{$\begin{array}{l}\text { DIARRHCEA AND } \\
\text { ENTERITIS. }\end{array}$} & \multicolumn{3}{|c|}{$\begin{array}{l}\text { PNEUMONIA AND } \\
\text { BRONCHITIS. }\end{array}$} & \multicolumn{3}{|c|}{ PREMATURITY.I } & \multirow{2}{*}{$\frac{\begin{array}{c}\text { Total } \\
\text { per } \\
\text { cent. }\end{array}}{\text { 0-12. }}$} \\
\hline & $0-3$. & $3-6$ & 6-12. & $0-3$ & $3-6$ & $6-12$ & $0-3$. & $3^{-6}$ & $6-12$. & \\
\hline Manchester & 47 & $6 \cdot 5$ & $6 \cdot 9$ & $4 \cdot 5^{2}$ & 4.5 & 10.0 & II'3 & 一 & - & $48 \cdot 4$ \\
\hline Blackburn... & 47 & 6.5 & $5 \cdot 2$ & $45^{2}$ & 6.8 & II'9 & 12.9 & - & - & $52 \cdot 5$ \\
\hline Oldham ... & 37 & $5^{\circ} 4$ & $4^{\cdot I}$ & $4 \cdot 8$ & $4 \cdot 4$ & $10 \%$ & $12 \% 2$ & - & - & $44^{\circ} 6$ \\
\hline Finsbury ... & 4.6 & 53 & $7 \cdot 9$ & $5 \cdot 3$ & 3.9 & $9 \cdot 3$ & $15^{\circ} 6$ & - & - & $51 \cdot 9$ \\
\hline Brighton ... & $3^{\circ} \mathrm{O}$ & $7 \cdot 3$ & $6 \cdot 3$ & $5 \cdot 5$ & 43 & 86 & $12 \% 9$ & - & 一 & $47^{\circ} 9$ \\
\hline Glasgow & 37 & 3.5 & 47 & $6.9^{2}$ & 5.1 & $10 * 9$ & I3.I & - & - & $47^{\circ} 9$ \\
\hline
\end{tabular}

I Exclusive of wasting diseases.

Lung disease. 
It is thus apparent that prematurity is a fatal disease in the first trimester; that diarrhœa is fatal mainly in the second trimester; and that pneumonia and bronchitis fall on the last half of the year. If we further subdivided the deaths from diarrhœe and from prematurity, we should find practically no fatal diarrhœa in the first three weeks of life, but nearly all the premature deaths. From the above table, the percentages of which are taken out on the total infant deaths, it is clear what proportion, as a rule, of the infant deaths are due to each of these diseases. Broadly, it works out at diarrhœa I7 per cent., pneumonia and bronchitis 20 per cent., and prematurity 12 per cent., making a total of 50 per cent. in all. Prematurity would rise to about 30 per cent. if to it were added the deaths from all congenital conditions and atrophy.

The whole position is well illustrated in the interesting table ${ }^{\mathrm{I}}$ drawn up by Dr. Chalmers for the distribution of the chief fatal diseases in infancy in Glasgow in 1904. This shows that 32.5 per cent. of all infant deaths are due to immaturity, in which he includes all forms of prematurity, in addition to atrophy and debility (and more than half of the deaths included are due to these latter conditions). These diseases fall, of course, in the first trimester of the infant's life. Diseases of respiration cause $22^{\circ} 9$ per cent., and are common throughout the twelve months. To diarrhœa is due 16.6 per cent. of the deaths, chiefly in the second and third trimesters, and 9.8 per cent. are due to infectious diseases, which occur late in the year. The death rates in each of these diseases is higher for male than female infants, except that in diseases of digestion and in infectious diseases they are equal. ${ }^{2}$

There are three points which must not be lost sight of

Appendix, p. 336-337.

2 Ann. Rep. of Med. Off. of Health of Glasgow, I904, pp. 28-29. 
in drawing any conclusions from these facts. First, the quinquennial periods selected by Dr. Tatham seem to be in no way exceptional. The changes manifested are such as have been taking place not only for a longer period than that of a quarter of a century, but with a somewhat remarkable degree of uniformity. Secondly, that in the main the diseases which have declined in fatal issue in infants have been those against which the methods of preventive medicine have been applied. For example, there has been a decline in smallpox in England and Wales, in which the whole population has shared, from an annual mortality of 576 per million persons in $1838-42$ down to 13 per million persons in 189I-1900; scarlet fever has also declined generally from an annual mortality of $97 \mathrm{r}$ per million persons in $186 \mathrm{I}-70$ to 158 in $189 \mathrm{I}-$ 1900 , and is now one of the least fatal of all the infectious diseases; whooping-cough is in the same case, falling from 530 in $1861-70$ to 378 in $1891-1900$, and 285 in 1903 ; even diphtheria, which, of course, showed a recent increase, has now fallen enormously in fatality; and tuberculosis is no exception to this rule of decline. What is true of England and Wales is also true broadly of London. In fact, it becomes evident that certain infantile diseases have responded to methods of repression such as vaccination, antitoxin treatment, isolation, and the general advance in sanitation and public hygiene which has occurred. But it is otherwise with certain other diseases. Thirdly, it must be continually borne in mind that more accurate medical diagnosis, and therefore more accurate certification of the cause of death, has been secured in recent years, with the obvious result that there has been a tendency to a transference of deaths from indefinite to definite causes. Debility, atrophy, convulsions, teething, and so forth, are general terms which naturally are less used as diagnosis becomes more exact. Notwithstanding 
this reservation, it may be taken that the changes already indicated are so well marked that they represent with approximate accuracy the changes which have actually taken place.

Amid much that is obscure and some things that are doubtful there remain certain things of which we may be sure; and if the bills of mortality quoted above and the tables in the Appendix (pp. 334-336), tabulating the returns for England and Wales and London, and also for Glasgow, be taken as a whole, some of these broad and certain facts will be found to emerge :-

First, the causes of infant mortality are composite. It has been well said that every effect has an ancestry of causes. Pre-eminently is this the case in regard to infant mortality, which is due to a combination of factors closely inter-related.

Secondly, nearly one half (about 48 per cent.) of the infant deaths in towns occur in the first three months of life ;

Thirdly, the chief fatality in these first three months is caused by prematurity and immaturity;

Fourthly, by far the greatest fatality in the remainder of the first year of life is due to inflammatory conditions of the lungs and to epidemic diarrhoea; and

Lastly, infant mortality is not declining owing to the fact that while certain diseases have enormously decreased, prematurity, pneumonia, and epidemic diarrhoea have, in spite of all advance in science, steadily increased, particularly in the towns and where the lamp of social life burns low. 
ANTE-NATAL INFLUENCES ON INFANT MORTALITY

WE have seen that Immaturity is one of the largest contributors to infant mortality, and that it is increasing. In many districts it is the chief cause, and in most large urban districts it furnishes about 30 per cent. of all the infant deaths. The average for Finsbury during the last five years (I90I-5) has been $30^{\circ} 3$, and in Glasgow for two years (1903-4) the average has been 32:2. Similar percentages will be found to obtain in Manchester, Liverpool, Bristol, Brighton, and other large towns. In Dundee, where 57 per cent. of the female population are occupied, 34 per cent. of the infant deaths in 1905 were attributed to immaturity. Even in rural districts this is the cause of not less than 30 per cent. of all infant deaths. ${ }^{x}$ It has increased more in rural districts than in urban. The figures would of course vary from time to time, and would depend upon the diseases included in the term immaturity. In Glasgow, as will be seen in a table in the Appendix, "immaturity" is made to include premature birth, congenital malformations, atelectasis, atrophy, and debility, and the same classification is used for Finsbury, where somewhat less than half the

In I904 prematurity alone, exclusive of congenital atrophy, was the cause of death of 20 per cent. of all infants deaths in the rural districts of Worcestershire, 17 per cent. in rural Bedfordshire, and 13 per cent. in rural Wiltshire. 
immaturity deaths are attributed to prematurity. On the whole it appears to be legitimate to include under immaturity the various forms of developmental disease and the wasting diseases of infancy. The large number of these latter which occur in the early weeks of life points to an initial defect in vitality which makes necessary their inclusion under immaturity. For example, in Glasgow in 1904, out of 350 deaths of infants due to atrophy and debility, 250 occurred within the first twelve weeks, and in Finsbury a very similar proportion.

This striking fact then, that 30 per cent. of all infant deaths in this country are due to immaturity, would seem to require explanation. It is evident that if infants die within a few days or hours of birth or even if dying later, show unmistakable signs of being unequal to the calls of bare physical existence, that there must be something more than external conditions or food or management which is working to their hurt. The explanation is clearly to be found in ante-natal conditions. We must, therefore, address ourselves to the question, What are the antenatal conditions which lead to immaturity, and the other agencies which bring about the death of infants on the very threshold of life?

To understand the death or disease of the new-born infant it is necessary to take into account the circumstances through which the infant's organism has passed before birth, as well as immediately after birth when the infant is endeavouring to adjust itself to its new environment. The life before birth may be divided into three periods: the germinal, before conception; the embryonic, beginning in the first six weeks of intra-uterine life; and the fotal period, lasting from the sixth or eighth week of intra-uterine life to the moment of birth at or about the thirty-sixth or fortieth week. It is evident that the germinal period involves the growth and development of the germ cells 
of male and female, and this in its turn includes the personal health of both parents both before and after marriage, their ancestral stock, their hereditary characters, and some, if not all, of their more serious diseases. Amongst the last named must be included syphilis, alcoholism, and tuberculosis in either or both parents, and certain other special conditions of the generative organs in the mother. Into these matters we cannot enter in this place, though they include by no means all the factors which will play a part in the future offspring. There is, for instance, the whole question of fitness of selection in marriage ; and here, it is generally admitted, there is immense need for improvement. The "unfit" appear to marry more frequently than otherwise, and not infrequently both parents are "unfit." $A$ basis of health in selection is too rarely adopted, and socialıand financial exigencies are considered in practice of far greater importance. Whilst it may be impossible, or indeed undesirable, to arrange marriage purely on a basis of physical fitness, we must not lose from sight the fact that physical unfitness is the source in many cases of infantile disease in the offspring. ${ }^{x}$ There is also the question of marriage of consanguinity. These are all matters which exert an effect on the problem before us, though it is impossible to do more than merely mention them.

The embryonic period of ante-natal life, as Ballantyne points out in his epoch-making work, ${ }^{2}$ cannot be considered as limited by certain weeks of intra-uterine life any more than the germinal period, but extends, is so to speak, projected, through the fotal even into the neo-natal and post-natal periods. Pathology has taught us that there are signs indeed of its projection into

- See Francis Galton's Huxley Memorial Lecture, I9or.

2 Manual of Ante-natal Pathologv and Hygiene, by J. W. Ballantyne, M.D., F.R.C.P.E., I902, vols. i. and ii. 
infant life, and even into adult life, and a comparatively new science, known as embryonic pathology, or teratology, has arisen, which may serve to remind us of the long period through which embryonic influences are exerting a direct effect on the individual. While that is so the actual formative period occupies, of course, the early weeks of intra-uterine life, during which the morphology and organogenesis of the infant is developing. And so the fotal period is reached, and this fills by far the larger portion of intra-uterine existence, throughout which time the condition of the mother is exerting influences, direct and indirect, upon the fœtus. It is impossible to say which period of the three, germinal, embryonic, or fotal, most impresses the physique of the infant before birth. No man can measure the relative potentialities for health or disease which each stage brings to the sum total at the moment of birth.

The adjoining chart, which has been modified from Ballantyne, will serve to indicate in a general way the main divisions of the growth of an infant from the time of conception, through the intra-uterine period, to the time of birth, and onwards to the end of infancy at the twelfth month of life. The neo-natal period, which has been placed at four weeks, is occupied in the attempt of the new-born infant to correspond with, or adapt itself to, its new external environment, a period witnessing in particular to the adjustment of function. The commencement of the exercise of the vital functions, coupled as it is with some modification in structure, must of necessity be a crucial testing time as to physical fitness, or otherwise, for survival. As we have seen, thousands of new-born infants every year fail to survive. It is that non-survival which creates so large a part of the infant mortality. For the infant may be born already diseased or malformed; or it may be predisposed to disease by conditions acting upon 


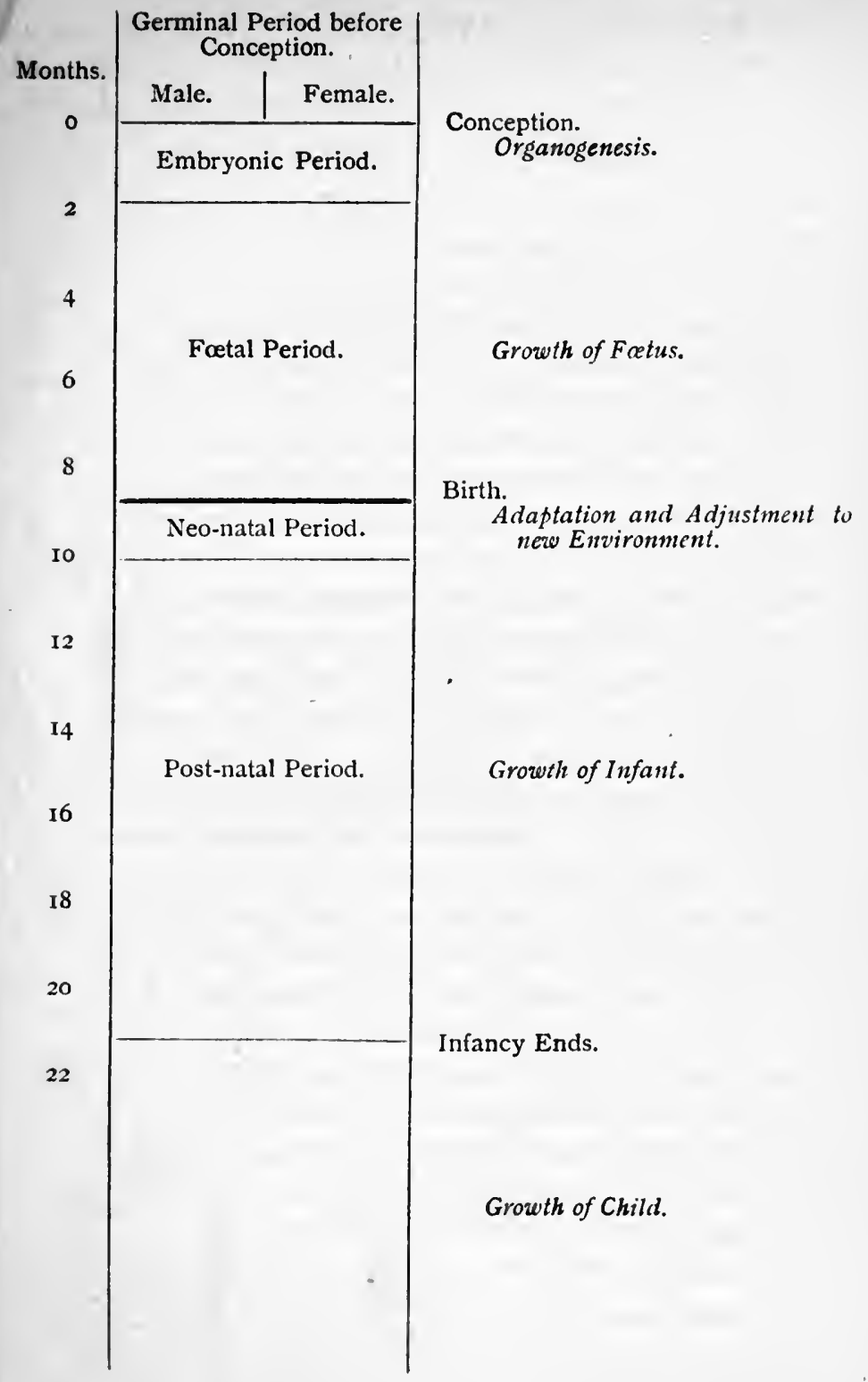


it during its fotal existence ; or it may be so frail, owing to similar conditions, as to find itself unable to cope with its new environment of a new diet, a new temperature, and a new medium of respiration ; or it may be born before it is fully equipped either for life or for growth and development. "Like pregnancy, neo-natal life is an epoch which has a physiology in many respects peculiar to itself, and which borders very closely on the pathological, tending very easily to pass over into it. Further, just as every woman brings with her into her pregnancy the results of her past pathological history, so the newborn infant brings with him out of his ante-natal life into his neo-natal existence, the effects of any morbid processes which may have attacked him in utero. In this way the pathology of pregnancy and the maladies of the new-born infant are both invested with peculiarities; in the former there is, among other things, the pathology of prereproductive maternal life; and in the latter there is, among other factors, the pathology of ante-natal, fotal, and embryonic life." I

Having this general view of the periods of ante-natal life clearly in mind, we must now consider the answer to the question before us, namely, the effect of ante-natal conditions upon the infant which may lead to its death, before or after birth. Some of these conditions, or a certain degree of them, will lead at once to a "dead-born" child, the still:birth ; others will lead to a premature birth, in which case the child may live for any period, from a few hours to many years ; and others again will, short of death, leave the child in such physical condition as to handicap it in the race of life. Keeping before us the problem of infant mortality, we need consider only such ante-natal conditions as directly concern us, and of these four types may be taken, namely, infections, toxcemias,

\footnotetext{
${ }^{x}$ Ballantyne, loc. cit., vol. i. p. 76.
} 
prematurity, and immaturity. I In all foetal diseases, be it infective diseases or toxæmia, it is necessary to remember that pathological conditions in the child or in the unborn foetus are broadly and generically the same, for foetal disease is the same as post-natal disease except that it is modified by the intra-uterine environment, and more remotely by embryonic factors.

\section{INFECTIONS.}

Of the infective diseases the briefest mention will suffice. Smallpox has been contracted not infrequently by the foetus, both when the mother was suffering from the disease, and when she had only been in contact with the disease. Cases of fœtal malaria, measles, scarlet fever, erysipelas, influenza, whooping-cough, typhoid fever (possibly without intestinal ulceration), and tuberculosis have been recorded. Nor are these the only diseases the bacteria or virus of which may pass through the placenta from mother to fotus. The infection of anthrax has been thus conveyed, and possibly pneumonia, and certainly septic diseases. Lastly there is syphilis, of which the only sign in the fotus may be its death. But it may be far otherwise. For not only may the infant be born with the ordinary symptoms of "infantile syphilis," but there may be an indefinite variety of ills and weaknesses derived from the primary syphilitic infection. On the other hand, as in the infective diseases previously mentioned, it may possibly happen that no infection is conveyed to the foetus of syphilitic parents. It may escape as entirely as it escapes typhoid fever, and further it is believed that it may in some degree possess an immunity after birth, although this may be of a temporary character only. The obverse

'See Ballantyne, loc, cit., p. 175, for complete classification of fotal morbid states, 
is also true that, according to Colles, the apparently healthy mother may nurse her syphilitic child, the risk to her being infinitesimal but not to be absolutely excluded.

The symptoms of Infantile Syphilis are those of "secondary" syphilis, a coppery-coloured shrivelled skin with scaling cuticle, mucous tubercles at the angle of the mouth, "snuffles," malformed teeth, inflammation of the eyes, and ear disease. These symptoms may be absent or represented by an extensive anæmia, and either condition may be followed by laryngitis, stomatitis, specific inflammation of liver and spleen, bone disease, and ulceration of the tongue. The effects of fotal syphilis are various. It is a common cause of miscarriage or premature birth, owing partly to the fact that it produces marked placental changes. Indeed, the still-born infants resulting from the disease may be 100 percent. D'Aulnay recorded 19 dead infants out of 19 pregnancies. Ballantyne gives the average results of private and hospital practice as 46 per cent. of the pregnancies which end disastrously, with an infant mortality of 42 per cent. Fournier states that when infection has occurred before conception the mortality is 65 per cent. and the morbidity, or actual occurrence of the disease, 70 ; while when infection has taken place after conception the mortality is 39 , and the morbidity 72 per cent. Or, again, if infection be derived from the father, Fournier holds that the mortality is 28 per cent.; if from the mother, 60 per cent.; and if from both, 85 per cent. Further, the period of infection and its relation to conception bears a direct influence upon mortality. The three years following infection are much more fatal to pregnancy than later years. Fournier states that of 90 women infected by their husbands, and who became pregnant in the year following their infection, 50 aborted or had dead-born infants, 38 gave birth to children 
who soon died, and only 2 gave birth to children who survived. ${ }^{\mathrm{r}}$

Syphilis appears to have been declining, since 1876 , as a cause of death in infants and in the general population. From 1876-80 the deaths of infants per 1,000 births in England and Wales was 1.77 , and in $1896-1900$ it was $1 \cdot 23$, having shown a fairly regular decline in the twenty years. A more marked decline has occurred at all ages, from 8.5 per million in $1876-80$ to 5.8 in $1896-1900$. But though declining, there is still abundant evidence that syphilis is one of the most active of all maternal infections in the production of congenital weakness and degeneracy in the offspring. It has been said that no child in a syphilitic family in the first or second generation escapes during its whole life from some effect, or is really a healthy individual. Sooner or later the offspring of syphilitic parents suffer. Numbers of, children, moreover, die in infancy from what is called "bronchitis," but which is in truth congenital syphilis of the lung.

\section{Toxmmias.}

The toxæmias which exert ill effects upon ante-natal life are mainly metallic poisonings and alcoholism. Of the former the chief are lead, mercury, and phosphorus.

Lead-poisoning is known to produce abortion in animals, and the passage of the lead through the placenta to the fœtus has been demonstrated. Direct evidence of such transmission has not been forthcoming in the human subject, but the nature of the effects produced on antenatal life are known by clinical observation. In 1860 Constantin Paul published the results of a research into the influence of lead "intoxication" upon the new-born infant. He set out with the view of determining whether

s Ballantyne, loc. cit., pp. 188-257. 
lead-poisoning exerted effects at all comparable to those of syphilis, making his observations on workers in type foundries. He divided his observations into six series which may be briefly tabulated. It will be convenient to place the final results in terse form, as follows :-

\begin{tabular}{|c|c|c|c|c|c|c|c|}
\hline Observations. & & Pregnancies. & Abortion. & $\begin{array}{c}\text { Premature } \\
\text { Birth. }\end{array}$ & $\begin{array}{l}\text { Still- } \\
\text { born. }\end{array}$ & Dead. & Living. \\
\hline I. 4 Women & & 15 & 10 & 2 & I & I & I \\
\hline 2. 5 Women & $\ldots$ & 36 & 26 & $\mathbf{I}$ & 2 & 5 & 2 \\
\hline 3. [See note] & $\ldots$ & - & - & - & 一 & - & 一 \\
\hline 4. [See note] & ... & - & - & 一 & - & - & - \\
\hline 5. 7 Women & $\ldots$ & 32 & I I & - & I & 18 & 2 \\
\hline 6. 6 Women & $\ldots$ & 29 & 8 & I & - & I2 & 8 \\
\hline Total ... & $\ldots$ & 112 & 55 & 4 & 4 & 36 & I3 \\
\hline
\end{tabular}

In the first group Paul placed 4 women definitely suffering from plumbism; in the second 5 who had normal pregnancies prior to working in lead, but after working in lead only 2 out of 36 pregnancies turned out well ; in the third series was a single case who, while at work at the type foundry, had 5 abortions out of 5 pregnancies, but after ceasing work had one pregnancy yielding a living, healthy child; in the fourth group were two women who ceased work and had healthy pregnancies, and then returned to work and had abortions; the fifth series contained 7 women whose husbands suffered from plumbism; and in the last group were 6 women whose only sign of plumbisin was the blue line on the gums. It will be noticed that in this last group the results of the lead on the pregnancies was less severe.

Paul concluded that though lead-poisoning did not prevent pregnancy, and did not act injuriously upon fecundity or upon menstruation, it did act upon the infant. Of the 36 deaths included in the table, 20 died under twelve months of age, 8 in the second year, 7 in the third, and I in the fourth. ${ }^{x}$

Since Paul's observations a number of similar cases of interrupted pregnancy have been recorded, which have involved not only a high infant mortality rate among lead workers, but have resulted in frequent imbecility, idiocy,

× Arch.Gén. de Med., 186o, vol. i. pp. 513-533. 
and epilepsy. Roque and Rennart furnished particulars of eleven families in which father or mother or both were affected with lead-poisoning as a result of occupation in pottery works, and in the groups where the mothers were affected 92 per cent. and 94 per cent. of all the children born were either dead or found to be suffering from cranial disease. ${ }^{x}$ Dr. Oliver has shown the remarkable ecbolic effect of lead on pregnant women in this country. Mrs. H., aged 35 , worked in a white lead factory for six years, before which she had four children born at full time. After going to the lead works she had nine miscarriages in succession and no living child. Mrs. K., aged 34, had four living children before going to the lead factory and two living afterwards. Then she had six miscarriages, and became the subject of plumbism. But she recovered and left the lead works. Then she had another living child.2 Miss Paterson and Miss Deane, two of H.M. Lady Inspectors of Factories, found that out of 77 married women reported as suffering from lead-poisoning (year ending March 3I, 1897), I 5 were childless, 8 had 21 stillborn children, 35 had 90 miscarriages, and of these 15 had no child born; out of IOI living children 40 died in infancy, mostly from convulsions. 3

Abortion, premature labour, and still-born infants may also follow as a result of mercurial poisoning in pregnant women, but the results are not so fatal as in lead.

In maternal phosphorus poisoning there is evidence to show that certain lesions exist in the foetus somewhat similar to those found in the mother.

It should also be remembered that all kinds of toxæmia, arising from general causes may do harm to the foetus. For instance, constipation, which may apparently cause no

Tarnier and Budin, vol. ii. p. 32.

- Dangerous Trades (1902), p. 302.

3 Ann. Rep. of Chief Inspector of Factories, 1897, p. 53. 
ill-effects in the non-pregnant state, may set up a toxæmia in pregnancy.

\section{Alcoholism.}

Since the work of Nicloux it may be considered to be proved that alcohol may pass as such from the mother to the fotus, and in considerable quantities. ${ }^{\mathrm{H}} \mathrm{He}$ not only proved this fact by animal experiment, but by examining the fotal blood from the umbilical cord and placenta of infants born of women to whom alcohol had been given one hour before labour. Other experiments are confirmatory of these results, and in the region of clinical and social investigation the results of this fact have been studied by many workers.

Dr. W. C. Sullivan has shown, in particular, the influence of maternal inebriety on the offspring by inquiring into degeneracy in the descendants of the alcoholics. ${ }^{2}$ For this purpose he selected a series of chronic drunkards from the female population of Liverpool Prison who had borne children. He excluded as far as possible cases in which alcoholism was complicated by other degenerative factors, such as tubercle, syphilis, and neurotic constitution. In the cases comprised in the investigation, the special nervous localisation of the poison was very marked; 31 of the women had suffered from one or more attacks of alcoholic delirium, while 24 others had had occasional visual hallucinations. Cases were chosen in which the alcoholism occurred prior to the procreative career, and the intoxicants chiefly consumed were beer, whisky, and rum. These being the conditions, it was found that of $\mathrm{I} 20$ such inebriate women there were born 600 children, of whom 335 (or 55.8 per cent.) died under two years of age or were dead-born. Sullivan compared these figures with similar

I L'Obstetrique, 1900 .

2 Four. of Mental Science, I899, vol. xlv, pp. 489-503. 
returns from sober branches of the same families where possible, with the following result:-

\begin{tabular}{|c|c|c|c|c|c|}
\hline & & $\begin{array}{l}\text { No. of } \\
\text { Mothers. }\end{array}$ & $\begin{array}{l}\text { No. of } \\
\text { Children. }\end{array}$ & $\begin{array}{c}\text { No. of } \\
\text { Chlldren } \\
\text { dead in } \\
\text { Two Years. }\end{array}$ & $\begin{array}{c}\text { Percentage of } \\
\text { Dead } \\
\text { Children. }\end{array}$ \\
\hline Drunken Mothers & ... & $2 I$ & 125 & 69 & $55^{\prime 2}$ \\
\hline Sober Mothers ... & $\ldots$ & 28 & 138 & 33 & $23 \cdot 9$ \\
\hline
\end{tabular}

These figures tell their own story, which is no doubt in part a story of heredity or ante-natal injury, and in part a story of environment.

It was also found that there was a progressive death rate in the alcoholic family, the number of dead births or of those who died under two years of age increasing as time went on. Sullivan tabulates these results thus:-

\begin{tabular}{llr|c|c|c|c}
\hline & & Cases. & $\begin{array}{c}\text { Dead and } \\
\text { Dead-born. }\end{array}$ & $\begin{array}{c}\text { Dead and } \\
\text { Dead-born } \\
\text { Percentage. }\end{array}$ & $\begin{array}{c}\text { Dead-born } \\
\text { Percentage. }\end{array}$ \\
\hline First Born & $\ldots$ & $\ldots$ & 80 & 27 & $33 \cdot 7$ & $6 \cdot 2$ \\
Second Born & $\ldots$ & $\ldots$ & 80 & 40 & $50 \cdot 0$ & $11 \cdot 2$ \\
Third Born & $\ldots$ & $\ldots$ & 80 & 42 & $52 \cdot 6$ & $7 \cdot 6$ \\
Fourth and Fifth Born... & III & 73 & $65 \cdot 7$ & $10 \cdot 8$ \\
Sixth to Tenth Born & $\ldots$ & 93 & 67 & $72 \cdot 0$ & $17 \cdot 2$ \\
\hline
\end{tabular}

"These figures illustrate very clearly the progressively augmenting character of the influence of the mother's alcoholism. From that point of view it is especially noteworthy that the rate of still-births shows almost as marked a tendency to regular increase as does the death rate among children born alive" (Sullivan). In 3 I 
of the women drinking habits were well established at least two years before the first pregnancy, and of 118 children born of these women 74 died in infancy or were still-born, giving a percentage mortality of 62.7 . as compared with $54^{\circ} \mathrm{I}$ for the rest of the series. Sober paternity seemed to have but little influence; indeed, Sullivan remarks that "as regards the vitality of the offspring the influence of maternal drunkenness is so predominant a force that the paternal factor is almost negligible." As illustrating the effect of drunkenness on conception, it may be added that in seven cases the condition was noted. Six of the infants died in convulsions in the first months of life, and the seventh was stillborn. These figures are small, but they suggest a causation of high infant mortality rates of illegitimate children. Lastly, of the children comprised in Sullivan's series, 219 lived beyond infancy, and of these 9 or $4^{.1}$ per cent. became epileptic as compared with $O^{\prime} I$ per cent. of the whole population. It should be added that other observers have found 12 and even 15 per cent. of the children of alcoholic parents to be epileptic. Sixty per cent. of all the deaths of the children in these series was stated to be by "convulsions," and Io per cent. were due to violent deaths.

Arrivé, investigating 1,648 conceptions in 402 poor, working-class families in Paris, found a percentage of I I. 5 per cent. of abortions, and 3.5 per cent. of premature births in those in which one or both parents were alcoholic.

Dr. Clay Shawe, some time the chief medical officer of the London County Asylum at Banstead, holds that pregnant women who are decided alcoholics miscarry to a much greater extent than others, and that when deprived of alcohol at an early stage of the pregnancy (as when sent early to prison and subsequently delivered 
there) they may go through the full period of gestation. "We have," he says, "inebriate mothers, and either abortions or degenerate children. The teleological relationship of the two seems to be as certain as any other conditions of cause and effect." I

There is no doubt that alcohol circulating in the maternal blood of a pregnant woman does reach the foetus, and either injure its tissues and stop the proper development of its cells or indeed bring about its death and a miscarriage. But that is in all probability not the chief way in which alcoholism in the mother injures the offspring. There is the subsequent effect on the child. Hence when we think of the influence of alcoholism among women on infant mortality we must think of two stages: first, injury of the child before birth; and secondly, injury after birth. The former is difficult to prove in a scientific sense. We can only judge of it, as a rule, by its effects, which, of course, if carefully observed, furnish evidence of the truest scientific value, such as the statistics already given from the observations of Dr. W. C. Sullivan. ${ }^{2}$

In his evidence before the Interdepartmental Committee

Report of Interdepart. Com. on Phys. Deterioration, I904, vol. iii. p. 68.

There is now indisputable evidence of a practical and clinical kind that alcoholism in the parents is one of the causes of mental degeneration of all kinds. "In regard to the effects of alcohol upon the descendants," says Dr. Robert Jones, Chief Medical Officer of the London County Asylum at Claybury, "anything which devitalizes the parent unfavourably affects the offspring, and clinical experience supports this in the lowered height, weight, and impaired general physique of the issue of intemperate parents. It also records the fact that no less than 42 per cent. of all periodic inebriates relate a history of either drink, insanity, or epilepsy in their ancestors." (Rep. Interdcpart. Com. Phys. Deterioration, 1904, vol. iii. p. 67). Dr. Kerlin, Superintendent of the Pennsylvania Institution for Imbeciles, calculated that the alcoholic taint was a factor in 38 per cent. of his cases if the habits of grandparents be included. Dr. Shuttleworth, formerly medical superintendent in the Royal Albert Asylum for Idiots at Lancaster, puts the figure at 13.2 (out of 1,200 cases), and Dr. Beach, of the Darenth Schools for Imbecile Children at $19^{\circ} 5$, but if grandparental histories be included $2 \mathrm{I}^{4} 4$ (1,180 cases). From these figures, which could be duplicated many times over by similar returns, it is evident that parental intemperance is a large factor in the degeneracy of offspring, both mental and physical. 
on Physical Deterioration in 1904, Dr. Wiglesworth, the Medical Superintendent of Rainhill County Asylum, said that "there is reason to believe also, from the great frequency with which a history of gross parental intemperance is found in the antecedents of persons who become insane, that a habit of excessive drinking tends in some cases to a poisoning of the germ cells of the parent by means of the alcohol circulating in the blood, and a consequent tendency on the part of these germ cells to develop into an organism with an unstable or badly developed brain. This may probably result even if the sperm cells of the father are alone affected. ... .

"It is difficult to prove a thing of that kind, but those of us who have seen a great many of these cases have all come to that conclusion, that a very large proportion indeed of cases of insanity have intemperate parents. I worked it out that a sixth part of all the cases had a history of alcoholic intemperance in the parents. That was excluding all cases in which there was any hereditary tendency. It was necessary to exclude those. It is my opinion that the sperm cells of the fathers get so injured by the alcohol that the union of the sperm cell and the germ cell will produce unstable offspring. Of course the mother might be healthy and counteract it and so onit does not necessarily follow. We know that perfectly healthy children are born of drunken parents, but in many cases it does operate. There is no question with regard to drunken mothers that alcohol exerts an extremely pernicious influence on the young, and poisons the nerve centres when the child is in a very susceptible condition....

"One must go back to the question of the original constitution of the germ in these cases, that is to say, the hereditary influence is very important indeed. The different stresses of life-whether it is alcohol or anything 
else-which people are subjected to of course act with greater effect on people who have a tendency to certain conditions. It does not follow necessarily; there may be an actual tendency as reflected in the family history. We know frequently there is a union between germ and sperm cells which produces an unstable offspring, for some reason we do not know. Then, again, there is this special cause, the actual poisoning of the germ cells. I think it is very important to look at the development of insanity from the point of view of the development from the germ. There is no question that amongst exciting causes alcohol is one of the most frequent." I

Further evidence was given on the same point by Dr. Leslie Mackenzie, of the Local Government Board of Scotland, who said that in his belief certain unstable nervous systems are directly affected more than others, and that probably the alcoholism of the mother after and preceding conception might have an effect upon the nutrition, and possibly might poison the ovum to the extent of interfering with its development. But that is really the infection of the ovum in its environment.2

Finally, there is the after-effect of alcoholism among women on the child after birth which is observable in various directions. An alcoholic mother may yield a milk of poor quality, or one actually containing alcohol in an excreted form, and in this way the child may be really starved or may itself take alcohol. Then again, the whole environment with which the infant is so intimately connected becomes disarranged, unclean, irregular, and this at once exerts an injurious influence. The child of an alcoholic mother is a neglected child, and neglect in infancy may be a direct cause of death.

Report, vol. ii. p. 337.

a Ibid., vol. ii. p. 267 . See also The Alcohol Problem in its Biological Aspect (Kelynack), I906. 


\section{Prematurity.}

It is well known that in both the vegetable and animal kingdoms many separate organisms never arrive at an individual existence. Every springtime myriads of seeds fail to germinate, and every breeding season myriads of spawn perish. In the human species the same apparent waste of germinal cells occurs. And more than that, if we neglect all forms of death in the germinal and embryonic periods, there yet remains, before we come to still-births and premature deaths, a vast toll of deaths of fœetal individuals which had not arrived at the age of viability. These are known as abortions, ${ }^{\mathrm{x}}$ and their frequency, though it varies widely, is believed to be about 20 or 25 per cent. of all pregnancies (Guillemot and Devilliers).2 Next in order come, of course, the premature births, and in maternity hospital practice premature births, according to Hahn, occur in about 16 per cent. if infants weighing less than 2,500 grms. be regarded as prematurely born, and $4 \mathrm{I}$ per cent. if the standard weight of prematurity be 3,000 grms. For practical purposes Ballantyne puts the figure at 20 per cent. in maternity hospitals. It must not, of course, be supposed that premature birth necessarily means fœtal death, or, indeed, death at or immediately following the event of birth. A certain number survive and even grow up to adult life, and owing to improved obstetric practice and a steadily improving environment this number is, of course, increasing.

r The following somewhat mechanical definitions of terms may be convenient :-

Abortion.-Expulsion of ovum before end of fourth month of uterogestation.

Miscarriage.-Expulsion from end of fourth to end of sixth month.

Premature Birth.-End of sixth month to end of pregnancy.

But on the whole it is better to consider births as "abortions" if under a viable age, and if over that age as "prematurity." All these hard and fast terms, however, have considerable disadvantage, and can only be used as general indications.

' Traité de l'art des Accouchements, 1886, Tarnier and Budin, vol. ii. p. 474. 
The causes of abortion and premature birth are various. They may be fœtal or maternal in origin. The former may be summed up in anything which produces the death of the fœetus, the latter in anything which attacks the placenta, and probably this is a much more frequent cause of interrupted pregnancy in an early stage than any condition of the fœtus itself, which would operate more largely in the case of premature labour. It is not proposed to enter at length upon a discussion as to the etiology of these conditions of interrupted pregnancy, with which many textbooks on obstetrics deal adequately. Our only concern here is to obtain a simple and clear view of the fact that the causes of premature birth and of abortion are broadly the same and are very numerous. Tarnier and Budin divide them into those which are general and those which are local, or those which belong directly to the physical condition of the parents during the pregnancy and those belonging to an anterior stage which may be designated germinal. For purposes of summary it will be sufficient to classify the main causes in three groups, as they concern respectively local disturbances of the organs concerned in pregnancy, infective diseases and toxæmias, and general conditions.

I. It is obvious that the present volume is not the place to discuss in detail the causes under the first head. They concern broadly pathological states of the reproductive organs of a woman during pregnancy, such, for instance, as disease of the lining membrane of the uterus, irritability of the genital canal, which in some cases seems to be the result of diathesis leading to a tendency to abort, displacements and retroversions of the uterus, a low insertion of the placenta, mechanical injury, \&c. It is clear that these are matters of importance, though not directly concerned with the practical problem of infant mortality, for the reason that they are conditions which may be 
common to pregnancy and lie in some measure outside control.

2. Infections and toxæmias form, as we have seen, a very different group of causes of premature birth. They include not only the ordinary infectious diseases, but also tuberculosis, syphilis, alcoholism, "ptomaine poisoning," and metallic poisonings. ${ }^{I}$ We have seen how frequently these diseases may lead to interrupted pregnancy by their pathological process or by causing the death of the fœtus. Some of these diseases, e.g., syphilis, undoubtedly act injuriously in successive pregnancies.

3. Under the general state must be included a number of conditions which arise more or less directly from the environment of the pregnant woman or her general habits. Tarnier and Budin state that "Une hygiène très défectueuse, un travail excessif ont évidemment une action plus marquée; il en est de même de la constipation opinâtre, de l'accumulation de matières fécales dans le rectum. L'alimentation insuffisante, dans les cas de disette, peut être la cause d'avortements si nombreux, qu'il semble en exister une véritable épidémie." 2

And to these must be added profound emotion, fright, anxiety, and sudden shock, and such conditions as living in over-heated and ill-ventilated rooms, the activities and pleasures of society, and physical causes such as a blow, a fall, or accidents and strains. Physical fatigue, particularly if accompanied by strain and stress, are likely to exert a decided effect in the production of premature birth, particularly if these conditions are accompanied by long hours of work and poor or insufficient nourishment. It cannot be too clearly understood that a pregnant woman requires not only additional nourishment but all the physical

× For a discussion of the influence of these conditions upon pregnancy, see Traité de l'art des Accouchements, by Tarnier and Budin, 1886, vol. ii. pp. II -52 .

2 Tarnier and Budin, pp. $475^{-480}$, and p. 512 . 
advantage of a hygienic life. If these conditions are not obtained and a pregnant woman works at industrial occupations throughout her pregnancy and in point of time close up to the date of labour, the result to herself and her offspring must inevitably be injurious. During the last two months of pregnancy no woman should undergo laborious physical toil, for it is a most important time in the development of the fotus, which gains weight in that period from $3 \frac{1}{2}$ to $7 \frac{1}{2} \mathrm{lbs}$. Pinard has shown the variation in weight due to such employment throughout pregnancy by weighing 500 children in each of the following classes with the following results: (a) 500 infants of women working right up to the commencement of labour, 3,000 grams; (b) 500 infants of women who spent the last few months of pregnancy in a lying-in hospital, 3,290 grams; and (c) 500 infants of women who spent the whole pregnancy in hospital, 3,368 grams.

Before leaving this subject it is necessary to mention the somewhat delicate matter of artifical abortion and its alleged increase. In the case of Rex $v . W m$. Brown and others tried in the Queen's Bench in I899, evidence was furnished of the prevalence of this habit in England. It was shown that even poor women were willing to pay from I 5s. to 40s. for certain widely advertised drugs for the procurement of abortion. One proprietor trading in these drugs was sufficiently confident of lucrative returns to expend $£ 2,800$ on advertising alone. In the same year medical experience confirmed the "extremely common" use of certain forms of lead (particularly diachylon) as abortifacients, to which Dr. Pope, of Leicester, had drawn attention in $1893 .^{.}$In the following year (1900), Dr. Ransom, of Nottingham, described some of the ill-effects of lead-poisoning brought about

s Brit. Med. Four. (July), 1893. 
by the use of this drug, which he declared to be "an uncertain abortifacient" which "always endangers and often destroys life, or leaves permanent bodily and inental enfeeblement." I He showed that diachylon, of amount the size of a walnut, might contain 86 per cent. of oleate of lead and 46.7 grains of lead, and that half a dose was sufficient to produce prolonged disease. The pills contain but a small amount of lead. Quite recently medical evidence has shown that there appears to be an increasing use of lead as an abortifacient chiefly in an area of the Midlands bounded on the north by South Yorkshire, and on the south by Bedfordshire. But cases have been recorded in London and other parts. In the prescribed area some 200 cases have been met with recently. Dr. Hall, of Sheffield, believes that "several hundred women have taken diachylon in this district alone during the last two years." 2 He thinks there is evidence to show that the custom is spreading and is assuming serious proportions, that it is spread as information from woman to woman, and that it is responsible for a considerable degree of plumbism. The most frequent forms of this disease are four, namely, brain disease, chronic disease of the peripheral nerves leading to "wrist drop" and other paralyses, colic, and chronic plumbic cachexia. It appears that 'in poisoning by diachylon the chief symptoms are those of acute lead-poisoning, colic with vomiting, constipation, and encephalopathy ; those attending abortion; and those of chronic lead-poisoning, such as anæmia and occasionally "wrist drop." In some cases it has caused death, and it is believed that short of that and short even of abortion the drug may exert injurious effects upon the infant.

Brit. Med. Four., I900, vol. i. pp. r590-9r.

2 Ibid., I906, vol. i. p. 428. 


\section{Reality of Increase of Deaths from Premature Birth.}

It has been suggested that the rise in the mortality rate from premature births indicates merely an apparent increase owing to one of two causes: first, that there was a transference of deaths from general terms, such as atrophy and convulsions, to conditions which are now looked upon as congenital in origin; and secondly, that the death registers now include a number of dead infants who would formerly have been buried as still-births. The former suggestion borrows support from the fact that infant deaths attributed to atrophy and convulsions have declined steadily since 1876 , and that diagnosis is now more perfect. The latter gains plausibility from an alleged decline in still-births. But as still-births are not registered that is a difficult matter to measure. The argument for transference on account of more perfect diagnosis can only carry weight where it is found, that in actual practice medical knowledge has increased or medical appliance advanced in such a degree as to differentiate the finer points in medical diagnosis. But ability to certify prematurity as a cause of death was surely as much in evidence twenty years ago as it is to-day. In regard to the suggestion as to transference of still-births, Dr. McCleary has shown that in London in the decennial period, $1894-1903$, the percentage of burials of still-born infants on total interments stood at about $5{ }^{\circ}$, and in the previous decennial period it was almost precisely the same. In any event there was no decline in the burial of still-births in the metropolis from $\mathrm{I} 88 \mathrm{I}$ to $\mathrm{r} 900$. But during the very same period the deaths from premature birth advanced in London from $13^{.2}$ to $19^{\circ} 7$ per $\mathrm{I}, 000$ births. ${ }^{x}$ But as $\mathrm{I}$ have already pointed out in a previous chapter, the deaths from premature birth have increased too greatly to be explained in this way. Moreover, they have increased in all kinds of districts, both urban and rural, varying enormously in external conditions.

\section{IMMATURITY.}

This term is here used to include all those conditions of congenital disability other than prematurity. For it

? Brit. Med. Four., 1904, vol. ii. p. 322. 
happens that the conditions, which may end in a premature birth or the death of the infant, produce in survivors closely allied physical deficiencies, but of a sort different in kind or degree, and which result not immediately in death but in physical under equipment. Atrophy, debility, some forms of "wasting" disease, congenital defects, nonexpansion of the lungs (atelectasis) and general frailty are conditions of this kind. Infants thus heavily handicapped may yet survive for some weeks and even grow up to adult life. But the mark of death is upon them.

On the whole this would appear to be a question of nutrition. It has been shown by Prochownick that the size of a child may be reduced by restricting the diet of the mother. He gives forty-eight cases in which as a result of such restriction the average weight of the child at birth was in 24 males 2,960 grams, and in 24 females 2,735 grams, as compared with the normal weight of 3,333 grams and 3,200 grams respectively. The male children were, therefore, I I per cent. and the female I4 per cent. below the average standard. From this it is perfectly clear that nutrition of the mother exerts an influence on the weight of her offspring. Noel Paton has shown by experiment similar results in the guinea-pig, an animal which breeds freely and enjoys a short period of gestation (IO weeks). He found that the weight of young guinea-pigs of well-fed mothers is independent of the number in the litter, and that their weight bears a close relation to the weight of the mother. Another set of guinea-pigs were kept on a low diet, with the result that the weight of the heaviest litters following was Io per cent. less per gram weight of mother than the smallest litter in the well-fed animals. The average weight of the litter was no less than 3 I per cent. below that of normal animals. In no case was there any indication that the births were premature, the young animals always presenting th 
character of full-time guinea-pigs and being active and vigorous.

"These observations," writes Dr. Noel Paton, "although few in number, are so concordant that they warrant the conclusion that the size of the offspring depends very directly upon the diet and nutrition of the mother during pregnancy. While this explains the easy labours among the healthy lower classes, and confirms Prochownick's conclusion that by dieting the mother the children of rickety women may be so reduced in size as to be viable, it also probably helps to explain the very high infant mortality among the very poor. The infant starts life at a low level, and readily succumbs to the hardships to which it is too often subjected.

"To the physiologist, the point of chief interest seems to be the demonstration of the limitations in the extent to which the tissues of the mother can be utilised for the construction of the embrýo. The nourishment of the maternal tissues seems to take precedence over the nutrition of the fotus. Were this not the case-had the embryo the prior claim to nourishment-we should find that in badly-nourished mothers each gram would produce a greater proportionate weight of young than in well-nourished mothers. This is exactly the reverse of what occurs. The mother thus appears to pass on the surplus nourishment to the foetus; and the better the nutrition of the maternal tissues, the greater is the growth of the young in utero." I

Obvious as the teaching of these facts appears to be the evidence in actual life on this point of nourishment of the mother is conflicting and by no means so clear as people suppose. Few things are more remarkable in the life of the very poor than the apparent vigour and equipment of their offspring at the time of birth. There would

' Lancet, July 4, I903. 
appear to be "a mean physical standard" which, as Professor D. J. Cunningham, the President of the Anthropometric Committee of the British Association, has 'said, seems to be "the inheritance of the people as a whole, and that no matter how far sections of the people may deviate from this by deterioration" owing to evil habit, poverty, or injurious or insanitary environment, "the tendency of the race as a whole will always be to maintain the inherited mean." I Nature, so to speak, reverts to a type, and does not transmit inferior physical characters acquired from evil environment, but only or chiefly those characters which are present in the individual at the time of birth. So that each generation of new-born infants tends to revert to the inherited mean. This does not indicate that the health or environment of the mothers during pregnancy is of no account. For such is not the case. The physique of the mother does unquestionably exert an effect on her offspring, but the tendency of nature is on behalf of the infant. ${ }^{2}$ It is well indeed that it is so, and it

I Rep. Interdepart. Com. on Phys. Deterioration, vol. ii. p. 97.

2 In giving evidence before the Physical Deterioration Committee, Dr. Henry Ashby, of Manchester, said there were "three chief causes" of infant mortality, $(a)$ heredity, $(b)$ unintelligent mothering, and $(c)$ effects of improper feeding. He further stated that "there are a large number of infants born who are weakly from the very first; their start is a bad one ; they are, perhaps, late members of a large family in which the mother is exhausted with child-bearing as well as from the effects of hard work and poverty. Before the child's birth development has been proceeding badly on account of the ill-health of the mother, and the infant comes into the world really handicapped from the very first. . . . The effects of poverty and hard work and weakness of the mother while the child is being formed in the womb do undoubtedly have the effect of producing weakly children, who either grow up weakly or die" (Report, vol. ii. p. 325). Subsequently Dr. Ashby emphasised this view in the Lancet (Oct. I, 1904) in the following words :-

"My own experience in the out-patient room entirely confirms the opinion that the nutrition of the mother has a very important bearing on the nutrition of the fœetus, and that the statement that the percentage of unhealthy births among the poor is small is not justified by facts. We constantly see fully developed infants a day or two old brought by midwives or neighbours exceedingly badly nourished, blue and feeble, and who are clearly ill-fitted, as the event indeed proves, to withstand the con- 
is this that brings, perhaps, $70-80$ per cent. ${ }^{x}$ of all new-born infants up to a mean physical standard in spite of illenvironment or the poverty of the mother's physique. In Finsbury we have recently made an extended inquiry through two trained lady visitors into the conditions of motherhood in 357 dead infants of the poor, special regard being paid $(a)$ to the physique and health of the mother; (b) to her past history in respect of miscarriage, abortion, and premature birth; $(c)$ to her general environment, poverty, and feeding; and $(d)$ to hard work during pregnancy.

The 357 dead infants were subdivided into those dying from all causes within twelve months of birth, 175 similar deaths but within the first three months, and II I which were deaths due to immaturity.

The results have been as follows :-

(a) Of 357 infants dead of all causes, 140 mothers (39 per cent.) had.a poor physique and a history of ill-health during and before pregnancy; of 175 infants dying in the first trimester of life 86 mothers (or 49 per cent.) were in the same case; and of III infants dying from immaturity 62 mothers (or 55 per cent.) were physically unfit.

ditions of an external existence. There must be numbers of such born in this city that perish within a few weeks of their birth, and who fail to thrive for even a day. There is no question of syphilis; they are the children of poor mothers who have lived lives of hard wear and tear during pregnancy, are themselves badly nourished and weakly, and have felt the pinch of poverty, though often perhaps poverty of the secondary sort. I have a strong conviction also that the infants of the poorer and weaker mothers, even though they are born fairly well nourished, are difficult to rear, and easily waste-even when under fairly favourable conditions in a home or hospital." A number of authorities hold similar views, and believe that the physique of the mother exerts a marked influence on the offspring.

I In Finsbury, of 1,859 mothers of the artisan class and of the class of very poor, as many as 73.5 per cent. gave birth to healthy infants, $15^{\circ} \circ$ per cent. to fair healthy, and $I I \cdot 3$ per cent. to unhealthy infants. 
(b) Of the 357 group I 59 mothers (or 44 per cent.) had a previous history of miscarriage, abortion, or premature birth; of the 175 group 109 (or 62 per cent.) had such a history; and of the II I group 89 mothers (or 80 per cent.) had a history of previous catastrophe.

(c) Of the 357 group 18 mothers (or 5 per cent.) had a pernicious social environment, and marked poverty and insufficiency of food; of the 175 group I 5 mothers (or 8 per cent.) were in that case; and of the III infants' deaths from immaturity I I mothers (or Io per cent.) were in extreme poverty and insufficiency.

(d) Of the 357 group 44 mothers (or I 2 per cent.) were occupied during pregnancy in doing very hard work; of the I75 group 35 mothers (or 20 per cent.) were so occupied; and of the III group 27 (or 24 per cent.) were employed almost continuously through pregnancy in prolonged and hard work. A comparatively small percentage of Finsbury married women are occupied in factories (not more than 12 per cent).

The conclusions to be drawn from these figures as they concern immaturity are, briefly :-

First, that about half the mothers of infants dead of immaturity suffer from marked ill-health and poor physique. As many as I 74 out of the 357 mothers ( 48 per cent.) were unable to suckle their infants from "want of milk."

Secondly, 80 per cent. of the mothers whose infants died of prematurity, congenital conditions, or debility, had previously had miscarriages, abortions, or premature births. This goes to support the view commonly held by medical men that a woman who has aborted once has a tendency to abort in future ( 15 per cent of the deaths were first children).

Thirdly, that only Io per cent. of the mothers of im- 
mature infants that died were underfed, though nearly a quarter of them had undergone exceptionally hard work during their pregnancy.I On the whole it may be more accurate to take underfeeding and overwork together. Work of itself, unless of an exceptionally straining character, seldom causes premature birth, but if combined with underfeeding and an insanitary environment the effect is almost certain to be injurious.

An inquiry into the condition of new-born children by Dr. Sinclair in a district of Glasgow having a high infant mortality, showed that of 212 less than 9 per cent. of the "well-nourished," and less than I 2 per cent. of the "fairly nourished" infants were artificially fed. Of obviously illnourished children, 22 per cent. were artificially fed, and this leaves a large proportion of badly nourished infants as being breast fed. Of the 212,46 (or $21^{\circ} 6$ per cent.) were found to be "badly nourished," and of the mothers of these 46 infants 39 per cent. were definitely underfed, 39 per cent. were addicted to alcohol, and $4 \mathrm{I}$ per cent. were working away from home during pregnancy. The history of these 46 families in which the children were "badly nourished" showed that there had been 243 births and 85 infant deaths, yielding the high infant mortality of 349 per 1,000 births. $^{2}$

After a study of these findings in Finsbury and Glasgow it seems impossible to resist the conclusion that, in spite of the tendency of nature on behalf of the new-born child, poor physique and ill-nutrition of the mother exerts, in a considerable percentage of cases, an injurious effect upon the infant. Indeed, the facts presented throughout this chapter must surely leave but little doubt in the mind that pre-natal as well as post-natal conditions may exert a profound influence upon the problem of infant mortality.

It should be added also that 24 per cent. of the immature infants were twin-births.

$=$ Report of Medical Officer of Health of Glasgow, I904, pp. 34-37. 
THE OCCUPATION OF WOMEN AND INFANT MORTALITY

$\mathrm{T}$ the middle of the eighteenth century industry in 1 England was domestic, and spinning and weaving were done at home in the cottages. The man worked the loom, working what hours he pleased; his wife and children spent their time spinning yarn. Spinning, in fact, was a by-industry practised as a subsidiary employment when the day was ended and it was too dark to labour in the fields. There were, practically, no factories and no manufacturers in the modern sense. No machines were worked by power in the textile trades, except those used by Lombe at Derby. But in I8I 5 how complete is the contrast. We have the master and the mill. Men have become "hands," working regular hours. Women and children also have taken their places beside the machinery that is fast superseding all the old methods. ${ }^{\mathrm{I}}$

The chief stages in that revolution were mainly the wonderful series of inventions made at the end of the eighteenth and in the nineteenth century, particularly in respect of the textile industries. Between 1761 and the end of the century we have the great inventions of Hargreaves (the carding machine and spinning jenny), of Arkwright (the rolling spinning frame), of Crompton (the spinning mule), of Cartwright, and others. And before them came Brindley's canals, and after them the

- See Traill's Social England, vol. v. I714-18r5, pp. 818-89. 
epoch-making development of steam power. These changes, which worked an industrial revolution, profoundly affected the relations of master and servant. With machines which worked almost of themselves neither skill nor age was necessary. The labour of children and young persons was in demand, no apprenticeship was needed for efficiency, every child of seven or eight years of age became a possible worker. In some instances even younger children were in the mills. These were not the only evils. The first factories erected were often unhealthy, badly ventilated, the machinery was unfenced, and damages for which the workman had no redress were frequent. The system was described as making the machine every day more and more of a man, and the man more and more of a machine. The factory system here and elsewhere, at all events in certain districts, threatened to bring. about the physical, moral, and mental deterioration of large classes of the community. ${ }^{x}$ The first Factory Act was passed at the beginning of the last century; and this idea of checking the evils which arose out of the factory system spread from this country to other countries, for wherever the factory system had arisen on any large scale the same evils had appeared, and so everywhere legislators endeavoured to regulate unhealthy industries, to limit the hours of labour of women and children, to insist that certain hygienic conditions should be complied with, and to protect the health and efficiency of the body of the worker as an important asset in the national life. Thus arose the necessity of taking measures to preserve it, and especially of saving women and children from work calculated to deteriorate generations to come. ${ }^{2}$

See Traill's Social England, vol. vi. pp. 298, 312, and 750.

- For an historical survey of factory legislation see Miss A. M. Anderson's articles in Oliver's Dangerous Trades (1902), pp. 24-62. 
It was not, however, till the middle of last century that the science of public health and preventive medicine was actually brought to bear upon these questions in their relation to infant mortality.

Sir John Simon and his colleagues showed by their investigations into the sanitary condition of England between 1859 and I 865 "that in proportion as adult women were taking part in factory labour or in agriculture the mortality of their infants rapidly increased; that in various registration districts which had such employment in them the district death rate of infants under one year of age had been from two and a quarter to nearly three times as high as in our standard districts; and that in some of the districts more than a few of the infants were dying of ill-treatment, which was almost murderous." I

Simon, indeed, believed that the "acute non-infectious diseases" (convulsions, diarrhœea, and respiratory inflammation), which caused the high infant mortality rates in the forties and fifties, were due to the varying prevalence of two local causes ; first, to differences of degree in common sanitary defects of residence, some places abounding more than others in the foul air and foul water of undrained, unpaved, unscavenged, unwashed, unlighted, and unventilated localities and houses; and secondly, "to occupational differences among the inhabitants: there being certain large towns where women are greatly engaged in branches of industry away from home, where consequently these houses are ill-kept, where the children are little looked after, and where infants who should be at the breast are improperly fed or starved, or have their cries of hunger and distress quieted by those various fatal opiates which are in such request at the centres of our manufacturing industry." 2

Englisi Sanitary Institutions (1890), p. 298.

2 Papers relating to the Sanitary State of the People of England, 1858, p. xxxiv. 
Since the day when those words were penned, much has been done to elucidate the relation of the factory occupation of women to infant mortality. The records of the work done, first by the pioneers, and latterly by medical officers and inspectors of the Home Office, the Local Government Board, and the 1,800 local authorities, the network of whose spheres of influence covers every inch of England, are among the most deeply interesting and even romantic labours ever performed in the service of a people. Nor has it been necessary in the intervening years since 1858 greatly to modify the view then expressed by Sir John Simon that "infants perish under the neglect and mismanagement which their mothers' occupation implies." But we must not anticipate.

The inquiry into this subject was first prosecuted by Dr. Greenhow, who found in $1848-54$ that in the four lace-making districts of Newport Pagnell, Bedford, Towcester, and Wycombe, the female death rate greatly exceeded the male death rate, particularly in pulmonary affections and phthisis. ${ }^{x}$ The table on the following page shows the male and female pulmonary death rates in I 848-54 in places "remarkable for the industrial employment of women," and it may be quoted here as one of the first exact records ever made on this subject.

This table shows that the higher the percentage of occupation of adult women in manufactures the higher was their pulmonary death rate, and that it compared unfavourably with similar death rates among men in the same towns, and also unfavourably with the total rates for England from these diseases. Little wonder that Dr. Greenhow concludes that "one of the most evident effects brought to light by the present investigation is the influence of occupation on health. This

x Papers relating to the Sanitary State of the People of England, 1858, p. 82. 
influence is either direct, as in the case of the cutlers of Sheffield, the lead miners of Alston, the lace makers of Towcester and Bedford, or the silk manufacturers of Macclesfield; or it is indirect, as where the employment of women in factories seems to aggravate the infantile mortality." I

This latter point it is necessary now to consider in some detail. But before doing so we cannot do better than

\begin{tabular}{|c|c|c|c|c|c|c|}
\hline \multicolumn{2}{|c|}{$\begin{array}{l}\text { Percentage } \\
\text { of Adult Males } \\
\text { occupied. }\end{array}$} & \multirow{2}{*}{ 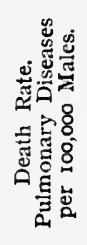 } & \multirow{2}{*}{ Towns. } & \multirow{2}{*}{ 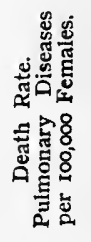 } & \multirow{2}{*}{ 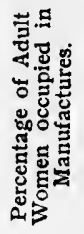 } & \multirow{2}{*}{$\begin{array}{c}\text { Nature of } \\
\text { Female } \\
\text { Ocupation. }\end{array}$} \\
\hline $\begin{array}{l}\text { Agri- } \\
\text { culture. }\end{array}$ & $\begin{array}{l}\text { Manu- } \\
\text { facture. }\end{array}$ & & & & & \\
\hline $48 \cdot 6$ & - & 419 & Bedford $\quad \ldots$ & 527 & $25 \cdot 3$ & Lace \\
\hline $52 \cdot 3$ & - & 430 & NewportPagnell & 545 & $33 \cdot 3$ & Lace \\
\hline $37^{\circ} \mathrm{I}$ & $26 \cdot 2$ & 449 & Wellingborough & 531 & $20 \% 2$ & Lace \\
\hline 49.5 & - & 475 & Towcester $\quad$... & 573 & $26 \cdot 7$ & Lace \\
\hline 19.6 & $29 \cdot 6$ & 508 & Basford... & 577 & $20 \%$ & Hosiery \& lace \\
\hline $5 \cdot 1$ & $43^{\circ} \mathrm{O}$ & 664 & Radford $\quad \ldots$ & 672 & 253 & Lace \& hose \\
\hline $40^{\circ} 2$ & $2 \cdot 6$ & $49 I$ & Berkhampstead. & 566 & $28 \cdot 9$ & Straw plait \\
\hline $35^{\circ} \mathrm{O}$ & $8 \cdot 2$ & 528 & Yeovil $\ldots . \quad \ldots$ & $59 I$ & $29^{\circ} 0$ & Gloves \\
\hline 135 & 14.9 & 598 & Wigan ... & 644 & $18 \cdot 0$ & Cotton \\
\hline $7 \% 7$ & $42 \cdot 6$ & 708 & Blackburn & 734 & 349 & Cotton \\
\hline $37 \cdot 4$ & 149 & 588 & Leek $\quad \ldots \quad \ldots$ & 705 & $17 \cdot 2$ & Silk \\
\hline $18 \cdot 9$ & 345 & 691 & Macclesfield ... & 804 & $29^{\circ} I$ & Silk \\
\hline $26 \cdot 5$ & 1377 & 569 & England \& Wales & 535 & $7^{*} I$ & \\
\hline
\end{tabular}

understand what facts and conditions Sir John Simon, Dr. Greenhow, and their colleagues found to bear on the question half a century ago. These conditions are best stated in the words with which Sir John Simon summarises the main facts.

"Factory women," he wrote, "soon return to labour after their confinement. The longest time mentioned as the average period - Papers relating to the Sanitary State of the People of England, 1858, p. I32. 
of the absence from work in consequence of child-bearing was five or six weeks; many women among the highest class of operatives in Birmingham acknowledged to having generally returned to their work at the expiration of a month. ${ }^{x}$ And it was stated that the factory women even sometimes return to work as early as eight or ten days or a fortnight after confinement. The mother's health suffers in consequence of this early return to labour, especially if, as is often the case, it is carried on in a standing position; and the influence on the health and mortality of children is most baneful. . . . Mothers employed in factories are, save during the dinner hours, absent from home all day long, and the care of their infants during their absence is entrusted either to young children, to hired nurse-girls, sometimes not more than eight or ten years of age, or perhaps more commonly to elderly women, who eke out a livelihood by taking infants to nurse. Young girls, aged seven or eight years, are frequently removed from school for the purpose of taking charge of younger children while the mother is absent at work, and are sometimes said to return, on the death of the child, evidently rather pleased that this event has released them from their toil. . . Pap, made of bread and water, and sweetened with sugar or treacle, is the sort of nourishment usually given during the mother's absence, even to infants of a very tender age ; and in several instances little children not more than six or seven years old were seen preparing and feeding babies with this food, which in such cases consisted only of lumps of bread floating in sweetened water. . . . Illness is the natural consequence of this unnatural mode of feeding infants. . . . Children who are healthy at birth rapidly dwindle under the system of mismanagement, fall into bad health, and become uneasy, restless, and fractious. To remedy the illness caused by mismanagement various domestic medicines are administered, more particularly some kind of opiate such as Godfrey's cordial or laudanum. Wine, gin, peppermint, and other stimulants are often given, for the purpose, as alleged, of relieving flatulence, the actual effect being, however, rather to stupefy the child. The quantity of opiates sold for the purpose

This is the period of abstention from work prescribed since I $\$ 9 \mathrm{I}$ under the Factory Act. 
of being administered to infants in some of the manufacturing towns is very large. . . . Indeed, there seems to be no doubt that the habitual administering of opiates to infants must be included among the causes of a high infantile mortality in certain manufacturing towns, not only on account of an overdose being given, but also because infants kept in a state of continued narcotism will be thereby rendered disinclined for food and be but imperfectly nourished. . . . Parents who thus entrust the management of their children so largely to strangers become more or less careless and indifferent about them, and as many of these children die, the mothers become familiarised with the fact, and speak of the deaths of their children with a degree of nonchalance rarely met with among women who devote themselves mainly to the care of their offspring. . . . Abundant proof of the large mortality among the children of female factory operatives was obtained during the inquiry. An operative of the better class in Birmingham reported that he collects money for the expenses attendant on the deaths of children among the workers in a factory where 150 women were employed, and that he believed ten out of every twelve children born to the married women in this factory died within a few months after birth. Many married women were questioned, as opportunity served, in the several factories visited, regarding their families, the number of children they had borne, the number that survived, and the manner in which they were brought up. The evidence of these women tallied exactly with that of other persons. . . . It was frequently found that two-thirds or three-fourths of the children borne to these women had died in infancy." I

On the other hand, as Dr. Greenhow wrote in his own report, it was remarkable how, in other instances, the majority of the children were reared when the mothers did not work in factories, or discontinued doing so whilst nursing, or when the infants' supplementary food consisted partly or chiefly of milk.

Nor was it alone in the towns, as Sir John Simon

' Fourth Report of the Medical Officer of the Privy Council, 186I, pp. $187-196$. 
pointed out, that an unnecessarily, high infant mortality occurred.

"The discovery that an enormous infantile mortality was prevailing in several purely agricultural districts, suggested at first sight that perhaps in these districts some third sort of destructive influence was at work [in addition to the two influences named on p. 92]. The result of this new inquiry, however, has been to show that the monstrous infantine death rate of the examined agricultural districts depends only on the fact that there has been introduced into those districts the influence which has already been recognised as enormously fatal to the infants of manufacturing populations-the influence of the employment of adult women. 'The opinions,' says Dr. Hunter, 'of about seventy medical practitioners, with those of other gentlemen acquainted with the conditions of the poor, were obtained. With wonderful accord, the cause of the mortality was traced by nearly all these wellqualified witnesses to the bringing of the land under tillage - that is-to the cause which has banished malaria and has substituted a fertile though unsightly garden for the winter marshes and summer pastures of fifty or a hundred years ago. It was generally thought that the infants no longer received any injury from soil, climate, or malarious influences, but that a more fatal enemy had been introduced by the employment of the mothers in the field.' On this agricultural employment of women there follow identically the same results as have been traced to result from the employment of women in manufacture." ${ }^{\prime}$

On surveying all the facts which he had collected, Dr. Greenhow arrived at the following conclusions :-

First, that the infantile death rate bears no definite relation to the general death rate, but their comparative proportions to each other vary in different districts.

Secondly, that the infantile death rate bears the largest proportion to the general death rate in districts where the infantile population is specially exposed to unwholesome

I Fourth Report of the Medical Officer of the Privy Council, 1861. 
influences, as in Coventry, Nottingham, and certain other manufacturing towns.

Thirdly, that the unwholesome influences to which infants are exposed in the manufacturing towns comprised in the present inquiry may be attributed mainly to the industrial employment of the married women, which leads them to consign the tendance of their infants at a very early age to young children or strangers.

Fourthly, that infants thus deprived of the mother's care are habitually fed on diet ill adapted to their digestive powers, and are very frequently drugged with opiates, in order to allay the fractiousness arising from the illness induced by improper food.

Fifthly, that infants in manufacturing towns where women are much engaged in factory labour are likewise exposed to other causes of sickness, proceeding from the ignorance or carelessness of the mothers or nurses, such as deficiency of exercise and exposure to inclement weather." $I$

Several years before the above conclusions were stated, Dr. Greenhow had shown that circumstances attendant on a town life were largely operative in the production of the chief diseases of infancy, which, in 1858 , appeared to be pulmonary diseases, diarrhœa, and convulsions. He had shown also that infant mortality was higher in manufacturing towns than in others, that it was higher in those manufacturing towns in which much female labour was in request, and highest of all, in his opinion, where female labour was occupied away from home, and that this last condition brought about a higher infant death rate even if the district were a rural one. ${ }^{2}$

We cannot now, with the new facts and experience of half a century behind us, wholly subscribe to these conclusions. But broadly they represent the position, and it is

Loc. cit., p. 196.

2 Papers on Sanitary Condition of People of England, 1858, pp. 120-122. 
now necessary to examine into the evidence in support of them at present existing.

Of the 13,189,585 females in England and Wales over the age of ten years, $4,171,751$, or $3 \mathrm{I}^{\circ} 6$ per cent., were returned in 1901 as engaged in occupations. They may be tabulated thus:-

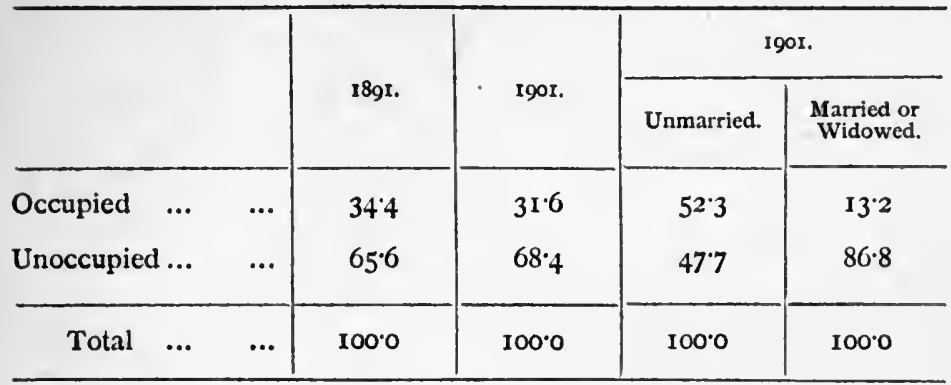

Unfortunately, however, the figures relating to domestic service in the 1891 census were not strictly comparable with those for other censuses, and therefore it is not possible to say definitely that the proportion of women occupied was really higher at all age groups in 1891 than 190r. But, on the whole, it works out for England and Wales in the total as a decrease from $26^{\circ} 4$ per cent. of females engaged in occupation in $189 \mathrm{I}$ to 24.8 in 190I. If, however, domestic servants be excluded from both sets of figures the returns for I90I show an increase over those for the preceding census in the proportions occupied at ages 15 to 25 , but a decrease at every group above 25 years. ${ }^{x}$ Thus there appears to have been in occupations other than domestic indoor service a substitution of younger for older women, which involves also a substitution of the unmarried for the married or widowed, and consequently a decrease in the employment of the latter. Further, in 190r, the proportion of occupied

I In her paper in the Four. of the Statistic. Soc. (1898, vol. 1xi. pp. 217 , 
females was higher in the towns than in the country at all ages.

The avocations of the four millions of occupied females over ten years of age are distributed broadly as follows: About 40 per cent: are employed in domestic service, and as charwomen or laundry workers; $16 \frac{1}{2}$ per cent. in making articles of dress; 14 per cent. in textile manufactures; 8 per cent. in various other manufactures; 7 per cent. as shopkeepers, shop assistants, \&c ; 4 per cent. in teaching, and 3 per cent. in services connected with hotels, inns, boarding-houses, restaurants, \&c. This leaves about 7 per cent. as engaged in other undefined occupations. For convenience the following table may be added:-

\begin{tabular}{|c|c|c|c|c|}
\hline & & Unmarried. & $\begin{array}{l}\text { Married or } \\
\text { Widowed. }\end{array}$ & $\begin{array}{c}\text { Total Female } \\
\text { Population. }\end{array}$ \\
\hline A. & $\begin{array}{l}\text { All occupations } \\
\text { Unoccupied ... }\end{array}$ & $\begin{array}{l}3,254,242 \\
2,971,399\end{array}$ & $\begin{array}{r}917,509 \\
6,046,435\end{array}$ & $\begin{array}{l}4,171,751 \\
9,017,834\end{array}$ \\
\hline B. & $\begin{array}{l}\text { I. Domestic offices or ser- } \\
\begin{array}{cc}\text { vices... } & \ldots\end{array} \\
\begin{array}{l}\text { (a) Charwomen } \ldots \\
\text { (b) Laundry work }\end{array} \\
\text { 2. Textile fabrics } \ldots \\
\text { 3. Dress } \ldots \\
\text { 4. Bricks, Pottery, Glass }\end{array}$ & $\begin{array}{r}\mathrm{I}, 378, \mathrm{I} 56 \\
25,378 \\
86,474 \\
518,252 \\
553,485 \\
23,947\end{array}$ & $\begin{array}{r}312,566 \\
86,463 \\
109,667 \\
144,970 \\
157,476 \\
9,201\end{array}$ & $\begin{array}{r}1,690,722 \\
\text { I I I,84 I } \\
196,141 \\
663,212 \\
710,961 \\
33,148\end{array}$ \\
\hline
\end{tabular}

270), Miss Collett has tabulated the variations in occupied females at various periods of census since I85I, as follows:-

INCREASE OF WOMEN AND GIRLS OCCUPIED PER IO,000.

\begin{tabular}{l|c|c|c|c|c|c}
\hline & I0-15. & I5-25. & $25-45$ & $45-65$. & $\begin{array}{c}65 \text { and } \\
\text { upwards. }\end{array}$ & $\begin{array}{c}\text { Io years and } \\
\text { upwards. }\end{array}$ \\
\hline $\mathrm{I} 85 \mathrm{I}$ & - & - & - & - & - & - \\
$\mathrm{I} 86 \mathrm{I}$ & -2 & +284 & +90 & $+\mathrm{I} 56$ & +270 & +142 \\
$\mathrm{I} 87 \mathrm{I}$ & -26 & +187 & -13 & +132 & +73 & +50 \\
$\mathrm{I} 88 \mathrm{I}$ & $-6 \mathrm{I} 4$ & $+9 \mathrm{I}$ & -255 & -319 & -765 & -253 \\
$\mathrm{I} 89 \mathrm{I}$ & $+\mathrm{I} 20$ & $+\mathrm{I} 22$ & +60 & $-\mathrm{III}$ & -230 & +37 \\
\hline
\end{tabular}


From these census returns it would appear that of the total female population over ten years of age of thirteen millions, four millions are occupied. And of the four millions nearly two millions are engaged in domestic occupations (including laundry work), and one and a half millions in textile work, dress, and potteries. Some of this work is regulated under the Factory and Workshop Act, much of it is unregulated, and all of it is of a nature very difficult to analyse. There is no record obtainable showing the occupation of those women who become mothers, though it might easily have been obtained through the registrars of births. Therefore it is necessary for us to consider what light upon the problem before us can be obtained from elsewhere.

The census return for I9OI supplies a large body of useful facts respecting the percentage and age of the female population occupied in administrative counties and in towns. Unfortunately, from the point of view of the present inquiry, these figures include that vast indefinite group of occupations known as "domestic," carried on for the most part in the home. And even so the local variations in the percentage of women occupied are much greater than in the case of males, ranging from 16.2 per cent. in the county of Durham to 56.8 per cent. in the county borough of Blackburn. The lowest proportions are naturally found in districts where the prevailing industries are such as can only be followed by males. Such, for example, occur in the Middlesbrough district, Barrow-in-Furness, Burton-on-Trent, and Devonport.

It is then to these facts of the census that the inquiring minds of investigators into this intricate problem of infant mortality have turned. Some have taken the counties, comparing the varying rates of infant mortality with the percentage of all women and of married women occupied. But the results are almost valueless, and except very 
generally indicate but little. For example, here are Northumberland and Durham with a high infant mortality and some 32 per cent. of women occupied, and here are Dorset and Westmoreland or Herefordshire and Wiltshire, all of them with the lowest infant death rates in the country, and yet with nearly 50 per cent. of women occupied. There is here, of course, abundant fallacy, derivable not only from the differences of trade, but also from the inclusion of domestic occupations, the whole being further complicated by the area involved in the counties.

For these reasons other investigators with more reason have turned to the towns. They have tabulated "the high mortality towns" in one class, and "the low mortality towns" in another. One such table is before me. Each class contains ten towns, the former yielding an average infant mortality rate of 190 per 1,000 , the latter 153 . The high mortality towns further average 62 per cent. of occupied women, $2 \mathrm{I}$ per cent. being married. The low mortality towns average, on the other hand, a mortality among infants of 153 per 1,000 , and percentages of occupied women and occupied married women of 58 and I 3 respectively. Now these twenty towns cover a wide field. They are representative and include a number of manufacturing towns of widely different character, as well as smaller trading towns, one residential town, and several of mixed character. It is this very width of survey which introduces fallacy, and yet, taken as a whole, the two lists show a distinct correspondence between infant mortality and the occupation of women. The high mortality towns have a higher percentage of occupied women than the lower mortality towns, and the difference is more marked in regard to married women than to all women. So far, so good. But as the tabulator fully admits, beyond this broad conclusion discrepancies appear, the most marked of which is that among the high mortality towns are some 
with a low proportion of occupied women. The high death rate among infants in these towns is therefore attributed to other conditions, and chiefly to a higher birth rate. But this is scarcely admissible, for in point of fact differences between the birth rates in all the towns are comparatively small, and do not extend over a generation. Moreover, the birth rates are for I90I, though the infant death rates are $1890-1903$.

As a matter of fact, as I have said, the very width of the field covered in any such comparisons introduces a serious

\begin{tabular}{|c|c|c|c|c|c|c|}
\hline & & & \multirow{2}{*}{$\begin{array}{l}\text { Population, } \\
\text { rgor. }\end{array}$} & \multirow{2}{*}{$\begin{array}{c}\text { Infant } \\
\text { Mortality, } \\
\text { 1896-1905. }\end{array}$} & \multicolumn{2}{|c|}{$\begin{array}{l}\text { Percentage of Women } \\
\text { Engaged in Occupations, } 190 \mathrm{r} .\end{array}$} \\
\hline & & & & & Total. & $\begin{array}{l}\text { Married or } \\
\text { Widowred. }\end{array}$ \\
\hline $\begin{array}{l}\text { Burnley } \\
\text { Preston } \\
\text { Blackburn } \\
\text { Nottingham } \\
\text { Leicester } \\
\text { Oldham } \\
\text { Bolton } \\
\text { Bury ... }\end{array}$ & $\begin{array}{l}\ldots \\
\ldots \\
\ldots \\
\ldots \\
\ldots \\
\ldots\end{array}$ & \begin{tabular}{l|}
$\ldots$. \\
$\ldots$. \\
$\ldots$. \\
$\ldots$. \\
$\ldots$. \\
$\ldots$
\end{tabular} & $\begin{array}{r}97,043 \\
112,989 \\
127,626 \\
239,743 \\
211,579 \\
137,246 \\
168,215 \\
58,029 \\
\end{array}$ & $\begin{array}{l}208 \\
208 \\
183 \\
180 \\
175 \\
170 \\
166 \\
164\end{array}$ & $\begin{array}{l}75^{\circ} 4 \\
73^{\circ} 8 \\
76.5 \\
67^{\circ} 7 \\
69^{\circ} 8 \\
70^{\circ} 4 \\
7 r^{\circ} 7 \\
73^{\circ} 7\end{array}$ & $\begin{array}{l}33^{\cdot 8} \\
30^{\circ} 5 \\
37^{\circ} 9 \\
24^{\circ} \cdot 1 \\
25^{\circ} \cdot 2 \\
20^{\circ} \cdot 0 \\
15^{\circ} \cdot 1 \\
25^{\circ} \cdot\end{array}$ \\
\hline Ave & erage & $\ldots$ & 128,052 & 182 & $72^{\circ} 3$ & 26.5 \\
\hline
\end{tabular}

fallacy. To arrive at accurate results as to the relation, if any, which exists between occupation of women and infant mortality, it is necessary (a) to compare towns which are comparable, the occupied female population of which is engaged in similar trades; $(b)$ to take the percentage of occupied women and occupied married women at the child-bearing age ; and $(c)$ to look mainly to occupations away from home. Bearing these three requirements in mind, let us take some representative towns in which the textile trade (in which women are mostly employed) provides the chief occupation. of the occupied women 
away from home. As fair examples we may take six towns in the centre of the cotton trade-Burnley, Preston, Blackburn, Oldham, Bolton, and Bury-and two others, which represent a greater variety of occupation, but still in the main are textile-Nottingham and Leicester. These towns may be placed in the order of their infant mortality, and the returns for 1901 as to the occupied women and the occupied married women placed opposite each, as in table on the previous page.

This arrangement gives a clearer view of the relation existing between women occupied in a similar way and the infant mortality rate. The infant mortality rate is for a decennial period made up of five years each side the census year. Compare these figures with the following table, comprising eight towns selected, not as having a particularly low infant mortality rate, but as having a low percentage of occupied women.

\begin{tabular}{|c|c|c|c|c|c|}
\hline & & & \multirow{2}{*}{$\begin{array}{c}\text { Infant } \\
\text { Mortality } \\
\text { Rate, } \\
\text { I896-1905. }\end{array}$} & \multicolumn{2}{|c|}{$\begin{array}{l}\text { Percentage of Women Engaged } \\
\text { in Occupations. }\end{array}$} \\
\hline & & & & Total. & Married or Widowed. \\
\hline $\begin{array}{lc}\text { Sunderland } & \ldots \\
\text { Swansea } & \ldots \\
\text { Lincoln } & \ldots \\
\text { South Shields... } \\
\text { Newport } \quad \ldots \\
\text { Cardiff } & \ldots \\
\text { Barrow-in-Furness } \\
\text { Burton } & \ldots\end{array}$ & $\begin{array}{l}\cdots \\
\cdots \\
\cdots \\
\cdots \\
\cdots \\
\cdots \\
\cdots\end{array}$ & $\begin{array}{l}\cdots \\
\cdots \\
\cdots \\
\cdots \\
\cdots \\
\cdots \\
\cdots\end{array}$ & $\begin{array}{l}166 \\
160 \\
157 \\
155 \\
153 \\
147 \\
144 \\
119\end{array}$ & $\begin{array}{l}38 \cdot 2 \\
42^{\cdot 1} \\
47^{*} \cdot 2 \\
34^{\circ} \cdot 9 \\
44^{\circ} 4 \\
43^{*} \cdot 6 \\
40^{\circ} \cdot 7 \\
41 \cdot 8\end{array}$ & $\begin{array}{l}7 \cdot 7 \\
8 \cdot 7 \\
7 \cdot 8 \\
7 \cdot 4 \\
7 \cdot 0 \\
8 \cdot 4 \\
5 \cdot 8 \\
6 \cdot 9\end{array}$ \\
\hline Average ... & ... & ... & 150 & $4 I^{\circ} 6$ & $7 \cdot 4$ \\
\hline
\end{tabular}

The towns in the former table have a higher percentage of occupied women than in the latter, though the difference is less marked in regard to married women than to all women. The average percentage of occupied women in the latter table is $30 \% 7$ less than in the textile towns, and 
the average percentage of married women who are occupied is 19.1 less than in the textile towns. The difference in the average infant mortality is 32 per 1,000 on the decennium.

But if now we go a step further and introduce a comparison between the percentage of occupied women married and unmarried, and the percentage of such women occupied at the period of child-bearing activity, or rather reproductive potentiality (15-35), we obtain the following figures for the textile towns :-

\begin{tabular}{|c|c|c|c|c|c|c|}
\hline & & & & \multirow{2}{*}{$\begin{array}{c}\text { Infant } \\
\text { Mortality } \\
\text { Rate, } \\
\text { 1896-1905. }\end{array}$} & \multicolumn{2}{|c|}{$\begin{array}{l}\text { Percentage of Women Occupied } \\
\text { between Ages 15-35. }\end{array}$} \\
\hline & & & & & Total. & Married or Widowed. \\
\hline $\begin{array}{l}\text { Burnley } \\
\text { Preston } \\
\text { Blackburn } \\
\text { Nottingham } \\
\text { Leicester } \\
\text { Oldham } \\
\text { Bolton ... } \\
\text { Bury ... }\end{array}$ & $\begin{array}{l}\ldots \\
\ldots \\
\ldots \\
\ldots \\
\ldots \\
\ldots \\
\ldots\end{array}$ & $\begin{array}{l}\ldots \\
\ldots \\
\ldots . \\
\ldots \\
\ldots \\
\ldots \\
\ldots\end{array}$ & $\begin{array}{c}\ldots \\
\ldots \\
\ldots . \\
\ldots \\
\ldots . \\
\ldots \\
\ldots \\
\ldots\end{array}$ & $\begin{array}{l}208^{x} \\
208 \\
183 \\
180 \\
175 \\
170 \\
166^{2} \\
164\end{array}$ & $\begin{array}{l}90^{\circ} 9 \\
89^{\circ} 4 \\
91 \cdot 8 \\
84^{\circ} 6 \\
87^{\circ} 6 \\
87^{\circ} 3 \\
87^{\circ} 4 \\
88^{\circ} \cdot 9\end{array}$ & $\begin{array}{l}59 \cdot 7 \\
50 \cdot 5 \\
63 \cdot 9 \\
27 \cdot 5 \\
41 \cdot 6 \\
33 \cdot 4 \\
24 \cdot 7 \\
44^{\circ} \cdot 8\end{array}$ \\
\hline Average & ... & ... & ... & 182 & $88 \cdot 4$ & $43^{2} 2$ \\
\hline
\end{tabular}

In 1904 the infant mortality rate was 233 . In order to bring about a decrease in this high death rate the Corporation has engaged three lady sanitary inspectors, and has opened a sterilised milk depot. But the Medical Officer believes the principal cause is the factory occupation of women. He writes : "Burnley is the largest textile manufacturing town in Europe, that is, it contains more looms for the weaving of cloth than any other town or city, and, as a larger number of women than men are employed in weaving, it follows that many infants are put out to nurse whilst the mothers are engaged in the weaving shed. When infants a few weeks old are thus put into the hands of unskilful nurses, it becomes certain that the food will be at times unsuitable, and the natural requirements of the infant not attended to. A sensible mother's care is necessary for the up-bringing of a healthy child, and this motherly care cannot be obtained where mothers are extensively employed in factories. It need excite no surprise, then, that in manufacturing towns the infant inortality is large, very much greater than in non-textile towns where mothers usually nurse their own children and are not compelled to put them out to nurse " (Rcp. on Health of Burnlcy, 1904, p. 5).

- There are, it appears, some favourable social conditions in Bolton which may in part account for its somewhat lower infant mortality than say, Burnley. See Industrial Efficiency, vol. i. pp. 68-83. 
And for the non-textile towns the table will be as follows :-

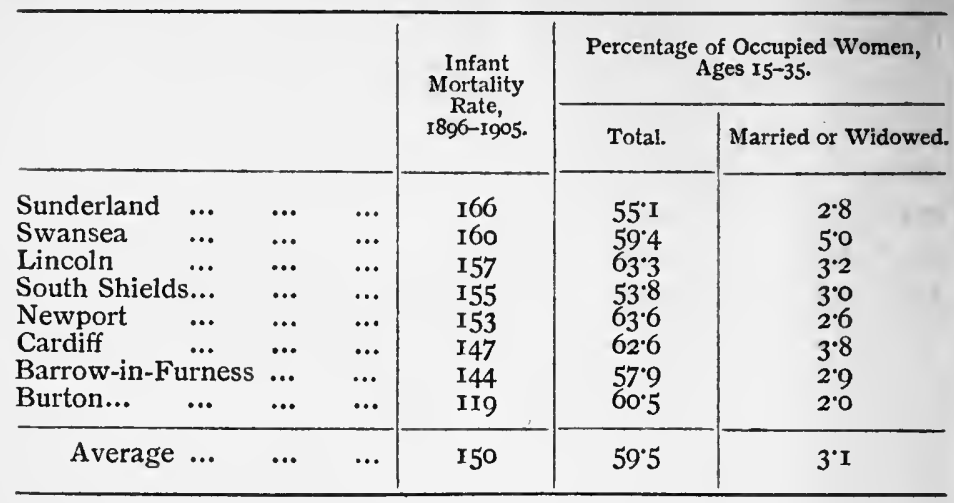

It will be seen at once that these more apposite figures from the point of view of infant mortality tell the same story. The high-mortality or textile towns have a higher percentage of occupied women at child-bearing ages than the low-mortality towns (28.9)-a percentage almost equal to that shown in the previous tables. But the percentage of occupied married women at child-bearing ages in the textile towns is 40 per cent. higher than in the low-mortality towns. This is more than double the difference shown in the former tables. A difference so marked as this demonstrates surely, beyond all question, that there is an intimacy - if not a relationship at least a correspondenceexisting between the occupation of married women and a high infant mortality.

Now whilst it is evident that the correspondence between the percentages of women at child-bearing ages and the infant mortality is intimate and possibly indicates a relationship of cause and effect, it is also clear that even so there are discrepancies. Miss Collett endeavoured to determine a relationship in this matter, the results of 
which also showed discrepancy, which she thought might be amended by comparing the infant mortality with the percentage of domestic servants in certain towns. ${ }^{\mathrm{I}}$ The following is a table showing the results of both comparisons :-

\begin{tabular}{|c|c|c|c|}
\hline $\begin{array}{l}\text { Percentage of } \\
\text { Females above } \\
\text { Io Years, Occu- } \\
\text { pled in } 1891 .\end{array}$ & Towns. & $\begin{array}{c}\text { Infant } \\
\text { Mortality Rate, } \\
\text { 1889-93, per } \\
\mathbf{1}, 000 \text { Births. }\end{array}$ & $\begin{array}{c}\text { Percentage of } \\
\text { Females above } \\
\text { 10 Years of Age } \\
\text { returned as } \\
\text { Indoor Domestic } \\
\text { Servants, } 189 \mathrm{I} .\end{array}$ \\
\hline 60 & Blackburn $\quad .$. & 207 & 5 \\
\hline $55-60$ & $\begin{array}{llll}\text { Preston } & \ldots & \ldots & \ldots\end{array}$ & 244 & 6 \\
\hline $45-50$ & $\left\{\begin{array}{cccc}\text { Bradford, Bolton, } & \text { Leicester, } \\
\text { Oldham, } & \text { Halifax, } & \text { Not- } \\
\text { tingham } & \ldots & \ldots & \ldots\end{array}\right\}$ & I8I & 6 \\
\hline $40-45$ & $\left\{\begin{array}{c}\text { Manchester, Huddersfield, } \\
\text { Brighton, Norwich, Bir- } \\
\text { mingham, Bristol, Salford }\end{array}\right\}$ & 177 & 9 \\
\hline $35-40$ & Leeds $\quad \ldots$ & 180 & 7 \\
\hline $30-35$ & $\left\{\begin{array}{r}\text { Plymouth, Liverpool, Derby, } \\
\text { Portsmouth, Birkenhead }\end{array}\right\}$ & 177 & II \\
\hline $25-30$ & $\left\{\begin{array}{l}\text { Wolverhampton, Sheffield, } \\
\text { Newcastle, Hull, Cardiff ... }\end{array}\right\}$ & 175 & I0 \\
\hline Under 25 & Sunderland ... & 175 & I0 \\
\hline
\end{tabular}

This view contends that the lower the percentage of domestic servants the lower the social standard and the greater the poverty, and therefore the higher the infant mortality, which, thus viewed, is more nearly related to home conditions than factory conditions. In a general way this is undoubtedly true, and much of the evidence furnished in the present book lends support to it. At the same time it is important to remember, as Farr pointed

- Four. of Statistical Soc., 1898, vol. 1xi. pp. 217-270 (Miss Clara E. Collett, M.A.). 
out in $187 \mathrm{I}$, that even in towns where the census returns credited a large domestic occupation of women at home, infant mortality might still be high. Farr showed that in Oldham of women above 20 years of age 346 per 1,000 were engaged in the textile factories, and 493 per I,000 in domestic duties, and the infant mortality rate was 180 per 1,000 ; whereas in Leicester 122 per 1,000 worked in factories and 543 at home, and the infant mortality was $2 \mathrm{I} 7$; at Leeds 93 per I,000 women over 20 years of age worked in factories and 658 per 1,000 at home, but the infant mortality was 201 ; and, lastly, he selected Norwich where only 58 per 1,000 worked in factories and 539 at home, and yet the infant mortality was 183 , higher even than Oldham.

The textile towns are not peculiar in possessing a high infant mortality associated with a high percentage of occupied married women at child-bearing ages. The towns in the Potteries yield a similar result. Hanley, with 78.7 per cent. of occupied women at child-bearing ages (I5-35), and 23 per cent. of married women at the same age period, has had an infant mortality rate in the last decennium (1896I905) of 204 per I,000. Longton, with an even larger percentage of occupied women, had an infant mortality rate (I895-1904) of 234 .

Dr: Reid, the Medical Officer of Health for the County of Stafford, has repeatedly drawn attention to a number of the Staffordshire towns which year after year have a high infant mortality. The following is a table from his report for $1903:-$

\begin{tabular}{l|c|c|c|c|c|c|c}
\hline Five-year Periods. & Burslem. & Fenton. & Longton. & $\begin{array}{c}\text { New- } \\
\text { castle. }\end{array}$ & $\begin{array}{c}\text { Quarry } \\
\text { Bank. }\end{array}$ & Tunstall. & $\begin{array}{c}\text { Wednes- } \\
\text { field. }\end{array}$ \\
\hline $1889-93$ & 193 & 186 & 225 & 168 & 164 & 213 & 175 \\
$1894-98$ & 204 & 220 & 247 & 188 & 152 & 224 & 134 \\
$1899-1903$ & 199 & 185 & 227 & 181 & 142 & 200 & 152 \\
\hline
\end{tabular}


This mortality is attributed by the District Medical Officers to "neglect and ignorance," or "sanitary defects," or "ignorance of proper feeding," but the County Medical Officer urges that the excessive mortality which he finds to exist in varying degree in twenty-six artisan towns is "attributable to the nature of the trades carried on as affecting the facilities for the employment of women away from home, and as a consequence the proportion of wholly artificiallyfed to entirely or partially breast-fed infants." x $\mathrm{He}$ furnishes the following interesting table which leads to the same conclusions as the tables I have already discussed:-

\begin{tabular}{|c|c|c|c|c|c|}
\hline \multirow{2}{*}{$\begin{array}{l}\text { Class according to } \\
\text { percentage of Married } \\
\text { and Widowed Workers } \\
\text { to Female Population } \\
\text { between } 18 \text { and } 50 \text { years. }\end{array}$} & \multirow{2}{*}{$\begin{array}{l}\text { No. of } \\
\text { Towns. }\end{array}$} & \multirow{2}{*}{$\begin{array}{l}\text { Total Popula- } \\
\text { tion, } \\
\text { Igor Census. }\end{array}$} & \multicolumn{3}{|c|}{$\begin{array}{l}\text { Deaths of Infants under } \mathrm{r} \text { year } \\
\text { per } \mathrm{I}, 000 \text { registered births. }\end{array}$} \\
\hline & & & 1881-90. & $189 \mathrm{r}-1900$ & I90r-4. \\
\hline 1. $12 \%$ and over ... & 5 & I32,299 & 195 & 212 & I93 \\
\hline $\begin{array}{c}\text { II. Under } 12 \% \text { and } \\
\text { over } 6 \%\end{array}$ & 13 & 263,868 & 165 & I75 & 156 \\
\hline III. Under $6 \%$ & 8 & I31,508 & 156 & 168 & 149 \\
\hline
\end{tabular}

These figures are emphatic, though perhaps less so than in a similar table for Lancashire. And for a very simple reason, in Lancashire there are seven times more married women employed than in Staffordshire.

Nor are the pottery towns any more exceptional than the textile towns. Broadly, it is true that to whatever town or district we turn the same general conclusion is inevitable, namely, that where there is very much occupation of women away from home, there will be found as a rule a high infant death rate, unless there are exceptional circumstances counteracting it. The following table of districts and towns not hitherto mentioned, with an infinite

× Annual Report of Medical Officcr of Staffordshire, 1904, p. 30. 
variety of other conditions existing, but having in common a high percentage of occupied women, all yield, broadly, the same result, namely, a high infant death rate.

\begin{tabular}{|c|c|c|c|c|c|}
\hline \multicolumn{3}{|c|}{ Town or District. } & $\begin{array}{c}\text { Percentage of } \\
\text { Women Occupied. }\end{array}$ & $\begin{array}{c}\text { Infant } \\
\text { Mortality. }\end{array}$ & $\begin{array}{l}\text { Decennial } \\
\text { Period. }\end{array}$ \\
\hline $\begin{array}{l}\text { Lancashire } \\
\text { Leicestershire } \\
\text { Manchester } \\
\text { Stockport ... } \\
\text { Bristol ... } \\
\text { Norwich ... } \\
\text { Coventry ... } \\
\text { Birmingham } \\
\text { Northampton }\end{array}$ & $\begin{array}{l}\cdots \\
\cdots \\
\cdots \\
\cdots \\
\cdots \\
\cdots \\
\cdots \\
\cdots\end{array}$ & $\begin{array}{l}\ldots \\
\ldots \\
\ldots \\
\ldots \\
\ldots \\
\ldots \\
\ldots \\
\ldots\end{array}$ & $\begin{array}{l}62 \cdot 2 \\
56 \cdot 5 \\
63 \cdot 3 \\
68 \cdot 1 \\
57 \cdot 7 \\
60 \cdot 1 \\
63 \cdot 8 \\
63 \cdot 6 \\
62 \cdot 2\end{array}$ & $\begin{array}{l}179 \\
164 \\
187 \\
204 \\
142 \\
176 \\
148 \\
184 \\
150\end{array}$ & $\begin{array}{l}I 89 I-I 900 \\
189 I-I 900 \\
1895-I 904 \\
1894-I 903 \\
1894-I 903 \\
1894-I 903 \\
1894-I 903 \\
I 894-I 903 \\
I 894-I 903\end{array}$ \\
\hline
\end{tabular}

But the mere fact of extensive employment of women, and particularly of mothers in factories, cannot be regarded as significant of itself. To gauge the effect of such employment on the children of such women reference must be made to some of the following factors which play a part in the problem, namely, $(a)$ the character and condition of the work, (b) the length of hours, (c) employment before and after childbirth, and $(d)$ the sanitation of factories and workshops. To these also should be added the variations in the birth rate prevalent in different trades, the effect of certain industries upon maternity in the way of raising (if such be possible) or reducing the standard and practice of mothers as to the care of infants, and, lastly, the causes of the mothers' employment.

\section{The Character AND CONDition OF THE WORK.}

A moment's reflection will make it evident that it is not what is called "the factory system," which per se exerts an injurious influence upon women, and particularly married women, engaged in one or other of the many industries in 
which women are now employed. It is rather the conditions which obtain and the neglect of home life which is involved in certain trades or in certain factories. The mere fact of a woman working for a livelihood, be it in a factory or workshop, or be it at home, does not necessarily affect her health, or, if she become a mother, the health of her offspring. Many and various conditions which may arise therefrom furnish the real influences which are injurious. Some of these are considered elsewhere in the present volume, but here it is necessary to discuss those which are directly associated with the factory environment.

We may take it as a general axiom that both unmarried and married women enter factories as a rule to gain a necessary livelihood and not merely to make "pin-money." Occasionally one comes across women thus working for the pleasure of it, or to occupy their time, or to obtain a personal remuneration not absolutely necessary to their living. But such cases are the exception, and the very rare exception in married women. The latter work either because the industry of the locality is mainly a woman's industry (as in Blackburn, Preston, or Dundee), or in order to eke out the failing wage of a sick or unemployed husband. They are frequently persons struggling against adversity and endeavouring in an unequal combat to act as wage-earner and house-mother. And experience shows that as a rule it cannot be done without evil results. For in addition to the natural anxiety and stress thus thrown upon the woman there are the added strains of factory life, such as piece-work, hard physical labour, injurious trade processes, fatigue, and so forth. Some of these must now be considered.

In some trades women act as beasts of burden. In brick-making, tin-plate works, iron hollow-ware, certain hardware trades, some jam and sauce factories, mat- 
makers, postcard manufacturers, and other industries, women are not infrequently employed in carrying or lifting weights which cannot fail to exert serious injury to some. "Many are the complaints of weariness and overstrain," writes a lady factory inspector, "made to me by girls and young women-some of them mothers-who are too poor or too unskilled to leave an employment which is making too great a demand upon their physical powers, and which in some instances has caused serious injury." 2 Nor is lifting or carrying heavy weights by any means the only physical strain which women undergo in many trades, as becomes very apparent if one studies the records of women's labour in brushmaking, in the linen industry, as hat furriers, or as laundresses.

The results of fatigue become manifest in various ways, not the least being the occurrence of accident or of physical breakdown.3 The former, as is now well

I The following may be cited as examples: Girls carrying $72 \mathrm{lbs}$. of bricks resting on a pad strapped on the hips; wheeling barrows containing 40 bricks weighing 9 lbs. each; pushing buggies containing 100 bricks of same weight ; handling clay during "walk-flatting," weighing 35 tons every day, \&c. Four women employed solely as clay carriers, each making 128 journeys a day, some of which, as the factory is a large one, are a fair distance, and at each journey carrying a piece of clay weighing half a cwt. Young women of superior class employed in counting and packing postcards lift and carry from cutting machine to their benches stout wooden iron-bound boxes containing 12,600 to 13,440 postcards, weighing up to 138 lbs. Women and girls carrying bulky bags of cocoa-nut mat weighing $48 \mathrm{lbs}$. to $59 \mathrm{lbs}$. Girls carrying pans of boiling jam weighing about I cwt. each.-Annual Report of Chief Inspector of Factories, 1902, p. I73; 1903, p. 221 ; 1904, p. 267.

2 Ibid., I900, p. 375.

3 There are two forms of fatigue-fatigue of the motor system and fatigue of the nervous system. "When fatigue [of the motor system] is caused by activity of the large muscle masses, it is not in them mainly that the troubles appear, but much more in the circulatory and respiratory system ; if the fatigue is very considerable the troubles pass to the digestive and urinary system. The most exact measure of fatigue is given by comparative analysis of the respiratory gaseous exchange during and after work, consumption being so much the greater for a given amount of work as the fatigue is the greater. Close examination of the pulse reveals, in increasing length of the systole and diminution of the diastolic pause of the heart, good criteria of fatigue. Loss of body weight, caused by the fact that activity of the digestive system does not grow at the same rate as 
recognised, occur most frequently in fatigued workers. For example, since 1900 there has been a steady, though not marked, increase in the number of accidents to women over 18 years of age in laundries. In 1900 such accidents numbered 131; in 1904, 157. Now it has been shown that whilst the first half of the day yields about the same number of accidents as the second half, more accidents, amounting to nearly double the number, occur between the hours of II a.m. and I p.m., and between 4 p.m. and 7 p.m., than at any other time of the day.

The latter, physical breakdown, is more apparent in certain trades than others, and more frequently occurs than is supposed. Dr. McCleary, for instance, has shown that phthisis was more prevalent among laundresses attending the Wandsworth and Clapham Union Infirmary from 1895-1903 than among other occupied women, or among unoccupied women. Between the ages of $15-25$ years 10'6 per cent. of all the cases of phthisis occurred in laundresses as compared with 3.2 per cent. in other occupied women, and 3.9 per cent. in unoccupied women. ${ }^{x}$ There are other trades, such as working in lead, in the potteries, as hat furriers, or in the linen industry, and elsewhere, which reveal a marked degeneration in the physique of women. In England, lead-poisoning shows a substantial decline from 1,258 cases, notified to the Chief Inspector of Factories in 1899, to 597 cases notified in 1904. The chief incidence of the disease falls upon workers in white lead, and next upon china and earthen-

the work, shows, when regular work is in quest, that work is excessive. In the case of acute overstrain it is above all the kidneys that should be kept under observation. Appearance of albumen and casts in the urine reveals a trouble which may quickly disappear with rest, but which, nevertheless, is not negligeable." - Dr. Zuintz in the Ann. Rep. of Chicf Inspector of Factories, I903, p. 307. See also Dangerous Trades (1902), pp. I04-117 (Dr. Oliver on "Physiology and Pathology of Work and Fatigue ").

Report on Health of Ballersca, 1903, p. 129. 
ware workers. It will be necessary to refer to leadpoisoning in women subsequently. Dr. Glibert, Principal Medical Inspector of Factories in Belgium, considers that hat-furriers' work is distinctly injurious, but not so serious and undermining to health as lead-working. $\mathrm{He}$ found 68 per cent. of women employed as hat furriers to have good health, 65 per cent. in the linen industry, and 84 per cent. of rag pickers. ${ }^{\mathrm{I}}$

The same observer found only 65 per cent. of the women employed in the linen industry in Belgium had good health, which deteriorates pari passu with their age. The health of women is more gravely affected than that of the male workers because the women begin at a much earlier age in the linen industry, 53.4 per cent. of the women employed in spinning having commenced work before attaining their twelfth year. More than half the women are married. Dr. Glibert also shows that the influence of illness in early childhood, and the "employment of the mother, exert an unfavourable effect on women in this industry when their turn has come to go to work. ${ }^{2}$

The general effect of the factory system, when improperly controlled, is witnessed at Dundee, where 24,879 women and girls are employed in the jute and hemp factories (9,479 men are also employed). In the same town another 3,000 women are employed in other textile works. As many as 16 per cent. of all the girls in Dundee, between the ages of 10 and 14, are employed in these trades. The corresponding figures for Glasgow are 3 per cent. Jute is used for the manufacture of sacking, coarse cloths, cheap carpets, curtains, and furniture hangings, \&c., and this industry is almost confined to Dundee. The average wages for women are below I2s. per week in

I Ann. Rep. of Chicf Inspector of Factories, 1903, p. 300.

2 Ibid., Ig02, pp. 284-293. 
eight processes, and above I2s. but under $18 \mathrm{~s}$. for the remaining five processes. The women are largely employed in the preparing processes, which for the most part require little skill, and in the spinning flats. One quarter of the women, or about 6,000 , are married. "To a great extent, owing no doubt to the want of well-paid employment for men, a very large proportion of the women have to neglect their homes in order to earn subsistence, or else to wear themselves out in an attempt to be both bread-winner and house-mother. The extent to which the work of the jute mills, and especially the roughest kind of the work, is carried on by married women and by children, is a matter which must give serious concern to those who are interested in the development of Dundee, and in the health and character of its people. The wages earned in the mills are not such as will permit the employment of a substitute who will give proper oversight to the house, and most often the baby is left in charge of a grandmother or some already burdened neighbour, while the street is the refuge of the bigger children. Engaged from six in the morning until six in the evening in the dust and heat and noise of a jute or flax mill, can we wonder that when she reaches home she is without strength or interest to make her then take up her domestic duties, and that the number of those who do make an effort to do the work of two women is not a large one." I

Further, it has been found that Dundee boys and girls, between the ages of II and I 5 years, are much below the average standard both in height and in weight. One of the factory inspectors writes of them as follows :-

Ann. Rep. of Chief Inspector of Factories, 1901, p. 183-184 (Miss Paterson). 
Many of these children are born and brought up in single-and double-roomed houses, or in large tenements, where the conditions of life are almost as unnatural and injurious as it is possible to imagine. Overcrowding often exists, in conjunction with general squalor, and intemperance on the part of one or both parents. Injudicious and unsuitable feeding during the susceptible period of infancy, exposure to inclement weather, and general neglect appear to be largely the cause of infantile deaths, as the children who survive seem to suffer more or less from weak constitutions throughout life. The latter class are often very short and far below the normal standard in weight. Undoubtedly factory life, although not specially injurious to workers who have naturally strong constitutions or who commence labour after having reached maturity, nevertheless neither fosters growth nor development, and has a distinctly harmful effect on undersized or badly nourished young persons. Thus I have frequently conversed with full-grown men of twenty years and upwards who do not stand more than five feet or five feet one inch in height and who scale less than nine stone. These men have not the physical strength for heavy manual labour, or indeed any task which demands prolonged effort, but must accept unskilled labourers' wages in mills or factories all their lives. Such wages are usually very small and quite inadequate to support a wife and family. The degeneracy exhibited in males is similarly remarked in females, but in a slightly less degree. The present race of mill workers in Dundee are the descendants of generations of operatives, there being little intermarriage in this class with persons of rural origin. 'The operatives in the surrounding towns of Forfar, Arbroath, and Brechin are taller and more robust looking than their colleagues in Dundee. ${ }^{x}$

It will not surprise the reader of these reports on Dundee to learn that the infant mortality rate is exceptionally high, and for the decennial period 1893-1902 was 176 per 1,000 births. In 1904 it was 174. There were 788 infant deaths, 129 of which (or 16.4 per cent.) occurred within the first week. Out of these 129 deaths, 125 were

I Ann. Rep. of Chief Inspector of Factories, 1900, p. 336. 
medically certified as due to prematurity and immaturity. Almost exactly half (393) of the total infant deaths (788) occurred in the first three months of life. The chief diseases which caused this high infant death rate were prematurity and immaturity, 28.7 per cent. of the total ; bronchitis, 23.3 per cent.; gastro-intestinal disease and malnutrition, $21^{\circ} 6$; and zymotic disease (tuberculosis, whooping-cough, measles, and other infectious diseases), II6. Inquiry was made into the social conditions of the home life of 364 of these infant deaths, to the findings of which we refer elsewhere. Here it may be added that the occupations, or former occupations, of the mothers of these dead infants were as follows : 84 weavers, warpers, or winders, 105 spinners, piecers, or shifters, 88 preparers, 12 sack machinists or sack sewers, 27 miscellaneous, 20 unoccupied, and 25 concerning which there was no return obtainable. ${ }^{\mathrm{I}}$ Of the cases inquired into $13^{.2}$ per cent. of these mothers worked at the factory to within a week of childbirth. Fifteen women worked to within a few hours of childbirth.

It is interesting to compare the condition of things existent in Dundee with those obtaining in Paisley, where female labour also predominates, although the population is smaller. Dr. Robb, the medical officer of health, writes to me that the total number of women employed in Paisley is approximately 14,500, of whom 9,250 are engaged at textile fabrics, and 1,000 at dressmaking. In textile fabrics, probably 8,500 are employed in one cotton thread factory, which possesses the following characteristics, namely $(a)$ it is excellently kept, the conditions surrounding the workers being of the best, and $(b)$ nearly all the women employed are unmarried. In some bleaching and finishing works in Paisley there are some married women employed, but most of these

- Rep. of Dundee Social Union, 1905, pp. 73-74. 
have grown-up families. Dr. Robb adds, that as far as he can form an opinion, "the practice of married women working right up to the time of their confinement, and returning to work immediately after that event, practically does not exist in Paisley." There appears also to be a greater amount of interest taken by their employers in the women workers than occurs in Dundee, the occupation of married women being discouraged. ${ }^{\mathbf{T}}$ The infant mortality rate for Paisley during the last three years has been in 1902,121 ; in $1903,129^{\circ} 4$; and in 1904, 133.8, as compared with an average of 175 in Dundee.

Quite apart, however, from particular towns there appear to be conditions in special industries which call for mention. On this point of difference of industry Dr. Arthur Shadwell has recently furnished some interesting notes. ${ }^{2}$ He compares textile towns in Saxony with metal towns in the Ruhr district of Westphalia. I have chosen eleven typical towns in the former to compare with the eleven towns selected by him in the latter.

TOWNS OF SAXONY, IgOI (TEXTILE).

\begin{tabular}{|c|c|c|c|c|c|}
\hline Town. & & Population. & Birth Rate. & Death Rate. & $\begin{array}{c}\text { Infant } \\
\text { Mortality. }\end{array}$ \\
\hline $\begin{array}{ll}\text { Chemnitz } & \ldots \\
\text { Plauen } & \ldots \\
\text { Zwickau } & \ldots \\
\text { Löbtau } & \ldots \\
\text { Meissen } & \ldots \\
\text { Zittau } & \ldots \\
\text { Freiberg } & \ldots \\
\text { Bautzen } & \ldots \\
\text { Glauchau } & \ldots \\
\text { Reichenbach } \\
\text { Meerane } & \ldots\end{array}$ & $\begin{array}{l}\ldots . \\
\cdots \\
\cdots \\
\cdots \\
\cdots \\
\cdots \\
\cdots \\
\cdots \\
\cdots \\
\cdots\end{array}$ & $\begin{array}{r}210,004 \\
75,605 \\
56,465 \\
35,522 \\
31,976 \\
31,247 \\
30,279 \\
26,297 \\
25,766 \\
24,509 \\
23,941\end{array}$ & $\begin{array}{l}39 \cdot 5 \\
39 \cdot 6 \\
34 \cdot 4 \\
44^{\circ} \cdot 8 \\
31 \cdot 9 \\
25 \cdot 5 \\
26 \cdot 6 \\
26 \cdot 9 \\
30 \cdot 1 \\
37 \cdot 7 \\
39 \cdot 1\end{array}$ & $\begin{array}{l}23 \cdot 8 \\
17 \cdot 5 \\
22 \cdot 5 \\
19 \cdot 6 \\
19 \cdot 3 \\
17 \cdot 4 \\
19 \cdot 3 \\
16 \cdot 2 \\
22 \cdot 9 \\
23^{\circ} \cdot 3 \\
23 \cdot 9\end{array}$ & $\begin{array}{l}331 \\
198 \\
271 \\
280 \\
225 \\
196 \\
220 \\
158 \\
333 \\
333 \\
306\end{array}$ \\
\hline Average & $\ldots$ & - & $34^{\circ} 2$ & $20 \cdot 6$ & 259 \\
\hline
\end{tabular}

I Ann. Rep. Chief Inspector of Factories, 1904, p. 274.

2 Industrial Efficiency: A Comparative Study of Industrial Life in England, America, and Germany (Igo6), vol. i. pp. 157-242. 


\section{THE OCCUPATION OF WOMEN}

TOWNS OF WESTPHALIA, I9OI (METAL).

\begin{tabular}{|c|c|c|c|c|c|}
\hline Town. & & Population. & Birth Rate. & Death Rate. & $\begin{array}{c}\text { Infant } \\
\text { Mortality. }\end{array}$ \\
\hline $\begin{array}{l}\text { Alten-Essen } \\
\text { Bochum ... } \\
\text { Dortmund ... } \\
\text { Duisburg ... } \\
\text { Essen } \\
\text { Gelsenkirchen } \\
\text { Hagen ... } \\
\text { Hamm } \quad . . \\
\text { Hörde } \quad . . \\
\text { Mulheim ... } \\
\text { Oberhausen }\end{array}$ & $\begin{array}{l}\cdots \\
\cdots \\
\cdots \\
\cdots \\
\cdots \\
\cdots \\
\cdots \\
\cdots \\
\cdots \\
\cdots\end{array}$ & $\begin{array}{r}34,599 \\
66,917 \\
146,408 \\
95,350 \\
187,385 \\
37,560 \\
64,042 \\
31,695 \\
25,822 \\
39,079 \\
43,547\end{array}$ & $\begin{array}{l}54^{\circ} 1 \\
42^{\circ} 4 \\
43^{\circ} 0 \\
46^{\circ} 1 \\
46^{\circ} 1 \\
49^{\circ} 0 \\
39^{\circ} 2 \\
39^{\circ} 4 \\
47^{\circ} 1 \\
39^{\circ} 0 \\
5^{\circ} 2\end{array}$ & $\begin{array}{l}24^{\cdot} 8 \\
25 \cdot 1 \\
19 \cdot 9 \\
21^{\circ} \cdot 2 \\
20^{\circ} 7 \\
25^{\circ} 0 \\
18^{\circ} 5 \\
17^{\cdot} \cdot 2 \\
20^{\circ} \cdot 5 \\
19^{\cdot} 2 \\
20^{\circ} 7\end{array}$ & $\begin{array}{l}239 \\
184 \\
190 \\
182 \\
165 \\
190 \\
167 \\
162 \\
185 \\
208 \\
221\end{array}$ \\
\hline Average & ... & - & $45^{\circ} \mathrm{O}$ & $2 I \cdot I$ & I90 \\
\hline
\end{tabular}

Dusseldorff has a birth rate of $3^{\circ}{ }^{\circ} \mathrm{O}$, a death rate of $18^{\circ} 7$, and an infant mortality of 206 .

It will be noticed at once that both textile and metal towns have a high infant mortality rate. Then it will be seen that the textile infant mortality is much above the metal, but that the birth rate in the former is low and in the latter is high. Dr. Shadwell holds that the birth rate is usually low in textile towns $\left(24^{\circ} 7\right.$ in England and 35.5 in Germany) and high in metal towns (33.9 in England and 46.2 in Germany). I Finally, it will be observed that the general death rate is lower in the textile towns, though the infant mortality is so much higher, than in the metal towns. These figures are certainly deeply interesting, and denote, one must add, a condition of things open to grave apprehension. It is difficult to select from Dr. Shadwell's absorbing chapter on the conditions of life obtaining in industrial Germany. On the whole, however, what strikes one most is the marked vitality - a high birth rate, a fairly low death rate, and a not very high infant mortality - of the metal towns as

$\times$ Rep. of Interdepartmental Committee on Phys. Deterioration, I904. vol. iii. p. 57 . 
compared with, say, Chemnitz. This town, it appears, is overcrowded, and tenement life is universal. In the most densely populated parts the number of persons to a house may run to 130 or 173. The medical officer of health of Chemnitz ascribes the high infant mortality to lack of medical advice, bad housing, overcrowding, bad feeding, and dirty feeding-bottles-all of which conditions, as Dr. Shadwell remarks, are not peculiar to Chemnitz. The real explanation is probably this: "In Saxony wages are low," writes Dr. Shadwell, "and the people have never learnt to enjoy and look for a standard of comfort." They still take life as it comes, and the children are weak, "and the parents let them die." They do not call in a doctor, nor do they tend the child with carefulness and knowledge. "They take death as it comes; it is part of life. And more children succumb in textile than in other districts because the mothers go out to work. This may seem very sad and shocking, but the alternatives are worse." r

\section{LENGTH OF HOURS OF WORK.}

In the English textile factories there is a twelve-hours' day with two hours for meals; on Saturdays six hours, and half an hour; work not to continue more than $4 \frac{1}{2}$ hours at a stretch without a break of at least half an hour. Overtime, except under special circumstances, and Sunday and all-night work is prohibited. The annual holidays are Christmas Day, Good Friday, and four Bank Holidays. These limits work out at $65-66$ hours per week, and about 3,400 hours per annum. In I9OI there were in the United Kingdom 867,259 women occupied in textile fabrics.

In the non-textile factories and workshops the same hours obtain, except on Saturday, when the standard is eight hours with $1 \frac{1}{2}$ hours for meals, stretch of work not to

- Industrial Efficiency, vol. i. p. 237. 
continue beyond five hours without a break. Overtime is allowed up to two hours on three days a week, and thirty days a year, with extra half-hour for meal. The holidays are the same as in textile factories. These limits work out at a minimum of $66_{2}^{1}$ hours per week.

In "women's workshops" other than domestic workshops and laundries, the same hours hold except that there the five hours' spell may be exceeded, and there is no overtime allowable. In domestic workshops women's hours, meal-times, holidays, and overtime are all entirely unregulated, and depend upon pressure, need, and physical endurance. In laundries 60 hours is the weekly limit exclusive of meal-times. Overtime is permitted three days a week or thirty days in the year, without extra meal-time, and Sunday and all-night work is allowed.

Finally, there are certain processes, such as fish-curing, fruit-cleaning, \&c., in which women are engaged which are exempted from regulation for hours of employment. In a general way it may be said that the hours of women's employment, according to statute, vary from $60-70$ hours per week.

The question remains as to infringement of these limits. Of this we can only judge in part, for it is a difficult matter to check. But since the new Factory Act of I90I numerous instances are recorded of "time-cribbing." A factory inspector at Manchester reports : "The majority of firms always run from $1 \frac{1}{2}$ to $2 \frac{1}{2}$ minutes beyond the legal times, and for this small amount it is almost impossible to take any action. It is only when cribbing exceeds $2 \frac{1}{2}$ minutes that the inspector feels on sure ground. Yet the habitual cribbing of only two minutes at each starting and stopping time represents a clear gain of a week per year." $\mathrm{I}$ He concludes that heavier penalties for infringement might act as a deterrent. An inspector

I Aun. Rep. Chief Inspector of Factories, 1902, p. 118. 
at Oldham writes: "'Time-cribbing' shows no sign of cessation or even of diminishing. Nearly all cotton mills crib time of from 2 to 10 minutes in each meal-time. Offenders readily pay the fines imposed upon them; these are generally very light, and utterly inadequate to reduce the frequency of the offence." I

The case of a laundry in Liverpool is recorded in the same report (where women were employed) which was working $82 \frac{1}{2}$ hours per week, exclusive of meal-times. In the report of the following year (1903) a number of particulars are given of the way in which legal overtime or illegal "time-cribbing" occurred.2 In 1904, in a large factory laundry a woman was found to have been employed $76 \frac{3}{4}$ hours in the week, and a girl of seventeen $68 \frac{1}{2}$ hours, exclusive of meal-times. 3 And many other similar instances could be quoted. Since the passing of the Factory Act of 1901 , that is to say, during the three years I902-4, 713 complaints as to illegal hours have been received at the Home Office, and 343 cases have been upheld, and report is made that "the abuse known as 'time-cribbing' is still prevalent in the north-western division, often with the connivance of the operatives." The practice does not prevail in Scotland.

But we may take it that these are the exceptions, and in most places it would appear that any serious degree of "time-cribbing" is now a thing of the past.4

× Ann. Rep. Chief Inspector of Factories p. II9.

Ibid., I903, pp. 32-33. 3 Ibid., I904, p. 268.

4 Since these words were written the following paragraph appeared in the Times (February, I906) :-

\section{“'Time-Cribbing' in Lancashire Mills.}

"Acting on behalf of the Home Secretary (who was detained in the House of Commons), Mr. Herbert Samuel, the Under-Secretary, received a deputation yesterday from the United Textile Factory Workers' Association, who complained of 'time-cribbing ' in Lancashire cotton mills.

"Mr. Shackleton, M.P., introduced the deputation, and the spokesmen were Mr. J. Crinion, president of the Amalgamated Society of Card Room Operatives, and Mr. W. Marsland, representing the cotton spinners. It 


\section{EMPLOYMENT BEFORE AND AFTER ChILdBIRTH.}

\section{In the Factory Act of 1891 (S. 17) and in the Act of} I90I (S. 6I) the law lays down a standard as to the employment of women after childbirth in the following words :"S. 6r. An occupier of a factory or workshop shall not knowingly allow a woman or girl to be employed therein within four weeks after she has given birth to a child." 1

was stated that many employers in Lancashire kept their factories at work at least two or three hours per week beyond the legal time to their own profit, but to the loss of the operatives, who were employed upon the day-work system. The comparatively small fines inflicted upon employers had no deterrent effect.

"Mr. Herbert Samuel in reply, said the matter had already been brought before the Home Secretary by a Trade Union deputation, who approached him on a number of labour questions, and received a very sympathetic reply. Undoubtedly 'time-cribbing' was notorious in the textile districts, and it had long been known to the Home Office. Whatever could be done ought to be done and would be done to stop the practice. The factory inspectors for some time past had been giving constant and close attention to it, and between July and October last there were thirty-six prosecutions with thirty-four convictions. Nevertheless, the practice continued unchecked, and for two reasons. One was the difficulty of securing evidence, and the other was the inadequacy of the penalty. It actually paid an employer habitually to crib time and run the risk of being called on to pay a comparatively small fine. It had been suggested that a remedy might be found in an increase in the number of factory inspectors. Undoubtedly the factory inspectorate was understaffed, but Mr. Gladstone hoped to increase the number of inspectors of various classes. Another suggestion was that there should be a cumulative fine, or that the maximum fine should be made the minimum. That was done now in some cases, and the question of whether the principle could be extended would be carefully considered. The suggestion that the law could be more efficiently administered if the services of the police were requisitioned was one with which personally he had considerable sympathy. It would, however, require legislation, and when Parliament would be able to deal with amendments in the Factory Acts he could not say."

Similar legislation exists in Belgium, Holland, Denmark, and Austria. In Germany the four weeks must be extended to six, unless a medical certificate is furnished approving of employment at the end of four weeks. In Spain the period of prohibited work is three weeks, and the employer must allow one hour at least in the ordinary period of employment to nursing mothers to nurse their children. There must be no deduction of wages for this hour, which may be divided into two separate half-hours. In Switzerland a total absence from employment in factories of women during eight weeks before and after childbirth must be observed, and on their return to work proof must be tendered of an absence since the birth of the child of at least six weeks.-Oliver's Dangerous Trades, 1902, pp. 53-54. 
It will thus be seen that no legal offence has arisen unless the occupier has employed or re-employed the mother of a child knowing that she has given birth to a child within four weeks. Further, no responsibility is laid upon the mother or father of the child, no means are prescribed by which the employer may find out the fact of the birth or its date, and up to the present it appears that no action can be taken to prove "knowledge" against a limited liability company. Hence it has come about that although the prohibition is well known in factory districts it remains more or less a dead letter, the spirit of the law in any event being broken. Since rgor the Home Office has received 27 informations of infringement of S. 6r, of which 24 proved to be genuine. But this is no guide as to the degree of infringement, nor is it, of course, concerned with the time of leaving off work before confinement, which is also a matter of great importance. Miss Squire, one of H.M. Lady Inspectors of Factories, made an inquiry into the time of leaving off work before, and of resuming after, confinement in 124 women employed in cotton mills in Preston, with the following result :-

\begin{tabular}{|c|c|c|c|c|c|c|c|c|c|c|}
\hline & \multicolumn{4}{|c|}{ BEFORE CONFINEMENT. } & \multicolumn{6}{|c|}{ AFTER CONFINEMENT. } \\
\hline & $\begin{array}{l}9-6 \\
\text { mo. }\end{array}$ & $\begin{array}{l}6-3 \\
\text { mo. }\end{array}$ & $\begin{array}{l}3-1 \\
\text { mo. }\end{array}$ & $\begin{array}{l}\text { Under } \\
\text { I4 days. }\end{array}$ & $\begin{array}{c}\text { Before } \\
\text { I mo. }\end{array}$ & $\begin{array}{l}1-2 \\
\text { mo. }\end{array}$ & $\begin{array}{l}2-3 \\
\text { mo. }\end{array}$ & $\begin{array}{c}4-6 \\
\text { mo. }\end{array}$ & $\left|\begin{array}{c}6-12 \\
\text { mo. }\end{array}\right|$ & $\begin{array}{l}\text { Not } \\
\text { returning. }\end{array}$ \\
\hline No. of Women & IO & 36 & 57 & $2 \mathrm{I}$ & 2 & 38 & 42 & 34 & 6 & 2 \\
\hline
\end{tabular}

Two of the medical men with whom Miss Squire conferred in Preston attributed the large number of premature births to continued work in the mill during pregnancy, and all considered that an exceptional number of cases of uterine trouble existed and was attributable to 
too early return to work.I A special sub-committee of the Corporation of Preston arrived at much the same conclusion two years earlier, and in particular laid emphasis upon the grave injury following " the return of the mother to her work within a short period after confinement." 2 In Longton and Hanley, in the Potteries, the usual practice is to continue work until within a few weeks of childbirth, and most of the women return to work six weeks or longer after childbirth, though nearly all of them do their housework at the end of two weeks.3 In Dundee, out of an inquiry involving 267 mothers of young children, six returned within four weeks of childbirth. The average absence before confinement is a month or more.4

Another inquiry in the same town showed that 13 out of I Io mothers had returned to work within the month.5 In Paisley, as we have seen, there is probably very little infringement.

A hint in the above paragraph suggests that in the event of the mother's work being at home, employment would commence at an earlier date after childbirth than if the mother was occupied in a factory. Section 6I has, of course, no application to home-workers, and yet there are an immense number of such persons, most of whom are women (in Finsbury 86 per cent.) and a high percentage of whom are married.

The result is that the limit of time of return to work laid down in S. 61. is disregarded by home-workers. ${ }^{6}$

- Report of Interdcpartmental Committce on Physical Detcrioration, I904, vol. i. p. 124 (Miss A. M. Anderson).

2 Loc. cit., p. I0. 3 Ibid., p. I24.

5 Rep. of Dundec Social Union, I905, p. 74 .

6 The following typical cases, which occurred in Central London, may be cited :-

(a) Mrs. H., blouse and children's costume machinist, at home, has three children, the youngest $2 \frac{1}{2}$, two very delicate. After confinement she has usually begun her blouse work again at the end of a fortnight. But a year ago after a premature confinement (the baby died immediately after birth), 
In home-workers, as in others, the cause of the early return to work is almost invariably poverty.

The limit of four weeks is almost universally recognised as the least restriction that is compatible with the health of the mother, and far less than most authorities would consider needful or desirable in the interests of the child. Further, it should be added that the need for restriction is "on medical testimony in the textile districts greater than in any other owing to the greater strain and more trying conditions of work." $\mathrm{x}$

\section{Sanitation of Factories and Workshops.}

The health conditions for which legislation is provided in the Factory and Workshop Act of I90I are cleanliness, freedom from effluvia, the avoidance of overcrowding, sufficient ventilation, the drainage of floors, and the provision of sanitary conveniences. ${ }^{2}$ The principles of sanitation applicable to dwelling-houses also apply broadly of course to factories and workshops, and it is therefore

as her husband had been out of work, she could not afford to lie up at all. The baby was born between 6 and 7 a.m., and before midday of the same day she was sitting at her sewing-machine blouse-making. She is now again expecting her confinement. She always machines straight on up to the time of her confinement.

(b) Mrs. B., a young woman, and her husband work at home in the finishing of nursery boots. They have had two children, both now dead ; one died at thirteen days, the other at eight months. The birth of the first baby was premature; the second, very delicate, was born while Mrs. B. was suffering from pneumonia. The doctor thought she got pneumonia because she so often got wet in "going to the shop." Her husband worked for two shops, and "to get a living at all" he had to work straight on ; he could not spare time to fetch and carry the work backwards and forwards. So she had to do it and she often got very wet. Her share of the work was to make holes in the boot heels. She resumed her employment fourteen days after each baby was born.

(c) Mrs. D. is a boot machinist. Her husband is a painter and often short of work. Since her marriage she has done boot machining at home. She has lost five out of nine children; one was still-born. She usually machines till within a month of confinement, and resumes work about three weeks afterwards.-Ann. Rep. of Chief Inspector of Factories, rgo4, p. 275 .

Ibid., p. 275.

- Factory and Workshop Act, I90I, Sections I-9. 
unnecessary to dwell at length either upon the necessity for and means of sanitation or the evil results arising from neglect in these respects. Cleanliness, fresh air, and freedom from insanitation are as necessary in a factory as in a home. It may, however, be convenient to state in respect of overcrowding that not less than 250, or during any period of overtime, 400 cubic feet of space must be provided for each person, and this standard is now enforced. $r$ Somewhat more extended reference is necessary to ventilation and the supply of sanitary conveniences.

Ventilation in the proper sense, that is supply of fresh air as distinguished from mere air space, was not required under former Factory Acts, but this omission has been remedied in the Act of $190 \mathrm{I}$ (S. 7), and any standard fixed by the Home Secretary must now be observed. 2 In general it is found that 3,000 cubic feet of fresh air per head per hour, if uniformly diffused, will keep the respiratory carbonic acid gas down to the limit of 6 parts per I0,000. 3 There is comparatively little evidence to show that the presence of $\mathrm{CO}_{2}$ in atmosphere is itself directly injurious, and it is not used as a standard on that account, but for the reason that it serves as an available and convenient index of the exhaustion of the air. But though specific disease cannot be directly traced to the inhalation of stagnant air containing, say, upwards of 12 parts of $\mathrm{CO}_{2}$ per 1,000 , it cannot be doubted that such reduced air, in some degree deoxidised, exhausted, and containing organic impurity, does exert an injurious effect upon persons work-

I In certain special industries, c.g., in match factories in which yellow phosphorus is used, the ordinary minimum is 400 cubic feet.

2 A limit of 9 vols. of $\mathrm{CO}_{2}$ per 10,000 in humid cotton cloth factories, and 600 cubic feet of fresh air. per head per hour in other humid textile factories; $\mathrm{CO}_{2}$ in ordinary factories and workshops should not exceed I2 parts per 10,000.

3 For an explicit statement on this subject see Ann. Rep. of Chief Inspector of Factories, 1902, pp. vii-x: 
ing in it and spending many hours daily breathing it. Nor can it be doubted that this general proposition finds abundant confirmation in factories and workshops where women are employed. Haldane and Osborn found more often than not that the amount of $\mathrm{CO}_{2}$ present in the air of such places was much above the permissible degree of impurity (6 per 10,000). Taking the standard of outside air as containing 3.5 parts of $\mathrm{CO}_{2}$ per 10,000 , they found the amount of $\mathrm{CO}_{2}$ in the air of workshops in which women were employed to vary considerably. In tailoring workshops the $\mathrm{CO}_{2}$ varied from 3.2 parts per IO,000 (i.e., even purer than fresh-air standard) to 53.2 parts; in collar factories, from 13.3 to 38.6 ; in dressmaking workrooms, from 5.0 to 26.6 ; in laundries, from 3.6 to 8.2 ; in bookbinding workrooms, from 3.5 to 25.7 ; in textile factories (non-humid), from 3.2 to $47^{\circ} \circ$; in humid textiles, from 3.5 to 32.0 ; and in cotton-spinning, from 3.5 parts to 56.6 parts of $\mathrm{CO}_{2}$ per 10,000 . In tailoring and other industries under Jewish control the air was much fresher than in similar industries under English control. I

These figures leave us in no uncertainty as to the wide prevalence of atmospheres in factories and workshops which are so stagnant, stuffy, and "close" that they cannot but exert an injurious physical influence on women working in them. In point of fact it is a matter of common knowledge that the breathing of such atmospheres for lengthened periods is one of the conditions which results, in the long run, in actual disease. ${ }^{2}$ Local ventilation for the removal of dust, gases, vapours, and other impurities generated in the course of work, which are a nuisance or injurious to health, must be such as will

- First Report of Departmental Committee on Ventilation of Factorics and Workshops, 1902 (Appendices).

${ }^{2}$ The Science and Practice of Midwifery, W. S. Playfair, 1886, vol. i. p. 287. 
render them harmless as far as possible. Usually this involves exhaust ventilation applied at or near the point of origin, or other means such as fans, draft chambers, respirators, and for dust wet processes. The temperature must be regulated in every workroom of a factory or workshop, and humidity must be regulated in humid textile factories.

The standard as to sanitary conveniences is laid down in the Factory Act, I90I, $\mathbf{r}$ and determined and interpreted by special Order of the Home Secretary. The Sanitary Accommodation Order came into force in July, 1903, and lays down that "where females are employed, or in attendance, there shall be one sanitary convenience for every 25 females," properly and suitably separated and appointed.

The public do not yet recognise how grave may be the physical results of a failure properly to exercise the physiological functions of the kidneys and bowels. Such results are not, it is true, manifested in a way which permits of clear statement, and the effects may not become evident for months, or even years. But they are none the less existent. A failure to rid the body promptly and regularly of the excretal products of animal metabolism may lead not only to habitual constipation, but to diseased conditions of the blood, may predispose to constitutional diseases, and may be the original cause of disease and misplacement of internal organs. There can be little doubt that much of the widespread anæmia and chlorosis among factory women and girls arises from absorption into the blood of retained by-products in the alimentary canal, and it is a well-recognised fact that

Sec. 9 (1). "Every factory and workshop must be provided with sufficient and suitable accommodation in the way of sanitary conveniences, regard being had to the number of persons employed in, or in attendance at, the factory or workshop; and also where persons of both sexes are, or are intended to be, employed or in attendance, with proper separate accommodation for persons of each sex." 
headache and conditions of lassitude and debility frequently arise from a similar origin. From these facts it is clear that ample accommodation should be provided, not only for actual usage, but such that there may be no undue deterrence or postponement of the exercise of these functions. A standard must therefore be adopted which will in no way and under no passing circumstances of ill-health allow of insufficient provision. Under the Sanitary Act of 1866 the local authority was required to make regulations in this respect for tenement-houses, and from that time to $190 \mathrm{I}$ factories were treated in a somewhat similar way. In the latter year, however, the new Act furnished a definite standard for all workplaces, and though the condition of things has been bad in the extreme in the past, there is now evidence to show great improvement.

In 1902 the Blackburn mills were found to be sadly lacking in adequate sanitary accommodation, only one sanitary convenience on an average being provided for 40 women, compared with one for 26 in similar mills in the same part of the country. In Preston 28 out of 53 cotton factories were found with insufficient and unsuitable accommodation. Many of the arrangements provided were insanitary. I In 1903 the factory inspector for South Wales reported fourteen factories and workshops without any sanitary accommodation whatever.

During 1903-4 a systematic survey of every cotton mill in the north-west division of the country yielded defective or insufficient sanitary accommodation as follows: In Manchester, 25 per cent. of the factories visited; in Salford, 29 per cent. ; in Failsworth, 25 ; in the country districts of Swinton and Walkden the percentages were 33 and 66 respectively; in Oldham, 47 ; in Ashton, 25 ; in Mossley, 50 ; in Shaw, 25 ; in Rochdale, 42 ; and in Hey-

- Ann. Rep. of Chief Inspector of Factories, 1902, p. 97. 
wood, 64.x In many of the Staffordshire pottery towns a high percentage of unsuitable, insufficient, or insanitary conveniences also occur. It cannot be doubted that there has been great improvement in respect of this matter of sanitary accommodation in recent years, but there is still much to be done in the direction of more suitable provision. ${ }^{2}$

\section{ConClusions.}

We had previously seen that town life is disadvantageous to the health and life of infants. That is a commonplace and obvious fact. But after the present chapter we must now add that in towns where women are largely employed in factories, away from home, the disadvantages are enormously increased. Broadly, that is the inevitable conclusion. There are reservations and differences, but the fact remains. And the operations of this fact are threefold. First, there are the ordinary injuries and diseases to which women and girls in factories are liable; secondly, there is the strain and stress of long hours and hard work to the pregnant woman; and thirdly, there is the absence from home of the mother of the infant. It cannot be doubted that these are the factors in the relation between factory occupation of women and a high infant mortality.

The direct injuries to women and girls employed in factories and workshops are (a) accidents from machinery, materials, and other external agents ; $(b)$ injury or poisoning from toxic substances, or injury from excessive dust, fumes, vapour, or extremes of temperature, such as anthrax in horse-hair factories, tetanus in jute works, lung diseases in dusty trades, and abortion in lead works; (c) injury through fatigue and strain, long hours, insuffi- Ann. Rep. of Chicf Inspector of Factories, 1903, and also 1904, pp. 138-140.

I Ibid., I904, pp. 24 I-243. 
cient periods of rest for food, as in some clothing and dress factories, or the carrying of heavy weights, as in brick-making, \&c. ; (d) injury derived from defective sanitary conditions, such as ill-ventilation, dampness, or an insufficiency or unsuitability of sanitary conveniences ; and (e) too short a period of rest at the time of childbirth. Over and over again in the official reports of factory inspectors or medical officers of health does one meet with evidences of these injuries. Where the conditions resulting in these evils, coupled with the absence of the mother from home, are present, the infant mortality is high; where they are not present it is usually low. The Medical Officer of Health of Kearsley (J. C. Eames, M.D.), a town in Lancashire of 9,500 population, puts the matter in a nutshell in his annual report for 1904 . He began his official study of the health of the town in I885, and in his report he animadverts upon the changes which twenty years have brought.

"On looking back some remarkable changes are shown. We had then a population of 7,250 , against our present 9,500 . The death rates were about the same [18.0 per 1,000$]$, but our birth rate has fallen from 39 to 27 , there being no less than 286 births in 1885 , against 257 last year. Our death rate of children under I shows even more striking figures, it being then $\mathrm{r} 43$, and much the same for several years, against our present 229 .

" Undoubtedly during the twenty years much good sanitary work has been done and improvements made, and these have helped to keep down our general death rate. How, then, account for our very high infant mortality? It really looks as if people were less anxious to have families, and took less care of any they had. In the old times children were welcomed as likely soon to be a help to their parents; now, in spite of free education, it is felt that beginning work so much later, and being so much more independent (is this a result of education ?), they will no sooner be able to earn something than they will want to set up for themselves. We have developed into more of a manufacturing district, 


\section{THE OCCUPATION OF WOMEN}

and future mothers are tempted to remain in the mill too near to their confinement, and thus not be in a state to bear healthy children. Again, they return to the mill too soon after, thus leaving their children to others' care. This, of course, entails artificial feeding, which can never be as beneficial as natural, and is often simply poisonous. This improper feeding is generally due to ignorance, which also accounts for the errors made in clothing, and the cleanliness of the child and its surroundings."

Dr. Eames, addressing his authority, adds : "On the whole, I can safely congratulate you on the changes made since 1885 in the sanitary condition of the district. If these changes have not resulted in diminishing the death rate [of infants], that is because other evils have increased, and steps must now be taken to put them down also." x For ten years the infant mortality has been steadily increasing at Kearsley. In 1894-I903 it was 179 (the general death rate being 17 per 1,000 ), in 1903 it rose to 192 , and in 1904 to 229 , 'as much as 34 per cent. of the infant deaths being due to prematurity and immaturity, and this change is attributed by the medical officer to the town having "developed into more of a manufacturing district."

In Preston the infant mortality rates and the general death rates since $\mathrm{I} 88 \mathrm{I}$ have been as follows:-

\begin{tabular}{c|c|c}
\hline Year. & $\begin{array}{c}\text { General Death } \\
\text { Rate. }\end{array}$ & $\begin{array}{c}\text { Infantile Deaths per } \\
\text { I,000 Births. }\end{array}$ \\
\hline $1876-80$ & $27 \cdot 42$ & - \\
$1881-85$ & $24 \cdot 73$ & 208 \\
$1886-90$ & $26 \cdot 23$ & 229 \\
$1891-95$ & $23 \cdot 16$ & 235 \\
$1896-1900$ & 20.80 & 236 \\
\hline
\end{tabular}

Medical Officcr's Report for Kearsley, 1904, pp. I-2. 
In consequence of the fact that while there has been a steady and continuous decline in the general mortality of Preston during the past thirty years, the infant mortality has shown an increase, a sub-committee was appointed to inquire into the causes, and after careful consideration of the question and the examination of numerous witnesses having special facilities for correct observation, it submitted certain conclusions :-

I. "First among these causes is the employment of female labour in mills. An occupation requiring a woman to stand during the greater part of the day when continued up to within a few days or even hours of the time of parturition, must act to the detriment of the offspring, and there is less chance of the latter coming into the world fully grown, well formed, and in good health. Many deaths taking place during the first month which are returned as due to premature birth, immaturity, congenital debility, convulsions, and the like, may safely be ascribed to this cause.

2. "Again, the return of the mother to her work within a short period after confinement, thus depriving the infant of a mother's care and of the sustenance which nature intended for it, constitutes a still greater evil. With this is connected the nursing out of infants, which exposes them to violent and sudden changes of temperature during their removal night and morning through the cold air of the streets. Some mothers are compelled to resume work as early as possible, as they are the main support of the families, but there is a marked disinclination on the part of many young mothers to stay at home and tend their children, preferring as they do the life at the mill to that of nursing.

3. "But a third and more important cause consists in the very habits of the operative classes themselves, in their ignorance of the first laws of health, and in their blind adherence to customs which have long since been deservedly condemned. There are few people with less knowledge or experience of household duties than the ordinary factory girl, and as a consequence when she becomes a wife and a mother, knowing little of the duties required of her, she is content, as regards the manage- 
ment of her children, to follow the example of her parents and the customs of those amongst whom she lives. Accustomed to a heated atmosphere, the factory operative above all things fears a draught, and so the bedroom doors, windows, and fireplaces are kept closed; thus the air soon becomes foul and poisonous, and in this way the seeds of tubercular and scrofulous disease are engendered and transmitted from one member of the family to another.

4. "A high mortality is also met with among children of mothers who have children in quick succession, as also of mothers (e.g, small shopkeepers) who are very actively employed for many hours each day.

5. "Unwholesome food and the want of cleanliness in its preparation and administration are the direct causes of many infantile deaths. Bread and starchy preparations are substituted for milk, and where the latter is given, the feeding-bottle from its dirty condition is frequently a source of danger to the infant. After the first week or two, proper and systematic washing of the infant is less and less frequently done, fresh air and sunlight are not recognised as necessities, and altogether there is an absence of proper nursing, a word pregnant with meaning as applied to infant life.

6. "Among the causes may be mentioned 'insurance,' by which the death of a child brings a monetary gain to the parents; the habit of allowing very young children to sleep in the same bed with the parents, resulting in deaths from suffocation, or overlaying; and the use of sleeping stuffs to quiet a fractious child or to ensure a good night's sleep.

7. "Of causes which are more especially associated with the increase in the infantile mortality may be named: $(a)$ The diminished stamina of the parents. In Preston, as in the older manufacturing towns, where there is little importation of fresh blood, there is a risk in the intermarriages (often at an early age) amongst persons of the same class, and a danger of the offspring becoming more and more enfeebled. (b) The increasing use of means to prevent conception or procure abortion, which, if unsuccessful, must have a prejudicial effect on the health of the child. ( $c$ ) The alarming increase in the consumption, by young women and mothers, of alcoholic beverages, exercising a baneful 
effect on the constitution of the child before birth, but more especially leading to carelessness and neglect of the child after birth, and at that period of its life when care and attention are most needed.

"These, then, are the causes which sometimes separately, but more frequently in combination, lead to the heavy infantile death rate in Preston." I

These two extracts from the records of Lancashire towns not only lay emphasis upon the fact that the occupation of women away from home plays a part in the causation of infant mortality, but they illustrate, in concise form, the ways in which this factor operates.

In a general way it may be said that it is the employment of women from girlhood, all through married life, and through the period of child-bearing-the continual stress and strain of the work and hours and general conditions prevailing in women's labour-that is exerting its baneful influence on the individual and on the home. And it is necessary to view the matter in this way to escape its fallacies. Statistical returns do not entirely support the assertion that factory employment of women is the main cause of high infant mortality. Statistics are useful to guide us as to the general tendency, but it is their actual meaning in terms of social life and custom which should form our conclusions in the matter. To take a single example, it has been alleged that factory employment of women is the only cause of the heavy incidence of fatality from premature births. No doubt it bears a relation, but the fact is that prematurity is more a cause of infant death in districts where there are no factories than where there are. It is admitted that prematurity and immaturity is the chief cause of death in infants in the first trimester of their life. Is it not then a

Report on Health of Preston, 1902, pp. 10-12. 
strange fact that only 47.6 per cent. of the infant deaths in Lancashire occur within the first three months of life, whereas in the three counties where there is least factory employment of women and the lowest infant mortality (Westmoreland, Dorset, and Wiltshire), the percentage of deaths in the first three months is 61 (or 34 per cent. higher)? Or again, in Preston and Blackburn the employment of women has been declining since the census of 189r, but the infant mortality has been increasing. Or once more, in the Durham coalfield and in South Wales, districts in which women are not much engaged in industrial occupations, infant mortality has been increasing since the middle of last century, and now stands among the highest rates, whereas in the West Riding of Yorkshire, where women are much employed in the mills, the infant mortality has been declining within the same period.

The fact is, as I have pointed out, that something much more than mere percentage occupation of women is required to guide us. We need to know the percentage occupation of married women at child-bearing ages, and when we have secured that we need to give the facts a wide connotation. No doubt the factory plays a part, but the home plays a vastly greater part, in the causation of infant mortality in the towns where women are employed at the mills. There are two influences at work: first, the direct injury to the physique and character of the individual caused by much of the factory employment of women; and secondly, the indirect and reflex injury to the home and social life of the worker. We cannot afford to forget either of these points in attempting to estimate the operations of the factory in infant mortality. It is because they have not been sufficiently correlated together that fallacy has arisen in the past. But even yet we have not finished. "Infantile mortality in Lancashire," writes an 
experienced medical officer of health for a town in that county with an infant mortality in I904 of 222, "is, I am sorry to say, as much a financial as a hygienic question." Why do married women work in the mills? is the question this medical officer has reached. His answer is that "A weaver's wages will not allow of the wife's remaining at home, considering the high rents and rates, and so both go-which is the rule-and a hand-to-mouth existence results even for themselves, let alone the little ones, who are left in the intervals to the mercies of the nurse, who, as a rule, takes in the babies to eke out her own husband's wages. Much good may be done by hygienic tuition, but I am certain that the root of the whole matter with us is, as I have said, comparatively low wages and high rents and rates." And then at the end of his letter he adds : "The great trouble in dealing with this question [of infant mortality] from a hygienic point of view is caused, as in most social problems, by the people themselves." It is the old story of a vicious circle. 


\section{VI}

\section{EPIDEMIC DIARRHOEA}

F PIDEMIC diarrhœa (zymotic or epidemic enteritis) C may be defined as an acute infective disease affecting chiefly children under two years of age, occurring during the summer months in epidemic form, and characterised as a rule by the occurrence of diarrhœa, vomiting, convulsive phenomena, and wasting, accompanied in severe cases by toxæmia and collapse. About 75 per cent. of the total registered deaths in England and Wales from this disease occur in children under one year of age, and about 78 per cent. in London and other large towns. We have already seen that this disease is not only one of the most fatal of all the diseases of infancy, but that it is increasing in prevalence. It is, indeed, the typical condition to which urban infant mortality is due, and therefore it calls for somewhat full treatment.

\section{Pathology and Clinical Character of Diarrhoea.}

General.-The facts seem to show that, although the specific cause, if sufficiently potent, may operate generally throughout the system with the suddenness of the action of a virulent chemical poison, the disease usually first shows its presence in the body by more or less general, and sometimes only comparatively slight, disturbance of the nervous and vascular systems; as a rule, other parts 
of the body are disturbed before the gastro-intestinal system. It should be added that the length of the attack before death or recovery varies from a few hours to six or eight weeks. Ballard found a majority of fatal cases terminated between the fourth and fourteenth day. $x$

The following are the leading phenomena which, in varying degree and with varying certainty, are observed in the course of the disease as ordinarily met with: Diarrhœea, vomiting, convulsive phenomena, a bodily temperature sometimes above sometimes below the normal, reduction in quantity or actual suppression of urine, embarrassed breathing, and, as a rule, physical indications of pulmonary inflammation, pallor of surface of the body, loss of flesh, and exhaustion with its various well-known clinical features. Occasionally there is jaundice, and now and then a fugitive rash occurs.

Diarrhoea.-Ballard believed that this malady usually characterised by diarrhœa may run its course from first to last, and even to death, without any diarrhœa at all. In other cases, although diarrhœa occurs, it is by no means the prominent symptom; it may be comparatively of trifling amount or of short duration. More frequently, however, it is the prominent symptom, thus giving the malady its name, lasting throughout the illness, or only disappearing shortly before death. It may be intermittent or remittent. The quantity and daily frequency of the diarrhoal discharge vary, but in very sharp and acute cases, or towards the termination of more prolonged cases, bowel discharges may be incessant and abundant. In prolonged cases a change from diarrhœa moderate in quantity and frequency to a diarrhœa of this lastmentioned sort may take place very suddenly. It is not

× Dr. Ballard's classical researches were published in part as a Supplement to the Report of the Medical Officer of the Local Government Board, 1887. 
uncommon for the diarrhœal discharge to cease some hours and even some days before death. There is nothing essential about the colour of the stools ; they may be decidedly mucous or watery, or, on the other hand, lumpy and cheesy. For the most part the stools are offensive, but not invariably. If not offensive at first, they are apt to become so as the diarrhœa proceeds or the fatal illness approaches its termination. A description which has been given of the odour is "horrible and deathlike." In some cases the stools are stained with blood.

Vomiting.-In only Io or 20 per cent. of cases is vomiting absent altogether throughout the course of the illness. In the vast majority of cases the vomiting occurs concurrently with the commencement of the diarrhœa, or, if not concurrently, within a few hours. Occasionally it stands alone, perhaps for a whole day, as the prominent feature of the attack, the diarrhœa not appearing until the second day of the illness. As a rule, the shorter and sharper the illness, the earlier in its course does vomiting appear. Once it occurs it usually recurs from time to time until the termination of the case. In about a third or fourth of the cases, however, it ceases in the course of the first day's illness, and does not recur. In still fewer instances it only ceases, like the diarrhœa, shortly before death. Occasionally, in cases of over a week's duration, diarrhœa and vomiting have alternated as the prominent symptoms of gastro-intestinal disturbance. It varies in severity, occasionally being the prominent symptom from first to last, and now and then is so severe as to be apparently the principal cause of the fatal prostration. Its association with the diarrhœa has led to the familiar hospital formula of "D. and V."

Convulsions.-Only a small percentage of fatal cases run their course without presenting convulsions of some kind. Mostly they consist of the ordinary well-known 
"fits" of infants, but in about a fifth of the cases they consist of such minor phenomena as clenching or "working " of the hands, rolling of the head and eyes, twitchings of the limbs, "sawing the air" with the arms, or "inward convulsions," such phenomena being mostly observed towards the close of the illness. Convulsions, however, may occur quite early in the illness; sometimes even they occur on the first day of the illness, accompanying the commencement of the diarrhœa. After this they may not recur, or, on the other hand, they may recur from time to time during the whole illness, and be even its most prominent feature, sometimes appearing to take the place of the vomiting. There is no apparently necessary connection, however, between convulsions and the symptom diarrhoea, for the convulsions occur sometimes when the diarrhœa has throughout been moderate in amount. The occurrence of convulsions may indicate the onset of uræmia. The comatose condition in which the patient often dies appears as a rule to be due to the same condition of the blood; but in some cases evidences of intra-cranial inflammation have been observed.

Bodily Temperature.-At the commencement there appears to be slight febrile disturbance, but sooner or later, in the cases about to become fatal, the temperature falls more or less below the normal range, being lower in the morning than in the evening, and even then it mostly fails to attain a normal standard. Towards the end of a fatal case the temperature is apt to rise. In cases of very short duration, where the child is rapidly prostrated with deluging watery stools, the temperature falls rapidly, and the child may die in collapse. The quantity of urine voided is naturally reduced by the diarrhœe. Actual suppression occurs towards the close of some cases. The kidney is usually implicated quite as early as the intestine, with lesions quite as severe. 
Age Incidence.-Finally, a word must be said as to age incidence. The chief incidence of attack is upon children under five years of age, and particularly those under two years. After five years the disease rapidly declines, and occurs least between the ages of five and twenty-five, after which it gradually increases. On infants under one year of age the incidence is small under three months, after which age it definitely increases up to a varying time between the first and second years. Probably the chief fatality is in the second and third trimesters of the first year. ${ }^{\mathrm{I}}$ Infants die almost indifferently whether the attack be sudden and acute or slow and protracted, whereas in children above one year death seldom occurs unless the attack be virulent. Dr. Bruce Low pointed out in 1887 that the disease was not infrequently communicated from person to person by direct infection, multiple cases thus occurring.

"Diarrhœa," wrote Ballard, "is a malady always present in a lesser or greater- degree," at all seasons of the year, cases being often quite as acute and rapidly fatal as in the late summer. There is no week in the year in which deaths from diarrhœa are not recorded by the RegistrarGeneral. But in the summer the disease is so common as to constitute an epidemic of yearly occurrence. Excessive prevalence in the summer, above the average epidemicity, largely affects persons over five years of age, and, as a rule least of all infants. It is least prevalent in the first quarter of the year, next in the fourth quarter, more prevalent in the second, and most prevalent in the third quarter. Lastly, the disease attacks almost as many healthy infants as weakly ones. It is not the case that it only attacks weakly infants.

In I904, in the six typical towns-Birmingham, Manchester, Oldham, Blackburn, Brighton, and the Metropolitan Borough of Finsbury-37 per cent. of the infantile mortality from diarrhca fell on infants in the second trimester of their first year. 


\section{The Cause of Epidemic Diarrhoea.}

From what has preceded it is obvious that epidemic diarrhœa is a general disease of a specific character within wide variations.

Some writers speak of the disease as catarrhal rather than infective (the two forms are not very definite, and it is possible that the latter is an aggravated type of the former), but there is increasing evidence as to its infectivity, and this must be briefly considered, even though the exact cause of the disease is not at present known. In I887 Ballard formulated certain propositions, "as a working hypothesis that would best accord with the totality of the evidence" in his possession, which still serve as a basis for future inquiry. They were as follows :-

"That the essential cause of diarrhœa resides ordinarily in the superficial layers of the earth, where it is intimately associated with the life processes of some micro-organism not yet detected, captured, or isolated.

"That the vital manifestations of such organism are dependent, among other things, perhaps principally upon conditions of season and on the presence of dead organic matter which is its pabulum.

"That on occasion such micro-organism is capable of getting abroad from its primary habitat, the earth, and having become air-borne, obtains opportunity for fastening on non-living organic material, and of using such organic material both as nidus and as pabulum in undergoing various phases of its life history.

"That in food, inside of as well as outside of the human body, such micro-organism finds, especially at certain seasons, nidus and pabulum convenient for its development, multiplication, or evolution.

"That from food, as also from the contained organic 
matter of particular soils, such micro-organism can manufacture by the chemical changes wrought therein through certain of its life processes, a substance which is a virulent chemical poison; and that this chemical substance is, in the human body, the material cause of epidemic diarrhœa." $x$

Bacteriology of Diarrhoca.-The three causal agents which Ballard mentions as playing a large part in the production of this disease are the soil, season, and food-and the causa causans is "some micro-organism not yet detected or isolated." It must be said that we have not got much further than this during the last twenty years.

In 1885 , Escherich published his classical researches on $B$. coli communis. He pointed out that the excreta (meconium) of the newly-born infant is free from bacteria, but by the second day they are present in large numbers, and in the ordinary excreta of healthy infants he found chiefly two organisms, $B$. lactis arogenes and $B$. coli communis. Of these the former was the more abundant in the upper part of the small intestine, and the latter in the lower part and in the colon, so that in the excreta $B$. coli was abundant and $B$. lactis comparatively scarce. Booker, working in 1886 , subsequently found that the constant bacteria of the healthy excreta of the infant $(B$. coli and $B$. lactis arogenes) do not disappear in the excreta of diarrhœa. B. cali, however, does not predominate in the same degree, and $B$. lactis is present generally in greater numbers than in the healthy excreta. Booker examined the excreta of thirty-one children, and isolated thirty-three different species of bacteria. The actual number of bacteria was, he found, as great in healthy excreta as in diarrhœal excreta. Proteus vulgaris was found very generally, and in the most serious cases. No chromogenic bacteria were isolated, and cultures from a large number of green stools failed to develop green colonies. From these facts Booker concluded " that not one specific organism, but many different varieties of bacteria, are concerned in the etiology of the summer diarrhœas of children."

Supplement to the Report of the Medical Officer of the Local Government Board, 1887, p. 7. 
From 1889-95 Booker continued his studies, isolating bacteria from the rectum in ninety-two infants affected with epidemic diarrhœa, and also from the organs of thirty-three infants who died from this disease. He found the conditions for the development of bacteria in the intestine of infants affected with summer diarrhœa different from those in the healthy intestine of breast-fed infants, in that they favoured more varied bacterial vegetation, a rich growth of the inconstant species of intestinal bacteria, and a more uniform distribution through the intestine of the two constant varieties of healthy excreta bacteria ( $B$. coli communis and $B$. lactis arogenes). The first step in the pathological process-and this is a matter of great practical importance-Booker believes to be a direct injury to the epithelium from abnormal or excessive fermentation and from toxic products of bacteria; and secondly, a general intoxication brought about indirectly through the production of soluble poisons. He holds that, bacteriologically or anatomically, three principal forms of summer diarrhœa of infants may be provisionally distinguished: (i.) dyspeptic or non-inflammatory diarrhœa; (ii.) streptococcal gastro-enteritis; and (iii.) bacillary gastro-enteritis. ${ }^{I}$ As a result of his researches, Booker came to a general conclusion, which he expressed as follows: "No single micro-organism is found to be the specific excitor of the summer diarrhœa of infants, but the affection is generally to be attributed to the activity of a number of varieties of bacteria, some of which belong to well-known species, and are of ordinary occurrence and wide distribution, the most important being the streptococcus (enteritidis) and Proteus vulgaris." The streptococcus, termed $S$. enteritidis, varies in biological character, and seems to be associated with two classes of cases, one of which simulates cholera, the other typical enteric fever. It may be added that Cumston, Holst, Escherich, and Flexner, have also laid emphasis upon the causal relationship of several streptococci and diarrhœa.

I Fohns Hopkins Hospital Reports, r896, vol. vi. p. 253 . See also a paper "On the Growth of Bacteria in the Intestine," by Lorrain Smith and Tennant-Brit. Med. Four., 1902, vol. ii. p. 1941. Also Jeffries, Trans. American Pediatrics Society, vol. i., I889; and Baginsky, Archiv. $f$. Kinderheilkunde, xii., Nos. I and 2 ; and Berliner klin. Woch., I889. 
Klein was one of the first workers to isolate an anaërobic organism from cases of epidemic diarrhœea. This organism, which he named $B$. enteritidis sporogenes, was found in three successive outbreaks of diarrhœa occurring among patients in St. Bartholomew's Hospital. In the first two outbreaks the milk was evidently the channel of infection, in the third it was some rice pudding. $B$. enteritidis sporogenes is a widely-distributed organism, and occurs in normal and typhoid excreta, in sewage, manure, soil, dust, and milk. ${ }^{x}$ The etiological relationship between this bacillus and epidemic diarrhoa has been called in question, and it is not proved that the organism is the cause of the disease. On the other hand, it has been frequently found in the mucous flakes of the dejecta in patients suffering from the disease, and in the outbreak produced by the consumption of cooked rice pudding, it is difficult to understand how any organism except an anaërobe of highly resistant qualities could have produced the condition. It will be apparent, moreover, that $B$. enteritidis sporogenes fulfils in some degree the requirements suggested by Ballard.

That epidemic diarrhœe is caused by the $B$. coli either alone or in conjunction with other organisms, has been held by a number of authorities. Cumston, who investigated $\mathrm{I}_{3}$ cases of the disease, concluded that $B$. coli associated with Streptococcus pyogenes was the chief pathogenic agent concerned, and he claims that the virulence of $B$. coli is exalted by the association. ${ }^{2}$ Lesage also formed the opinion that the disease was due to $B$. coli, and investigated the agglutinative properties of the serum of children suffering from epidemic diarrhœe on $B$. coli isolated from the intestine. He obtained a positive result in 40 out of $5^{\circ}$ cases, and the serum of each of these 40 cases, also agglutinated samples of $B$. coli from 39 other children seized with the same disease. 3 Some of the most recent work on the relationship existing between $B$. coli and epidemic diarrhœa has been done by Delépine, who examined milk in an outbreak of epidemic diarrhœa which occurred in Manchester in 1894, and has also

- Reports of Medical Officer of Local Government Board, 1897-98; pp. 210-5I; 1902, p. 406 .

International Medical Magazine, February, 1897 .

3 La Semaine Mcd., October, 1897. 
examined a large number of town and country milks. His conclusion is that :-

"The infectious properties which food acquires frequently in summer and which give rise to the ordinary or common type of epidemic diarrhœa, are generally due to bacilli belonging to the colon group, of which $B$. coli communis (Escherich) and B. enteritidis (Gaertner) are probably two extreme types. I have come to the conclusion that the varieties of these bacilli, which are the most important sources of infection, are those which resemble the bacillus of Gaertner, and which therefore produce no permanent acidity, coagulation, or distinct smell when grown in milk. . . E Eidemic diarrhœa of the common type occurring in this country is apparently, in the great majority of instances, the result of infection of food by bacilli belonging to the colon group of bacilli, and which are present at times in fæcal matter. It appears that this infection of food does not generally lead to serious consequences, unless the infection is massive from the first, or the food is kept for a sufficient length of time, and under conditions of temperature favouring the multiplication of these bacilli.

"Milk, which is the most common cause of epidemic diarrhœa in infants, is usually infected at the farm, or (through vessels) in transit. Of the bacilli of the colon group which are capable of rendering the milk infectious, those which do not produce a large amount of acid, and :do not coagulate milk, are the most virulent, and are probably the essential cause of epidemic diarrhœa." I

In 1898 the subject was advanced a step further by Shiga's isolation of the $B$. dysenterice from dysentery in Japan. This organism is now.regarded as the cause of epidemic dysentery, and by some authorities as an important, if not the most important, cause of epidemic diarrhœa. In any case, there is substantial evidence for believing that it is a type of the diarrhœal organism, producing the disease either by itself or in association with streptococcus. As a result of investigation into epidemic diarrhœa in the United States Flexner is of this opinion. ${ }^{2}$

× Four. of Hygiene, 1903, vol. iii., No. I, pp. 89-go.

2 Studies from the Rockefeller Institute, vols, i. and ii. (1904). 
It is evident that our knowledge of the bacteriology of diarrhœa is not sufficiently established to permit of any very definite conclusion on the matter. It may be that the whole group of choleraic, enteric, and diarrhoeal diseases are caused by a group of micro-organisms having many similarities and relationships to each other; or it may be that different forms of diarrhoea have their own specific causal organism; or, lastly, it may be a question of association of organisms or of toxins which brings about the disease. ${ }^{x}$ In any event there is abundant evidence that epidemic diarrhœa is a specific disease caused by bacteria.

\section{Conditions favourable to Epidemic Diarrhoea.}

Though not by any means complete, our knowledge of the conditions which favour the occurrence of this disease are, on the whole, further advanced than our knowledge of its Etiology. And here again we may well accept the provisional conclusions of Ballard as a startingpoint. They may be stated as follows :-

(a) "The summer rise of diarrhœal mortality does not commence until the mean temperature recorded by the four-foot earth thermometer has attained somewhere about $56^{\circ} \mathrm{F}$, no matter what may have been the temperature previously attained by the atmosphere or recorded by the one-foot earth thermometer.

(b) The maximum diarrhœal mortality of the year is usually observed in the week in which the temperature recorded by the four-foot earth thermometer attains its mean weekly maximum.

(c) The decline of the diarrhœal mortality is in this connection not less instructive, perhaps more so, than its rise. It coincides with the decline of the temperature recorded by the four-foot earth thermometer, which temperature declines very much more slowly than the

- See also Report of Medical Officer to Local Government Board, 1902, p. 395 (Martin), 404 et seq. (Klein). 
atmospheric temperature, or than that recorded by the one-foot earth thermometer; so that the epidemic mortality may continue (although declining) long after the lastmentioned temperatures have fallen greatly, and may extend some way into the fourth quarter of the year.

(d) I do not wish it to be inferred that the atmospheric temperature and the temperature of the more superficial layers of the earth, exert no influence on diarrhœe. Their influence, however, is little if at all apparent until the temperature recorded by the four-foot earth thermometer has risen as stated above; then their influence is apparent, but it is a subsidiary one." I

In addition to these conditions of soil, Ballard and other workers have pointed out that insanitation in the widest sense of the term favours epidemic diarrhœa. Density of population or houses upon an area, unclean soil, dusty surfaces, bad light, absence of ventilation, maternal neglect, contaminated food, \&c., all have a share in creating an environment favourable to the disease. ${ }^{2}$

We may take the inquiry into predisposing conditions a stage further, by quoting the conclusions of Dr. Newsholme, of Brighton, who published an elaborate paper on the causation of epidemic diarrhœa in 1899 . Some of his chief conclusions, which are now widely accepted, were as follows :-

"( $\mathrm{r}$ ) Epidemic diarrhœa is chiefly a disease of urban life.3 (2) Epidemic diarrhœa as a fatal disease, is a

Loc. cit., pp. 2-3.

2 To remedy these conditions, which are favourable to the occurrence of diarrhœa, Ballard proposed nine sanitary reforms, viz., the removal of filth from the soil, domestic and social cleanliness, sealing of the soil around dwelling-houses, lowering the ground water by drainage, prevention of soil emanations, free ventilation about dwellings, protection of food from infection, improved drainage and sewerage, and an advance in general sanitation.

3 In $1898-1902$ the death rate from epidemic diarrhœa was II' 5 in urban districts and $5^{\circ} \mathrm{O}$ in rural, but in particularly-affected large towns it may rise to 48 (Preston). 
disease of the artisan and still more of the lower labouring classes to a preponderant extent. This is probably largely a question of social status per se; that is, it is due to neglect of infants, uncleanly storage of food, industrial occupation of mothers, \&c. (3) Towns which have adopted the water-carriage system of sewerage have, as a rule, much less diarrhœa than those retaining other methods of removal of excrement. (4) Towns with the most perfect scavenging arrangements, including the methods of removal of house refuse, have the least epidemic diarrhœea. It has recently been suggested that epidemic diarrhœa is due to surface pollution derived from street dust, particularly dried horse manure (Waldo). (5) The influence of the soil is a decided one. Where the dwelling-houses of a place have as their foundation solid rock, with little or no superincumbent loose material, the diarrhœal mortality is, notwithstanding many other unfavourable conditions and surroundings, low. On the other hand, a loose soil is a soil on which diarrhoeal mortality is apt to be high (Ballard). The pollution of soil is probably the important element in the causation of diarrhœea in towns on pervious soils. (6) Given two towns equally placed so far as social and sanitary conditions are concerned, their relative diarrhœa mortality is proportional to the height of the temperature, and the deficiency of the rainfall in each town, particularly of the third quarter of the year." I

Dr. Newsholme concludes that "the fundamental condition favouring epidemic diarrhœa is an unclean soil, the particulate poison from which infests the air and is swallowed, most commonly with food, especially milk." In other words, epidemic diarrhœa is a so-called "filth-disease," preventable by improved sanitation in the broadest meaning of the term.

${ }^{2}$ Public Health, 1899-1900, vol. xii. pp. 139-213. 
From the facts and suggestions quoted above, and they are but representative of many other similar views receiving the general support of epidemiologists, it will be evident that, at the present time, the belief is held that the cause of epidemic diarrhœa is to be found in four conditions, which may be expressed shortly as two propositions, thus: (I) Epidemic diarrhœa is a bacterial disease; and (2) its occurrence depends, wholly or partly, upon surrounding temperature and deficiency of rainfall, upon urban and social conditions, and upon pollution of food, chiefly milk, or other articles intimately associated with the life of infants. The exact relationship which these conditions bear to each other is not known. Some authorities hold that a certain temperature affects food unfavourably. Others believe that it is a question of pollution of milk by dust and dirt carried by flies or air currents, which transmit to the milk the causal microorganisms, and that deficient rainfall favours this contamination, and increased temperature favours the growth and multiplication of the bacteria thus conveyed to the infant. As Dr. Newsholme says, "Whatever be its mode of operation, a frequent fall of rain during the summer weeks, even though its total amount be not great, is one of the most effectual means of keeping down the diarrhœal death rate "; ${ }^{\mathrm{I}}$ and whilst he considers temperature conditions of great importance, "rainfall is more important than temperature in relation to epidemic diarrhœa." Rain washes the air, if the expression may be allowed, and carries to the surface aërial dust. It reduces the atmospheric temperature, and of course it also washes the surface of the soil and removes surface pollution, and with it micro-organisms capable of infecting infants either by food or in some other way to be hereafter discussed. It should be added that Dr. Niven, of Manx Annual Report on Health of Brighton, 1902, p. 48. 
chester, believes " that it is temperature rather than rainfall which is the determining factor of a high diarrhœal death rate." I

The practical problem of this disease as distinct from the scientific which deals with the causa causans is therefore reducible to fairly simple terms. It is a question (a) of meteorology, (b) of contaminated or injurious food, and $(c)$ of social conditions and domestic insanitation. It is now our business to consider these three matters.

\section{The Relation of Meteorology to Diarrhoea.}

The crucial meteorological conditions believed by Ballard to initiate fatal epidemic diarrhœa were mainly three :-

(a) The four-foot earth temperature, which he held as an essential datum, must be somewhere about $56^{\circ} \mathrm{F}$. before the summer rise of diarrhœal mortality commences;

(b) The maximum diarrhœal mortality occurs in the week in which the four-foot earth temperature attains its weekly maximum ;

(c) The mortality decline coincides with the decline of the temperature recorded by the four-foot thermometer.

These conclusions were arrived at twenty years ago, and although in recent years many observers have found that these three propositions do not hold good in all localities or in every season, there has been a general agreement with the principle underlying them, and an increasing body of evidence obtained in support of the intimate relation existing between earth temperature at the depth of four feet and the mortality of epidemic diarrhœa.

In applying these propositions, however, to actual experience over a number of years, it has been found that

s Report of Health of Manchester, 1903, p. 166. 


\begin{tabular}{|c|c|c|c|c|c|c|}
\hline \multirow{2}{*}{ FINSBURY. } & \multirow{2}{*}{$\begin{array}{c}\text { A verage } \\
\text { Temp. } \\
\text { Earth } \\
\text { Thermom. }\end{array}$} & \multirow{2}{*}{$\begin{array}{c}\text { Total } \\
\text { Rain- } \\
\text { fall. }\end{array}$} & \multicolumn{4}{|c|}{ INFANT DEATHS FROM DIARRHCEA. } \\
\hline & & & $\underset{\text { months. }}{0-3}$ & $\begin{array}{l}3-6 \\
\text { months. }\end{array}$ & $\begin{array}{c}6-12 \\
\text { months. }\end{array}$ & Total. \\
\hline 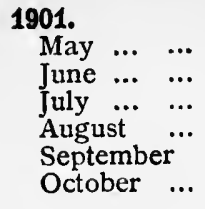 & $\begin{array}{l}50^{\circ} 2^{x} \\
57^{x} 6^{x} \\
62 \cdot 5^{x} \\
63^{x} x^{x} \\
60 \cdot 2^{x} \\
56 \cdot 5^{x}\end{array}$ & $\begin{array}{l}1 \cdot 83 \\
0.56 \\
2 \cdot 73 \\
I .94 \\
I \cdot 35 \\
2 \cdot 58\end{array}$ & $\begin{array}{l}- \\
1 \\
6 \\
4 \\
4 \\
-\end{array}$ & $\begin{array}{r}1 \\
13 \\
15 \\
5 \\
-\end{array}$ & $\begin{array}{l}- \\
18 \\
12 \\
10 \\
-\end{array}$ & $\begin{array}{r}1 \\
1 \\
37 \\
31 \\
19 \\
\end{array}$ \\
\hline & $58 \cdot 3$ & I0.99 & I5 & 34 & 40 & 89 \\
\hline $\begin{array}{ccc}1902 . & & \\
\text { May } & \ldots & \ldots \\
\text { June } & \ldots & \ldots \\
\text { July } & \ldots & \ldots \\
\text { August } & \ldots \\
\text { September } \\
\text { Septober } & \ldots\end{array}$ & $\begin{array}{l}48 \cdot 0^{x} \\
54^{\circ} 0^{x} \\
57 \cdot 3 \\
57 \cdot 9 \\
57 \cdot 6 \\
54 \cdot 5\end{array}$ & $\begin{array}{l}3 \cdot 33 \\
2 \cdot 84 \\
1 \cdot 44 \\
2 \cdot 28 \\
2 \cdot 30 \\
1 \cdot 22\end{array}$ & $\begin{array}{l}- \\
1 \\
2 \\
6 \\
1\end{array}$ & $\begin{array}{l}2 \\
1 \\
2 \\
7 \\
8 \\
2\end{array}$ & $\begin{array}{r}2 \\
3 \\
9 \\
12 \\
2\end{array}$ & $\begin{array}{r}4 \\
1 \\
6 \\
18 \\
26 \\
5\end{array}$ \\
\hline & $54^{*} 9$ & 13.41 & IO & 22 & 28 & 60 \\
\hline $\begin{array}{ccc}1903 . & & \\
\text { May } & . . & \ldots \\
\text { June } & \ldots . & \ldots \\
\text { July } & \ldots & \ldots \\
\text { August } & \ldots \\
\text { September } \\
\text { Sctober } & \ldots\end{array}$ & $\begin{array}{l}48 \cdot 3 \\
52 \cdot 7 \\
57 \cdot 1 \\
58 \cdot 7 \\
58 \cdot 2 \\
56 \cdot 4\end{array}$ & $\begin{array}{l}I \cdot 77 \\
6.20 \\
5 \cdot 27 \\
4 \cdot 80 \\
3.05 \\
4.43\end{array}$ & $\begin{array}{r}- \\
- \\
9 \\
4\end{array}$ & $\begin{array}{l}- \\
1 \\
1 \\
5 \\
6 \\
4\end{array}$ & $\begin{array}{r}I \\
I \\
\text { II } \\
9 \\
6\end{array}$ & $\begin{array}{r}1 \\
2 \\
2 \\
16 \\
24 \\
14\end{array}$ \\
\hline & $55^{\cdot 2}$ & $25 \cdot 52$ & 14 & I7 & 28 & 59 . \\
\hline $\begin{array}{ccc}1904 . & & \\
\text { May } & . . & \ldots \\
\text { June } & . . & \ldots \\
\text { July } & \ldots & \ldots \\
\text { August } & \ldots \\
\text { September } \\
\text { October } & \ldots\end{array}$ & $\begin{array}{l}48 \cdot 6 \\
53 \cdot 5 \\
58 \cdot 0 \\
60 \cdot 2 \\
58 \cdot 3 \\
55^{\circ} 0\end{array}$ & $\begin{array}{l}I \cdot 49 \\
I \cdot 42 \\
2 \cdot I 0 \\
I \cdot 84 \\
0.94 \\
I \cdot 5 I\end{array}$ & $\begin{array}{r}1 \\
4 \\
13 \\
4 \\
3\end{array}$ & $\begin{array}{r}1 \\
1 \\
7 \\
23 \\
9 \\
2\end{array}$ & $\begin{array}{r}2 \\
1 \\
7 \\
23 \\
3 \\
3\end{array}$ & $\begin{array}{r}4 \\
2 \\
18 \\
59 \\
16 \\
8\end{array}$ \\
\hline & $55^{\circ} 6$ & $9 \cdot 30$ & 25 & 43 & 39 & 107 \\
\hline $\begin{array}{ccc}1905 . & & \\
\text { May } & . . & \ldots \\
\text { June } & . . & \ldots \\
\text { July } & \ldots & \ldots \\
\text { August } & \ldots \\
\text { September } \\
\text { Septober } & \ldots\end{array}$ & $\begin{array}{l}48 \cdot 9 \\
53^{*} 3 \\
59^{\circ} 2 \\
60^{\circ} 9 \\
5^{\circ} \cdot 9 \\
54^{\circ} 8\end{array}$ & $\begin{array}{l}1 \cdot 57 \\
4 \cdot 37 \\
0 \cdot 82 \\
2 \cdot 33 \\
2 \cdot 28 \\
0 \cdot 50\end{array}$ & $\begin{array}{r}- \\
\text { II } \\
\frac{3}{-}\end{array}$ & $\begin{array}{r}- \\
5 \\
13 \\
4 \\
3\end{array}$ & $\begin{array}{r}1 \\
8 \\
16 \\
5 \\
2\end{array}$ & $\begin{array}{r}1 \\
1 \\
13 \\
40 \\
12 \\
5\end{array}$ \\
\hline & $56 \cdot 0$ & II 87 & I5 & 25 & 32 & 72 \\
\hline
\end{tabular}

I These temperatures are of the three-foot earth thermometer at Greenwich. The remaining temperatures are of the four-foot earth thermometer at Finsbury. 


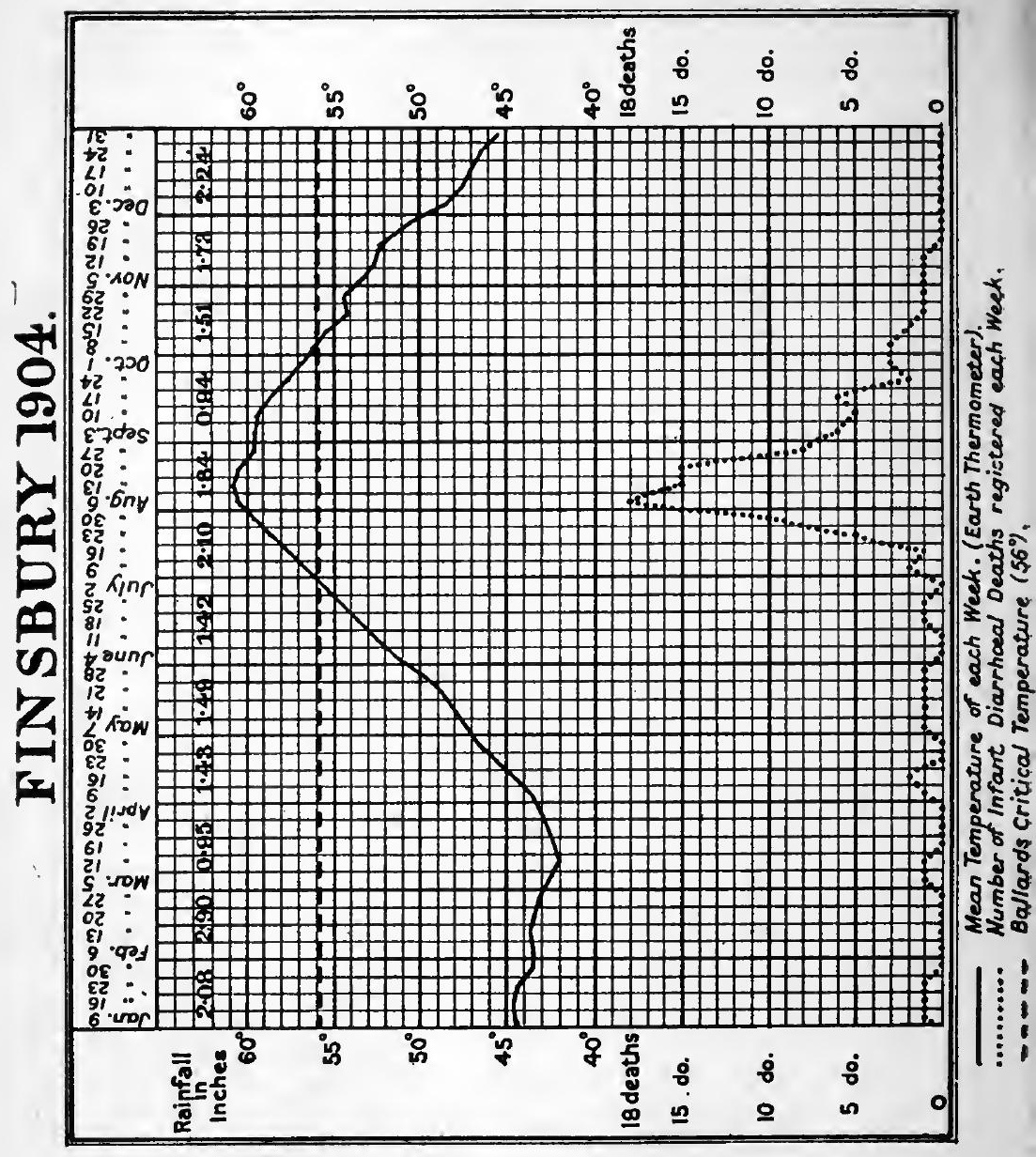


a margin of variation must be allowed. In Finsbury we have for several years kept daily record of the temperature recorded by a four-foot thermometer placed in the soil near the Town Hall and the incidence of fatal diarrhœa, and it will be convenient briefly to refer to our findings, which are set out in the table on opposite page. Each year's results possesses its own interest, and the inter-relation of rainfall and temperature are clearly shown. But for convenience we may take 1904 as a typical year of heavy diarrhœal fatality, and by means of the attached chart follow some of its indications.

In the first place it will be noticed that the four-foot thermometer registered a temperature above $56^{\circ}$ in the first week in July, and the number of deaths of infants from diarrhœa began to increase in the week following. Secondly, the maximum mortality (I8 deaths in a week) occurred one clear week before the maximum temperature was reached. Thirdly, the mortality decline did not coincide with the decline in temperature, and the epidemic of mortality was practically over a week before the fourfoot earth thermometer fell below the critical temperature of $56^{\circ} \mathrm{F}$. Throughout the epidemic period the rainfall was lower than usual, and the temperature, though not exceptionally high, was over $56^{\circ} \mathrm{F}$. for fourteen weeks. In August (with favourable temperature and low rainfall) the mortality reached a high figure, 40 per cent. of the infants dying in the second trimester of their life. From these facts it becomes clear that two out of the three propositions of Ballard did not hold in Finsbury in 1904, but the broad fact of the earth temperature acting as an indication of forthcoming fatality is almost perfectly illustrated.

The same may be said generally of the other years in the five included in the table. But there are other points to notice. In I90I an exceptionally high temperature in June gave no result, but its continuance into July, even though 
there was a good deal of rain, yielded the highest return of infant mortality for that month in the quinquenniad. The infants dying were in the second and third trimesters of their first year of life. And in each of the other years as the total mortality declines the decline is chiefly in the second trimester. In each of the years the infants under three months of age respond less to temperature than at the other two age periods. In 1902 and 1903 the conditions of season were unfavourable to a high mortality among infants partly on account of lower temperature, but, as far as one can judge, mostly on account of increased rainfall. There is, however, this singular characteristic, that in both years with a temperature and a rainfall unfavourable, in September there is an explosion of mortality which does not occur in the other three Septembers. Further, this feature of "ferocity," as it is described by Ballard, affects infants under three months as much as the older infants. The percentage total of infants under three months on total infant deaths in 1903-the lowest mortality year-and in 1904-the highest mortality year-is the same (23 per cent.). In 1905 we also see signs of the ferocity of the disease in August.

Such being the outstanding facts for Finsbury, we may now turn to consider the experiences of other districts, and to illustrate the complexity of this influence of temperature and to bring out some important points as to its moment of operation, we may briefly consider the recent experience of ten towns where observation is kept on the matter:-

r. At Brighton, in 1903, the four-foot temperature reached $5^{\circ} \mathrm{F}$. on June rst, and in 1904 on June 12 th, but no deaths from diarrhoea occurred in 1903 until the week ending July 4 th (i.e., a month later), and none in 1904 until the week ending June $25^{\text {th }}$ (i.e., a fortnight later), and then none during the three subsequent weeks, although the earth temperature remained over 
$5^{\circ} \mathrm{F}$. from June 26 th onwards. Indeed, in both years there was no substantial increase until the latter half of August, some ten weeks after the four-foot temperature had reached the critical point of $56^{\circ} \mathrm{F}$. Expressed in another way, it happens that in both years the average earth temperature from July to October was almost identical $\left(60^{\circ} 6^{\circ}\right.$ and $\left.60^{\circ} 7^{\circ}\right)$, and the deaths from diarrhoea were low, 44 in 1903 and 48 in 1904 . But in 1904 the average of the maximum temperature of the air during each week was higher by $4 \frac{1}{2}$ per cent., the aggregate rainfall was less by 60 per cent., and the number of rainy days was fewer by 23 per cent. than in 1903 , and yet the excess of fatal diarrhœa in 1904 was only four deaths. ${ }^{x}$

2. In 1904 the four-foot temperature at Blackburn reached $56^{\circ} \mathrm{F}$. in the week ending July $23^{\mathrm{rd}}$, but there was no marked increase in diarrhœal deaths until September, six weeks later. ${ }^{2}$

3. "In the case of Nottingham the temperature of the fourfoot thermometer, at which a serious increase of diarrhœa is to be looked for, is not commonly $56^{\circ}$ but about $58^{\circ}$." Dr. Boobbyer considers that of the general truth of Ballard's theory there can be no doubt, but he adds, "the incidence of epidemic diarrhœa is also largely dependent upon the rainfall." 3

4. At Croydon, in 1903, the four-foot temperature rose above $5^{\circ}$ in the week ending July $4^{\text {th }}$, and remained above that temperature until the end of the second week in October. There was no increase in diarrhœal fatality until the beginning of September (seven weeks later), and even then but a very slight increase. In 1904 the critical temperature of $56^{\circ}$ was reached in the week ending June $25^{\text {th }}$, and the rise in the number of deaths from diarrhœea began in August. In the former year the atmospheric temperature was over $60^{\circ}$ in May, and in the latter year reached $60^{\circ}$ in June, without any apparent result on the disease. 4 The effect of rainfall in combating the evil influence of sustained high temperature is also shown. "During the summer of 1903 there were 49 days on which rain fell and only 22 deaths under one year from diarrhoeal diseases, while in the summer of 1904

- Annual Report on Health of Brighton, I904, p. 44 (Newsholme).

- Annual Report on Health of Blackburn, I904, p. 75.

3 Annual Report on Health of Nottingham, I904, p. 71.

4 Annual Report on Health of Croydon, I904, p. I9 (Richards). 
there were only 28 days on which rain fell, and as many as 96 deaths under one year from diarrhœal diseases."

5. In Dublin, in 1904, the atmospheric temperature was above $60^{\circ}$ in the second quarter of the year, and the four-foot temperature above $56^{\circ}$ on July roth, but there was no substantial difference in the diarrhœal diseases until August. ${ }^{x}$ The mean of the readings of the four-foot earth thermometer in the third quarter was $57^{\circ}$.

6. Or if we now take some examples of towns where the atmospheric temperature is used as indicator the difficulties do not become less. The experience at Hull furnishes some facts of interest. The periods in three decennia may be taken as illustrations:-

\begin{tabular}{|c|c|c|c|}
\hline Years. & Deaths from Diarrhœea. & $\begin{array}{l}\text { Mean Max. Air Temp. } \\
\text { in Third Quarter. }\end{array}$ & $\begin{array}{l}\text { Total Rainfall in ins } \\
\text { in Third Quarter. }\end{array}$ \\
\hline 1884 & 273 & 70.9 & $4^{\cdot 68}$ \\
\hline I885 & 26 & $64^{\circ} \cdot I$ & $5 \circ 03$ \\
\hline 1893 & $43 \mathrm{I}$ & $68 \cdot 9$ & $6 \cdot 39$ \\
\hline I894 & 35 & $64 \cdot 6$ & $5 \cdot 29$ \\
\hline 1902 & 53 & $64 \cdot 5$ & $5: 30$ \\
\hline 1903 & 252 & $65^{\prime 2}$ & $9 \cdot 00$ \\
\hline
\end{tabular}

Here the atmospheric temperature is taken in place of the earth temperature and averages in place of actual figures. We should expect to find, however, some meteorological differences sufficiently marked to account for the enormous divergence in the number of diarrhœal deaths. But such differences in temperature are not marked. On the contrary, with the exception of the fact that each of the low diarrhoal years had a similar low atmospheric temperature, there is no explanation for the great differences in the diarrhœal fatality, particularly in 1903 , when the rainfall was exceptional. One cannot study such returns without being impressed by the fact, not only that there is some other factor

× Earth Temperature and Diarrhoeal Diseases in Dublin in 1904. (1905.) (Sir J. W. Moore.) 
besides temperature, but that temperature was here exerting a subsidiary and indirect influence upon differences in diarrhœa deaths so enormous. ${ }^{\mathrm{I}}$

7. Dr. Niven states his experience as to the relation of meteorological conditions to diarrhœa in Manchester as follows: "The autumnal rise in the number of deaths [from diarrhœa] is usually sharp in one particular week, and corresponds to the rise of the mean daily temperature in the week preceding up to or about $60^{\circ} \mathrm{F}$. There is no doubt that the temperature of the atmosphere is in close relation with the increase of Summer Diarrhœa. The influence of the rainfall is, in the main, I believe, a secondary one. The rainfall may be high and yet the Summer Diarrhœa death rate be high; or it may be low and the Summer Diarrhœa rate may be low. Thus in the third quarters of 1893 and 1895 the rainfall was high, yet the Diarrhœa death rate was also high. In the third quarter of 1902 the rainfall was unprecedently low, and so also was the Diarrhœa death rate. On the other hand, the mean temperature of the quarter was bigh in 1893 and 1895 , and in I 902 it was low. A high rainfall tends to lower the temperature, but where it fails of this effect Diarrhœa is in excess. On the other hand, in spite of a low rainfall, the atmospheric temperature may be low, and then there is no excess of Diarrhœa. In no year, however, is the death rate from Diarrhœa in excess of the mean without a corresponding excess in the mean temperature of the atmosphere." 2

In his report for 1903 , Dr. Niven recalls that in 1900 a study of the daily curves of temperature and of the diarrhoea deaths, arranged according to dates of attack, show that "atmospheric temperature reacts in a day or two on the incidence of diarrhœa," but he adds that the experience in that year (1900) shows also that "neither the highest death rate nor the greatest increase of cases coincides with or closely follows the maximum atmospheric temperature." 3

8. At Bolton in 1904 the four-foot earth thermometer registered an average temperature of $57^{\circ} \mathrm{F}$. in August, and in the latter half of the month the diarrhœa deaths increased, the total for the

- Annual Report of Medical Officer of Kingston-upon-Hull, 1904, p. 53.

2 Report on Health of Manchester, 1904, p. 172 et seq.

3 Ibid., 1903, p. 167. 
month being 35. In September the temperature of the four-foot thermometer fell to $55^{\circ} 5^{\circ} \mathrm{F}$, and each week as the temperature went down the number of deaths rose to a total of 62 for the month. There were 44 deaths in a fortnight ending October 1st, when the earth thermometer registered only $54^{\circ} 5^{\circ} \mathrm{F}$.

9. For Glasgow Dr. Chalmers has tabulated the record of the last five years $(1900-4)$ as follows :-

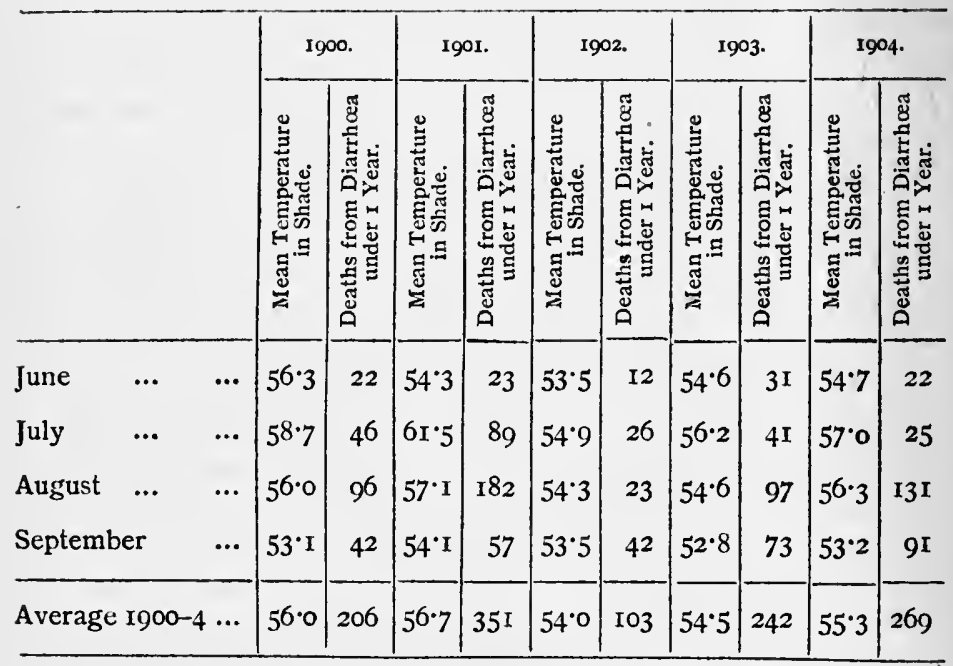

This table affords illustration of the variation which occurs in different years even when the mean temperature of the air is approximately the same. In 1902 and 1903 the temperatures were much alike throughout the four months, but the yield of deaths in 1903 was more than double that of 1902 . No doubt there were other factors present, one of which was probably rainfall. And even if we compare the mean temperature of the months with the yield of deaths we shall see marked discrepancies.

ro. Dr. Hope, of Liverpool, has furnished in a recent report four charts for the four third quarters of $1901-4$, in which he illustrates the relation of rainfall and mean temperature of air to diarrhœa deaths, and upon which two remarks may be made. 
First, in comparing 1901 and 1904 with the intervening years, it is found that the mean temperature in the former frequently rose far above the thirty years' average, and remained so for several days together. It seldom fell below the average, and the rainfall was scanty. The result was much diarrhœa in both years. The years 1901-2, however, had a heavy rainfall and a low mean temperature, and the death rate from diarrhœa was less than half of that which occurred in I90I and I904. Secondly, it is noticeable that in each year the atmospheric temperature was above $60^{\circ} \mathrm{F}$. for a number of weeks before there was any increase whatever in the diarrhœa deaths. ${ }^{I}$ Even though, unfortunately for purposes of comparison, these four charts record the atmospheric temperature instead of the four-foot earth temperature, it may be said that on the whole they represent the broad relationship between temperature and rainfall and diarrhœa fatality as clearly as could be desired. ${ }^{2}$

Now whilst there appears to be considerable conflict of evidence as to the exact temperature at which diarrhœal mortality increases, dependent upon other meteorological conditions such as rainfall, and, as we shall see subsequently, dependent also upon certain urban and social conditions, there are some broad and well-recognised facts which are indisputable and upon which all observers are agreed. It is not only simpler, but it is also likely to be more accurate, to be guided by such findings than by the differences and divergencies of detail.

The first among such proved facts is that epidemic diarrhoea becomes both most prevalent and most fatal in the third quarter of the year. It is unnecessary to produce statistical tables on this point, for it is universally recognised as obtaining throughout the United Kingdom Infantile diarrhoea is a disease of the late summer months. Of that there can be no possible doubt. And translated

Report on Health of Liverpool, I904, p. 42.

$=$ In these abstracts it has been impossible to quote exact returns in detail. In the Appendix (p. 339), however, will be found the admirable tables of Dr. Cameron for Leeds for the past fifteen years. 
into terms of temperature, this means that an excess of diarrhœa, both in attack and fatality, occurs only when there is, or has been in the immediate past, an excess of atmospheric temperature. In relation to the occurrence of diarrhœa such temperature is best measured by the four-foot earth thermometer, for the simple reason that at that depth in the soil temperature varies but slightly from day to day, and therefore indicates only in slow and longmeasured steps the seasonal changes of a year. It does not tell a different story from the atmosphere, but as a medium it is less affected by hours of sunshine and shade, and so reveals what may be called the common denominator of the sun's effect on the earth's surface.

Secondly, we shall only mislead ourselves if we study temperature, whether of atmosphere or soil, as if it were the only factor in the causation of epidemic diarrhœa. Its influence, as Ballard pointed out, is " exerted indirectly," and it is but one factor, possibly a fundamental one, yet only one among many operating in the production of this disease.

The following conclusions, though of a less certain character, also seem admissible :-

I. That whilst Ballard's critical temperature $\left(56^{\circ} \mathrm{F}\right.$.) broadly indicates the principle of an intimate relation existing between earth temperature and diarrhœal mortality, the maximum mortality and its decline do not coincide with maximum temperature and its fall, nor is $5^{\circ} \mathrm{F}$. invariably the earth temperature at which diarrhœal mortality rises. (The records of Bolton in 1904, Glasgow in 1901, Brighton and Croydon in 1903 and 1904, Finsbury in 1904, Liverpool in 1902-3, illustrate these variations from Ballard's rule.)

2. That rainfall and temperature must be taken together, the fallacy of taking them separately being very clearly seen in comparing 1903 and 1904 in Finsbury, both years 
having an earth temperature of $55^{\circ} \mathrm{F}$., but the former being a low mortality year and the latter a high mortality year. In fact, it does not appear to be possible to take temperature alone, at any figure, as a fixed standard.

3. The variations in earth temperature and its effect on infant mortality, be it what it may, does not materially affect infants under three months of age, except when great in volume or "ferocious" in fatality.

4. High temperatures at four-foot depth in June or earlier do not produce an effect on infant mortality from diarrhœa. The same remark applies to high atmospheric temperature in June, as may be witnessed in the Glasgow record in 1901 and Hull in I894 and 1902. The contrary is true also, for mortality from diarrhœa may be high with low temperature.

5. A prevalence of fatality among infants higher than the average towards the end of the summer appears to be connected with a deficiency in the earlier weeks of the epidemic period, and it is greater in proportion as the epidemic period falls late in the season.

These variations are of importance in guiding us amid the devious ways of diarrhœal epidemicity, but we must not allow them to obscure the broad principle which emerges from the facts presented and which is beyond dispute, namely, that a sustained high atmospheric temperature, as indicated by the four-foot earth thermometer, particularly if simultaneous with a low rainfall, conduces to a high diarrhoal mortality and a low atmospheric temperature to a low diarrhœal mortality.

\section{The Operation of Temperature.}

Before leaving this subject of the relation of temperature to diarrhœe, it is necessary to inquire as to the way in which temperature operates in favouring diarrhœa. Upon this point there is much diversity of view and on the 
whole but few facts. Some hold that a sustained high temperature depresses the system of infants, who thus become more susceptible to illness. It may be so, but in such event there remains unexplained the comparative health of infants on the south coast of England, where the mean temperature of the atmosphere is some degrees higher than in the north, which yet has a higher infant mortality. Still more so is it difficult to explain, if this view be true, the survival of infants in the tropics and in many other parts of the world where the mean temperature is higher than in temperate

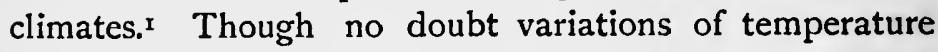
exert an effect on infant life, it becomes clear that this cannot be the only or indeed the chief means of operation.

Others maintain, and they claim Ballard in support of their view, that a temperature of $56^{\circ} \mathrm{F}$. at a depth of four feet stimulates or favours the growth or increase of a "miasm" which is produced by organic agency in the superficial layers of the soil and finds its home there. This miasm, they urge, however it be formed and to whatever bacterial action it may be due, emanates from the soil after the critical temperature has been reached, and produces an effect on persons comparable to miasmatic influences which give rise to certain forms of low fever in the tropics. The provisional findings of Ballard which we have quoted (see p. 144) are claimed in support of this view, and the incidence of the disease on children and infants is further held to lend it support. But the advocates of this theory have difficulties not less formidable to explain than those who hold that high temperature operates mainly by de-

1 The Secretary of the Royal Observatory at Greenwich informs me that at five meteorological stations in India where earth thermometers are used, Lahore, Jaipur, Dehra Dun, Allahabad, and Calcutta, the monthly mean temperature at four feet is above $56^{\circ} \mathrm{F}$. throughout the year, and at Calcutta is over $70^{\circ} \mathrm{F}$. 
pressing the physical condition of the individual. There are at least three such difficulties. In the first place there is the fact to be hereafter proved, that epidemic diarrhoea is an urban disease, that the more town-like is the community and the more dense the buildings per acre, so much the more is the diarrhœa. Yet the greater the density of the buildings per acre, the greater is the open soil sealed and the more complete is the land drainage. What "miasm," it may be asked, can emanate through the concreted surface of the metropolis? The underground soil in our large towns consists, moreover, in no small measure, of the necessary foundations of buildings, streets, drainage, and means of communication. It comes indeed to this, that epidemic diarrhœa is frequently most prevalent where miasmatic emanations are impossible in any large measure. Then, again, if high temperature operates by favouring a soil miasm, we should expect persons of both sexes and all ages to be attacked. But the malady falls in a preponderating degree upon children under two years of age, and "the male sex is distinctly more liable to it than the female, and this at all ages from birth upwards" (Ballard). With the exception of the aged this is largely, though not exclusively, a children's disease. There must be in its causation some factor mainly concerned with children of tender years. If that be so it is quite certain that such a factor cannot be found in an influence having a universal operation. But it may be argued, as indeed it often is, that the influence, though universal, is of a character to which only the very youngest and the very oldest, that is presumably the most susceptible portions of the community, are prone. There is, however, a third difficulty to be met with in face of such argument, namely, that it is not the youngest who are attacked. No age incidence whatever enjoys complete immunity, but by far the chief burden of this disease falls not upon the youngest infants but upon 
infants aged four months to eight months. A disease with such definite limitations of scope as this, that it mainly attacks town infants in the middle of their first year of life, is not one which can be explained by a general soil miasm.

We must therefore look elsewhere for the explanation of the operation of high atmospheric temperature on diarrhœa. And we shall probably find the true explanation is a simple one requiring but few conditions for its fulfilment. Epidemic diarrhœa is a disease mainly affecting the alimentary system. Its other phenomena, convulsions, fever, and collapse, are reflex and secondary to a general disease of a specific character. It is not, in kind, a new growth like a tumour or cancer; nor is it a traumatism like a fracture or mechanical injury; nor yet is it a constitutional disease like syphilis or tuberculosis. It is a plain and straightforward infection, or, as we have seen, not infrequently an intoxication, of the alimentary canal, of such a kind and in such a degree as affects the whole body, and in time nearly every organ. Such a disease must be conveyed by food, and perhaps chiefly by a fluid food. Not always or invariably in the same form or way, but as a rule the vehicle of infection or intoxication must be food. And here a most important fact should be remembered, namely, that the stomach of an infant has but a small digestive power and secretes a low percentage of acid. Hence infected food is likely to pass undigested and "unsterilised" into the intestine, there to set up irritation.

Now, what is the effect of a sustained high temperature of the atmosphere on food? The answer is that such a temperature favours the growth of infective bacteria and processes of decomposition. Moisture, pabulum, and a high temperature are the three cardinal requirements of bacteria. Those conditions being granted, their multiplication and toxin-producing power becomes 
exceptionally great. This has been shown in respect of milk by many workers. ${ }^{x}$ The moisture and pabulum of milk are a fit nidus, and if its temperature be raised to summer heat the increase in the number of organisms is extremely rapid. Unclean milk is almost a solution of bacteria and little short of rank poison to an infant. Nor is it the number of organisms alone which is affected. There is now abundant evidence to show that pathogenicity or virulence of milk is increased by rise of temperature. ${ }^{2}$ Professor Delépine of Manchester found that mixed milk coming from a distance of more than forty miles, and generally kept for from twenty-four to sixty hours or longer, showed an increase of virulence on inoculation into guinea-pigs in proportion to the mean temperature in the shade in Manchester during the time the specimens were kept.3 What is produced in a few hours in summer may occur also in winter when the milk has been kept a long time.

A sustained high atmospheric temperature, however, exerts an indirect effect on milk and other foods in a threefold manner. First, it favours the occurrence of dust and dirt, especially when combined with a low rainfall; secondly, it favours the growth of bacteria in such dust and dirt; and thirdly, it is one of the chief agencies favourable to the breeding of flies, which with air-currents and domestic manipulation, serve as the means by which milk and other foods become polluted with dust and dirt, and the organisms conveyed by such particulate matter. Every one knows that in hot, dry summers, particularly in towns, dust is increased in amount and "gets everywhere." Such dust particles act, as Tyndall showed thirty years ago, as "rafts" for the conveyance of organismal life.

- See Bäcteriology of Milk (1903), Swithinbank and Newman, pp. I16-I48.

- Ibid., p. 137.

3 Four. of Hygiene, 1903, vol. iii. p. 83. 
Now, if it be granted that the causal organisms of diarrhœea may exist in such dust, here, indeed, is ample means for the contamination of milk and other articles. But, in addition to these facilities of pollution, there are flies, which undoubtedly increase in number normally in the late summer, if the atmospheric temperature be high.

Dr. Niven, the Medical Officer of Health of Manchester, has argued that by a process of exclusion we come to the house-fly as an agency in the dissemination of diarrhœal infection. ${ }^{x}$ By means of a number of beer-traps Dr. Niven contrived to count the flies in some dozen houses in Manchester during the summer months of 1904, and from these

3 In 1904 Dr. Niven carried out an extended inquiry into the causation of summer diarrhoea in Manchester, with the following results :-

The conclusions arrived at as the result of this inquiry may be thus summed up. (I.) The high fatality from sumner diarrhoa is largely due to the ailing condition of the infants when attacked. Their previous bad health is due to a variety of causes. Of these the most serious are slovenliness on the part of the mothers and ignorance of what is necessary so that an infant may be well nourished. But their health is also assailed by a variety of unhealthy conditions, especially by dirty floors, insanitary closets and back passages, dirty fingers, \&c., introduced into their mouths, occasional clouds of dust, and so forth.

(II.) Yet, in spite of all this, infants fed at the breast, cven in unfavourable situations remain comparatively well, and generally escape diarrhoea, and even when fed on cow's milk they may enjoy good health when reasonable precautions are taken. The immunity of breast-fed infants is surprising in the light of what we have found parents doing in the way of rubbing children's gums, and of other errors. The percentage of such children attacked is fully explained. It is probable that children fed at the breast are not allowed to crawl about dirty floors to the same extent as other infants.

(III.) With regard to the mode in which infection is introduced, we have seen that dircet infection plays a large part. This does not explain why the disease attacks so many fresh houses within a comparatively short time in the late summer and autumn. Partly it may be that the disease is imported from without by milk. We have seen, however, that there is strong reason to doubt whether the autumnal rise can in this way be explained.

(IV.) There does appear, on the other hand, to be considerable reason for believing that the disease is often carried from one house to another by the common house-fly... . which will cause inoculation of infection in all liquids capable of nourishing the specific organism, as well as on over-ripe fruit, \&c. If capable of explaining transmission from house to house, the migrations of the house-fly are also capable of explaining a general and rapid increase of the infective micro-organisms (Rep. on Health of Manchester, 1904, p. 2 IO). 
data he concludes that the advent of the house-fly in numbers precedes by a short time the increase in the number of deaths from diarrhœa. In the fortnight ending August I 3 th, for instance, the number of flies caught in these traps was $37,52 \mathrm{I}$, the maximum in any fortnight, and in the fortnight following the maximum number of deaths from diarrhœa occurred-namely, 192. It is true the descent in the number of deaths preceded the diminution in the number of flies, but that may well have been due to other factors, and does not invalidate the theory, which was indeed strengthened when the number of flies was compared with the attacks rather than the deaths from diarrhœa. Dr. Niven summarises his view at the end of 1904 by saying that his observations "increase the probability that flies act as transmitters of summer diarrhœea, and that they may take a considerable share in producing the autumnal rise. ${ }^{\mathrm{r}}$ Dr. Newsholme and many other medical officers of health have repeatedly drawn attention to some relation they believe to exist between flies and the occurrence of epidemic diarrhœa. In 1902, Dr. Newsholme proclaimed "a crusade against the domestic fly, which is most numerous at the seasons and in the years when epidemic diarrhœa is most prevalent, and probably plays a large part in spreading infection." The evidence that flies do carry bacteria on their feet or bodies is positive though meagre. On the whole it would appear that at present more cannot be said than that the house-fiy may act in conjunction with other agents as a means of food contamination with the infective virus of epidemic diarrhcea.

From the evidence obtainable it is shown that an intimate relation exists between high atmospheric temperature and epidemic diarrhœa. The influence is, however, indirect, and is concerned, it is believed, with the food of

× Report on Health of Manchester, 1904, pp. 200-210. 
infants-with its pollution and the increase of its toxicity and infectivity. It is that broad conclusion which continues to receive the support of ever accumulating facts and which guides us as to the means of prevention. But even so, we shall be misguided if we neglect the factor of the infant itself. It is idle to consider the seed apart from the soil.

\section{The Relation of Contaminated Food to EPIDEMIC DIARRHœA.}

There are two series of facts which have been collected throwing light upon the relation of contaminated food to epidemic diarrhœa. The first series is concerned with outbreaks of the disease of a sudden and epidemic character; the second deals with infantile summer diarrhœa of the ordinary kind apparently arising from contaminated food.

In 1892, Gaffky recorded an instance in which three men connected with the Hygienic Institute at Giessen were suddenly taken ill. They had chills, fever, diarrhœa, and general symptoms. The only article of diet of which they had all partaken was milk, which was traced to a cow suffering from enteritis. The milk of this cow as it left the udder contained no bacteria. But bacteria gained access during the milking from the dried particles of fæcal matter on the posterior portion of the udder. In these particles was found a bacillus which proved pathogenic for mice and guinea-pigs, and which corresponded to an organism isolated from the stools of the patients. ${ }^{x}$ In 1894 an outbreak occurred at Manchester, ${ }^{2}$ characterised by diarrhœa, sickness, and abdominal pains. The cases numbered 160 in forty-seven houses, or just 50 per cent.

I Deut. Med. Woch., vol. xviii. p. I4.

${ }^{2}$ Annual Report of Medical Officer of Health of Manchester, 1894 (Dr. Niven). 
of the houses served by one and the same milk-seller. Raw-milk drinkers were the chief sufferers, and those not drinking the implicated milk did not suffer. Near the farm were 40,000 tons of privy-midden refuse. The water used for washing the milk-pails was polluted. The stored milk could be readily contaminated from emanations from the cowshed. Professor Delépine examined the milk, and found B. coli communis abundantly present, and Dr. Niven elicited the fact that a cow affected with inflamed udder ("garget") had been removed from the farm and slaughtered. The outbreak was attributed to milk in any case, and to the probable infection of it by the diseased cow. But Delépine has pointed out that it is more probable that the milk was contaminated with frcal pollution rather than infectious disease of the cow. ${ }^{\mathrm{r}}$

In $1895^{2}$ and 18983 three outbreaks of epidemic diarrhœa occurred amongst the patients at St. Bartholomew's Hospital, London, traceable in the first two instances to milk, and in the third to rice pudding made with milk.4 On Sunday night, October 27, 1895, an outbreak of diarrhœa affected 59 in-patients, all of whom had recently taken milk, and from the evacuations the spores of $B$. enteritidis sporogenes was isolated by Klein. The patients suffered quite irrespective of whether or not the milk had been boiled. Some milk, also derived from the same source as the milk which had caused the poisoning, was examined by Klein, and found to contain the spores of the same organism. On Sunday, March 6, 1898, a second outbreak of severe diarrhoea occurred in this hospital affecting 146 patients, and there was evidence on this occasion also that the medium of infection had been milk. On August 5, 1898, a third outbreak affecting 84

Four. of Hygiene, 1903, vol. iii. No. 1, pp. 76, 77.

- Report of the Medical Officer of Local Goverument Board, 1895-96, pp. 197-204.

3 Ibid., I 897-98, p. 235 .

4 Ibid., I898-99, p. 336. Lancet, January 7, 1899. 
patients and two nurses took place at the same hospital, the vehicle of infection in this instance being some rice pudding made with milk, also said to contain an organism similar or identical with the $B$. enteritidis sporogenes. There can be little doubt that milk was the agent of infection in each of these three outbreaks. In these outbreaks $B$. enteritidis sporogenes (Klein) was isolated, and held to be the specific organism, not only of these outbreaks, but of ordinary summer diarrhœa. ${ }^{x}$

The second series of facts, those, namely, concerned with the contamination of the food of infants suffering from epidemic diarrhœa in the summer, will be dealt with in a subsequent chapter (see p. 22I). Here it is only necessary to say that there is now a large body of evidence which has been steadily accumulating since Ballard wrote, in I887, to the effect "that infants fed solely from the breast are remarkably exempt from fatal diarrhœa, and that infants fed in whatever way with artificial food, to the exclusion of breast-milk, are those which suffer most heavily from fatal diarrhœe." 2 Such artificial food may be cow's milk or condensed milk or other article of diet liable to contamination or infection.

Delépine has urged that milk is infected at the farm or in transit, as many of the milks which he examined and proved to be virulent had not been exposed to any influence attributable to a consumer's home, but was, in fact, infective before it reached the consumer. $3 \mathrm{He}$ considers the injurious properties of such milk is due to fæcal pollution and the action of $B$. coli, $B$. enteritides of Gaertner, or allied organisms. Newsholme considers such contamination may be responsible for setting up epidemics of

$\therefore$ Reports of Medical Officer of Local Govcrnment Board, 1895-96, 1896-97, $1897-98,1898-99$.

2 Supplement to Report of Medical Officer of Local Government Board, 1887, p. 6.

3 Four. of Hygienc, 1903, p. 86. 
diarrhœa occurring in connection with a particular milk supply, as in the analogous case of epidemics of infectious diseases, such as typhoid, but he holds that the ordinary sporadic cases of diarrhœa, which carry off single children in large numbers in urban districts, are due "chiefly to domestic infection of milk or other foods, or to direct swallowing of infective dust." I It is possible that we have a double pollution of milk in actual practice, one originating at the farm, one brought about subsequently. The latter may be produced by flies from manure heaps, or from dust in roads and yards of towns, or from the generally filthy manipulation of the milk from the time when it becomes the property of the milk-seller to the moment of consumption. It should not be forgotten in this relation that stale milk may contain toxic properties altogether apart from, and in addition to, actual bacteria, and that such products of organismal action have a much greater effect in the causation of diarrhoa than is generally supposed. ${ }^{2}$

However that may be, it can scarcely be denied that the evidence which Newsholme and others have produced in support of the view that diarrhoe is mainly due to domestic infection-of milk or other articles-is overwhelming. It must not be forgotten that farm infection or infection during transit of milk must involve massive results among milk consumers, which, excepting epidemics, does not occur. 3

\section{iII. The Relation of URban and Social Con- DITIONS TO DIARRHEA.}

We shall find in a later chapter that "urbanisation" bears an intimate relation to infant mortality as a general

Report on Health of Brighton, 1902, p. 50.

- For a fuller discussion of the whole question of the disease-producing power of milk, see Bacteriology of Milk, I903, pp. 210-39I.

3 See also four. of Hygienc, vol. vi. (I906), pp. 77-92 (Sandilands). 
problem. In the present section we need consider such influences only in so far as they operate directly upon epidemic diarrhœa.

We have already seen that infant mortality is higher in the towns than in the country. The same applies to epidemic diarrhœa, the occurrence of which is indeed one of the chief factors in the high infant mortality of the towns. ${ }^{I}$ For whilst this disease may cause death in rural districts at a rate of only 5 per 1,000 , the death rate rises in the towns to between 20-30 per I,000 (Liverpool, Wigan, Warrington), or between 30-40 per I,000 (Manchester, Salford, Blackburn, Burnley, Bury, and Bolton), and even to rates per I,000 above 40 (Preston). The most notable difference indeed between rural districts and the towns is in just this matter of diarrhœa of which the mortality may be as much as seven or eight times as great in the towns as in the country.

Nor is the difference less marked when we come into towns and compare the most urban portion of large towns with the least urban portion. The medical officer of the administrative county of London has shown that it is the most central of the metropolitan districts, and those which are most densely populated with the poorer classes, which suffer most from epidemic diarrhœa.

In Manchester it has been found that not merely on the average of ten years but for individual years the death rates from diarrhoa show that the fatality from this disease is much higher in the Manchester township than in the South Manchester or the Northern districts. ${ }^{2}$ The same is true of Birmingham, in the wards of which city the diarrhœal death rate in 1904 varied from 4.3 per 1,000 in St. Bartholomew's Ward to only I'I 2 in Edgbaston and

- Fifty-fourth Annual Report of Registrar-General, r89r, pp. xi.-xvi.

Rep. on Health of Manchester, 1904, p. I77. 
Harborne. I Indeed so marked is the difference, that Dr. Robertson adds that "for practical purposes all the deaths [from diarrhœa] occurred in small houses occupied by the artisan classes, that is to say, this enormous mortality among infants [from diarrhœa] is limited to the working classes. No deaths occurred in any middle-class or better-class houses during the time of the inquiry. In a few instances cases were investigated of deaths in houses of six, seven, or eight rooms, but in each of these there were special circumstances which brought them within the meaning of artisan houses." $\mathrm{He}$ then gives a table showing that 6.5 one-room houses per 1,000 were invaded, 5.4 two-room houses, 16.5 three-room houses, 10.4 fourroom houses, and 0.6 houses of more than four rooms each, and adds :-

"In a general way it has always been recognised that diarrhœa in its fatal form was more prevalent among the poorer classes than among the better classes, but the foregoing statement gives this general impression in a much more accurate form. Indeed, it indicates very clearly that, for one reason or another, the middle and better classes are able to prevent their infants from contracting this fatal disease, whether the children be breast-fed or bottle-fed. It also clearly indicates that effort in the direction of preventing the spread of the disease must be chiefly directed among the working classes-981 per cent. of the deaths having occurred in houses of five rooms or under, and only $1 \frac{1}{2}$ per cent. in houses of over five rooms." 2

The same is true of every large town. In Glasgow the

Rep. on Health of Birmingham, 1904, p. 36.

Ibid., pp. 38-39. As long ago as 1879-83 Dr. Tatham showed that diarrhœea was exceptionally fatal in back-to-back houses. In districts having no such houses the death rate was $1 \cdot 54$, whilst in districts having 50 per cent. of back-to-back houses the diarrhoea death rate rose to 2.83 . Dr. Sykes has shown a similar rise of infantile death rate from diarrhœa in stable dwellings (Public Health and Housing, I90r, p. 45). 
diarrhœa mortality rate varies from 1,698 per million in the Dalmarnock Ward, and 1,686 in the Calton Ward, to 238 per million in the Park Ward, and 201 in Kelvinside. ${ }^{x}$ But there is no need to furnish elaborate evidence on this point, for the view that epidemic diarrhœea is mainly an urban disease has been long established and was abundantly confirmed by Dr. Newsholme in 1899 (p. I 50). ${ }^{2} \mathrm{He}$ showed that the disease is most fatal among the lower labouring classes, especially in towns with imperfect scavenging arrangements and without a water-carriage system of sewage.

The last twenty years have but added weight to Ballard's dictum that "domestic darkness and general dirtiness of dwellings are conducive to diarrhœa mortality; dirtiness with bad ventilation constitutes the condition known as 'fustiness'; and it is very much in the parts where these conditions prevail that the diarrhœa mortality is highest." On the other hand, it is instructive to observe that although Ballard's nine proposed sanitary remedies have, with two exceptions, all been carried out in large measure, epidemic diarrhœa is still increasing. The two exceptions are domestic and social hygiene and the protection of food from infection and contamination.

Rep. of Medical Officer of Health of Glasgow, 1904, p. 93.

2 Public Health, 1899, vol. xii. pp. $15 \mathrm{I}-158$ and 169-2II. In this reference particulars will be found concerning the incidence of epidemic diarrhoa in thirty-one large towns. 


\section{VII}

THE INFLUENCE OF DOMESTIC AND SOCIAL CONDITIONS

$\mathrm{T} T$ is a well-known fact that communities in which there $I$ is a large measure of poverty have a higher mortality from all causes at all ages than communities better circumstanced. This, of course, is not due only to poverty per se, but to all that poverty involves-heredity, upbringing, education, food, housing, overcrowding, \&c. The life expectation of Hampstead, for instance, is greater than in Southwark, of Mayfair than of Stepney, and at all age periods, although the excess is greater at some ages than others. The difference in the figures between Hampstead and Southwark, to cite an example, is striking, and the infant mortality during 1897-1900, which was for Hampstead 136 per I,000 for males and 104 for females, rose to 203 and 170 per 1,000 for the same age and sex in Southwark.I The same thing occurs, as we have seen, in every large town. In the three poorest wards of Birmingham the infant mortality was 232,263 , and $33 \mathrm{I}$ in 1904, as compared with 133 in Edgbaston. In Ancoats, Manchester, it was 202 per I,000 in 1904, but in Chatham and Crumpsall it was 9I and 108 respectively. ${ }^{2}$

I Report of Medical Officer of Health for County of London, 1902 (Life Tables for Hampstcad and Southwark), pp. I6-2I.

2 In Capetown, in 1904, the infant mortality of European children was I I 4.4 per I,, 00 , but amongst coloured races it was $271 \cdot 5$ per I,000, showing the difference in social life and infant management in the same town. 
It is necessary in the present chapter to consider the reason for this phenomenon.

In his first annual report the Medical Officer of Health for the county of London (Sir Shirley F. Murphy) published a chart showing the infant mortality in the various metropolitan districts for the years 1885-92. Hampstead, Hackney, Plumstead, Lewisham, and Wandsworth on the circumference, and St. George's, Hanover Square, in the more central part of London, yielded an average infant mortality rate over the eight years of under I4I per I,, 000 , whereas the Strand, Holborn, St. George's-in-theEast, and Limehouse, and what is now Southwark, yielded a rate of over 180 per 1,000 . The difference between these infant mortalities represents not a difference in occupation only, but in domestic conditions and in social life. Occupation, no doubt, is indirectly concerned, as was pointed out by the Sanitary Commission of the Metropolis in 1843 , a return of which shows that the proportion of deaths of infants to children born was 1 in 10 in the professional and well-to-do classes, $I$ in 6 in the families of tradesmen, and $I$ in 4 among the working classes. Ansell also showed that the infant mortality of the professional classes was exceptionally low, namely, 804 , as compared with an average of 150 among the nonprofessional classes, and in some of the large towns an even higher figure. ${ }^{\mathrm{I}}$ But in these cases occupation has been taken as an index of social conditions of wealth and poverty. As recently as 1898 it was shown that in Hamburg the infant death rate was $2^{\circ} \mathrm{O}$ per 1,000 in the rich quarter and 10.8 in the poor quarter.

These differences depend upon the varying circumstances of the districts affected, and it will be necessary to discuss the chief of these seriatim. Broadly, the conditions which operate in greatest force are urbani'Statistics of Families of the Upper and Professional Classes, 1874. 
sation, housing and poor social life, alcoholism, and birth rates.

\section{(a) URBANISATION.}

According to the classification adopted in the census returns for England and Wales, the urban population is 77 per cent. of the whole, whereas fifty years ago it was only just over 50 per cent. It is the fact that for two persons who in $185 \mathrm{r}$ lived in a town, three or more are so situated at the present time, but it must be remembered that the term "urban" merely means those districts that for the purpose of local administration have an urban organisation. In reality, much of the urban districts is rural, and enjoys in some ways even superior advantages, owing to the greater completeness of sanitary legislation and administration for such areas. A better way, perhaps, to represent the increase in urbanisation which has taken place is to state it in terms of large towns. For example, a century ago, the total population of England and Wales was $8,892,536$, of whom $I, 486,017$, or 16.7 per cent., lived in towns of over 20,000 persons. In I904 the population of England and Wales was 33,763,434, of whom 19,965,055 lived in towns of over 20,000 persons. This gives $59^{\circ} 1$ per cent. of the population living in large towns now, as against 16.7 in 1801 , or an increase of $7 \mathrm{I}^{\circ} \mathrm{I}$ per cent. in 1904 . In I80I there were five "great towns" having a population of more than 50,000, and eight "smaller towns" with a population of between 20,000 and 50,000, making thirteen towns in all. In 1904 there are 76 great towns and 142 smaller towns, or 218 in all.

Now, with all the advantages which urban life offers in the way of better sanitation, it cannot be doubted that this profound change of the growth of the towns has not a little to do with a stationary infant mortality. For not only is country life a better environment for infancy, but 
town life brings with it many conditions and circumstances which counteract in respect of infancy its advantages. Nor am I thinking now of overcrowding, polluted atmosphere, condition of employment, and so forth. It is not these things which mainly affect infancy, though even these exert an indirect effect. It is rather the habits and customs of town life which militate against healthy infancy, especially in the artisan classes, to whom infant mortality is almost confined. Life in a large city means for the artisan limited accommodation (not necessarily overcrowding), late hours, short nights, manufactured foods, stress and strain, alcoholism, small excesses, and an almost total absence of restfulness, leisure, and home life. The homelessness of the people is one of the worst features of town life, and is operating injuriously on infancy. Of that I do not think there can be any doubt in the mind of a careful observer of the life of the poor in a great city. He may not be able to put his finger upon any one item which is affecting the mother and killing the infant, for an infant is a complex organism, and bears within itself a temperament, a physique, and an heredity composed of a vast array and medley of influences inextricably interwoven. But he will be able to say that the general conditions of domestic life in a city tenement are such as to make the rearing of infants a difficult and doubtful undertaking. Sanitation and preventive medicine have in the past done much to protect the individual from the evil in his environment. The future will lie with the State that is able to protect the individual against himself. And to do that it must build on the family life in the home, for the home is the unit of the State.

The evidences, therefore, of the effect of urbanisation upon infant mortality are of a general character. Many years ago Dr. Farr pointed out that in a healthy district 
the infant mortality under one month was 145 per 1,000 , in England as a whole $57 \mathrm{I}$ per 1,000 , and in an urban community, such as Liverpool, 672 per 1,000 , and that it declined as the months went by, but in the healthy community it declined 86 per cent. in the first year, whereas in the urban district it declined only 59 per cent. ${ }^{\mathrm{I}}$

INFANT MORTALITY STATED IN MONTHS.

\begin{tabular}{|c|c|c|c|}
\hline & In Healthy Districts. & By English Life Table. & Liverpool. \\
\hline 0 & $447 \cdot 5$ & $57 \mathrm{I} \cdot 3$ & $672 \cdot 1$ \\
\hline I & 145.4 & $218 \cdot 3$ & $316 \cdot 7$ \\
\hline 2 & $102 \cdot 0$ & $157^{\circ} \mathrm{I}$ & $226 \% 7$ \\
\hline 3 & $87 \cdot 1$ & 131.8 & 2093 \\
\hline 4 & $8 \mathrm{I} \cdot 0$ & 126.0 & $205 \cdot 2$ \\
\hline 5 & $75 \cdot 5$ & 120.5 & $203^{\circ} 6$ \\
\hline 6 & $70 \cdot 5$ & II $5 \circ$ & $204 \cdot 8$ \\
\hline 7 & $65 \%$ & 109.9 & $209^{\circ} \mathrm{I}$ \\
\hline 8 & $6 \mathrm{I} \cdot 8$ & $105 \%$ & $216 \% 4$ \\
\hline 9 & $58 \cdot 3$ & 1003 & 227.3 \\
\hline Io & $55 \cdot 2$ & $95^{\circ}$ & $24 \pi \cdot 8$ \\
\hline II & $52 \cdot 8$ & 91.6 & $280 \%$ \\
\hline 12 & - & - & - \\
\hline
\end{tabular}

This is the almost universal experience, and in that which follows this grave disadvantage of urbanisation to infancy will become abundantly clear.

\section{(b) Housing and Poor Social Life.}

The effects of overcrowding on death and sickness rates is a difficult matter to measure. That the effect is considerable and detrimental there cannot be the least doubt. ${ }^{2}$ It is admitted on all hands that where there is most overcrowding there is the highest death rate from phthisis, from infectious diseases, and indeed from all causes. But beyond that it is difficult to go with any assurance of

- Vital Statistics, p. 200.

2 See Evidence of Royal Commission on Housing of the Working Classes, 1885, vol. ii. 


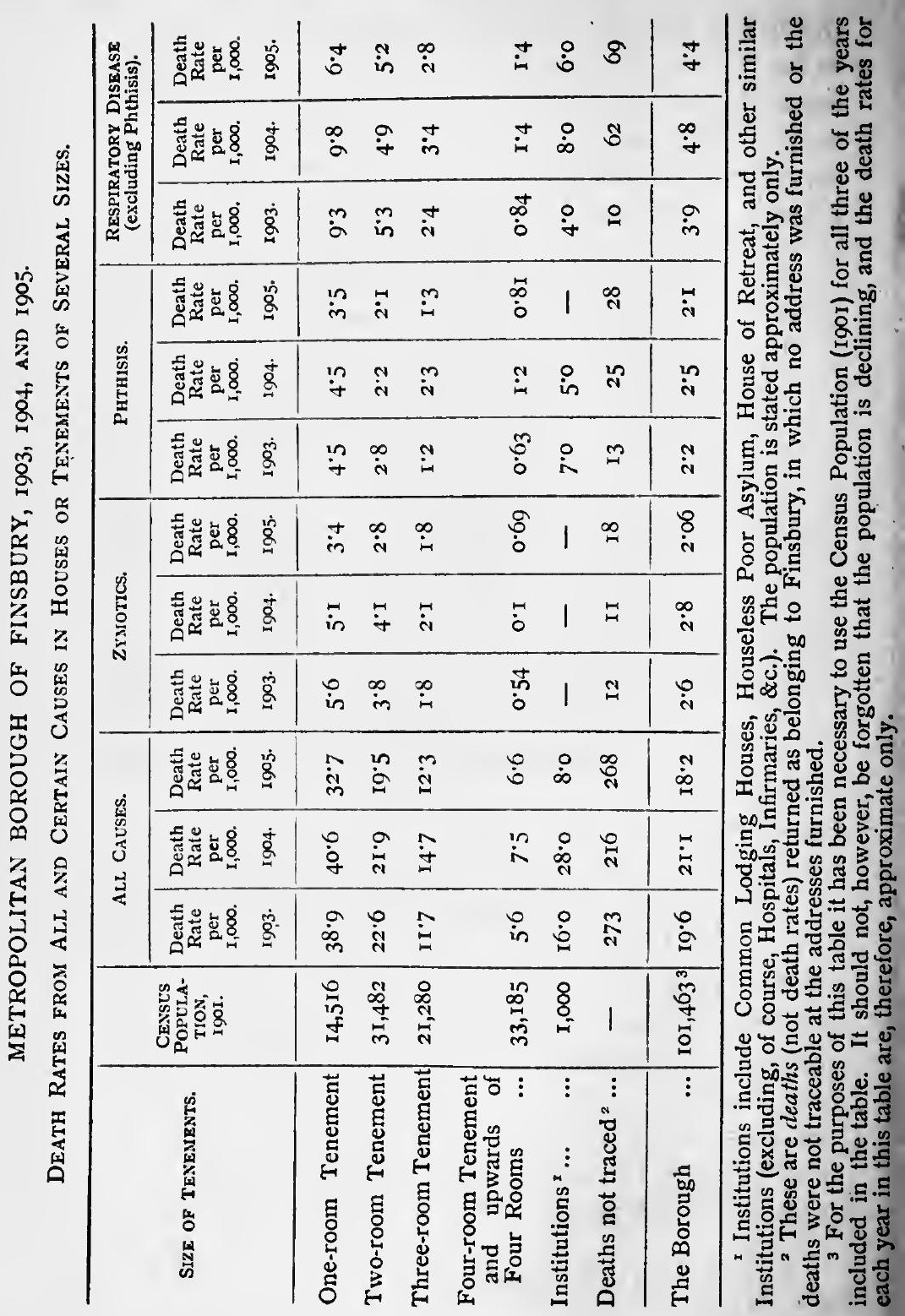


accuracy. If we could observe a community all living continuously under conditions of marked overcrowding, each individual spending his whole life under such conditions, then we should be in a position to state with more confidence the exact part which this social evil takes in the causation of disease and death. But as it is we can only judge the matter broadly. The table on the opposite page is an attempt to state this matter in figures. ${ }^{\mathrm{I}}$

The results appear to show that the smaller the tenement, i.e., the more "overcrowded" the family, the higher is the death rate from all causes and from the diseases named. This is an instructive result when it is considered that each of the three years tells the same story, and that as many as 4,000 deaths are tabulated on a population of approximately 100,000 persons. It is necessary, however, to recognise that the figurés are of relative value only, for it must not be assumed that a man dying, say, of phthisis in a one-roomed tenement in 1905 has lived all his life in that tenement. He may only have been living there a few months or years, his disease having been contracted elsewhere. Indeed such is highly probable, for phthisis leads to poverty, and poverty leads to smaller tenements. But even as a relative return the figures are instructive, and illustrate in a marked manner the broad fact of the evil effects of living under "overcrowded" conditions.

It should be borne in mind that these death rates have not been "corrected" for sex or age incidence, and are not, therefore, comparable with other districts of a like character.

The following table, with similar drawbacks, has been drawn up to illustrate the same conditions of housing in relation to infant mortality from all causes and from certain causes :-

× Report on the Public Health of Finsbury, I905, p. 31. 
METROPOLITAN BOROUGH OF FINSBURY, I905.

Infant Mortality Rates from All and Certain Causes in Houses or Tenements of Several Sizes.

\begin{tabular}{|c|c|c|c|c|c|c|c|c|}
\hline \multirow{2}{*}{ SIZF OF TENEMENT. } & \multirow{2}{*}{$\begin{array}{l}\text { CENSUS } \\
\text { POPULA- } \\
\text { TION, } \\
\text { IgOI. }\end{array}$} & \multirow{2}{*}{$\begin{array}{l}\text { NUMBER } \\
\text { OF } \\
\text { BIRTHS. }\end{array}$} & \multicolumn{2}{|c|}{ Ald Causes. } & \multicolumn{2}{|c|}{$\begin{array}{c}\text { DIARRHGEA, } \\
\text { MEASLES, } \\
\text { WHOOPING-COUGH } \\
\text { SCARLET FEVER, } \\
\text { DIPHTHERIA. }\end{array}$} & \multicolumn{2}{|c|}{$\begin{array}{l}\text { PREMATURITY. } \\
\text { IMMATURITY. }\end{array}$} \\
\hline & & & 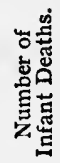 & 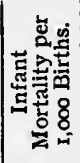 & 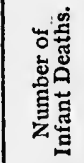 & 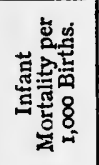 & 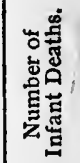 & 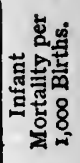 \\
\hline One-room Tenement ... & 14,516 & 532 & 117 & 219 & 28 & 53 & I6 & 30 \\
\hline Two-room Tenement... & 31,482 & 1,216 & 192 & 157 & $5 I$ & 42 & 32 & 26 \\
\hline Three-room Tenement & $2 \mathrm{r}, 280$ & 468 & 66 & $14 \mathrm{I}$ & 16 & 34 & 2I & 44 \\
\hline $\begin{array}{c}\text { Four-room Tenement } \\
\text { and upwards of Four } \\
\text { Rooms ... }\end{array}$ & 33,185 & 464 & 46 & 99 & 9 & I9 & 9 & I9 \\
\hline $\begin{array}{l}\text { Institutions and Deaths } \\
\text { and Births not traced }\end{array}$ & 1,000 & $206 x$ & 8 & 39 & - & - & - & - \\
\hline The Borough $\quad \ldots$ & 101,463 & 2,886 & 429 & 148 & 104 & 37 & 78 & 27 \\
\hline
\end{tabular}

These figures show a much higher fatality among infants from all causes living in one-room homes in Finsbury in 1905 than in infants in two-, three-, or four-room homes. On the whole, too, it is evident that the effect is more accurately denoted in these rates than in the rates in the former table for the simple reason that there is no fallacy on account of different age incidence, the infants all being of one age, namely, under twelve months. Moreover, in very few cases indeed did the infant die in any other tenement, whether larger or smaller, than that in which it was born. We have, therefore, here an approximately accurate representation of the distribution

x This number includes those births which took place in institutions, were not traced, or had removed. 


\section{of infant mortality as regards tenement property in cen-} tral London. ${ }^{\mathrm{T}}$

The infant deaths from diarrhœa show the same distribution, though the percentage fall of infant mortality from this disease from one-room homes to four- or more roomed homes is even more marked ( 64 per cent. $c f$. with 55 ) than the infant mortality from all causes. But the results are different when the infant mortality from prematurity and immaturity be taken, for in such diseases there is

There has been proceeding for a number of years a change of usage more than a change of actual property. Whole streets and squares of houses, formerly occupied by single families and often good-class families, are now occupied as separate dwellings on separate floors. The private house has become a tenement house. There is a common passage and a common staircase, both of which are open to the public, and the passage and staircase act as the ventilating shaft for the foul atmosphere derived from the dwelling-rooms opening on to the stair. The history of such a house is a dismal record of degeneration. Year by year the state slowly but surely becomes worse. The house was structurally designed for one family and is now occupied by four or more families. The sanitary conveniences were also designed for one family and now provide for four families. The same must be said of the water supply and wash-house accommodation. There can be no doubt that the ill-ventilation and the difficulty of access to the sanitary convenience, scullery, ivash-house, or dust-bin may indirectly act as causes of ill-health and undesirable habits. Hence it comes about that both house and tenants degenerate.

Another of the general characteristics of house property in Central London is that the yards in the rear of the houses have, in many cases, been built over. The condition of things constantly to be observed is this: Between two streets, running parallel, there existed, when the houses were first built, an open space, subdivided into yards. Thus fresh air was obtainable in the rear as well as in the front of the houses. In the yards were constructed various conveniences for sanitary purposes, washing, refuse collection, \&c. Thus the house, as a private house, was equipped. But in addition to the invasion of tenants, to which reference has already been made, there has been an industrial invasion. The yards became covered in or otherwise built over for workshop premises. Even when such buildings are only small they effectually prevent through ventilation on the ground floor. But so extensive have such buildings become in certain cases, that a large portion of the open space originally existing between the street backs has been filled in. The houses thus become, practically speaking, back-to-back houses. Moreover, the immediate proximity of some kinds of workshops to dwelling-houses readily gives rise to nuisances of various kinds.

Here, then, are two general conditions prevailing somewhat widely in Finsbury and Central London. First, the invasion of "self-contained" houses by an industrial population for whose accommodation the houses have been let in tenements. Secondly, the growth of warehouse and workshop accommodation. 
an increased mortality in infants living in three-room homes. Any deductions drawn from this table must, of course, be stated with reserve, as it deals with only one year and only 429 deaths, and particularly does this remark apply to the column of death rates due to prematurity. Broadly, however, its meaning is obvious. ${ }^{\mathrm{I}}$

"In the poor and crowded districts," writes Mr. Booth, "infantile deaths represent on the average 6.3 out of a total death rate of 23 per $1,000 . "$ And to illustrate the distribution he selects eleven districts of $(a)$ a central class, $(b)$ an upper class, and $(c)$ a lower class as judged by social conditions, and then he works out the infant mortality rate for the years 1894 and 1895 , making needful allowance for deaths in institutions by returning the deaths to the districts from which the patients had come. In his previous volumes he had shown that poverty and overcrowding go together on the whole. From these later tables he is able to demonstrate, what indeed has been known for long enough, that both birth rate and death rate from all causes and in infants are high in proportion to the degree of poverty and overcrowding. In the "central"

- Sir Shirley Murphy has drawn attention to the relation of overcrowding in tenement property to infant mortality in the following table :-

LONDON.

\begin{tabular}{|c|c|c|c|c|}
\hline \multicolumn{4}{|c|}{$\begin{array}{l}\text { I891 -1900. } \\
\text { Proportion of Population living more than two in a } \\
\text { room in tenements of less than five rooms. }\end{array}$} & $\begin{array}{c}\text { Infant Mortality Rate. } \\
142 \\
180\end{array}$ \\
\hline $\begin{array}{r}\text { Districts with } \\
\qquad " \\
\text { " } \\
\text { " } \\
\text { " }\end{array}$ & 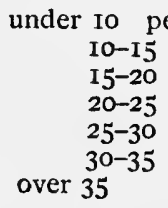 & $\begin{array}{l}\text { cent. } \\
" \\
" \\
" \\
" 1 \\
" 1\end{array}$ & $\begin{array}{l}\ldots \\
\cdots \\
\cdots \\
\cdots \\
\cdots \\
\cdots\end{array}$ & $\begin{array}{l}142 \\
180 \\
196 \\
193 \\
210 \\
222 \\
223\end{array}$ \\
\hline
\end{tabular}

Rep. on Interdepart. Com. on Physical Deterioration, 1904, vol. iii. p. 52. 
division infant deaths count for 4.7 out of 17.7 as the death rate after infancy, in the upper-class division for 3.2 out of 14.7 , and in the poorer classes 6.3 out of $16 \%$ In all classes infant life is very precarious, and in this respect the advantage of the well-to-do is perhaps less than might be expected. But of the total born in the poor section, 16.9 per cent. or one-sixth die in the first year; in the central section, 14.8 per cent.; and in the upper division, 13.2 per cent. No doubt the presence of a good many poor, even in generally well-to-do districts, is among the causes which tend to equalise the figures. How marked is the difference between districts wholly poor and wholly well-to-do may be seen by selecting such districts from the three tables. ${ }^{\mathrm{I}}$

LARGEST PROPORTION POOR AND CROWDED.

\begin{tabular}{|c|c|c|c|c|c|c|}
\hline \multirow{2}{*}{\multicolumn{3}{|c|}{ DISTRICT. }} & \multirow{2}{*}{$\begin{array}{l}\text { Birth Rate, } \\
\text { I89I-95. }\end{array}$} & \multicolumn{2}{|c|}{ Death Rate. } & \multirow{2}{*}{$\begin{array}{c}\text { Proportion } \\
\text { Dying in } \\
\text { Infancy, } \\
\text { 1894-95. }\end{array}$} \\
\hline & & & & After & & \\
\hline \multirow{2}{*}{\multicolumn{3}{|c|}{$\begin{array}{l}\text { St. Saviour's and Waterloo ... } \\
\text { Old Street and S. Shoreditch... }\end{array}$}} & $\begin{array}{l}\text { Per } 1,000 . \\
39^{\circ} 4\end{array}$ & $\begin{array}{l}\text { Per } 1,000 . \\
\text { I } 8.2\end{array}$ & $\begin{array}{l}\text { Per } 1,000 . \\
6.5\end{array}$ & $\begin{array}{l}\text { Per Cent. } \\
\text { I6.4 }\end{array}$ \\
\hline & & & $39^{\circ} 9$ & I 8.5 & $5 \cdot 7$ & $14 \% 3$ \\
\hline \multicolumn{3}{|c|}{ Bethnal Green ... } & 38.9 & $160^{\circ}$ & $5 \cdot 2$ & 13.4 \\
\hline \multicolumn{2}{|c|}{ St. George's-in-the-East } & ... & $36 \cdot 6$ & I $7 \cdot 8$ & $7 \cdot 6$ & 20.7 \\
\hline \multirow{2}{*}{\multicolumn{2}{|c|}{$\begin{array}{l}\text { Bermondsey } \ldots \\
\text { Hoxton and Haggerston }\end{array}$}} & ... & $37 \cdot 3$ & I5.4 & 6.9 & $18 \cdot 5$ \\
\hline & & ... & $37 \cdot 6$ & $15 \cdot 2$ & 6.9 & 18.4 \\
\hline \multicolumn{2}{|c|}{ Lambeth... } & ... & $38 \cdot 3$ & $15 \cdot 6$ & $7 \cdot 5$ & $19 \cdot 6$ \\
\hline \multicolumn{2}{|c|}{ Poplar and Limehouse } & ... & $35^{\circ} \mathrm{I}$ & 1777 & 57 & $16 \cdot 2$ \\
\hline \multicolumn{2}{|c|}{ Newington and Walworth } & $\ldots$ & 357 & $16 \circ 0$ & 5.9 & $16 \cdot 5$ \\
\hline North Camberwell & ... & ... & $34 \cdot 8$ & $13 \cdot 8$ & $5 \cdot 6$ & $16 \cdot \mathrm{I}$ \\
\hline Rotherhithe & ... & $\cdots$ & $35^{\circ} 4$ & $15 \cdot 1$ & $4 \cdot 9$ & $13 \cdot 8$ \\
\hline Averages & ... & ... & $37^{\circ} \mathrm{I}$ & I6.7 & $6 \cdot 3$ & 16.9 \\
\hline
\end{tabular}

- Life and Labour of the People of London. By the Right Hon. Charles Booth, F.R.S. Final vol., 1902, pp. 16-27.

2 This percentage represents in each table the proportion of those born who die within a year of their birth. 
LARGEST PROPORTION COMFORTABLE CENTRAL CLASS.

\begin{tabular}{|c|c|c|c|c|c|c|}
\hline \multirow[b]{2}{*}{ DISTRICT. } & & & \multirow[b]{2}{*}{ Birth Rate. } & \multicolumn{2}{|c|}{ Death Rate. } & \multirow{2}{*}{$\begin{array}{l}\text { Proportion } \\
\text { Dying in } \\
\text { Infancy. }\end{array}$} \\
\hline & & & & After & In & \\
\hline South Camberwell & ... & ... & $\begin{array}{c}\text { Per } 1,000 \\
27 \cdot 8\end{array}$ & $\begin{array}{c}\text { Per } 1,000 . \\
\text { I } 1 \cdot 8\end{array}$ & $\begin{array}{c}\text { Per } \tau, 000 . \\
4 \% 3\end{array}$ & $\begin{array}{c}\text { Per Cent. } \\
\text { I5.5 }\end{array}$ \\
\hline Peckham, \&c. ... & ... & $\ldots$ & $3 x^{\circ} 7$ & I37 & $5 \cdot 1$ & I6.I \\
\hline Battersea (W.) ... & ... & $\ldots$ & $3 \mathrm{r}^{\circ} \mathrm{O}$ & 120 & 50 & $16 \cdot 1$ \\
\hline Deptford... $\quad \ldots$ & $\ldots$ & $\ldots$ & $32 \cdot 5$ & $\mathrm{r} 43$ & $4 \cdot 8$ & $\mathrm{r}_{4} \cdot 8$ \\
\hline Woolwich & ... & ... & $3 I^{\circ} 9$ & I 2.5 & $3 \cdot 9$ & I $2 \cdot 2$ \\
\hline Hackney... & $\ldots$ & $\ldots$ & $30 \cdot 5$ & 13.0 & 4.5 & $14 \cdot 8$ \\
\hline Greenwich & $\ldots$ & $\ldots$ & $30 \% 4$ & $13 \cdot 8$ & $4 \cdot 1$ & 13.5 \\
\hline Kennington $\quad \ldots$ & $\ldots$ & ... & $34^{\circ} \circ$ & I2.5 & $4 \cdot 6$ & 135 \\
\hline Bow and Bromley & $\ldots$ & ... & $36 \cdot 1$ & 14.5 & 6.0 & 16.6 \\
\hline Battersea (E.) ... & $\ldots$ & ... & $34^{\circ} 9$ & $12 \cdot 3$ & $5 \cdot 3$ & $15 \cdot 2$ \\
\hline Upper Holloway & ... & ... & $29: 3$ & 117 & $4 \div 3$ & 147 \\
\hline Averages & ... & $\cdots$ & $3 I^{\circ} 7$ & 13.0 & 47 & $14: 8$ \\
\hline
\end{tabular}

LARGEST PROPORTION UPPER CLASSES.

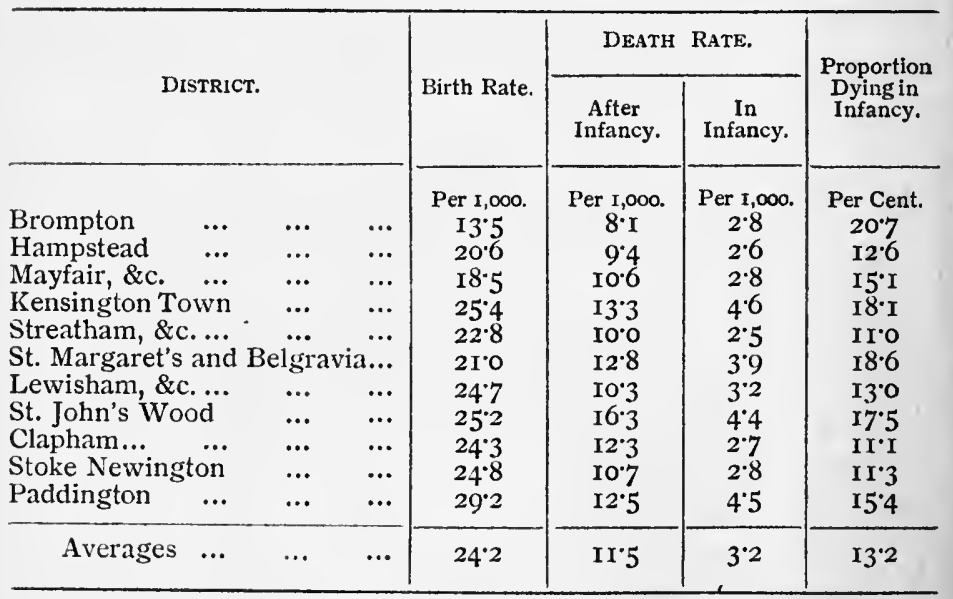

What Mr. Booth did for London, Mr. Seebohm Rowntree did for York with the same result. I The mortality of

'Poverty: A Study of Toven Life (Igor), by B. Seebohm Rowntree, pp. 198-209. 
infants in those working-class districts representing the poorest, a middle, and the highest class of the artisan population worked out in 1898 , the year of Mr. Rowntree's inquiry, was as follows :-

\begin{tabular}{|c|c|c|c|}
\hline Areas. & $\begin{array}{c}\text { Infant } \\
\text { Mortality } \\
\text { Rate. }\end{array}$ & $\begin{array}{c}\text { General } \\
\text { Death Rate. }\end{array}$ & $\begin{array}{l}\text { Death Rate } \\
\text { over } 5 \text { Years } \\
\text { of Age. }\end{array}$ \\
\hline Area I. Poorest Working Class... & 247 & 2777 & $13 \cdot 8$ \\
\hline Area 2. Middle Working Class ... & 184 & $20^{\circ} 7$ & $10 \% 2$ \\
\hline Area 3. Highest Working Class... & 173 & 134 & $7 \cdot 5$ \\
\hline $\begin{array}{lll}\text { Servant-keeping Class } \quad \ldots & \ldots\end{array}$ & 94 & - & - \\
\hline City of York as a whole $\quad \ldots \quad \ldots$ & I76 & $18 \cdot 5$ & II $\cdot I$ \\
\hline
\end{tabular}

The conditions in the working-class area (3) were favourable. "There is no overcrowding, there are no back-to-back houses, no public-houses, the streets are wider than Areas I and 2, and many of the houses have small gardens in front. Generally speaking, it may be said that this section consists of people who are comfortably off, and are living under sanitary conditions." The figures in the last two columns of the above table make it evident that the high infant mortality in Area $r$ is not due wholly, as might be urged, to ignorance in the feeding and management of infants rather than to causes arising out of the poverty and environment of the people. If that were so the high death rate would be confined to infancy, but as a fact it is common to all ages above infancy.

Similar evidence is forthcoming from almost every large town having "slum" conditions in some of its wards, particularly if those slum conditions concern domestic and social life in addition to external environment. Birmingham affords a marked example. Its infant mortality rate 
in 1904 was 195 per 1,000 births, which placed it at the bottom of the list, with Stockport 203, Hanley 212, and Burnley 229 for 1,000 births. When we come to inquire into this high rate of 195 we find that eight wards in the city of Birmingham in 1904 had an infant mortality rate of over 200 per I,000 births, the three highest being St. Stephen's Ward 232, St. Bartholomew's 263, and St. Mary's 33I. The chief diseases carrying off children, 3,000 infants per annum, appear to be (a) diarrhoa and enteritis, $(b)$ debility and marasmus, ( $c$ ) bronchitis and pneumonia, and (d) prematurity-diseases mainly due to evil social conditions and infant mismanagement. Dr. Robertson, the Medical Officer of Health of Birmingham, drew up a special report on the conditions existing in these three wards, and it is necessary to consider some of the facts to which he draws attention. ${ }^{I}$ The Floodgate Street area covers some II4 acres, and consists of some twenty-five streets (and courts) accommodating 9,878 persons. In fourteen of these streets the death rate from all causes was found to be 30 per 1,000 or above. In Allison Street it was $49^{\circ} 6$, and in Park Street $63^{\circ} 5$ per $1, \infty 00$. The whole area had a death rate of $3 \mathrm{I}^{\circ} 6$ as compared with 19.3 for Birmingham, that is to say, it was 60 per cent. higher than for the whole city. Some of the chief death rates for particular causes may be compared not only with Birmingham, but with a-more or less typical artisan district (All Saints' Ward) having an infant mortality of 173 per 1,000 , and with the satisfactory conditions of Edgbaston, as shown in the table opposite.

Here we see at a glance an ordinary district containing a large artisan population under fair sanitary and social conditions compared with the Floodgate Street

- Rcport of Medical Officcr of Health on Unhealthy Conditions in the Floodgate Street Area and the Municipal Wards of St. Mary, St. Stephen, and St.'Bartholomere (I904), pp. I-29. 
area, Edgbaston, and the City itself. Dr. Robertson describes the figures in the first column as "typical of a poverty-stricken, insanitary, and vicious population. Improper and insufficient food weakens resistance against many diseases, such as phthisis, marasmus, \&c., while this along with carelessness and exposure increases the deaths from inflammatory diseases of the lungs." I He recognises that bad housing, poverty, and evil social conditions are

\begin{tabular}{|c|c|c|c|c|c|c|}
\hline \multirow{2}{*}{\multicolumn{3}{|c|}{ Disease. }} & \multicolumn{4}{|c|}{$\begin{array}{l}\text { DEATH RATE PER I,000 PER ANNUM. } \\
\text { MEAN OF F1VE YEARS, 1899-1903. }\end{array}$} \\
\hline & & & \multirow{3}{*}{$\begin{array}{c}\begin{array}{c}\text { Floodgate } \\
\text { Area. }\end{array} \\
2.37 \\
3.71\end{array}$} & \multirow{3}{*}{ 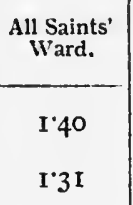 } & \multirow{3}{*}{ Edgbaston. } & \multirow{2}{*}{$\begin{array}{c}\begin{array}{c}\text { City of Bir- } \\
\text { mingham. }\end{array} \\
\mathbf{I} \cdot 80\end{array}$} \\
\hline Diarrhœa an & dd Enteritis & ... & & & & \\
\hline Phthisis & .. & $\cdots$ & & & & $I \cdot 62$ \\
\hline $\begin{array}{c}\text { Prematurity, } \\
\text { Debility }\end{array}$ & $\begin{array}{l}\text { Marasmus, } \\
\ldots \quad \text {... }\end{array}$ & $\begin{array}{r}\text { and } \\
\ldots\end{array}$ & $3 \cdot 5^{6}$ & I.68 & $\cdot 77$ & I'9I \\
\hline $\begin{array}{l}\text { Bronchitis, } \\
\text { Pleurisy }\end{array}$ & $\begin{array}{c}\text { Pneumonia, } \\
\ldots \quad \ldots\end{array}$ & $\begin{array}{r}\text { and } \\
\ldots\end{array}$ & $8 \cdot 04$ & $3^{\circ} 04$ & $2 \cdot 17$ & 370 \\
\hline All Causes & $\cdots$ & $\ldots$ & $3 I \cdot 5$ & 16.6 & I3'I & 19.3 \\
\hline Infant Morta & ality & $\cdots$ & $263^{2}$ & I73 & 133 & 195 \\
\hline
\end{tabular}

the main causes of this condition of things which works such havoc among the most susceptible portion of the population, the infants, and some of his findings must be quoted. He reports :-

(i.) House Accommodation.-In the inspection which has been made of the Floodgate Street area, I have taken into account certain other conditions, such as Housing, Poverty, \&c. The

- Report of Medical Officer of Health on Unitcalthy Conditions in the Floodgate Street Arca and the Municipal Wards of St. Mary, St. Stephen, and St. Bartholomew (I904), p. 9.

? For the whole of St. Bartholomew's Ward. 
rental of 1,577 of these houses was ascertained from the tenants :-

$3^{81}$ were under 4 s. rental per week;

655 were from 4 s. to under $5 \mathrm{~s}$. rental per week;

I 72 were from 5 s. to under $6 \mathrm{~s}$. rental per week; Ior ${ }^{1}$ were from $6 \mathrm{~s}$. to under $7 \mathrm{~s}$. rental per week; $268^{ \pm}$were $7 \mathrm{~s}$. or over rental per week.

Two-thirds of the recorded houses were of rentals under $5 \mathrm{~s}$. per week. By themselves, these figures indicate that a fair proportion of the houses are of what would appear to be low rental, but when the wages of the occupants are inquired into, so much poverty exists that it is somewhat remarkable that more effort to economise by taking two families into one house was not made than we actually found. . . .

Twelve hundred and thirty-six houses were of the back-to-back type, of which it is said there are between 30,000 and 40,000 in the City. Only 698 were "through" houses. The number of available through-cottage houses is, therefore, very small.

Excepting the shops and public-house premises, and a comparatively small number of houses mostly of recent construction, practically all the houses are built on the courtyard systemwhere a yard common to a number of houses supplies the air space-where one water-tap in the yard is the only water supply, and where one closet is for the common use of two or more houses.

In the large majority of the houses the old type of "settle," or undrained sink, still exists, so that, in addition to the above disabilities, the people have not reasonable facilities for disposal of slop water. Indeed, there is so much trouble entailed in getting water into the house, and afterwards disposing of it, as slops, that I am rather surprised to find so many people keeping their houses and themselves clean. ...

To return to the typical courtyard house. It is the prevailing type, not only in this district, but in the central part of our City generally. It has one living-room and a pantry on the ground. floor ; one, two, three, or even four bedrooms above, the number

$\therefore$ In some of these the front room was used as a shop. 
depending on the area of the living-room and the number of storeys. In a considerable number of houses a cellar is formed below the living-room, the floor of which is supported on an arch. Most of these houses are damp from one or more of the following causes :-

(r) Want of a damp course--few houses of this type were provided with a damp course; (2) the floor of the living-room being formed of tiles ("quarries") laid on the earth, or on the arch of a cellar, the stones of which are charged to their utmost with moisture; (3) defective pointing, roofing, spouting, or brickwork making the outside walls damp; (4) undrained "settles" (sinks).

A house with damp walls and floors is, I am convinced, a cause of much ill-health among a city population. Often, indeed, the damp may not be sufficient to make the paper fall off the wall ; but short of this such a house is cold, and has a moist atmosphere in it.

In a considerable number of cases the inner surface of the walls is broken and defective, allowing of lodgment of dust, and preventing proper cleansing. In many cases the ceilings are broken and bulged, and the woodwork of the windows, doors, floors, and skirtings are broken, rotten, or generally defective, so that the occupants have no inducement to keep their houses clean and tidy, as they can never get them to look well.

The air space attached to these courtyard houses in insufficient, and the general condition of gloom and dirt makes life far from what it ought to be. The courtyard itself should be cleansed twice a week, or oftener, by the tenants; but what is everybody's duty is nobody's, and, therefore, in the majority of cases it is seldom, if ever, cleansed unless the landlord pays for its regular cleaning.

In many of these courtyards pan-closets still exist. The stench from these, even when the pans are empty, pervades the courtyard, and can be smelled in the interior of the house. These closets, like the houses, are of the cheapest and most slim construction. They are constantly getting out of repair. They are, like the yards, used by more than one house, and it is only reasonable to expect that one tenant will object to cleanse away filth made by another. The housing conditions are distinctly 
bad in a considerable proportion of the houses, but these conditions are no worse than they are in many other areas in the City.

(ii.) Poverty in the Area.-The condition of poverty in which the people in this area live has impressed me more than any other feature. The time of our inquiry was one of trade depression, and such a condition falls more heavily on the poor class and inefficient craftsman than on the steady and efficient workman. Again, the area is occupied by a large number of unskilled labourers, whose average wages (in Birmingham), I am informed, varies from I $7 \mathrm{~s}$. to 2 Is. a week. Street-hawkers, barrow-men, and persons employed in a host of ways-all more or less with poor incomes-live in this area.

We therefore found that a very large number of persons were, from their own statements, in poverty. In addition, however, to the statements given, an inspection of the houses confirmed me in the opinion that great poverty did exist, even if one accepted the statements of the people with suspicion.

In the following tabular statement I have attempted to codify the information given us as to the total earnings of each family. The statement must be looked at as being probably inaccurate to the extent of 10 or even 15 per cent. The tendency is to understate one's income. Among casual labourers it is difficult at any time to obtain reliable information, but the statement on the next page is sufficiently accurate to indicate the extent of the poverty.

It is, I think, impossible for a man living in the centre of the City, and employed as a labourer at the standard rate of wages, to keep a wife and family of three children without being in poverty. This, notwithstanding the fact that he does not spend anything on drink or tobacco, or on travelling to and from his work. His only chance of getting enough for house rent, clothing, and fuel lies in the family earnings being increased by his wife's earnings, or by the earnings of a child, or by taking in lodgers. The necessity, therefore, exists among this large class for the wife to leave her young children to go to work, and of the children being put to work at the earliest opportunity. If anything be spent on drink, actual poverty is at once evident.

On the area we found a large number of skilled artisans who admitted receiving good wages, and who were apparently living in 


\section{DOMESTIC AND SOCIAL CONDITIONS 195}

conditions of poverty from drink, gambling, or other unnecessary expenditure. The amount of ill-health to which poor living, bad housing, and inferior surroundings give rise increases the poverty.

Many people have fallen into such a condition of poverty as to be unable to furnish a house of their own, and have to go into lodgings of one kind or another.

\section{STATEMENT AS TO TOTAL EARNINGS OF HOUSEHOLDS} PER WEEK.

\begin{tabular}{|c|c|c|c|c|c|c|c|c|c|c|}
\hline & \multicolumn{9}{|c|}{ No. of FaMillies EaRniNg. } & \multirow[b]{2}{*}{ TOTAL. } \\
\hline & 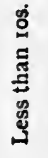 & 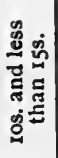 & 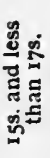 & 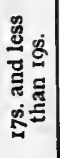 & 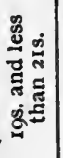 & 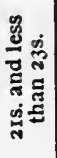 & 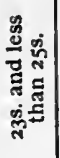 & 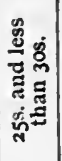 & 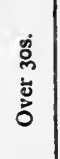 & \\
\hline $\begin{array}{c}\text { Class I. } \\
\text { Man, wife, and up } \\
\text { to } 3 \text { children ... }\end{array}$ & 36 & 102 & IOI & 128 & 156 & 107 & 103 & 232 & I99 & 1,164 \\
\hline $\begin{array}{c}\text { Class 2. } \\
\text { Man, wife, and } 4 \\
\text { to } 6 \text { children ... }\end{array}$ & 2 & 8 & 9 & I5 & 39 & I6 & I8 & $5^{6}$ & 105 & 268 \\
\hline $\begin{array}{l}\text { Class } 3 . \\
\text { Man, wife, and } \\
\text { over } 6 \text { children }\end{array}$ & 一 & - & - & - & $\mathbf{I}$ & $\mathbf{I}$ & 2 & 8 & 26 & 38 \\
\hline $\begin{array}{l}\text { Widowers and } \\
\text { Widows with or } \\
\text { without families } \\
\text { or lodgers } \quad \text {... }\end{array}$ & 68 & 80 & 24 & 24 & 23 & 10 & I3 & 8 & 4 & 254 \\
\hline
\end{tabular}

In addition to twenty common lodging-houses thẹre are fifty-four registered houses sub-let in lodgings, having accommodation for 297 persons. These are occupied by the most depraved and dirty of the population. They, however, fulfil a useful purpose, and, if further powers were obtained for their regulation, they form a means of housing the vicious and abandoned people who are a nuisance to their neighbours and a terror to landlords.

(iii.) Drink and Ignorance as a Cause of Ml-health.-In addition, however, to all the contributory causes already men- 
tioned, it is difficult to say whether drink, combined with ignorance and carelessness, does not play as important a part-or even a more important part-than all the conditions of bad housing, smoky atmosphere, and poverty. One cannot but be struck, in going over such an area in the evening, with the number of public-houses, and with the extent to which they are used as clubs. A large number of men and women in the area soak themselves with drink every day, thereby ruining their constitutions, bringing on poverty, and indirectly causing most unhealthy conditions. Bearing in mind such conditions resulting from the excessive use of drink, the drink question has a public health aspect of the greatest importance.

Such an area as this is the resort of a large number of the more careless and ignorant members of the population. This carelessness and ignorance are "catching," with a result that people who would lead clean and healthy lives are contaminated by living in proximity to these degenerates. There is no doubt whatever that much of the misery in the area arises from the carelessness and ignorance of the tenants, and it would be unjust to say that the property owner alone was at fault in regard to the condition of the houses.

Many of the houses, if occupied by clean, active persons, would have an entirely different appearance, and would be much more healthful than they are at the present time.

Nearly every one who has had experience of such areas must be impressed with the vicious circle which exists. Bad housing, drink, poverty -all have to be attacked along the broadest lines, and with a clear idea of the goal to be aimed at.

I have included this long quotation in the text of this chapter, not only because it is typical, according to Dr. Robertson, of the conditions which occur to a greater or less extent in each of the three wards in question, but because it is typical of other somewhat similar areas, though possibly not so bad, as exist in other large towns. It is impossible to rear a healthy physical race under such conditions as these, and it is patent and obvious that so long as domestic insanitation exists to this degree the life of 
infancy among the poor cannot be otherwise than injuriously affected.

Even in Hanley, where a high percentage of women are engaged in the pottery industry, it has been shown that domestic conditions and housing are exerting an influence which is probably even more injurious to women and infants than the conditions of employment. In 1872 Dr. Ballard, reporting to the Local Government Board upon the sanitary circumstances of the town (which then had a population of 40,000 ), wrote that "in all but the newer parts of the town the dwellings occupied by the operative and labouring classes are much neglected, dark, damp, unventilated, and often dilapidated. Many of them are utterly unfit for occupation, and ought to be closed; some are so incapable of improvement that they ought to be demolished." In 1894 Dr. Sweeting, and in 1905 Dr. Monckton Copeman, inspecting the town on behalf of the Board, found very similar conditions prevailing, although "considerable improvement" had taken place since I872. In Dr. Copeman's opinion the disposal and removal of refuse is a still more urgent problem. In the poorer parts of the town it appears that ashes and other household refuse are disposed of in ash-pits, usually of enormous size and frequently uncovered, so that the contents remain exposed to the effects of both sun and rain. "When, as is sometimes the case, these huge receptacles of semi-decomposing filth are situated within a short distance -3 feet or less-of the dwellings, their presence can hardly fail to exert an injurious effect on the health of the inmates, more especially the children. It would appear not unlikely, indeed, that this particular insanitary condition may play no inconsiderable part in the marked prevalence,

Report to Local Government Board on Sanitary Circumstances of Hanley; 1905 (No. 2I7). 
in the borough, of infantile diarrhœa during the second and third quarters of the year." I

Formerly the contents of ash-bins and pits were used in considerable quantity for filling up inequalities of the ground on building sites in the town, but at the present time practically all such refuse is cremated in a recently erected destructor.

The method employed in the removal of the contents of ash-pits and bins is decidedly unsatisfactory. The contents of the bins are removed in barrows and boxes by the men, and, in some instances, have to be carried through the living-rooms of the house. Once outside the house the material is "dumped" in heaps on the street alongside the footpaths; these heaps are, in turn, shovelled into the cart when it comes along. Where large ash-pits are being emptied considerable heaps of the material are thrown out on the street, awaiting the arrival of the cart, and portions of this material are liable to be distributed by wind, \&c.

If the views expressed in an earlier portion of this volume be correct, it cannot be surprising if diarrhœa is prevalent in Hanley, as in fact is the case. From 1900 to 1903,247 infants died of epidemic diarrhœa in the town (exactly 80 per cent. of all the diarrhœa deaths in that period), and the infant mortality rate was also exceptional (198 per I,000 from I899-1903). Upon this point of the relation obtaining in Hanley between domestic filth and infant mortality I cannot do better than quote Dr. Copeman's official report. He writes :-

"The Medical Officer of Health is of opinion that the heavy infantile mortality is due to 'the excessive employment of adult female labour in the potteries,' with the consequent result that infants are put out to nurse and artificially fed. In this connection he informs me that as the result of personal visits of inspec-

\footnotetext{
I Report to Local Government Board on Sanitary Circumstances of Hanley, 1905 (No. 217), p. 6.
} 


\section{DOMESTIC AND SOCIAL CONDITIONS 199}

tion to fifty-three houses in which deaths of infants from diarrhœa had occurred during 1904, he found that the methods of feeding in the various cases had been as follows:-

In 27 cases infants fed on cow's milk; currently reputed to have been boiled.

$\begin{array}{cccc}\text { I } 5 & \text { " } & \text { " } & \text { Swiss milk. } \\ \text { breast milk entirely [i.e., } 8 \text { per cent. of } \\ \text { total]. }\end{array}$

"One case was fed on breast milk and patent food. In the remaining cases information was not obtainable.

"However largely cow's milk, whether boiled or unboiled, has been responsible for fatal diarrhœa among Hanley infants, it is obvious that in the case of breast-fed infants the source of infection must be sought for in some direction other than milk contamination.

"Whether or not the prevalence of zymotic enteritis be due to infection, directly or through the medium of food products such as milk-by agency, for instance, of the bacillus coli communis or of bacillus dysenteria-there is gradually accumulating a consensus of opinion that contaminated dust or detritus, whether conveyed by air-currents or by flies, may be responsible, especially in towns, for many diarrhœa attacks. And in Hanley, as I have shown earlier in this report, most favourable opportunities are afforded for the dissemination of germ-laden particles from the contents of the huge middens, more especially during the process of removal of their contents. In my opinion, indeed, one of the most urgently needed sanitary reforms in Hanley is the entire abolition of midden privies, and of existing ash-pits, with the provision in their place of proper water-closets, and of comparatively small, covered, and easily movable iron receptacles for house refuse." I

The report states that the Town Council of Hanley were about to appoint a lady inspector under the Midwives Act, a part of whose duties would be to visit the dwellings of the poor and to endeavour to instruct the

x Report to Local Government Board on Sanitary Circumstances of Hanley, Ig05 (No. 217), p. 10. 
women in the proper methods of feeding and rearing infants, and in the elements of general hygiene. "Should a capable person be appointed to the post," adds Dr. Copeman, "it is not improbable that the work may result in an appreciable diminution of the present high infantile death rate, which is certainly due in large measure to neglect and ignorance on the part of the mothers among the lower classes."

One further instance may be taken, namely, a town situated in a manufacturing district in the north of England, having a population of not less than 20,000 persons, and characterised by two features, namely, a very high infant mortality and a very low percentage of occupied women. I have asked the Medical Officer of Health of this town, who has for years studied its life, to furnish me with the causes of the high infant death rate. For reasons which will appear, he stipulates that his name and that of the town shall not be mentioned. The following are the chief paragraphs in his letter :-

"The average infant mortality rate in A- for the past ten years has been 205 per I,000 births. The highest rates were, in 1895202 , in 1899220 , and in rgor 235. The lowest were, in r894 170 and in $1902 \mathrm{r} 84$.

"The average birth rate for the last ten years has been $4 \mathrm{r} 7$. There are upwards of 4,000 houses, and the average number of persons per house is $5^{\circ} 4$. The general average death rate is 22.7 .

"The working classes form at least 75 per cent. of the total population, and about 15 per cent. of the total population are small shopkeepers. The great majority of the men are colliers, or work in iron and steel works, and a few in other employments. There is one cotton mill in the district. Trade is fairly good, but subject to much fluctuation. . . . Less than ro per cent. of the total number of married women are occupied.

"Houses are held on weekly tenancy, and there are no slum areas, as the district is open everywhere. There are a good many 
old houses with common yards, but not many back to back. The yards of the older property are often unpaved and wet and dirty at times. The property built in the last ten years is better and with separate yards, not always flagged. The sanitary conveniences used in the town are privy-middens almost entirely. . . . I have often seen little children, even babies, playing and crawling about closets and middens, though we have a well laid-out park with plenty of grass open for children to play on, but it is little used.

"There is a great deal of poverty, especially in summer, improvidence, and drink, much as in other places-far too much. Ignorance, especially as to the care of infants, is almost universal, and carelessness is unfortunately much too common. . . Infants are usually put into a 'burying club' at birth, but all the parents draw in the event of death is 3 os., which only pays the funeral. It is the usual custom. . . Nursing-out or baby-farming is very rare, though there may be a few cases here and there. I should say about 30 or $4 \circ$ per cent. of all the infants are breast-fed, but I cannot be more definite. Of artificial food used by far the commonest is condensed milk, one or other brand, and then various advertised patent foods-very little fresh milk. The old-fashioned long-tube baby's bottle is very largely used. Of the reasons given for not feeding the child by the breast I have heard many. The commonest is perhaps that 'the child never seems satisfied,' or 'it cries.' Sometimes the mother has no milk, and this, I fear, is fairly common, especially after a month or two. Then a good many will not be 'tied.' It is 'too much trouble, can't attend to the house,' and so on, though I have not often heard this openly admitted."

The medical officer then furnishes me with particulars as to the causes of death, of which he names four as the chief: Diarrhœa, bronchitis, prematurity, and atrophy. From an examination of his official annual reports the following facts may be stated:-

Diarrhoea is the cause of some 25 to 27 infant deaths a year, though in the last four years the number has risen to an average of 39 . The large 
majority (90 per cent.) occur in hand-fed infants, and especially those fed on condensed milk which becomes contaminated and infected in the home. An inquiry into the deaths of 21 infants a year or two ago revealed the fact that the parents of these 2 I children had previously given birth to 98 children, of whom 55 had died in infancy. This would yield an infant mortality of 56I per I,000 births. The medical officer attributes the heavy mortality from diarrhœa in A- generally to poverty, drink, and lack of mothers' milk, and in particular to ignorance or carelessness, dirty bottles, improper food, and irregular feeding.

Bronchitis and Pneumonia produce some 35 or 40 infants' deaths per annum in this town, in many cases, it is reported, due to carelessness and ignorance on the part of parents. It appears that infants are left in charge of children hardly any older than themselves, and frequently exposed to cold air or wet clothing.

Prematurity carries off between 40 and 50 infants every year. This cause of infant death is attributed to poor health, underfeeding, and want - of care on the part of mothers, and to repeated pregnancies.

The medical officer of this town concludes his letter as follows :-

"I regard the heavy infant mortality [205 per 1,000 births] in this district as due in the main to social evils. Poverty, whether through lack of employment or drink, the dirty state in which houses and children are kept, and the ignorance and carelessness as to feeding and care of infants, are the main factors. So high a birth rate as we have in A- must mean poverty among the labouring classes, 
for the wages do not expand with the family, and the margin is at best small. It also helps to keep the mothers in poor health, and aids the establishment (through poverty) of the too common diet of tea and bread and butter. Most of the girls start with anæmia and chronic stomach complaints through this tea and bread-and-butter diet. They marry early, and soon have a succession of puny children, of whom perhaps half survive infancy.

"I do not think the sanitary condition of A- is worse than that of other similar districts. We have many yards still unpaved and common yards. We have the privy-midden system, which is bad, but against that we have no large congested slum areas, though there are houses here and there in many streets which taken by themselves are almost as bad inside as slum houses. But this is due in most cases to dirty tenants. By attention to the housing question and other sanitary improvements the general death rate has been reduced in the last 15 years from an average of 26 or 27 per I,000 to 20 or 21 per I,000. But the Infant Mortality is untouched, which seems to me to point distinctly to the truth of the view I take."

\section{(c) Alcoholism.}

Before mentioning the relation of alcoholism to infant mortality in the mass it is necessary to determine, if possible, the prevalence or otherwise of alcoholism amongwo men.

In 1894 Dr. Norman Kerr wrote that "England occupies the unenviable position of having a greater proportion, a proportion which has been steadily increasing of recent years, of cases of female inebriety than any other country. ... Twenty years ago I rarely ever saw a female drinking at a bar of a public-house or a beer-house. Now I see numbers so engaged from 
an early hour in the morning-not a few of these early risers and early drinkers having had an infant at the breast, and giving the child a share of the morning dram. ... Prison experience shows a marked increase of female inebriates." $x$ This opinion appears to be founded on personal observation-which, if accurate, is important evidence-and police returns. As to the former it is, of course, impossible to speak. The opinion is often expressed that alcoholism among women is not only prevalent but increasing. But the opinion may be incorrectly formed or based upon such limited experience that its value is relative only. To entitle such opinion to consideration it is necessary that is should be formed upon a wide body of actual facts, and not upon mere prejudices or assumptions. Even police returns may vary on account of alteration in law, custom, or standard of drunkenness. It appears that 28-30 per cent. of the total number of offences due to drunkenness are committed by women. In 1875, in the Metropolitan Police area, 47 per cent. of the total number of arrests for drunkenness were women, and in 1898 this had fallen to 39 per cent. In Manchester (1872-76) the percentage of female arrests was 29 per cent., which steadily rose to 37 in 1895 . In Liverpool there has been a decline from 26 per cent. in $1876-80$ to 24 per cent. in $189 \mathrm{I}-95^{2}$ In a similar

Inebriety or Narcomania (1894), pp. I58-159.

2 "These numbers of prosecutions for offences of drunkenness, as I have pointed out on more than one occasion, do not form a reliable measure of the vice of intemperance. It may be that intemperance among women is on the increase, as is so generally suggested, but that is a question beyond the scope of police statistics, and I feel bound to point out that offences of drunkenness by women are not on the increase.

"Public opinion is being increasingly directed to the deplorable amount of drinking by women, and it is quite possible that the extra light thrown upon a long-existent evil has produced the idea that it is a growing one. Whether it is a growing one or not, it is an enormous one ; and it is to be hoped that something can be done to save the homes of the working classes from the harm done by the women starting out to drink with each other as soon as they have seen their husbands off to work" (extract from Report on Police Establishment and the State of Crime, Liverpool, 1905). 
period there has been a slight rise ( 30 to 32 per cent.) in Glasgow, and also in Belfast from 1891 to 1897 (29 to 30 per cent.). In Dundee from 1857-61 the percentage of female arrests for drunkenness was 35 . It fell to $3 I$ in $1877-81$, and rose to 38 in $1892-96.1$ It is evident that there are local variations, and for reasons already stated such returns do not guide us accurately.

Another means of estimating the matter is by the death rates from alcoholism among women. In the Appendix (p. 34I) will be found a table comparing the death rates per million quoted from the annual reports of the Registrar-General. This shows that in I875 the death rate per million from alcoholism and delirium tremens among males was 73 and among females 24 ; in 1904 these figures had increased respectively to 85 and 55 . If the quinquennial periods be taken (1875-9 and 1900-1904) the rate per million in males rose from 65 to 105 , an increase of $6 \mathbf{I}^{\circ} 5$ per cent., and that for females from 25 to $7 \mathrm{I}$, an increase of 184 per cent. This change is so marked, and throughout the thirty years the rise is so steady, that it would seem to present a more satisfactory basis for opinion than police returns. But here also there are fallacies dependent upon medical diagnosis, certification, and custom, and upon the disease-producing effect of alcoholic beverages, which is by no means a constant quantity. On the whole, however, and after making allowances, they probably indicate the direction in which things are tending, namely, to increasing fatality, particularly among women.

In giving evidence before the Interdepartmental Committee on Physical Deterioration, Sir Charles Cameron and Sir L. Ormsby stated that in Dublin, in their opinion, the drinking of alcohol among women was increasing.

The Temperance Problem and Social Reform, by J. Rowntree and A. Sherwell, seventh edition (I900), pp. 85-87 and 677-679. 
Dr. Eichholz, Dr. Jones, and other witnesses spoke to a similar increase among women in England, and Dr. Scott believed the same was true of Glasgow. Of the women admitted to the Claybury Asylum in 1903 suffering from alcoholic insanity 80 per cent. were married, and many had families dependent upon them.

Mr. Charles Booth, in his inquiry into the life of the people of London, collected evidence from a variety of persons, most of which went to show increased frequenting of the public-house by women.

"As regards women: 'Many more women are seen in publichouses; the middle-aged are the drunkards, not the young. Young people do their courting in public-houses, since both sides are rather ashamed of their homes, and like to make themselves out a class above what they are. The young men treat the girls to a glass of wine. No harm comes of it. It is not till they get older that women take to gin and ale and become regular soakers.' Again: "Girls begin when they first go out "keeping company"; neither sex become confirmed soakers before twenty-five or thirty, or with women till after marriage. The drunkards are probably married women.' Another police officer said, 'Drunkenness among women is on the increase,' but added that he had never seen a girl under fifteen drunk, and that it was never common before marriage. "They take too much at times, but are surprised at their own state. They do not drink for drinking's sake, and very little upsets them, especially on an empty stomach. That is why so many are noisy on Saturday, when they are paid and let out early, having had no lunch. They take a nip and become hilarious in no time.' And another says : 'Factory girls drink, but it is more often the young married women and the middle-aged who indulge too much. Men drink beer; women more often spirits. Women drink more than they used to, perhaps because they earn more.'

"'There are various classes of women drinkers: the factory girl who drinks once in a way, the prostitute who drinks in the course of business and very seldom gets drunk, the 
laundry-woman who drinks by reason of the thirsty nature of her trade, and the married woman who drinks because her husband drinks.' 'Women have lost all shame of entering a public-house, and as they never drink singly, the evil spreads.' 'Public-houses are more attractive than they were; ladies' saloon bars are to be seen everywhere. Publicans tell you that it is in response to a demand, but it is difficult to distinguish between cause and effect.' Such are other police opinions.

"The clergy of the Church of England, Nonconformist ministers, and schoolmasters may be quoted to the same effect, though perhaps in some cases with more of a teetotal bias, or with less sense of proportion. That 'drinking has increased enormously among women' is heard again and again, very rarely anything to mitigate this opinion, only that it is added, "Young women do not get drunk, unless on bank holidays or at marriages or funerals.' 'Drink worse than ever,' we are told, ' especially amongst women'; and this it is felt is 'a funny thing in face of all the agencies.' 'Women drink to excess more than men. They take to it largely to carry them through their work.' And again: 'The women are worse than the men, but their drinking is largely due to their slavery at the wash-tub.' Of the same class it is said, 'Nearly all get drunk on Monday. They say, "We have our fling; we like to have a little fuddle on Monday." And of a yet lower class we hear that they "live on four-ale and fried fish.'

"The master of a poor school speaks of the habit of drinking among the women being very general; 'even quite respectable mothers, when they come to see him in the morning, nearly always smell of drink.' Two other masters also mention the large proportion of mothers who smell of beer when they come to see them at the schools ; while a schoolmistress, 'judging from the women who come to see her, infers that nearly all have a morning dram.' 'The poorest and most destitute seem,' she says, 'to look upon drink as the first necessity of life.' A boardschool teacher at school in a poor neighbourhood says that the attendance is worst early in the week, while the public-houses are full of women; 'the children being at home while the mothers drink.'

"The increase of the habit among women still applies as we 
pass slightly upwards in the social scale. It is said to be 'the regular thing for women to go in and have a drink when shopping '; and another witness notices the 'marked increase' in the number of respectably dressed young women who drink.' They may be respectable as well as respectably dressed. One of the East End clergy told how a woman who had been talking to him on the subject said, 'when she was young no one would have dreamt of going inside a public-house. But things have altered. Her son is engaged, and the girl goes with him there sometimes. In earlier years you would have put her down as not respectable, but not so now.' A member of an Anglican Sisterhood put it that 'the time had long since gone by for regarding it as a scandal that a woman should drink at a public-house.' And an 'old resident,' speaking of the increase of drinking among women, says: 'You cannot but see it; respectable women go into publichouses without any compunction, a sort of thing never seen until late years.'

"Amongst the better-to-do, also, drinking is stated to be worse than it used to be, 'especially among women.' 'Every doctor will tell you that women have acquired the habit of "nipping." " Some (said the witness) accuse grocers' licences, but he did not himself attach much importance to them. The real reason was, he said, that the women had so little to do. 'All round London are growing up suburbs of small houses, whose occupants have just enough to live on comfortably. Women left at home; small ailments ; immediate stimulus of drink ; that is how it begins.' Another agrees that 'the habit of drinking among women is most often contracted by young wives whose husbands are away all day.' 'Shop-girls who marry find the loneliness in the suburbs unbearable after shop life.' Emphasis is also laid by many on the increasing amount of secret drinking amongst strictly middleclass women, and the taking of morphia and other drugs, as a result, perhaps, of home troubles, and medical men are blamed for not being careful enough when they prescribe stimulants. But the most objectionable drinking is described as being found among retired men of the class who have nothing to do, and pass their time in going from saloon bar to saloon bar. Thus do 'city habits lead to disaster.'

"Of the increased and respectable uses made of public-houses 


\section{DOMESTIC AND SOCIAL CONDITIONS 209}

by young women we have, as our quotations show, heard much; and it may be noted that the age of limitation, the age at which liquor may be supplied to the young, agrees with their natural tastes; indeed, sweets remain in the ascendant for some years longer with most young women. Alcohol is seldom any temptation to the young, but, nevertheless, the habit may be acquired and become a temptation later. It is directly on this account and indirectly on others, that legislation has been introduced to check the practise of sending children to fetch the drink required by their parents."x

But the evidence on the matter is not wholly in support of the view that alcoholism is increasing among women.

Dr. Arthur Shadwell holds "that so far from women having recently taken to frequenting the public-house they have never frequented it less." 2 At the same time he remarks elsewhere, speaking for England, that "we certainly have a class of women already numerous and probably increasing who are a source of great national weakness. They are ignorant, idle, extravagant, and self-indulgent. They neglect their children and their homes, they drink and bet, and they exist in all ranks of society. The wretched appearance of so many working-class homes and children, which constantly horrifies visitors to this country, is quite as much due to this type of woman as to the self-indulgent man who matches her. Neither in America nor Germany nor in any other country that I have seen do women drink and bet as they do here." 3

Again, according to the "National Drink Bill" 4 the total

- Life and Labont of the People of London, by Charles Booth. Final volume. London, 1890-1900, pp. 6r-65.

2Drink, Temperance, and Legislation, I902 ; and Industrial Efficiency, I906, vol. ii. pp. 279-289.

3 Industrial Efficiency, vol, i. p. 44.

4 Times, March 6, 1906. 
expenditure in the United Kingdom in 1905 on distilled and fermented liquors was $£ \mathrm{I} 64,167,94 \mathrm{I}$, a decrease of $£ 4,819,224$ on 1904 . Indeed, there has been a decrease of $£ 21,759,286$ during the last six years. The average expenditure per head is now $£_{3}$ I5s. II $\frac{1}{2} \mathrm{~d}$., and per family of five persons $£$ I 8 19s. $9 \frac{1}{2} \mathrm{~d}$. The twelve most populous towns spent $£ 38,065,196$, or about 23 per cent. of the national expenditure on intoxicating liquors in 1905. ${ }^{\mathrm{x}}$

I have elsewhere referred to the results of alcoholism in women to infants in their charge (see p. 77). To that reference it is now only necessary to add two further facts which belong more appropriately to this chapter. The first is that there is reason to believe that exceptional mothers of the more careless class actually give alcohol in the form of brandy or spirits to their infants. This has evidently been done in some continental countries (see p. 236), and possibly to a small extent in this country. Here and there one has come across such cases, but they are happily few and far between. It is needless to say that alcohol is almost absolutely a poison to infants. There is no ground for believing that any perceptible portion of the infant mortality is now due to this cause. On the other hand, there is a body of unpleasant figures which show that some 500 to 600 infants are "overlain in bed" in London every year (584 in 1904). In the country generally this form of death claimed I,899 victims in 1904 . The Registrar-General discussed the distribution of these deaths in his Annual Report for I89o (p. xvi) and found from 2,020 inquests that the occasion of their occurrence was as follows :-

I These figures and the returns of alcoholic mortality (Appendix, p. 34I) concern recent years only. It should not, however, be forgotten that there is reason to believe that alcoholism was more prevalent formerly than now (Lecky, Hist. of England in Eighteenth Century (I878), vol. i. chap. iii. p. 478 et seq. ; and Traill, Social England, vol. vi. p. 862 et seq.). 


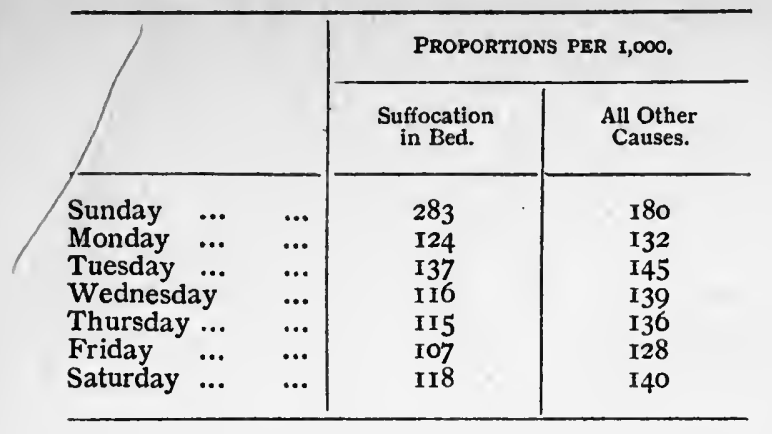

Suffocation in bed occurs mostly amongst the youngest infants, is more frequent in winter than in summer, is highest in the poorer districts, and usually more than twice as high on Saturday night and Sunday morning than on any other night in the week. The mother is at home, and there is more money in the family exchequer than at any other time in the week, so that the cause of this distribution of deaths cannot be due to absence of mother or shortness of food. It is more probably due to neglect or alcoholism. This cause of infant mortality is comparatively rare in Germany, owing to less alcoholism among women and to the fact that under Section 22 of the Penal Code the Public Prosecutor may charge the parents for "causing the death by carelessness." I

\section{(d) Birth Rates and Illegitimacy.}

It is frequently said that one of the causes of a high infant mortality is a high birth rate, and that where the latter obtains the former occurs. As a matter of fact this is by no means always the case. Ireland is an example in point. The birth rate is high, one of the highest as measured by fertility in Europe, and actually high in Dublin, but the infant mortality rate is low, even in

' See Brit. Med. Fourn., I903, ii. 1208. 
Dublin comparatively low. And there are instances of high birth rate and low infant death rate to be found elsewhere. But it may be admitted that very frequently districts yielding a high birth rate do also yield a high infant mortality, but this is due in large measure to the fact that the social conditions are favourable to both issues. For example, both occur in overcrowded districts, where there is a high proportion of people at childbearing ages. It is the facts of social position rather than the high birth rate which are the cause of the high mortality.

But to argue that a high birth rate necessitates a high infant death rate because there are more infants to die is to forget the influence of the birth rate upon the age-constitution of a population. An exceptionally high birth rate in one year out of a series of low birth-rate years might have the effect of increasing the number of deaths of infants and the total death rate. Dr. Newsholme has clearly stated the position in the following words: "It is evident," he says, "that if, owing to a high birth rate, there is a larger proportion of children in one community than in another, and the relative hygienic conditions of the two are equal, there will be more deaths of children in the former; and inasmuch as the rate of young children is higher than that of all others except the aged, the general death rate will be raised. But if the high birth rate be continued there will not only be a large proportion of children, but of others between 10 and 40 years of age, at which ages a low rate of mortality holds; and this factor counterbalances the other and causes a continued high birth rate to be associated with a low death rate." I

The relation, however, between the birth rate and infant mortality is of importance for three reasons. First, it is evident that however serious a high infant

Vital Statistics, pp. 96 and 133-4. 
mortality may be to a State with a high birth rate, it assumes increased gravity if the State have a low birth rate, for in such event the candle is being burnt at both ends. There is a smallness of output in births, and the output falls short of survival. If such conditions continue the physical life of such a nation is jeopardised. No one can read the conclusions of the Royal Commission on the Decline of the Birth Rate in New South Wales without realising the gravity of such a situation. In this country we also have a declining birth rate and a stationary and somewhat high infant mortality rate, which react upon each other, enhancing their importance to the State. "With the maintenance of high rate of natural increase is inseparably connected the preservation of infant life. We have shown that the defective birth rate is aggravated in its effects in reducing the natural increase by an excessive death rate among the newly born." I

Secondly, infant mortality has relation to the birth rate of illegitimate children. A child born out of wedlock is described as illegitimate. In 1858 there were 66 illegitimate births in every 1,000 births, since which date there has been a steady decline to 39 in 1903. The lowest proportions of illegitimate to total births occur in Monmouthshire, Essex, and Middlesex; the highest in Norfolk, Shropshire, and Herefordshire. Now, whilst there is no direct relation between a high illegitimate birth rate and a high infant mortality rate as they exist in counties, for the reason that there are many other factors affecting the question, it is well known that the mortality among illegitimate infants is much in excess of that of legitimate infants. Dr. Tatham drew up for the Interdepartmental Committee on Physical Deterioration a table which will be found in the Appendix (p. 342), and which puts the whole matter clearly both as regards London and certain rural

\footnotetext{
'Roy. Com. on Declining Birth Rate in N.S. Wales, Report, vol. i. p. 53.
} 
counties. From that table it will be seen that in London the illegitimate infant mortality is nearly double that of the legitimate, and in syphilis, in diarrhœa, and in atrophy more than double. ${ }^{I}$ Among male infants, indeed, the syphilis mortality is ten times greater among the illegitimate. Prematurity and congenital defects also cause excessive mortality among the illegitimate, especially in London. Comparison of the figures for London with those for the rural counties shows a great excess of mortality among illegitimate children in the former area; for, whereas, among legitimate children in London the death rates are in excess of those in the country by about onefifth part, among the illegitimate the London rates exceed the country rates by more than 50 per cent. among boys and by nearly 60 per cent. among girls.

Farr showed the heavier incidence of death upon illegitimate children in Glasgow as far back as I873, viz., 293 per I,000 compared with 154 for legitimate. Hence whilst illegitimate births form 4 per cent. of the total births, the deaths of illegitimate infants form between 25-30 per cent. of the total infant deaths.

In New South Wales in the years 1895-1902 the infant mortality of legitimate children was 98.5 per 1,000 as compared with 277.4 for illegitimates, which is two and three-quarter times higher. Taking the legitimate infants alone, 49. 1 per I,000 die during the first three months of life as compared with $145^{\circ} 9$ per $I, 000$ of illegitimates, which illustrates the fact that the illegitimate infants die early as well as from subsequent disease within the twelve months. In the second year of life the death rates of illegitimates are only one and one-third times higher, and in the third year no higher at all than those of the legiti-

I The figures are similar for other large towns. In Manchester in the decennium 1893-1902 the illegitimate infant mortality was $396^{\circ} 4$ per 1,000 births compared with $178 \cdot 4$ among legitimate infants. 
mate infants. The high returns of illegitimate infant mortality in New South Wales are particularly striking when it is remembered that the environment of New South Wales is so favourable to infant life that it enjoys one of the lowest of all national infant mortality rates. ${ }^{x}$

The causes of death in illegitimate infants are the causes of death in legitimate infants plus maternal indifference and social and economic disabilities of the mothers, the separation of infants from mothers, the secret adoption of infants for gain, and various rapid or slow forms of infanticide. The chief of these in actual terms of disease are diarrhœa, atrophy and inanition, and syphilis.

There is a third way in which infant mortality bears an important relation to the birth rate. This concerns the causes of a low birth rate. The Royal Commission in New South Wales found that there had been a very marked decline of birth rate in that country since 1889 amounting to 2.23 per 1,000 , with a definite tendency to decline commencing some few years anterior to 1889 , and followed by a continuous and rapid decline until in 1902 the total decline had exceeded Io per I,000 of the population (from $33^{.6}$ in 1871 to 23.3 in 1901 ). From the evidence placed before them, the Commission found that the main factor in producing this decline (which is shared by all the Australian States and New Zealand) was independent of any variation in age constitution of the population or of women of conceptive age, independent also of physiological tendencies towards lessened fertility or variation in marriage or other natural causes. The Commission held that the main factor was: "There was a diminution in fecundity and fertility in recent years due to the deliberate prevention of conception and destruction of embryonic life, and to pathological causes consequent upon

* See Appendix, p: 343. 
the means used and the practices involved therein." I These conclusions cannot here be considered, but the reader of Chapter IV. will not be slow to understand that what the New South Wales Commission calls "preventing conception by artificial means" and the marked increase of "induced miscarriage" may be operations having pernicious effects upon the life of infancy. In a word, the same practices which lower the birth rate tend to raise the infant death rate.

It will thus be seen that domestic and social conditions are exerting considerable effect upon the incidence of infant mortality. Much of it is no doubt due indirectly to unsatisfactory housing conditions. It is now well known that "slum" areas yield high death rates. ${ }^{2}$ But

x Report I904, vol i. pp. I4-I5. The Commission attribute the tendency to which reference is made in these words to $(a)$ the idea that want of adequate means is a sufficient justification for interference with the course of nature, and (b) unwillingness to submit to the strain and worry of children; a dislike of the interference with pleasure and comfort involved in child-bearing and child-rearing. Upon this subject Drs. Newsholme and T. H. C. Stevenson have recently written a valuable paper entitled The Decline of Human Fertility in the United Kingdom and Other Countries as Slowen by Corrected Birth Rates (Roy. Statistic. Soc., Dec., 1905), which should be consulted by students of this question. They conclude that in the majority of countries for which corrected statistics could be calculated, that there has been a great decline in the corrected legitimate birth rate, and an even greater decline in the corrected illegitimate birth rate. The former might be due to an increased number of sterile marriages or to smaller families. The authors believe it to be the latter, as there is no evidence of decreased fecundity. They therefore believe the fall in the birth rate is due to conditions within the control of the people, and is a form of social felo de se. In this country rural birth rates have declined more than urban birth rates, and among the rich in London the prevention of child-bearing appears to be largely practised, being probably less so ainong other classes.

2 In the Aylesbury Place area (in Finsbury), condemned under the Housing of the Working Classes Act, the average annual infant mortality for 1895-1899 was 447 per I,000 births, as compared with I68 for the parish in which it was situated, and 165 for London. After its "representation," and previous to demolition, this insanitary area grew steadily worse, and the infant death rate rose even higher than the enormous figure quoted above. (Some Notes on the Housing Question in Finsbury, I901, p. 3I, and Report on Health of Finsbury, I902, p. I34.) 
that this is not merely a simple relation of poor housing to the death of infants becomes clear when we turn to the infant mortality of certain parts of Scotland and Ireland, where crofters and fishermen are living in veritable hovels, amid gross forms of insanitation, and overcrowding of

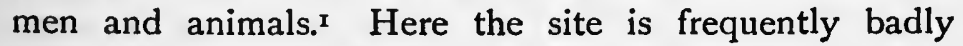
selected, and is damp and polluted; the crofter's cabin itself is dark, damp, and unventilated; the third compartment is for the cattle; and the whole is undrained and overcrowded. And yet the average infant mortality is lower than in any county of England. Subsequently we shall discover the cause of this remarkable immunity. Here it is only necessary to note that it is not good or bad housing of itself which affects the problem. It is the results of overcrowding which, in their turn, act as causes of infant mortality.

"Carelessness on the part of mothers is an accompaniment of overcrowding, and to these causes was ascribed the high death rate among infants under five years of age in certain areas which were the subject of special investigation." So concluded the Royal Commission on the Housing of the Working Classes. And the Report continues :-

"But there is a great deal of suffering among little children in overcrowded districts that does not appear in the death rate at all. In St. Luke's ophthalmia, locally known as the blight, among the young is very prevalent, and can be traced to the dark, ill-ventilated, crowded rooms in which they live; there are also found scrofula and congenital diseases, very detrimental to the health of the children as they grow up. Among adults, too, overcrowding causes a vast amount of suffering, which can be calculated by no bills of mortality, however accurate.

- See, for example, Sixth Report of Local Government Board for Scotland, I901, p. 79, and Eighth Report, 1903, p. 65. 
Even statistics of actual disease consequent on overcrowding would not convey the whole truth as to the loss to health caused by it to the labouring classes. Some years ago the Board of Health instituted inquiries in the low neighbourhoods to see what was the amount of labour lost in the year, not by illness, but by sheer exhaustion and inability to do work. It was found that upon the lowest average every workman or workwoman lost about twenty days in the year from simple exhaustion, and the wages thus lost would go towards paying an increased rent for a better house. ... That overcrowding lowers the general standard, that the people get depressed and weary, is the testimony of those who are daily witnesses of the lives of the poor. The general deterioration in the health of the people is a worse feature of overcrowding even than the encouragement by it of infectious disease. It has the effect of reducing their stamina, and thus producing consumption and diseases arising from general debility of the system, whereby life is shortened. Nothing stronger could be said in describing the effect of overcrowding than that it is ever more destructive to general health than conducive to the spread of epidemic and contagious diseases." $x$ And it is this decline in physical stamina among an overcrowded population that leads to premature birth, to lack of maternal nourishment, and to carelessness and degeneration.

Recently inquiries have been instituted in two typical high-mortality towns as to this very point of the influence of domestic and social conditions on the death of infants, namely, at Preston and at Dundee. Amid many differences there is a significant similarity in the two reports. We have already quoted the conclusions respecting the Committee of Inquiry at Preston.2 The results of the

Report of Roy. Com. on the Housing of the Working Classes, 1885, p. I4.

- Vide supra, pp. 134-136. 


\section{DOMESTIC AND SOCIAL CONDITIONS 219}

inquiry in Dundee show that housing is often poor, that overcrowding frequently exists, that there is lack of ventilation and cleanliness, but the chief emphasis falls upon negligence and ignorance. In the three years' observations at Dundee young children and infants were found left alone or in charge of incapable persons in 207, 237 , and 147 cases respectively, and the two lady health visitors sum up their report in these words :-

"The greatest difficulties experienced in our work arises from the indifference, thriftlessness, and the intemperance of a considerable number of the persons visited. Most of the cases of neglect of home and children proceed from drunkenness on the part of one or both parents, and from a want of knowledge on the part of many women as to the judicious spending of their money on cheap and nutritious articles of food. With many of them their staple diet is tea, with bread and butter, and from want of knowledge or from laziness they do not use many cheap or nourishing foodstuffs which require cooking. In such cases we do what we can to instruct them in this matter.

"We have been specially struck with the large amount of drunkenness which prevails amongst the women of the lower classes, especially on Mondays, when we frequently find several under the influence of drink congregated in a house which is dirty and neglected." I

It is clear that it is not external environment which only, or in fact mainly, affects the problem under consideration. During the last half-century external environment has enormously improved, and the advance has never been greater than in the last twenty-five years. ${ }^{2}$ Yet

Report of Medical Officer of Health of Dundee, 1905, p. 31 ; see also Report of Local Government Board for Scotland, 1904, pp. 157-158; and Child Mortality in Dundee (Dr. Templeman), 1898.

2 Report of Interdepart. Com. on Physical Detcrioration, vol. i. pp. 14-I 5. 
infant mortality remains as grave a problem as ever. And we shall not, perhaps, be far from the mark if in judging of the evil effects of bad housing and of poor social conditions we give chief place to the "laziness, want of thrift, ignorance of household management, and particularly of the choice and preparation of food, filth, indifference to parental obligations, and drunkenness," which "largely infect adults of both sexes, and press with terrible severity upon their children." I "The people perish," it has been truly said, "for lack of knowledge."

Report of Interdepart. Com. on Physical Deterioration, vol. i. p. 15. 


\section{VIII}

\section{INFANT FEEDING AND MANAGEMENT}

T T has probably become increasingly evident to the 1 student of the facts set out in the previous chapters that infant mortality is a social problem concerning maternity. From questions of occupation and environment, even from the question of earth temperatures, we must turn in the last instance to the actual feeding and management of an infant by its mother. The young of all animals are profoundly susceptible to their upbringing. The human infant is no exception. Therefore, more than any other single agency, infant mortality depends upon infant rearing. Ignorance and carelessness as to the physical necessities of life may mean little to the adult, but they are unpardonable where infancy is concerned, and may as likely as not result in death to the new-born child. And, expressed bluntly, it is the ignorance and carelessness of mothers that directly causes a large proportion of the infant mortality which sweeps away every year in England and Wales alone 120,000 children under twelve months of age. This ignorance reveals itself in many ways, but chiefly, perhaps, in feeding, uncleanliness, and exposure. $\mathrm{x}$ These influences operate amid every sort

- The means of estimating degrees of ignorance are indirect, and depend partly upon observation and general experience, and partly upon statistics of illiteracy. In the following table will be found the number of married women in the forty-two counties of England and Wales-counting Wales as two-who in 1900 werelunable to sign the marriage register, which fact 
of external environment, good, bad, and indifferent. It has been found, for example, that in the worst districts there are many instances in which parents have successfully reared every member of a large family, whilst side by side with these there are numerous examples of death in

is accepted by the Registrar-General as a rough test of illiteracy in married women. The average works out at about $25^{\circ} 30$ per thousand.

\begin{tabular}{|c|c|c|c|c|c|c|c|}
\hline \multicolumn{2}{|l|}{ County. } & $\begin{array}{c}\text { Infant } \\
\text { Mortality } \\
\text { Rate, } \\
\text { 1891-1900. }\end{array}$ & $\begin{array}{l}\text { Illiterate } \\
\text { Women } \\
\text { per } 1,000 \\
\text { Married. }\end{array}$ & \multicolumn{2}{|l|}{ County. } & $\begin{array}{c}\text { Infant } \\
\text { Mortality } \\
\text { Rate, } \\
189 \mathrm{I}-1900 .\end{array}$ & $\begin{array}{l}\text { Illiterate } \\
\text { Women } \\
\text { per } 1,000 \\
\text { Married. }\end{array}$ \\
\hline Dorset & $\cdots$ & 102 & I4 & Northampton & ... & 133 & 23 \\
\hline Wilts ... & $\ldots$ & 102 & I2 & N. Wales ... & $\ldots$ & 135 & 52 \\
\hline Westmorelar & & 107 & 22 & Middlesex & $\ldots$ & 139 & I2 \\
\hline Rutland & $\ldots$ & Iro & 23 & Essex $\quad \ldots$ & $\ldots$ & I4I & 23 \\
\hline Herts ... & ... & IIO & 22 & Cornwall ... & $\ldots$ & I4I & 42 \\
\hline Hereford & ... & 112 & 34 & Worcester & $\ldots$ & I4I & 37 \\
\hline Bucks... & ... & II3 & II & Lincoln $\quad .$. & $\ldots$ & 142 & $2 \mathrm{I}$ \\
\hline Oxford & $\ldots$ & II 3 & I4 & Norfolk ... & ... & 142 & 24 \\
\hline Shropshire & $\ldots$ & II 4 & 28 & Derby $\quad .$. & ... & 146 & $2 \mathrm{I}$ \\
\hline Berks ... & ... & II 4 & I7 & N. Riding & $\ldots$ & 146 & 36 \\
\hline Somerset & $\ldots$ & II 4 & 23 & Monmouth & $\cdots$ & 152 & 64 \\
\hline Hunts... & ... & II 8 & 6 & Cheshire ... & $\ldots$ & I56 & 30 \\
\hline Sussex & ... & I 18 & IO & Northumberland & H... & $16 \breve{I}$ & 34 \\
\hline Suffolk & ... & I2I & 20 & S. Wales ... & $\cdots$ & 163 & 50 \\
\hline Surrey & $\ldots$ & I 22 & IO & Leicester ... & $\ldots$ & 164 & 18 \\
\hline Cambridge & $\ldots$ & I 24 & 28 & W. Riding & $\ldots$ & 164 & 39 \\
\hline Bedford & $\ldots$ & 126 & 24 & Notts $\quad \ldots$ & $\ldots$ & 164 & 33 \\
\hline Hants... & $\ldots$ & 127 & II & E. Riding... & $\ldots$ & 166 & 24 \\
\hline Gloucester & $\ldots$ & 128 & 29 & Durham ... & $\cdots$ & I67 & 40 \\
\hline Kent ... & $\ldots$ & I29 & I7 & Warwick ... & $\ldots$ & 169 & 36 \\
\hline Cumberland & .... & 130 & 29 & Stafford $\quad .$. & $\ldots$ & 172 & 44 \\
\hline Devon & $\ldots$ & I3I & I5 & Lancashire & $\ldots$ & I79 & $4 I$ \\
\hline
\end{tabular}

Now if we divide the 42 counties equally in relation to their infant mortality rates, we shall find that only one of the counties (Hereford) in the first 22 with the low infant mortality rates has more than 30 per 1,000 illiterate married women. This may be a coincidence, and the argument must not be pressed too far ; but as a rough test of a relationship between high infant mortality rates and ignorance or slackness as indicated by illiteracy, it is interesting. It should be added that since $1876-80$, when 200 per 1,000 married women signed the marriage register by mark, the proportion has fallen to 37 per 1,000 in $1896-1900$, no doubt owing to the increase in elementary education. In 1903 the figure was 23 . As regards the topographical distribution of illiteracy the Registrar-General remarks that while the number of illiterate females is generally greater than the number of illiterate males in industrial and mining centres, the reverse is the case in the agricultural counties. 


\section{INFANT FEEDING AND MANAGEMENT 223}

infancy, and the distinction between these families has nothing to do with season, and is not wholly one of physical condition of parents, or sanitary condition of home, or even poverty, but it is a distinction of the amount of knowledge and intelligence, attention and care, which the mother is able to bestow upon her offspring. This applies in all times of the year, and not infrequently operates in a family for many years.

Indeed, if we could place two infants of one mother under precisely the same external conditions, good or bad, and feed the one by the breast and feed the other on artificial foods of various kinds, we should at an early stage in the proceedings begin to see a change which would be all the more marked the wider the difference in the methods and materials of feeding. No doubt such practical experiments have often occurred, but it is not often that it is possible to observe them throughout the twelve months.

Dr. Vivian Poore, however, recorded an interesting instance of three infants in one family in good social position. I Two were hand-fed and the third was breastfed. The differences in weight were as follows :-

\begin{tabular}{|c|c|c|c|c|c|}
\hline & & \multicolumn{3}{|c|}{ WEIGHT IN OUNCES. } \\
\hline & & & $\stackrel{\text { I }}{\text { Hand-fed. }}$ & Hand-fed & Breast-fed. \\
\hline \multicolumn{2}{|c|}{ 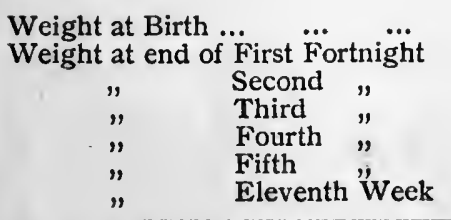 } & $\begin{array}{l}\cdots \\
\cdots \\
\cdots \\
\cdots \\
\cdots \\
\cdots\end{array}$ & $\begin{array}{l}138 \cdot 5 \\
127 \cdot 5 \\
146 \cdot 5 \\
153 \cdot 0 \\
165 \cdot 2 \\
189 \cdot 5 \\
193 \cdot 2\end{array}$ & $\begin{array}{l}145 \cdot 0 \\
151 \cdot 5 \\
162 \cdot 7 \\
170 \cdot 5 \\
172 \cdot 2 \\
175 \cdot 0 \\
180 \cdot 0\end{array}$ & $\begin{array}{l}144^{\circ} \circ \\
164^{\circ} 0 \\
196^{\circ} 5 \\
221^{\circ} \cdot 0 \\
241^{\circ} 0 \\
254^{\circ} 7 \\
265^{\circ} 7\end{array}$ \\
\hline \multicolumn{2}{|c|}{ Percentage of increase from Birth } & ... & $39 \cdot 8$ & $24 \cdot I$ & $84^{\circ} 0$ \\
\hline
\end{tabular}

- Clinical Fournal, I90I (January 9th). 
From I 884 to I 886 Dr. Hope, of Liverpool, made an investigation into the large proportion of deaths of infants from summer diarrhœa, and he reported that "investigation proves incontestably that the deaths of infants from this cause are closely associated with the method of feeding, putrefying food being the medium by which the specific poison is commonly introduced. The deaths amongst children under three months of age, either wholly or partially fed on artificial foods, are fifteen times as great as they are amongst an equal number of infants fed upon breast milk; e.g., investigation has tended to prove that, out of every $r, 000$ infants under three months of age, naturally fed upon breast milk alone, 20 die of autumnal choleraic disease; but if the same number of infants, at the same age, are artificially fed, then, instead of 20 dying, as many as 300 will die from this cause."

The last inquiry of this kind in Liverpool was made in 1904, twenty years later. During the period extending from the last week in July to the first week in October, the infant mortality, which had been normal, approximately I 50 per 1,000 , rose to 567 per 1,000 during the first week in August, and for three weeks it remained at this figure. No less than 1,950 houses where deaths had occurred were visited, and all the circumstances carefully noted. Inquiries elicited all the ordinary phases of the question. First, in regard to the weakness and immaturity, 127 came under this category, 42 of these having survived but a few minutes. Cases of obvious neglect accounted for some 400 , in the great majority of these the parents being intemperate. But this leaves a very large margin unaccounted for. And here comes the remarkable fact that these I,950 families have, as a whole, been particularly unfortunate families in rearing their children. They have had between them a total of 8, I69 children, but out of that total only 4,163 survived. The families, it will be observed, 
were not abnormally large ones, but the rate of mortality amongst them had been actually 490 per 1,000 . On another occasion in the same city it was found that in I2 families there had been in all I I 9 children born alive, of whom 98 had died before their first birthday. It is instructive that out of so large a number of families visited on account of death from infantile diarrhœa, the antecedent history should show so great a sacrifice of life. It is improbable that any other method of selection would find an equal number of families in which the rearing of infants had been attended with so much disaster. ${ }^{x}$

The incidence of a high infant mortality upon poor districts is, as we have seen, almost a universal experience wherever the conditions exist. The overcrowded and poverty-stricken districts of London, the dense populations on the banks of the Tyne, or in the huge manufacturing towns of the north, Glasgow, Dundee, Dublin, the teeming tenements of New York or Chicagothey all tell the same story with one remarkable exception, namely, that where by race or custom it is the practice to feed infants by the breast, the infant mortality rate drops even though the environment be highly insanitary. There is the instance of the low infant death rates obtaining among Jews, Italians, Scotch and Irish, when these races continue, even under adverse circumstances, to feed their infants by the breast. In I903 I made an inquiry for the Royal Commission on Alien Immigration into the mortality of Italians in the "I talian Quarter" in Finsbury as a result of which it was shown that the infant mortality for the Italians in the Quarter during $1901-1903$ was 140 per I,000, as compared with 167 among the English living in the Italian Quarter (in. 1903 there were no deaths of infants among the English; the rates for 1901 and 1902 were respectively 259 and 242 
per 1,000, as compared with the Italian infant mortality for those two years of 106 and 192). $\mathbf{x}$ These people were all living under the same external conditions, but the Italian women breast-fed their infants and the English did not. ${ }^{2}$

In giving evidence before a Committee of Inquiry into the health of the City of Dublin, Dr. Hope, the Medical Officer of Liverpool, referring to this racial characteristic, stated that in that city they found "that amongst the low-class English the loss of infant life is very much in excess of what it is amongst the same class of the Irish population; that the Irish infantile mortality is very much less, taken all round, than the English; and the reason for this is that the Irish mothers suckle their infants much more commonly than English mothers of the same class. The English mothers use bottles and artificial foods, which give rise to this mortality. The Irish mothers, by suckling their infants, give them the proper food at proper temperature, the supply being made when wanted, so to speak. It is pure, natural, unadulterated, clean, and it contrasts very much with the artificial foods given by the English mothers. To this we ascribe the lower infantile mortality from zymotic diarrhœa among the Irish population in Liverpool." 3

I Report on Health of Finsbury, I903, p. 257.

2 Again, the lowest infant mortality in Manchester occurs in the Cheetham Division (9I in I904), which is largely occupied by those of Jewish faith, who, it is true, are temperate and abstemious, but who also as a rule suckle their infants. Dr. Milson Rhodes has also drawn attention (in the Brit. Med. Four., I902, vol. ii. p. 82I), to the fact that the same experience is met with in New York, where the infant mortality in wretched wards in East Side, inhabited by Russian Jews, is lower than for all New York ( 15.9 as compared with $18 \cdot 5$ ).

3 Committee of Inquiry into Health of Dublin, 1900, p. 142. It is interesting in this connection to recall that the infant mortality rate for Ireland is one of the lowest national rates in the world. In Dublin even, where the general death rate is high ( $3 \mathrm{I}^{\circ} 0$ in $1894-98$, as compared with $19^{\circ} I$ in London), the infant mortality rate is 177 , as compared with London 159, and 33 English towns I7I. That is to say, whilst the general death rate of Dublin is 39 per cent. above London, the infant mortality rate is only ro per cent above it. 


\section{INFANT FEEDING AND MANAGEMENT}

One further series of observations may be selected, having relation to the fall which occurs in infant mortality when mothers are compelled to suckle their infants.

The American Civil War broke out in 1861 , and in the following year the import of cotton to Great Britain fell to 524 million lbs., against $\mathrm{I}, 257$ millions in $186 \mathrm{I}$. The war closed in 1865 , and trade with America was resumed, the imports rising again to 1,377 million lbs. At the crisis of the famine the mills in Lancashire were not working more than half time, and in December, 1862, 247,000 cotton operatives were out of employment, and 165,000 others only partially employed. Twenty-four per cent. of the total population in the affected districts were in receipt of charitable relief: The result of the privation existing was an increase in the general death rate, whereas the infant mortality rate declined. In Lancashire in 1861 the infant death rate was 184 , but in 1862 it fell to 168 , rising gradually again to 200 in 1866 . In England and Wales in the same period it fell to 142 (in I862), rising again to 160 in $1865-66$. For Coventry, too, owing to trade depression, in $186 \mathrm{I}$ there was a decline in infant mortality, which led the Registrar-General to remark that "the care of the mothers of Coventry has, it would seem, counteracted some of the effects of privation, so that neglect of their homes by mothers at work in factories is apparently more fatal than starvation." A somewhat similar condition of things has been found to prevail at Macclesfield when the silk mills are closed or working part time. During the siege of Paris (1870-71) also it is alleged that while the general mortality was doubled, the infant mortality fell 40 per cent. The interpretation of these facts is believed to be that in times of trade depression the women stop at home, and tend and suckle their infants more than in times of prosperity. 
These facts may serve as introduction to this branch of our subject. They are, however, insufficient for our real guidance. What is necessary to elucidate this issue and to indicate the directions for reform is something more intimate and based upon the most careful inquiry. We want to know, in the first place, why it is that the infant mortality rates of various countries differ so widely. . If it be true that infant mortality in the last resort is a matter of infant feeding, we require more information on the manners and customs of countries where infant mortality is low and of others where it is high. We may be sure that a problem which concerns most of the States of Europe is of a nature which, on investigation, should yield useful facts. In casting about for these facts, I came upon an old volume of papers read to the Royal Statistical Society of London forty years ago. Among these there was one by Dr. Farr, in the appendix of which is some valuable evidence collected by him on this very point, furnished by four writers experienced in their respective countries on the matter of infant management. These documents we will briefly consider, for they record a body of invaluable facts quite impossible to obtain now concerning the earlier years of excessive infant mortality in Europe. But we want to know also, in the second place, what is the actual position and custom as to infant feeding in this country where infant mortality is prevalent and otherwise. For that also we shall find the most carefully prepared evidence at hand.

I.

Among the countries of Europe where infant mortality. is low, Scotland and Norway and Sweden occupy the first place. Among countries unenviably affected are France and Austria. These four types will serve our purpose. In each case the infant mortality rates will be stated, to be 
followed by the evidence of four witnesses on the subject of infant feeding.

\section{SCOTLAND.}

Infant mortality (1879), 108; (1883-1892), 120 ; (1893-1902), 127.

DR. Stark, M.D., F.R.S.E.

"With all classes it is known to be essential to the infant to keep it warm" from the very beginning. "It sleeps all night and every night until it is weaned "with its mother. In the upper classes it sleeps at night with the nurse or "in a cradle in which is a flask of hot water."

" Eighty to 85 per cent. of all children born are suckled by their own mothers. .... As a general rule, when the mother is healthy, no infant gets spoon-meat till it is nine months old or has cut its front teeth. The cutting the teeth is generally recognised as the period when it is safe to give artificial food; and the Scotch generally are aware that spoon-meat given before that period is extremely apt to bring on convulsions. It is generally, therefore, withheld till nine months are completed, when the child is weaned, though if it be winter the weaning is delayed till spring, when the child will be from twelve to fourteen months old. It is generally recognised that the healthiest children are those weaned at nine months complete. Prolonged nursing hurts both child and mother."

Dr. Stark then describes the usual habits in regard to the management of infancy, and adds, " 80 per cent. of the children of Scotland, when infants, are rarely taken to the open air, unless to the door of the house in the mother's arms." "In the manufacturing districts, where the mother has to be absent all day at the manufactory, preparations of opium and whisky are largely used by the 
old women to whom is committed the care of the nursing infants, and artificial food is obliged to be given till the mother's return."

Dr. Stark gives a table of comparative causes of death in infancy in Scotland and England in 1860 as follows :-

\begin{tabular}{|c|c|c|c|c|c|c|}
\hline & & & & & \multicolumn{2}{|c|}{ PER CENT. ON YOO LIVING. } \\
\hline & & & & & England, r86o. & Scotland, 1860. \\
\hline \multicolumn{4}{|c|}{ Premature Birth, Atrophy, and Debility } & $\cdots$ & 449 & 3.32 \\
\hline Convulsions & ... & $\cdots$ & $\cdots$ & $\cdots$ & 3.50 & 0.61 \\
\hline Pneumonia and $\mathrm{Br}$ & hitis & $\ldots$ & $\ldots$ & $\ldots$ & $2 \cdot 82$ & $2 \cdot 57$ \\
\hline Diarrhœea... & $\cdots$ & $\cdots$ & $\cdots$ & $\ldots$ & 0.85 & 0.27 \\
\hline Other conditions & $\cdots$ & $\cdots$ & $\cdots$ & $\cdots$ & $5: 37$ & $8 \cdot 12$ \\
\hline Total... & ... & $\ldots$ & ... & $\ldots$ & $17^{\circ} 03$ & 14.89 \\
\hline
\end{tabular}

The two notable differences are in the percentage of deaths to every 100 infants living in convulsions and in prematurity. Thus in England 35 infants died per 1,000 from convulsions as compared with 6 in Scotland; and Dr. Stark, naturally concerned at the benighted condition of England, declares that "there is something terribly faulty in the present mode of treating infants in England, and there is most urgent necessity for something being done to arrest this fearful waste of human life, for if the English mortality from convulsions were reduced to the Scottish standard, I7,000 lives would be annually saved to England." Dr. Stark made various investigations into the causes of convulsions, and found they were due to irritation set up by "spoon-meat." "There cannot be the slightest doubt that the very high mortality among nursing children in England is that they get spoon-meat far too 
early in life, before the stomach of the tender babe can digest anything but the mother's milk. This is indeed the vital difference between the mode of feeding infants in Scotland and in England. As a general rule no spoonmeat of any kind is given to infants in Scotland until nine months from birth are expired, or until the child has cut its front teeth. On the other hand, we know it is almost the invariable practice in England to give spoonmeat of some kind from the third month. At this time nature dictates that the child should still be suckled, because no teeth are provided, and that very fact indicates that no other food but the natural milk will agree. The stomach at that tender age cannot digest properly two kinds of food ; the consequence is indigestion, terminating in convulsions, as the result of giving spoon-meat, and is the reason why 35 infants die from convulsions in England in every I,000 living, whereas only 6 die from the same cause in Scotland." I

Dr. Stark, Fournal of Statistical Socicty of London, xxix., pp. 13-19, 1866. Dr. Ross, the Medical Officer of Health for Barvas, a large crofting and fishing parish of Lewis, one of the four districts into which the island is divided, tells me that when he went there some twenty-one years ago the prevailing custom of the mothers was to suckle their infants for the first eighteen months or even up to two or three years. Now (I906) suckling is seldom prolonged beyond eighteen months and often not beyond the first twelve months. Nor is suckling now the invariable rule, as it used to be. Twenty years ago many infants were lost every year in their first week of life from trisnus neonatorum, brought about, in the opinion of Dr. Ross, by mismanagement after birth, "the prevailing custom being to treat the new-comer first of all to a teaspoonful of cheap 'castor oil,' with a little melted butter, and to feed it for the first three days with a solution of cheap impure sugar and water, coloured with milk. This caused gastro-intestinal disorder and convulsions, and simply killed many and ruined the digestive organs of others. Likewise it had an injurious effect on the mothers, as a rule, that the infant was not put to the breast till the third day." These habits have undergone a change for the better in recent years. "It goes without question," the Medical Officer adds, "that the deplorable condition of the dwelling-houses leads to a large increase in infant mortality here, which is especially noticeable in connection with the lung troubles of infants, such as bronchitis, pneumonia, \&c., and during epidemics of whooping-cough and measles in the cold season, December to May." In I891 the infant mortality in Barvas was 117 , in 1902,112 , and in 1905 , 143. These comparatively high returns were due to epidemics of whooping. In non-epidemic years the rate averages 74 . 


\section{NORWAY AND SWEDEN.}

Norway: $1851-60$, annual average rate of mortality percentage, $0-5$ years, $4^{\circ} 0$.

Sweden : 1860-6I, annual average rate of mortality percentage O-5 years, $5^{\circ} \mathrm{I}$; O-I, I4' $\mathrm{I}$.

Norway : Infant mortality (1883-93), 97 per 1,000 births ; (1893-1902), 94 .

Sweden : Infant mortality (1883-93), I08 per I,000 births; (18931902), 99.

\section{PKJFESSOR ASCHONG, of Christiania.}

It is upon the peasant proprietors and labourers that the average rate of infant mortality depends. "The diet of the children belonging to these classes," says Professor Aschong, "is everywhere most simple and frugal. In the first year of their life they are suckled by their mother; and in the poorest families it is not uncommon, although by no means a general custom, that the mothers continue to suckle the child until two or three years old. The reason they assign is that it diminishes the number of children; often it is only sheer want that forces them to choose this manner of nourishing their children as the cheapest. Afterwards the children must partake of the common fare-potatoes, cakes, and porridge made from oatmeal, or bigg and coffee generally without sugar." Large quantities of milk are consumed. Professor Aschong then draws attention to other features which he thinks may play a part in producing a low infant mortality, namely, a climate with a low temperature, a small urban population, only 12-13 per cent. living in the towns, and the majority living in detached farms and cottages rather than in villages, wooden houses, and dry soil.

Dr. Berg, the Director of the Statistical Department, adds some notes on the habits as to infancy in Sweden. "The rule," he says, "is that the mother in all classes of society suckles her infant. Very often the peasant women 
prolong the suckling two to three years. Only in the higher classes and in the towns are wet-nurses employed in the case of inability of the mother. A very remarkable exception must, however, be noticed. Since the first results of our statistics of population have been known in the middle of last century, the great mortality among infants $0-1$ attracted attention. The rate of mortality was higher in the province of Finland named Osterbotten than elsewhere, and it was proved that this high rate of mortality among infants of the peasant women was owing to the custom which prevails of not suckling the babies, but suspending a horn filled with sour milk over the cradle for their nourishment, as the mothers are obliged to work in the fields or woods at a great distance from home. To counteract this habit and its deplorable effects a tract was published in I755 On the Nursing of Infants, and distributed amongst the inhabitants.... At the same time a Royal edict prescribed a fine of ten dollars for mothers who by neglecting to suckle their babies for at least half a year had caused the death of the children."

"Cow-milk together with the mother's is of frequent use; and when the suckling is prolonged to the third year, as is very often the case in the country, the babies run after the mother, ask her to kneel down, and suckle standing before her, they naturally taking also other kinds of food."

"Formerly there was also a bad habit of giving brandy to the babies to silence them, through a notion that the effect was not injurious." There was a high percentage of illegitimate children in Sweden, and it was the custom to get the mothers of these children to act as wet-nurses in the more well-to-do families. ${ }^{x}$

- Four. of Statistic. Soc., vol. xxix., 1866, pp. 19-23. 


\section{FRANCE.}

Annual average mortality percentage, $0-5$ years $(1856-60), 8 \cdot 0$. Annual average mortality percentage, $0-1$ year (1856-60), 22.3. Infant mortality (1883-1893), 167; (1893-1902), $15^{8}$ per 1,000 births.

M. LEgovT, Chief of the Statistical Department in the Ministry of Agriculture, Commerce, and Public Works.

The treatment of infants, he says, continues to be deplorable, especially in country districts. The women there work in the fields nearly as much as the men, and consequently are obliged to be much absent from their homes, which not only affects the actual feeding of the children but all the domestic arrangements. But this does not wholly explain the high infant mortality, which is much due to the fact that a very large number of infants in the towns are not fed by their mothers. Some are fed by wet-nurses, who have given their own milk to their own infants and fed the others on a "horrible pap," which sets up internal inflammation. "From these inflammations," says M. Legoyt, "a great number succumb." Nor are they well looked after in other ways, cleanliness and necessary change of linen being frequently neglected. In case of illness the doctor is not called except as a last extremity. Then to these disadvantages of country-bred infants there is poor housing accommodation-unventilated, cold, and damp. There is also much careless exposure of infants in cold and wet weather. Not only is there exceptionally little breast-feeding, but even infants which are ill continue to be fed, as in the past, on insufficient cow's milk and pap, or bad soup and black, hard bread. Mothers of these infants either will not or cannot breast-feed their children, "because they have not any milk, or because they are obliged to go out to work," and in consequence the infant is fed on cow's milk. "It is the common experi- 


\section{INFANT FEEDING AND MANAGEMENT 235}

ence," says M. Legoyt, "that three-quarters of the infants thus fed succumb in a short time." Finally, M. Legoyt refers to the large amount of illegitimacy and the frequent abandoning of infants as one of the causes of the high infant mortality in France in $1860 .^{\mathrm{r}}$

\section{AUSTRIA.}

Annual average rate of mortality per cent., $0-5$ years (1856-60), 10\%4. Infant mortality (1895-1900), 227 per 1,000 births.

Dr. Herz, Assistant Physician to the Vienna Foundling Institution.

Wide differences in social position influence the habits of the Austrian people in regard to their treatment of infancy. "The higher classes follow a more or less rational way; in the lower classes it is very badly done, partly on account of ignorance, partly on account of poverty." Some difference exists also in the management of town children and those in the country.

In spite of their training, Dr. Herz thinks that the midwives are a principal source of many abuses, fibs, and superstitions in regard to infancy. "Many hundreds of children die annually in this country by the perverse means of these female doctors."

"The majority of our children are suckled, a small part of them by their own mothers, a greater part in Vienna by wet-nurses. In the better ranks of society it is now a common practice for the mother not to suckle her own offspring, while of course the wife of the working man is prevented from fulfilling this maternal duty by the necessity of working for her livelihood out of doors. The former hire wet-nurses, the latter feed their babies

' Four. of Statistic. Soc., vol. xxix., 1866, pp. 23-25. 
artifically. With regard to wet-nursing we do not send our children to the country as they do in Paris and other towns in France, but we take the wet-nurses as a kind of servant to our house." In the lower classes artificial feeding consists of "different stuff, pêle-mêle." "This part of popular knowledge is dreadfully neglected amongst the lower ranks, and from my experience I must certify that the majority of the diarrhœas, so frequent and so fatal during the first period of life, are chiefly caused by the neglect of the elements of hygiene. ... Brandy and strong liquors are much in use, and the child, even the youngest one, gets spirits. ... One of the greatest blessings for the lower classes proves to be the crêches, erected and supported by voluntary subscriptions in large and industrial towns (of which there are eight in Vienna receiving several hundred children daily, $\frac{1}{2} \mathrm{~d}$. and Id. each). ${ }^{\mathrm{x}}$

RUSSiA. Injant Mortality (1883-92), 270 per r,000; (189099), 272 per $r, 000$. Owing in part to the prevalence of early marriage among the peasants the birth rate is high, varying from 30 to 60 or more per 1,000 . (In 1903,48 .) The death rate is high, sometimes for whole provinces being 45 per $\mathrm{r}, 000$. The mortality among children is also exceptionally high, and the infant mortality is by far the highest in Europe. In October, 1905, I received a letter from H.H. General Roopa, the president of the association for collecting statistics about children's mortality in Russia, in which he reports that in 50 Governments of European Russia, having a population of $94,215,415$, there die annually $r, 196,674$ infants under one year of age, $r, 858,85^{\circ}$ under five years of age, and $2,190,757$ under 15 years. Infant mortality is greatest in the Governments of Perm (population $2,7 \times 3,987$ ), which in area is the second largest Government in European Russia, of Vyatka (population 2,9r4,344), of Nijni Novgorod (population $1,513,3 \times 8$ ), of Penza, Kaluga, and Sim-

r' Four. of Statistic. Soc., vol. xxix.; 1866, pp. $26-28$. 
birsk. In the South-western Governments of Russia, 23 of which have a population of $44,106,435$, the infant mortality is 197.3 per 1,000. The President quotes the following as the chief causes of the high infant death rate: ( $\mathrm{I}$ ) Miserable hygienic arrangements; (2) insufficient beds and accommodation for children, and therefore resulting bad infant management on the part of the mother, coupled with lack of breast-feeding because the mother is usually at work; (3) the ignorance and superstition of the masses; (4) the adulteration of milk in the towns ; (5) epidemics of infectious disease ; and (6) insufficiency of medical aid.

II.

The second class of facts concern methods of infant feeding and their result in England. Three districts, Derby, Finsbury, and Brighton, will be taken as types, and the county of Dorset has been selected for comparative purposes.

\section{DERBY.}

Dr. Howarth, the Medical Officer of Health for Derby, has published the results of an inquiry conducted from November, I900, to November, 1903, with the feeding of 8,343 infants born in that town with a view of showing the proportion which infants' deaths bear to the aggregate of children hand-fed and breast-fed.I He concludes that "the only children exposed to exceptional risk are those reared by hand, and born either during the second quarter of the year or during the first month of the third quarter." The tendency is for these children to succumb to diarrhœa. Dr. Howarth's results are so interesting that they must be quoted in some detail. He found that the mortality per I,000 from certain diseases among children who were breast-fed or hand-fed, or were at first breast-fed and subsequently hand-fed (mixed), was as follows :-

: The Influence of Feeding on the Mortality of Infants, 1905. 


\begin{tabular}{|c|c|c|c|c|c|c|c|c|}
\hline \multirow{2}{*}{$\begin{array}{l}\text { NUMBER OF } \\
\text { CHILDREN. }\end{array}$} & \multicolumn{2}{|c|}{ BREAST-FED. } & \multicolumn{2}{|c|}{ Mixed. } & \multicolumn{2}{|c|}{ HAND-FED. } & \multicolumn{2}{|c|}{$\begin{array}{l}\text { ALL THREE } \\
\text { CLASSES. }\end{array}$} \\
\hline & \multicolumn{2}{|c|}{5,278} & \multicolumn{2}{|c|}{1,439} & \multicolumn{2}{|c|}{1,626} & \multicolumn{2}{|c|}{8,343} \\
\hline Disease. & 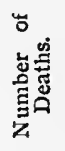 & 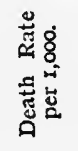 & 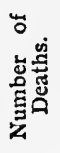 & 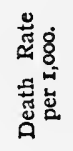 & 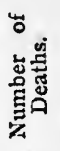 & 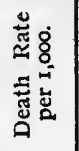 & 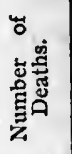 & 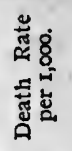 \\
\hline $\begin{array}{l}\text { Bronchitis and } \\
\text { Pneumonia! ... } \\
\text { Diarrhœa and }\end{array}$ & 76 & $14 \%$ & 18 & $12 \cdot 6$ & 43 & $26 \cdot 5$ & 137 & I6.5 \\
\hline $\begin{array}{cc}\text { Diarrhœa } & \text { and } \\
\text { Epidemic } & \text { En- } \\
\text { teritis ... } & \ldots\end{array}$ & 45 & $8 \cdot 6$ & $3 \mathrm{I}$ & $2 I \cdot 6$ & 84 & $5 I^{\prime} 7$ & 160 & $19 \cdot 2$ \\
\hline $\begin{array}{c}\text { Gastritis and Gas- } \\
\text { tro Enteritis ... }\end{array}$ & 7 & $I^{\prime} 4$ & 5 & 3.5 & I0 & $6 \cdot 2$ & 22 & 2.7 \\
\hline Marasmus $\quad \ldots$. & 29 & 5.5 & I7 & II.9 & 32 & $19 \cdot 7$ & 78 & $9 \% 4$ \\
\hline Atrophy and De- & 37 & $7 \cdot 1$ & 10 & $7^{\circ} 0$ & 32 & $19 \cdot 7$ & 79 & $9 \cdot 5$ \\
\hline $\begin{array}{l}\text { Tabes Mesen- } \\
\text { terica } \ldots . . .\end{array}$ & 6 & $I \cdot 2$ & $\mathbf{I}$ & 0.7 & I I & $6 \cdot 8$ & I8 & $2 \cdot 2$ \\
\hline $\begin{array}{l}\text { Various Abdomi- } \\
\text { nal Tuberculosis } \\
\text { AllotherTubercu- }\end{array}$ & 3 & 0.6 & 4 & $2 \cdot 8$ & 6 & 37 & 13 & $I \cdot 6$ \\
\hline lous Diseases & 9 & $I \cdot 8$ & 3 & $2 \cdot 1$ & 5 & $3 \cdot I$ & 17 & $2 \cdot 1$ \\
\hline Convulsions $\quad$... & 79 & $15^{\circ} \mathrm{O}$ & 30 & 20.9 & 42 & $25^{\circ} 9$ & 151 & $18 \cdot 1$ \\
\hline $\begin{array}{l}\text { Dentition } \\
\text { Zymotic Diseases } \\
\text { other thanDiar. }\end{array}$ & 7 & $I^{\circ} 4$ & 7 & $4^{\circ} 9$ & 7 & $4 \%$ & $2 \mathrm{I}$ & 2.6 \\
\hline rhœa...$\quad \ldots$ & 28 & $5^{\circ} 4$ & I I & $7 \cdot 7$ & $2 \mathrm{I}$ & $13 \cdot 0$ & 60 & $7 \cdot 2$ \\
\hline All other Diseases & 42 & $8 \cdot 0$ & 5 & 3.5 & 28 & $17 \cdot 3$ & 75 & $9^{\circ} 0$ \\
\hline Totals & 368 & $69 \cdot 8$ & I 42 & 98.7 & $32 \mathrm{I}$ & $197 \cdot 5$ & $83 I$ & $99^{\circ} \mathrm{I}$ \\
\hline
\end{tabular}

In this table it will be seen that in no case did the death rate in any class of disease among hand-fed children even approximate that recorded among breastfed children. Even bronchitis and pneumonia, and miscellaneous diseases other than diarrhœa, carried off 12 per I,000 more hand-fed and therefore less resistant children than breast-fed. The totals also tell the same story, namely, that the infant mortality for hand-fed is three times higher than that for breast-fed, although the social 
environment and housing conditions were, if anything, rather better for the hand-fed. ${ }^{\mathrm{I}}$

The next question Dr. Howarth set himself to answer was as to the kind of food used in the hand-feeding of infants in Derby and the relation it bore, if any, to infant mortality. He constructed the following table on this issue :-

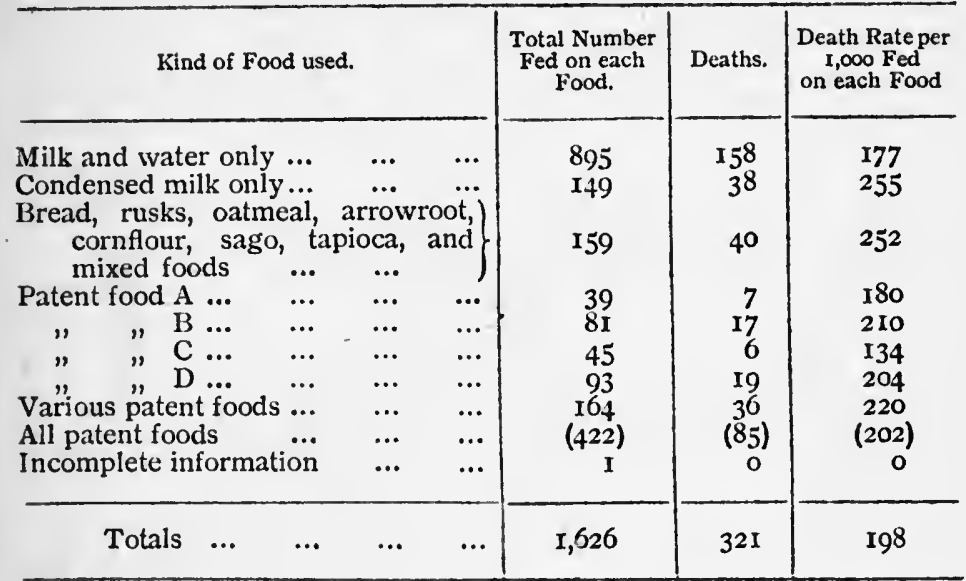

"From this table it will be seen that the lowest death rate was among children fed on patent food ' $\mathrm{C}$,' after which children who

I "The town of Derby," Dr. Howarth adds, "is neither markedly salubrious nor notably unhealthy. Its population is chiefly of the artisan class, and numbered 115,000 at the last census. Employments are at railway works, foundries, and mills. Trade is fairly constant, without violent fluctuations, and on the whole there is less acute poverty than in most towns of the same size. The percentage of married women engaged in occupation at the census of I90I was $9 \cdot 2$, as against $13^{\circ 2}$ in England and Wales. The slums are extremely limited in extent, and overcrowding is practically non-existent. The percentage of tenements with less than five rooms which were found to be overcrowded was $4^{\circ} \mathrm{I}$, as against $12{ }^{\circ} 0$ for England and Wales, and $I I .8$ for the aggregate county boroughs. The size of the tenements, which practically mean houses in Derby, is satisfactory, as $8 I^{\cdot} 8$ per cent. are of five rooms and upwards, against 46.7 in England and Wales. The town is built on heavy retentive clay, and is about Ioo feet above the sea-level at the market-place. There are a large number of privies and pail-closets, the objectionable influences dispersed by which are lessened to some extent by the large open space which is required at the rear of all buildings." 
were fed on milk-and-water survived in greatest proportion. : In the aggregate the various patent foods show a death rate of 202 per I,000, as compared with $\mathbf{I} 77$ for milk-and-water. The composition of these foods is interesting when considered in relation to these statistical details; it shows that very many more children survive who are brought up on malted food in which there is no starch than on such as contains unconverted starch in marked degree, whilst occupying a middle position between the two are the various foods prepared from desiccated cows' milk. Patent food ' $\mathrm{C}$ ' is a farinaceous food in which the whole of the starch has been rendered soluble. It contains no fat; this is supplied by the milk used in preparing it. Patent food ' $A$ ' contains no starch, and is a very fair imitation of human milk. It approximates the composition of dried human milk, but is deficient in both proteids and fat. Patent food ' $D$ ' contains starch which has not been predigested, and although perhaps even very young children can digest a certain amount of starch, it is not a suitable food before the period of dentition. It is this class of food which forms a large proportion of those classified under 'Various patent foods,' and as the results show, they are much less suited for children than the other two.

"Children fed on condensed milk show a very high mortalityviz., 255 deaths per $\mathbf{1}, 000$ of children so fed-and this is not surprising. The chief reason is, perhaps, to be found in the analyses of these milks. ${ }^{\mathrm{t}}$

"Unsweetened whole condensed milk, if no fat has been extracted, constitutes as suitable an article as cows' milk from which to prepare food for infants, and if care is taken in sufficiently diluting it and making suitable additions no serious

\begin{tabular}{|c|c|c|c|c|c|c|c|}
\hline & Proteids & & Fat. & & ilk-sugar. & & ane-sugar. \\
\hline Human milk (average) & I.5 & ... & 35 & ... & 6.5 & $\ldots$ & - \\
\hline Cows' milk ... $\quad .$. & $2 \cdot 5$ & ... & $4^{\circ} \circ$ & $\ldots$ & 4.5 & $\ldots$ & - \\
\hline $\begin{array}{l}\text { Mixture (cows' milk, } 2 \\
\text { parts ; water, I part) } \ldots\end{array}$ & I'6 & $\cdots$ & $2 \cdot 6$ & $\cdots$ & $3^{\circ} \mathrm{O}$ & ... & - \\
\hline $\begin{array}{l}\text { Unsweetened whole con- } \\
\text { densed milk }\end{array}$ & $8 \cdot 3$ & .. & 12.4 & .. & 16.0 & $\cdots$ & \\
\hline $\begin{array}{l}\text { Mixture (unsweetened } \\
\text { whole condensed milk, } \\
\text { I part ; water, } 4 \text { parts)... }\end{array}$ & I7 & ... & 2.5 & ... & $3 \cdot 2$ & $\cdots$ & - \\
\hline $\begin{array}{l}\text { Sweetened whole } \\
\text { densed milk }\end{array}$ & 97 & $\cdots$ & 1377 & $\cdots$ & $15^{\circ} \mathrm{O}$ & $\cdots$ & $37 \cdot 2$ \\
\hline Condensed separated milk & II 5 & ... & 20 & ... & 13.0 & ... & $45^{\cdot 8}$ \\
\hline
\end{tabular}


objection can be raised against its use, but the fact remains that for some reason or other practically none is used for feeding infants in this town. Analysis shows that to sweetened condensed milk a large amount of cane-sugar is added, so that if this milk is diluted to the proportions necessary to bring the proteids and fat to the same standard as average human milk, sugar is in excessive proportion. Condensed separated milk shows almost the same percentage composition as sweetened whole condensed milk, except that the fat is reduced to 2 per cent. Such a milk is absolutely unsuited for the food of infants, and its continuous use results in slow starvation of the infant. The death rate among children reared on bread, rusks, arrowroot, and other farinaceous foods is exceedingly high, being 255 per I,000. This is only what would be expected."

Dr. Howarth thinks the high death rate of 177 amongst children fed on home modified milk means domestic pollution (possibly from privy-middens) and ignorance of the mother. He concludes :-

"The deductions which it appears justifiable to draw from the mortality observed amongst hand-fed children fed on different foods are : that the use of sweetened condensed milk, either whole or skimmed, should be invariably discouraged, and whole, unsweetened condensed milk should only be permitted when one is satisfied that the milk is being used with a proper degree of dilution and with the necessary additions as in the case of modified cows' milk; also that since the death rate amongst children reared on patent foods is, on the average, higher than amongst those fed on diluted cows' milk, every attempt should be made to encourage parents to use this latter food and to educate them to an appreciation of the necessity for the additions to, and the dilution of, cows' milk to render it suitable for infants' food. The addition of patent foods to the dietary of very young infants is unnecessary, sometimes dangerous, and always expensive." 


\section{FinsBury.}

During the last four years careful inquiry has been made in Finsbury into the feeding of all infants dying of epidemic diarrhcea (37I) with the result that we find that-

68 , or 18.3 per cent., were wholly breast-fed ;

I29, or 34.7 per cent., were fed wholly or partly on artificial foods and milks;

I74, or 46.8 per cent., were fed wholly or partly on cows' milk. ${ }^{\text {I }}$

The actual figures were as follows :-

\begin{tabular}{c|c|c|c|c|c|c|c}
\hline $\begin{array}{c}\text { Age in } \\
\text { Months. }\end{array}$ & $\begin{array}{c}\text { Human } \\
\text { Mfilk. }\end{array}$ & $\begin{array}{c}\text { Artificial } \\
\text { or } \\
\text { Condensed } \\
\text { Milk. }\end{array}$ & $\begin{array}{c}\text { Human } \\
\text { and } \\
\text { Artificial. }\end{array}$ & $\begin{array}{c}\text { Cows' } \\
\text { Milk. }\end{array}$ & $\begin{array}{c}\text { Human } \\
\text { and } \\
\text { Cows' }\end{array}$ & Totals. & $\begin{array}{c}\text { Percentage } \\
\text { in each } \\
\text { Trimester } \\
\text { (breast-fed). }\end{array}$ \\
\hline $0-3$ & 26 & 23 & II & 39 & I9 & II8 & 22 \\
$3-6$ & 18 & 32 & 13 & 38 & 13 & 114 & 16 \\
$6-9$ & I1 & 21 & 13 & 30 & I4 & 89 & 12 \\
$9-12$ & I3 & I3 & 3 & 13 & 8 & 50 & 25 \\
\hline Totals... & 68 & 89 & 40 & 120 & 54 & 371 & 18 \\
\hline
\end{tabular}

But these returns do not guide us as to the degree of breast-feeding in living infants at various ages or as to the feeding of infants dying of other diseases than diarrhœa. Accordingly, in 1905 , new-born children (numbering 1,822 ) were visited in the first trimester. Of these it was found that 1,503 (or 80.8 per cent.) were wholly breast-fed ; 177 (or 9.5 per cent.) were partly breast-fed and partly artificially fed; 104 (or 5.0 per cent.) were wholly fed on cows' milk, and 38 (or $2{ }^{\circ} \circ$ per cent.)

× Report on Health of Finsbury, 1905, p. 56. 
wholly on condensed milk. ${ }^{I}$ Dr. Sandilands carried out in Finsbury a similar inquiry in the same year as to the feeding of 554 healthy infants at the ninth month, with the result that 69 per cent. were found to be fed on human milk only. A parallel investigation was made into 374 infant deaths from all causes, with the result that $35^{\circ} 8$ per cent. were breast-fed. These findings may be tabulated in percentages as follows:-

\begin{tabular}{|c|c|c|c|c|}
\hline 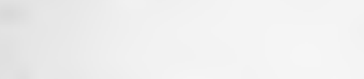 & $\begin{array}{l}\text { Breast- } \\
\text { fed } \\
\text { Only. }\end{array}$ & $\begin{array}{l}\text { Condensed } \\
\text { Milk } \\
\text { Only. }\end{array}$ & $\begin{array}{l}\text { Cows' } \\
\text { MIilk } \\
\text { Only. }\end{array}$ & $\begin{array}{l}\text { Mixed Diet } \\
\text { or Artificial } \\
\text { Foods. }\end{array}$ \\
\hline $\begin{array}{l}\text { 1. Living Infants at Third } \\
\text { Month }(1822) \ldots \\
\text { 2. Living Infants at Ninth } \\
\text { Month }(554) \ldots \\
\text { 3. Dead Infants : } \\
\text { Causes }(374) \ldots \\
\text { 4. Dead Infants : Diarrhœa } \\
\text { (37 I) ... } \ldots\end{array}$ & $\begin{array}{l}81 \\
69 \\
36 \\
18\end{array}$ & $\begin{array}{l}2 \\
10 \\
12 \\
24\end{array}$ & $\begin{array}{r}5 \\
19 \\
29 \\
32\end{array}$ & $\begin{array}{c}13 \\
2 \\
23^{2} \\
26\end{array}$ \\
\hline
\end{tabular}

In I 39 infant deaths from diarrhœa, forming the subject of another inquiry, Dr. Sandilands found that only 22, or 16 per cent., were breast-fed.

As a result of his inquiries in Finsbury Dr. Sandilands showed that the deaths from diarrhœa in breast-fed children under three months constituted only 24 per cent. of the total, whilst the remaining 76 per cent. were deaths in the artificially fed, that is to say, the deaths amongst the artificially fed were nearly four times the number that ought to have occurred, on the supposition of an average distribution of deaths from diarrhœa among infants fed in

2 If these figures could be accepted as fairly representing the method of feeding of all the new-born infants out of which the deaths in the same year occurred, it would yield the following result : Of 1,503 breast-fed infants 133 (or 8.8 per cent.) died in infancy, while of 319 artificially fed 201 (or $63^{\circ}$ ) died in infancy.

2 About 2 per cent. of these infants were not fed at all, dying within a few hours of birth. 
different ways. The same excessive mortality in the handfed continues up to the ninth month of life. In the last three months of the first year of life the diarrhœa mortality approximates to the average. The immediate cause of the high death rate from diarrhœa among children whose mothers do not suckle them is, in part, polluted milk, but there are other factors of importance.

Insufficient nourishment is not, strictly speaking, a cause of diarrhœa, but it may well be a potent predisposing cause of death from this disease. Whether the food is insufficient in quantity or in nutritive power, or whether the fault lies in the inability of a child to digest what it is given, the same condition of malnutrition will result, and ill-nourished children will always succumb rapidly to epidemic diarrhœa. The poorer classes in Finsbury dilute the condensed milk they give to their infants to an extent which makes it deficient in nutritive power, and give both condensed and cows' milk in insufficient quantities and in a manner totally unsuited to the digestive capacity of their children. So that if the pollution of milk is the cause of the onset of diarrhoea, it is at least probable that a previous condition of malnutrition is as often as not responsible for a fatal termination.

The diminution in the death rate from diarrhca in the artificially fed, after the ninth month, may be due to the well-nourished condition of bottle-fed children at this age. Sixty per cent. of them have been started in life with six months at the breast, and have thus acquired powers of resistance which result in the comparatively low mortality from which they suffer when they come to be fed on cows' milk of doubtful purity. Again, the mortality after the ninth month is comparatively high among the breast-fed, many of whom obtain insufficient nourishment from the milk of mothers who are not equal to the strain of lactation. 


\section{INFANT FEEDING AND MANAGEMENT 245}

If diarrhœa is excluded, the evil influence of artificial feeding, though less marked, is still apparent among other causes of death, whence it may be inferred that the debility of a child deprived of its mother's milk is a very real thing, and must be taken as a factor of some importance in the mortality from diarrhœa and other causes.

It appears that the mortality from diarrhœea amongst infants fed on condensed milk is nearly three times the average mortality in the first six months, whilst the mortality amongst those fed on cows' milk is less than twice the average. Between the sixth and ninth months condensed milk still gives a higher mortality, but the discrepancy is less marked. The difference in the two mortalities admits of both the following explanations, one that fermentative changes in the condensed milk are more deadly than similar changes in cows' milk, and the other that children fed on condensed milk are virtually starved and consequently ready victims to fatal diarrhœea.

- Further evidence of the unfavourable influence of condensed milk was shown by the deaths from "other causes." Between the third and ninth months the deaths from other causes in those fed on condensed milk was twice the average number, whilst the deaths in those fed on cows' milk were, in the first age period, equal to the average, in the second period, only slightly above, and in the third age period actually below. The enfeebled constitution resulting from the use of condensed milk is the direct cause of this high mortality in the case of wasting diseases, and the indirect cause of the fatal termination of other ailments less intimately connected with feeding.

It would thus appear that condensed milk is the worst food for infants, that cows' milk greatly increases their 
liability to death, and that all artificial feeding is attended by a high mortality. Some of the excessive infantile death rate in the artificially fed may with fairness be attributed to unsound milk, but the essential cause is the deficiency in the supply of human milk for which no adequate substitute can be devised. ${ }^{\mathrm{I}}$

There is one other point of interest connected with these Finsbury figures requiring explanation, namely, the occurrence of diarrhœea in breast-fed infants. It will be seen that as many as 18 per cent. of the infants dying of diarrhœa were breast-fed, and this seems definitely to indicate that it is by no means wholly or only from cows' milk that diarrhœal infection is obtained. It is possible that under exceptional circumstances the milk of the mother may set up irritation in the alimentary canal of the infant, but this may be set aside as not furnishing any appreciable contribution to the bills of mortality. Moreover, it has been shown that infants fed on a properly prepared and sterilised milk may also suffer from epidemic diarrhœa. At the Finsbury Infant Milk Depôt, to which reference will be made in the next chapter, I8 infants suffered from diarrhœa in 1905, I4 of them in August. In 5 cases it caused death. It is therefore clear that the feeding of infants on modified and sterilised milk does not necessarily prevent them from having epidemic diarrhœa, particularly in the third quarter of the year. The milk in the cases just mentioned was consumed direct from the bottle, through a clean teat, without a tube. The milk itself was of a high standard of purity, was absolutely sterilised, and was modified to suit the age of the infant; and yet with all this care a number of these infants contracted epidemic diarrhœa. It is impossible to believe they contracted specific infection from the milk, for the milk could not contain

s Report on Health of Finsbury, 1904, pp. 82-86. 


\section{INFANT FEEDING AND MANAGEMENT 247}

specific infection of any kind. Moreover, if it had contained such virus more than 16 out of 57 children (in third quarter) using it would have contracted the disease, for the whole of the milk came from one source and had been treated in the same way. It seems probable, therefore, that they contracted the disease through some channel other than the milk. We carefully inquired into all the possible channels, and we came to the conclusion that the virus of this disease had gained access to these infants through dried dust and dirt, and particularly by the use of "comforters," which are india-rubber rings or dummy teats, which this class of children, almost without exception, suck and chew during their considerable leisure. Such "comforters" are dipped in sugary messes or dirty milk to give them a palatable taste. They fall on the floor and so collect dust. Flies settle upon them. They are never cleaned except, perhaps, on a dirty apron. They are nearly always moist and warm owing to contact with - the child's mouth, and therefore afford an ideal nidus for the multiplication and development of germ life. It is, of course, almost useless to give a child milk which is free from all contamination and infection if between its meals it is supplied with a filthy and infected "comforter." There can, I think, be little doubt that "comforters" and the long tubes of milk-bottles are two sources of much disease, and it would be well if they could be entirely abolished.

No doubt there are other means also by which dust and dirt obtain this access to infants (see p. 326). In any event it is certain that infants fed on breast milk or sterilised bottle milk may contract fatal diarrhœa. And if milk be thus excluded and the infants are not otherwise fed it becomes clear that we must think of a vehicle other than food. What is that vehicle? It cannot yet be said that we know. It may be "comforters" or other articles 
sucked by the infant, or a mother's dirty fingers rubbed on the gums of the infant, or unclean clothing, or the dirty handling by a mother wanting in personal cleanliness, or dust-laden hands of an infant who has been crawling on the floor, or flies or currents of air carrying infective dust from filthy refuse-bins, or dry and dusty streets, or the surfaces of an unclean tenement. Evidence is accumulating to show the pollution of the air of houses by infective or injurious dust and dirt being present in the houses. Many years ago Cornet demonstrated the presence of the tubercle bacillus in the dust of houses, and others have proved the same fact. In $1905 \mathrm{Dr}$. M. H. Gordon showed that the air entering and leaving the House of Commons contained microbes and particulate matter of intestinal origin (from manure) derived from Members' boots. ${ }^{x}$ If that be so, it is much more likely that tenement houses will be affected in the same way, and in a greater degree.

These considerations bring us in a marked way face to face with uncleanliness as the channel of infection of diarrhœa, and therefore an indirect cause of infant mortality. Unclean milk in some cases, unclean articles, clothing, or person in other cases, but in both events uncleanliness as a primary and essential condition, affecting milk or other media, is, without doubt, intimately related to epidemic diarrhœa. ${ }^{2}$

There remains for mention, finally, one other point in connection with our investigations in Finsbury, and that is the cause of early weaning. We have no conclusive evidence, owing to an absence of previous records, that artificial feeding of infants is increasing, though some circumstances exist which seem to indicate that such is

- Report on House of Commons Ventilation, r905.

2 In Manchester, in 1904, of 106 cases of infant deaths from diarrhcea only 16 were found to be clean in house and person.-Rep. on Health of Manchester, 1904, p. 185 . 


\section{INFANT FEEDING AND MANAGEMENT 249}

the case. From a series of inquiries made at the Finsbury Infant Milk Depôt we are able to say, however, what are the alleged reasons for artificial feeding. The stated reasons were as follows:-

Mothers who had no breast milk or whose milk failed at an early date Mothers who had an insufficiency

of milk $\ldots$ bscess of the breast, \&c. ... $\quad \ldots$

The breast milk not agreeing with the infant ... ... $\quad \ldots \quad \ldots$ Mother too ill to nurse child $\ldots$ Infants unable to suckle or other.

$\begin{array}{ccc}\text { wise defective } \ldots & \ldots & \ldots \\ \text { The mother at work... } & \ldots & \ldots\end{array}$

Ioo or $5^{6}$ per cent.

\begin{tabular}{|c|c|}
\hline $\begin{array}{l}34 \\
16\end{array}$ & ", \\
\hline $\begin{array}{r}13 \\
9\end{array}$ & \\
\hline $\begin{array}{l}6 \\
2\end{array}$ & \\
\hline & \\
\hline
\end{tabular}

From the inquiries made into infant deaths throughout Finsbury, we find that these figures are fairly representative of reasons for early weaning. It will be seen that 75 per cent. of the mothers weaned their infants because they were unable to nourish them, owing to insufficiency or absence of milk. ${ }^{x}$

\section{BRIGHTON.}

One of the most notable series of inquiries into this question has been that of Dr. Newsholme at Brighton. For some years past his annual reports have contained particulars of feeding in healthy infants (now amounting to 1,259 ) and in infants dying of epidemic diarrhoea (now amounting to 121). The chief facts have recently been summarised, 2 and afford an excellent illustration of the subject under consideration. The methods of feeding these two classes

- This was found to be the chief cause of early weaning in Manchester in 1904. (Rep. on Health of Manchester, 1904, p. 178.)

- Four. of Hygiene, I906 (April), p. I39. 
of infants have been tabulated by Dr. Newsholme as follows :-

\begin{tabular}{|c|c|c|c|c|c|c|c|c|}
\hline & \multicolumn{4}{|c|}{$\begin{array}{l}\text { A. CENSUS OF I0,308 } \\
\text { HOUSES IN HOUSE-TO- } \\
\text { HOUSE INSPECTION IN } \\
\text { THE } 3 \text { YEARS I903-5. }\end{array}$} & \multicolumn{4}{|c|}{$\begin{array}{l}\text { B. INFANTS WHO DIED } \\
\text { FROM EPIDEMIC DIARR- } \\
\text { HOEA IN THE } 3 \text { YEARS } \\
\text { I903-5. }\end{array}$} \\
\hline & \multicolumn{4}{|c|}{ Age of Infants in Months. } & \multicolumn{4}{|c|}{$\begin{array}{l}\text { Age of Infants Dying in } \\
\text { Months. }\end{array}$} \\
\hline & $0-3$ & $3-6$ & $6-9$ & $9-12$ & $0-3$ & $3-6$ & $6-9$ & $9-12$ \\
\hline I. Suckled only $\quad \ldots$ & $27 \mathrm{I}$ & 237 & 186 & 92 & 5 & 3 & - & - \\
\hline $\begin{array}{c}\text { Ditto and farina- } \\
\text { ceous food }\end{array}$ & 14 & 29 & $4 I$ & 69 & I & I & - & $\mathbf{I}$ \\
\hline Ditto and cows' milk & 5 & 6 & 7 & 4 & $\mathbf{I}$ & - & - & - \\
\hline $\begin{array}{l}\text { Dittoand condensed } \\
\text { milk }\end{array}$ & 3 & 6 & 7 & I & $\mathbf{I}$ & $\rightarrow$ & - & - \\
\hline $\begin{array}{l}\text { II. Cows' milk only ... } \\
\text { Ditto and farina-) }\end{array}$ & 12 & 32 & 28 & 18 & II & 22 & 7 & 4 \\
\hline ceous food $\quad \ldots$ & 4 & 26 & 33 & 33 & I & - & 4 & 6 \\
\hline $\begin{array}{l}\text { III. Condensed milk only } \\
\text { Ditto and farina- }\end{array}$ & 6 & 12 & I0 & II & 2 & 16 & 12 & 7 \\
\hline ceous food & 2 & 6 & IO & 7 & 一 & 3 & 一 & $\mathbf{I}$ \\
\hline $\begin{array}{l}\text { IV. Farinaceous food, } \\
\text { including patent }\end{array}$ & & & & & & & & \\
\hline $\begin{array}{l}\text { food only men- } \\
\text { tioned, or "same } \\
\text { food as parents" }\end{array}$ & 4 & I & 2 & I8 & I & I & - & 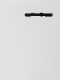 \\
\hline V. Unknown $\quad \ldots \quad \ldots$ & $一$ & - & I & 5 & 2 & 4 & 2 & 2 \\
\hline
\end{tabular}

The significance of the facts in this table becomes plainer when the different groups are stated as percentages of the total (see opposite page). The three main groups are shown in larger type, and it is with these that we are concerned.

Assuming that the dead and living infants belong to the same class of the population, these figures indicate that the number of deaths from epidemic diarrhœa among breast-fed infants was not more than one-tenth of the number which would have occurred had the deaths from diarrhœa been evenly distributed, and no deaths occurred among breast-fed infants aged six to nine months. It will 


\section{INFANT FEEDING AND MANAGEMENT 251}

be seen that eight breast-fed infants suffered from diarrhœa, which lends support to the view already expressed, that milk is not the only vehicle of diarrhœal infection. There is some other factor, and that factor is probably playing

PERCENTAGE OF INFANTS UNDER ONE YEAR OF AGE FED IN DIFFERENT WAYS.

\begin{tabular}{|c|c|c|}
\hline & $\begin{array}{l}\text { A. In 10,308 Houses } \\
\text { visited House-to- } \\
\text { house ( } 1,259 \text { Infants). }\end{array}$ & $\begin{array}{l}\text { B. Among Infants } \\
\text { Dying from Epidemic } \\
\text { Diarrhœa (1 21 Infants.) }\end{array}$ \\
\hline $\begin{array}{l}\text { I. Suckled only... } \\
\text { Ditto and farinaceous food } \\
\text { Ditto and cows' milk } \\
\text { Ditto and condensed milk }\end{array}$ & $\begin{array}{r}62 \cdot 3 \\
I 2 \cdot I \\
I \cdot 8 \\
I \cdot 4\end{array}$ & $\begin{array}{l}6.5 \\
2.5 \\
1 \cdot 7 \\
0.8\end{array}$ \\
\hline $\begin{array}{l}\text { II. Cows' milk only } \ldots \\
\text { Ditto and farinaceous food }\end{array}$ & $\begin{array}{l}7 \cdot 2 \\
7 \cdot 6\end{array}$ & $\begin{array}{r}36 \cdot 0 \\
9 \cdot I\end{array}$ \\
\hline $\begin{array}{l}\text { III. Condensed milk only } \\
\text { Ditto and farinacions food }\end{array}$ & $\begin{array}{l}3 \cdot 1 \\
2 \cdot 0\end{array}$ & $\begin{array}{r}30 \cdot 3 \\
3 \cdot 2\end{array}$ \\
\hline IV. Farinaceous foods only men- & & \\
\hline tioned $\quad \ldots \quad \ldots \quad \quad \ldots$ & $2 \cdot 0$ & $I^{\circ} 7$ \\
\hline V. Unknozen & 0.5 & $8 \cdot 2$ \\
\hline$\ldots \quad \ldots$ & $100 \cdot 0$ & $100 \cdot 0$ \\
\hline
\end{tabular}

some part in the diarrhœal deaths of some of the infants not breast-fed. Dr. Newsholme has further subdivided his cases into three-month periods as follows :-

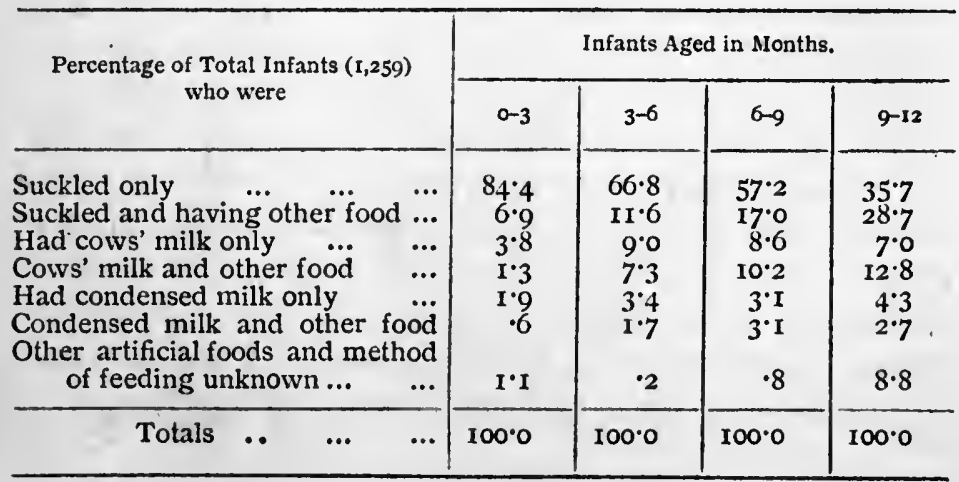


These figures correspond closely with what has been found in Derby and Finsbury, and indicate that a large degree of breast-feeding is being practised, as was found to be the case in Finsbury two years ago. It will be seen that 88.5 per cent. of the total deaths from diarrhœa were in artificially fed infants, and 5 per cent. in part suckled and partly fed artificially. It is clear that even partial breast-feeding protects in some measure against fatal diarrhœa. "Subdividing results of artificial feeding," writes Dr. Newsholme, "according to age, it is found that in the first trimester the liability to fatal diarrhœa is 8 times, in the second $4 \frac{1}{2}$ times, in the third 4 times, and in the fourth trimester $2 \frac{1}{2}$ times as great among artificially fed as among breast-fed babies." Further, the probability of death from diarrhoea is forty-eight times as great among infants fed on cows' milk, and ninety-four times as great among infants fed on condensed milk as among those which are breastfed. Dr. Newsholme again points out that the evidence obtainable is all in support of domestic-infection rather than farm-infection of milk. If diarrhoal infection came from the farm we should expect three events which we do not obtain. First, there would be massive infection in epidemic form. Secondly, there would be the ordinary characteristics of milk-borne epidemics. ${ }^{\text {I }}$ Thirdly, there would be a higher incidence of fatal diarrhœa among infants fed on fresh cows' milk than on condensed milk. Not one of these characteristics do we obtain. Instead of infection being massive and wide in distribution it is "sporadic," discrete, and isolated in distribution. Nor does it "follow the milk-cart," or reveal any sign of being what is ordinarily looked upon as a milk-borne epidemic of disease. Nor do infants fed on fresh cows' milk suffer worse than those fed on condensed milk, but on the contrary, the reverse is the case. It is the condensed milk-fed infants

s See Bacteriology of Milk, Swithinbank and Newman (1903), pp. 262-278. 
that mostly die from diarrhœa, not because condensed milk contains more organisms than fresh cows' milk (for it contains less), but in all probability because condensed milk is less nutritious and sustaining, and is more liable to home contamination than cows' milk.

Experience of Other Towns.-Evidence is now rapidly accumulating as to the evil effects of artificial feeding of infants. It is undesirable to burden these pages with details which would of necessity involve much repetition, and it is difficult briefly to tabulate such experiences. The following further facts serve, however, to confirm the findings in Derby, Finsbury, and Brighton :-

Inquiries have been made at Croydon for several years. In 190463 per cent. (previous inquiry $5^{8}$ ) of infants alive at six months of age are breast-fed, and of dead infants 42 per cent. (previously 45) of these dying from all causes, and only 9 per cent. (previously 14 ) of those dying from diarrhoea ${ }^{x}$ (Richards).

At Colchester Dr. Savage has shown that 62 per cent. of infants under six months, and 60 per cent. of all infants under twelve months, are wholly breast-fed. Only 4 per cent. of infants were found to be having condensed milk only. The chief cause of infant mortality in Colchester is prematurity, congenital conditions, and atrophy, which constituted 39 per cent. of all infant deaths in $1905 .{ }^{2}$

At Stockport, in I904, it was found that of 116 infants dead from diarrhoea 95 per cent. were fed wholly or partly by hand. Inquiry also showed that out of 977 breast-fed children only 2 per cent. were "delicate in health," whereas out of $3^{6} 3$ artificially-fed children 68 per cent. were delicate.

In Blackburn, in 1904, 85 per cent. of all children under seven months of age were nursed and tended by their mothers, but only 37 per cent. were wholly breast-fed. There were 595 infant deaths, of which about 70 per cent. were under six months of age. ${ }^{3}$

- Rep. on Health of Croydon, 1904, p. 2 I.

= Ann. Rep. of Med. Off. of Health, 1905, pp. 9 and 25.

3 Ann. Rep. on Health of Blackburn, I904. 
At Salford, in 1904, 109 infants dying under 1 year were breastfed, which gave an infant mortality of 128.6 ; the infant death rate for children fed on breast milk and other food was $190^{\circ} 4$, that for children fed on cows' milk only, $263^{\circ} 9$; and that for infants fed on other food (condensed milks, \&c.), $439^{\circ} \circ$ per $\mathrm{r}, 000$ births. ${ }^{x}$

Mr. Seebohm Rowntree tells me that at York it is very apparent that deaths of children under twelve months of age are largely due to wrong feeding. Out of roo deaths it was found that in only 16 cases had the babies been breast-fed, and in 5 of these some addition (generally bread or biscuits) had been admittedly made to the mother's milk. Of the 84 artificially-fed babies 39 died from diarrhœa, 8 from convulsions, and 4 from intestinal trouble other than diarrhœea. The remaining deaths were due chiefly to wasting or bronchitis. The proportion of children receiving natural nourishment in York is about 75 per cent. and of the 25 per cent. who are artificially fed a certain number are either wholly or partially breast-fed for longer or shorter periodsin some cases for six months.

In Birmingham Dr. Robertson calculates that the infant mortality rate for breast-fed infants is 7.8 per 1,000 births, for breastfed and otherwise fed children $26 \cdot 5$, and for children having no breast milk $25^{2} 3$. It appears that 86 per cent. of the mothers in Birmingham partly or entirely breast-feed their infants. Seventynine per cent. of infants under six months of age dying in the third quarter of 1904 were bottle-fed with tube-bottles, and 2 I per cent. with boat-bottles. ${ }^{2}$

These three urban districts may be suitably contrasted with the county of Dorset, which is characterised by one of the lowest county infant death rates in England. In I 845-54 the infant mortality rate was 123 per 1,000 births. It is now 92. In answer to inquiries addressed to the local medical officers of health as to the cause of this low mortality, I have received ten replies, covering the condition of things existing in the greater part of the county.

- Ann. Rep. on Health of Salford, I904, p. I7.

2 Ann. Rep. on Health of Birmingham, I904, pp. 42-43. 
The two chief conditions which are operating favourably are the breast-feeding of infants and the absence of factory occupation of women. The former is relative, but on the whole the usual practice appears to be to nourish infants in the natural way "for twelve months or more." As to the latter there is, speaking generally, but little occupation of married women in factories (only II.4 per cent., as compared with $37^{\circ} 9$ in, say, Blackburn). A third condition upon which there is agreement is the comparatively favourable circumstances obtaining as to housing accommodation. Dr. C. H. W. Parkinson of Wimborne, who has had a long experience in the county, names also the sanitary improvement which has taken place, particularly the abolition of the old privy system of conservancy, and improved land drainage and water supply. $\mathrm{He}$ also considers that the social life of the people accounts, in part, for the low infant death rate. Wages are fair, in some districts good, and there are few unemployed. "The general habits of the people," he adds, "have improved, and there is distinctly less drinking to excess." Most of the medical officers remark on the low incidence of epidemic diarrhœa, which indeed has been characteristic of this county since $187 \mathrm{I}-8 \mathrm{O}$. It is an interesting example of a locality where, in spite of a high earth temperature in the third quarter of the year, there is practically speaking no fatal diarrhœa of infants. This is attributed to the custom of breast-feeding and more careful infant management. It is also in part due, according to Dr. Carrington of Poole, to a good milk supply. Friendly Societies appear to prosper in the district, and consequently medical aid is readily obtainable. There is comparatively little overcrowding.

Such being the substantial facts as to infant feeding and management, we may attempt a word of summary as to 
the position. We have seen that before the child comes into the world ante-natal influences have already begun to mould its future, and that after its arrival the social and physical circumstances of the mother exert a dominating effect. The influence of occupation, great in many ways, is greatest in its indirect effect on the home environment and natural nourishment of the child, and this view is abundantly confirmed by a study of epidemic diarrhœa. Even the domestic and social conditions are reducible to terms of nourishment.

The present chapter has but added to the cumulative evidence as to the absolutely vital importance of suitable infant feeding. It is not everything, but it may be said that it is a greater factor than any other single thing. The problem of infant mortality is after all one of those elementary problems which depend more upon instinct and the physical faculties and functions which nature has provided in the mother than upon external environment. It is so with the young of all animals, and the human species is not an exception. And so it comes about that many of the facts set forth in the preceding pages have importance chiefly as they concern a fulfilment of the primitive needs of food and warmth and cleanliness. 
PREVENTIVE METHODS:(I) THE MOTHER

THIS book will have been written in vain if it does 1 not lay the emphasis of this problem upon the vital importance to the nation of its motherhood. Wherever we turn, and to whatever issue, in this question of infant mortality, we are faced with one all-pervading primary need-the need of a high standard of physical motherhood. Infant mortality in the early weeks of life is evidently due in large measure to the physical conditions of the mother, leading to prematurity and debility of the infant; and in the later months of the first year infant mortality appears to be due to unsatisfactory feeding of the infant. But from either point of view it becomes clear that the problem of infant mortality is not one of sanitation alone, or housing, or indeed of poverty as such, but is mainly a question of motherhood. No doubt external conditions as those named are influencing maternity, but they are, in the main, affecting the mother, and not the child. They exert their influence upon the infant indirectly through the mother. Improved sanitation, better housing, cheap and good food, domestic education, a healthy life of body and mind-these are the conditions which lead to efficient motherhood from the point of view of child-bearing. They exert but an indirect effect on the 
child itself, who depends for its life in the first twelve months, not upon the State or the municipality, nor yet upon this or that system of creche or milk-feeding, but upon the health, the intelligence, the devotion and maternal instinct of the mother. And if we would solve the great problem of infant mortality, it would appear that we must first obtain a higher standard of physical motherhood.

Without a moment's hesitation, I place this need as the first requirement. Other things, as we have seen, are important, but this is the chief thing. And, therefore, in the consideration of any measures for reducing the infant mortality, we must first attempt to solve the problem through the mother.

\section{The Reorganisation of Existing Agencies.}

There are in England a variety of charitable agencies which have for their ostensible purpose the assistance of mothers of the poor at the time of childbirth. Some of these are of an antiquated character, and their funds are being spent in a way which would not commend itself to their benefactors. Others are too small in scope and too little known to be of any material assistance in a problem so great; and both kinds are worked too greatly on a basis of "charity" rather than a basis of insurance. In view of what is being done in this country and America in ordinary life and accident assurance, and in Germany in the workmen's insurance, it is somewhat remarkable that no substantial organisation exists in England for the assistance and counsel of married women before, during, and after confinement. Yet no one can consider the facts as to the occurrence of infant mortality in industrial districts without perceiving that it is the occupation of women in factories and workshops up to the time of 
confinement, and the early return to work after confinement, which not only prejudices the prospects of the child before birth, but deprives it of the necessary nursing and tending after birth. By far the chief incidence of mortality falls on the infants of the working women who are thus compelled by their poverty or other circumstances, but almost invariably poverty, to deprive their offspring of even a fair chance of survival. In Germany a remedy has been found in a maternity fund, to which both employers and employed contribute, so that when the time of childbirth arrives the working mother receives a sum of money weekly, and on that account need not return to work at such an early date as formerly. No doubt this is good for the mother, but it is of even greater advantage to the child. In France there exists a Society for Nursing Mothers, which has been established since 1876 , and is recognised by the Government. The idea of preserving the mother's health for the sake of the child has prompted this piece of work. It is divided into two branches-before birth and after birth. The former branch consists of homes where destitute mothers are received for the last few weeks before the birth of their child. They are fed and cared for, until the time comes for them to be passed on to a maternity hospital and thence out into the world again. From the time the first refuge was opened, in 1892 , until the end of 1904, nearly 10,000 future mothers were sheltered; 3,902 of them were married women whose husbands were either away or ill, or had disappeared altogether, 922 had recently become widows, and 4,442 were unmarried and abandoned. The result of the receiving homes has been that no woman from these institutions has yet died in childbirth. Professor Pinard, in his report to the Academy of Medicine, said, "The children of our refugees are born in the best conditions of health and vigour; they always exceed the average weight, and are 
remarkably developed." I The second part of the work is maintenance or part maintenance of mothers during the first year of their infants' life, so that they may be free to nourish them from their own breast. For this purpose relief bureaux and dispensaries have been opened. Each woman is put under a lady patroness who knows about her, administers the allowance granted by the committee, and watches over her welfare, moral and material. A doctor visits also. Each month the child is undressed, weighed, carefully examined, and medically treated if necessary. In this way 39,119 children have been watched over since the beginning of the society in 1877 .

But this is by no means all that can be done. A mother suckling her infant requires nourishment, and it is lack of nourished mothers among the poor-many of whom are half-starved-that leads to the inability to provide milk for their offspring. This, in its turn, leads to early weaning, which involves artificial feeding, which is one of the most difficult undertakings in the tenement homes of the poor. And so it comes about that the earlyweaned infant is so often marked for death in infancy. The solution in some cases is undoubtedly a suitably modified milk for the infant, but in many other cases the solution, if we would but understand so simple a proposition, is to feed the mother.

This is now being done in France, where M. and Mme. Coullett have discovered that for less than the price of sterilised milk for the infant it is possible to give a meal to both mother and child. Instead of staking everything upon the provision of proper food for hand-fed infants these pioneers have gone one step nearer to the foundation of things by giving two good meals a day to nursing

I A somewhat similar movement exists among the Jews in East London known as the Sick Room Helps Society, which provides personal help in the homes of poor Jewish women at the time of confinement. 
mothers. Mme. Coullett's five restaurants in Paris are simple and homely. As little as possible is spent in rent, furniture, and accessories. They are situated in the poorer quarters, near to the homes of the mothers needing them. As a new neighbourhood is investigated, and as funds come in, a fresh dining-room is opened. The experiment has just been made at one centre of having the catering and cooking done by the serving woman. The meat is bought cheap at the meat market, the vegetables are collected from the shops in the cheapest streets, and the cost of each meal works out at $2 \mathrm{~d}$. per head. Beer is served to the women only when it is presented. Presents of beer, meat, fruit, barley, rice, and even tables, chairs, and pictures, are often made by sympathisers.

The principle on which the women are admitted to these meals is considered a distinguishing feature of the charity. No questions are asked. Are they married, are they single, are they Protestant or Catholic, are they rich, are they poor, who are they, where do they live?-none of these things need be said. "They are mothers, they are hungry - that is enough."

The notice of announcement states that "women nursing their children at the breast can be fed here gratis, in the morning from II to I, and in the evening from 5.30 to 7." Each mother is supplied with a large cup of broth, some meat, bread, and a glass of light beer, if such is presented. The charity is supported by private munificence, but the State and the municipality are, it is understood, also giving their support. The first of the Coullett restaurants was opened in November, 1904, and since that time some 70,000 meals have been given to these nursing mothers. It is not, of course, to be supposed that institutions of this kind will serve a useful purpose in all countries, and it is obvious that careful supervision is necessary to prevent 
abuse. But the fact remains that the nourishment of the mother is along the main line of reform.

\section{Education OF the Mother as to Infant MANAGEMENT.}

"Nothing seems to be wanting," writes the Medical Officer of Burnley, "but a department to teach the burgesses common sense, mothers how to feed a child till its teeth come, and how to nurse it when it is poorly." x Few facts receive more unanimous support from those in intimate touch with this question than the ignorance and carelessness of mothers in respect of infant management. Such ignorance shows itself not only in bad methods of artificial feeding, but in the exposure of the child to all sorts of injurious influences, and to uncleanly management and negligence. Death in infancy is probably more due to such ignorance and negligence than to almost any other cause, as becomes evident when we remember that epidemic diarrhœa, convulsions, debility, and atrophy, which are among the most common causes of death, are brought about in large measure owing to improper feeding or ill-timed weaning; bronchitis and pneumonia are due not infrequently to careless exposure (indoor or outdoor) $;^{2}$ and death from measles and whooping-cough is largely caused by mismanagement of nursing. To remedy this condition of things three different measures need to be carried out : $(a)$ instruction of mothers, $(b)$ the appointment of lady health visitors, and (c) the education of girls in domestic hygiene.

(a) It is now the usual practice in large towns for the Sanitary Authority to issue leaflets of instructions either

x Report on Health of Burnley, 1904, p. 4.

- In a London market street on a raw, cold, foggy night in November (I904), between the hours of 9 and Io, I have counted 67 infants in arms. A month later 66 were counted by another observer in the same street at the same time of night. (Report on Health of Finsbury, rgo4, p. 263.) 
through the birth registrars or through sanitary inspectors, or other visitors to the mothers of new-born infants. There is an almost infinite variety of these, some of which are too long and elaborate to be of service in the direction needed. A fairly good example of the shorter form of leaflet, which has the advantage of having been approved by two large London hospitals, will be found in the Appendix (p. 344).

A fuller and more adequate statement is that known as "The Elementary Counsels to Mothers and Nurses," edited by the Commission of the French Academy of Medicine on the Hygiene of Infancy (see Appendix, p. 346).

(b) Lady Health Visitors.-Some thirty-five or forty of the large towns now employ Lady Health Visitors to visit the homes of the poor where births have occurred and to give advice as to rearing of children. In other towns these duties are undertaken in greater or less degree by the Lady Sanitary Inspectors, whose duties, strictly, are confined to matters which concern the external environment, such as sanitation of premises and workshops, investigation of infectious diseases, \&c. In his annual report on the health of the county of Warwick for 1903, Professor Bostock Hill makes the difference clear:-

"It must not be thought the work of the health visitor trenches in any way on the duties of the sanitary inspector, or indeed any members of his staff. She is not an inspector in any sense of the word. Her functions are rather those of friend of the household to which she gains access, and it is very gratifying to know that although at first there may have been some opposition to her entering a house, this rapidly died away, and in numerous instances she has been asked to return and aid the mothers of families by her help and counsel. . . . In this new departure of carrying sanitation into the home I believe we have not only an important but almost the only means of further 
improving the health of the people. Sanitary authorities by providing water supply, drainage, and decent houses, have done much. In the future, however, the most important advance will come from an appreciation by the people themselves of the value of good health."

The qualifications required for a Lady Health Visitor are of a high character. The mere qualification of training is, of course, essential, but qualification by character and by natural gifts is equally necessary. Such an officer should be a trained hospital nurse if possible, and should hold a sanitary inspector's certificate. But in addition to such training, it is of the greatest importance that these women should have insight and tact, so that they will not only refrain from giving offence in their somewhat delicate duties, but they will actually by their sympathetic and tactful bearing gain the confidence, and even the friendship, of the parents whom it is especially sought to influence by their ministrations. At Huddersfield two lady doctors are engaged in the service of the Corporation in this task of visiting, and when possible there can be no doubt that medical visitors are the most suitably qualified of all. But even medical qualification requires the addition of the sympathy and tactfulness above mentioned. The scheme of visitation at Huddersfield, which is partially official and partially voluntary, and which came into full operation in 1906, is carried out as follows: The borough is divided into nine districts, from which births are notified to the Medical Officer of Health (on a voluntary system of payment of one shilling for each birth notified within twenty-four hours of its occurrence). Each of these nine districts has a voluntary worker known as a "Lady Superintendent," who is assisted by voluntary lady-helpers, and these various voluntary workers are supervised by two lady doctors appointed by the Corporation, who, of course, work under the Medical Officer of Health. The newly-born children are visited as 
soon as possible by the lady doctors, who give suitable advice and leave copies of the short or extended advice. Each Saturday a list of the cases in her district is sent to a Lady Superintendent, who distributes the cases among her Lady Helpers. These keep the cases under observation, and, where it appears necessary, invoke the aid of the Department. Great care is exercised to avoid touching upon the domain of the family doctor, and also to avoid any action which even might have the appearance of diminishing parental, and particularly maternal responsibility. ${ }^{\mathrm{I}}$

In the Longwood district of Huddersfield from November, 1904, to November, 1905, a promise was made by the Mayor of the town (Mr. Broadbent) to pay $£ \mathrm{I}$ as a birthday present to each baby born in the district on its completing its first year of life. The mere promise was, however, only part of the plan. The promise was made by means of a legally drawn promissory note printed on a card, on which was also given as much condensed good counsel as could be compressed into the space. The really effective "working part" of the scheme was a small committee of ladies. By means of the card the ladies obtained an introduction to the homes and paid visits periodically as occasion offered, helping the mothers with advice and sympathy. On various occasions, such as Christmas and Easter, little remembrances were sent to the individual babies, and at the commencement of the diarrhœa season and at the onset of cold weather short personal letters of advice as to the precautions needful were sent to each mother through the post.

It should be added that Longwood, though absorbed, is by no means merged in Huddersfield, but still keeps up a certain separateness and individuality. The population is 5,359 and the acreage 1,334; its height above

'Annual Report of Medical Officer of Health of Huddersfield, 1905. 
sea-level varies from $I 50$ feet to $I, 200$ feet; there is no congested population, there are no slums; portions of the area are really urban, whilst other parts are almost purely agricultural. By far the greater part of the population, male and female, are factory workers engaged in the manufacture of woollen goods, with a sprinkling of quarrymen, masons, labourers, and small farmers. It is, however, to be noted that a comparatively small number of married women go out to work; there is a strong public opinion against this in the village. The death rate for ten years has averaged 13.44 and the birth rate 19.39 , while the infantile mortality figure has been 122 per I,000 births. The infant mortality during the year in question showed marked reduction.

(c) The Education of Girls in Domestic Hygiene.-Among the conditions of modern town life tending to raise the infant mortality are the employment of married women as breadwinners for the family, and the comparative failure to educate girls in the elementary schools in matters of domestic hygiene. Attendance at school is now compulsory, and thus girls are deprived of much of the home-training they formerly received, and yet this serious loss is not made up to them by any similar instruction at school. It cannot be doubted that this has exerted an unfavourable effect in the home management of infants, and the only way to counteract it is to instruct and educate the elder girls in all elementary schools in these matters.

"Whatever else girls may or may not be taught," writes Dr. Niven, "it should be absolutely compulsory on them to get a thorough grounding in certain domestic branches of knowledge before leaving school, and they should not be allowed, generally speaking, to leave school until they can show a competent acquaintance with those branches, unless provision is made for their subsequent education. A girl should know how to cook a variety of common articles of food, and to sew and mend. She 
should know also how to clean a house, and when a house can be regarded as clean. She should be taught the dangers to health arising from filth. The course should comprise the properties and prices of suitable food. She should learn how to clean, manage, and feed infants and young children. She should also know something about infectious diseases, their dangers, and how to act when they occur. All boys and girls should be taught the elementary principles of personal hygiene.

"The knowledge embraced in the course which I have sketched should be intimate and practical. Such a course as the above should be regarded as the necessary feature of a girl's education, and nothing should be permitted to displace it." 5

It is evident that in order to conduct such studies it will be necessary also for the teachers to become qualified by special training in the elementary principles and practice of hygiene and infant management.

In 1905 the Board of Education issued "Suggestions for the Consideration of Teachers" of public elementary schools. ${ }^{2}$ This admirable memorandum (which extends to some $150 \mathrm{pp}$.) contains, unfortunately, very little reference to the importance of teaching domestic hygiene, which is only suggested incidentally. The Board Memorandum states that:-

"A course of instruction in hygiene should form part of the work for the two highest classes of every girls' school. Such instruction will naturally be included in a course of household management; and if that subject is not taken the lessons on common things should include a few lessons applicable to the home circumstances of the scholars, dealing in an absolutely non-technical way with questions of feeding, clothing, rest, air, light, warmth, exercise, cleanliness, and the general care of health. In some cases it will be well to include some instruction on the care of young children. Practical instruction in cookery,

Report on Health of Manchester, I904, p. 216.

- Board of Education, Cd. 2638, I905, p. 86. 
laundry work, and housewifery will be of very little value unless it bears some relation to the actual needs of the children in their own homes. Some simple ambulance lessons may also be included in the course.

"It is most desirable that every scheme of instruction for older children should include a short series of lessons enjoining temperance as regards the use of alcoholic beverages and stimulants.

"Such lessons, like those suggested above on hygiene, need not be grouped under a new separate head of the curriculum, but can be included among the lessons given in elementary science, knowledge of common things, cookery or household management, as may be most suitable in the particular circumstances. Some of the important points can be reasoned out, but others cannot he satisfactorily dealt with in this way, and must therefore be didactically impressed on the children by an appeal to the testimony of experience and to the authority of trained investigators of such matters. Sensational lessons, illustrated by physiological diagrams, or by exciting descriptions of the unhappy effects of drunkenness on society or the individual, are as likely to do harm as to do good.

"The purpose of the instruction given on this difficult topic should be to make the children understand that health and happiness are sure to be impaired if strictly temperate use is not made of food and drink."

The Appendix of the memorandum contains an outline scheme for teaching hygiene and temperance, which deals in elementary fashion with the home, the person, eating and drinking, fresh air, sunshine, cleanliness, \&c. All this is very appropriate and suitable, but has little to do with infant management. What is needed is a training in those arts of domestic management of which compulsory education has deprived the girls of the artisan classes. There are, no doubt, difficulties and there is expense; but this kind of instruction is now absolutely essential if we would have young women in the next generation not so ignorant as many of the young married women are to-day. 


\section{As to the OCCUPATION OF THE MOTHER.}

However much the employment of married women is open to criticism, the fact of their employment remains, and appears under present circumstances to be, in many cases at least, a necessary evil. Hence the immediately practicable measures must be applied rather to the protection and relief of such women than to any attempt at prohibition. Short of that there are three directions in which more should be done to reduce to a minimum the grave disadvantages to infancy of such occupation. First, there is needed amendment of Section 6 1 of the Factory Act; secondly, a more uniform enforcement of factory sanitation; and thirdly, the establishment and control of crèches.

In Section 6r of the Factory and Workshop Act, I90I, it is required that an occupier of a factory shall not knowingly allow a woman to be employed in his factory or workshop within four weeks of childbirth. Some authorities recommend that this period should be extended, say, to three months; others advise that a similar period of a month should be fixed before confinement as well as after. No doubt these are in every way desirable limitations, but not perhaps so practical as they may appear at first sight. Still, in this respect, as in many others, England is behind the best European practice. ${ }^{\mathrm{I}}$

As we have seen, the law in Switzerland has been extended to a total period of eight weeks before and after confinement, which, in the opinion of M. Schuler, an

x "The nation must set its face against the employment of married women in factories or workshops, and gradually extend the period of legal prohibition. There is only one proper sphere of work for the married woman, and that is her own home. In the case of factory workers, the employer must be made to furnish a maternity fund if he wishes to employ married women. Thus penalised he will probably prefer not to employ them, to the very great advantage of the labour market and the nation." (Riches and Poverty, L. G. Chiozza Money, M.P., 1905, p. I69.) 
inspector of factories in Switzerland, has had a beneficial effect in adding both to the weight of the infants born and to their survival. In Germany and Austria the existence of a compulsory system of workmen's insurance renders the carrying out of such regulations comparatively easy. In Germany the working woman who, owing to child-birth, is compelled to abstain from industrial labour receives, in addition to gratuitous medical assistance, a sum equal to half her ordinary daily wage. Compensation must, it would seem, accompany any extension of the present period of the one month (as is practised at Creusot).

Short of any such radical change there are three amendments of this section which seem practicable, namely, the omission of the word "knowingly," the introduction of medical certificates, and a provision against employment within the month by a fresh employer. It has been found in practice that the word "knowingly" suggests an adequate defence for culpable negligence, so that it is extremely difficult in many cases to bring home the responsibility of such employment to the actual offending manager or foreman. Then, again, it would be a step in the right direction if re-employment at, say, two or three months were made permissible only on production of a medical certificate showing that the child's health would not be injured by its mother's employment away from home. And thirdly, some new clause should be added by which a mother's services could not be obtained by any employer whatever within a month of her giving birth to a child. These may appear to be small points, but they are of great importance. At present Section $6 \mathbf{I}$ is being considerably evaded, which indicates negligence, at least, on the part of employers, and in some degree ignorance on the part of mothers, although there is no doubt that it is often a question of working or starving. "The spirit, if not the 
letter," reported Miss Anderson, Principal Lady Inspector of Factories, "of the present law is broken." The enforcement of factory sanitation will be mentioned subsequently.

Thirdly, if married women's labour be not prohibited, there is much urgent need, especially in some towns, for a greater protection of children in the absence of the mother. In the towns where married women are employed it will be found that the infant mortality is largely caused by the absence of the mother from home. It must be admitted that this is chiefly owing to absence of natural feeding, but it is also largely due to neglect, careless artificial feeding, exposure to cold, and all that follows in the wake of an absent mother. For such children some form of crèche is probably necessary where they may be tended and cared for daily.

Such crèches, or Day Nurseries, exist in most civilised countries. In France and Germany they are more strictly controlled and applied to the interest of the child than in this country, where there is room for considerable reform. The following facts are of interest in this connection. ${ }^{\mathrm{I}}$

\section{England.}

In England, almost without exception, Day Nurseries (of which there are about 75) are charitable undertakings, depending for their support upon private subscriptions. The average accommodation per nursery is for between 20 and 30 infants, and ranges from 10 to 65 , and the average attendance varies from 50 to 90 per cent. of the capacity of the nurseries. The ages at which the infants

- For the information as to crèches in England, France, and Germany, I am indebted to a comprehensive report on the subject by the Chief Officer of the Public Control Department of the London County Council, No. 884 (1904), and to a special report by Dr. S. G. H. Moore, Medical Officer of Health of Huddersfield, 1905. The latter has viewed the matter particularly from the point of view of infant mortality, and much of what follows on the subject of creches is derived from his report. 
are eligible for admission are from three or four weeks up to five years.

The staff of the nurseries, of course, depends upon the number of children received, and their age; but generally it is found that one nurse with a young girl as assistant can take charge of about 20 infants, and it is found that a nursery capable of receiving 50 infants will require a staff of Matron, Nurse, and two girls.

The nurseries are generally opened between 7 and 8 a.m. (although in exceptional cases the time of opening is as early as $5.30 \mathrm{a} . \mathrm{m}$.), and the children are fetched away between the hours of 6.30 and 8 o'clock at right, the average stay being about 12 hours. The charges vary from $2 \mathrm{~d}$. to $4 \mathrm{~d}$. per day, and in most nurseries only half the usual charge is made for the children of widows and widowers, and a reduction is also made if more than one child from the same house attends the nursery. The fees are usually paid day by day. The School Board creches in London (4) are free, as are also several others. Food is provided for the children according to their ages. At most of the nurseries clothing is not provided, with the exception of short pinafores, which are worn by the children over their ordinary clothes. In one or two instances the children are clothed during the time they are in the nursery with garments belonging to the Institution, their own clothes being kept in washable bags outside the nursery, separate bags being provided for each child. Provision is made for sleeping by means of cradles for the younger, and cots, large couches, and "pounds" for others. In some of the institutions each child has its own particular cradle or cot. The children are expected to be brought in a cleanly state as regards the person and clothing, and in some cases admission is refused unless this is done. In seven of the London crèches each child is bathed daily. 
To prevent the introduction and spread of infectious disease in the nurseries, an examination is usually made of infants brought for admission, and in several of the nurseries the child is required to be examined by a medical man, and a certificate given as to freedom from any infectious disease. Any suspicious case of illness is at once isolated until after medical examination, or sent home.

With reference to children who are suffering from diseases which are not of an infectious nature, the general rule appears to be to admit such as do not require any special attention, although in one or two of the nurseries children who are at all unwell are not admitted.

The cost of maintenance of the nurseries in England varies from $2 \mathrm{~s}$. to $4 \mathrm{~s}$. per child per week, the average cost being about 3 s. 3 d. - Many of the nurseries have the building provided free of charge and receive a good many gifts, which renders it impossible to state accurately the actual cost. The salaries paid appear to be approximately: Matron, $8 \mathrm{~s}$. to I2s. ; nurses, $4 \mathrm{~s}$. to $8 \mathrm{~s}$. ; and girls, from $3 \mathrm{~s}$. to 5s. per week.

In most of the nurseries only children whose parents are obliged to work during the day are received, such as children of widows and widowers, and children from houses where both parents work during the day. In some of the nurseries only fatherless children are received, and in some infants must be vaccinated, whilst in others the marriage certificate must be produced. In 27 of the 55 London crèches illegitimate children are not admitted.

From the manner in which the nurseries are used it would appear that they fulfil a want, and it is beyond doubt that at least while the infants are at the nurseries they are well fed, cared for, and kept in a cleanly condition. 


\section{France.}

In four towns which replied to the inquiries made by Dr. Moore, namely, Paris, Lille, Dieppe, and Nantes, there are Day Nurseries. In the sixty-six crèches in Paris the support is by means of contributions from the State and City, and subscriptions from private persons. All are under the supervision of the Administrative Authority.

In the Department du Nord, in which Lille is situate, there are forty-eight nurseries-thirty-eight at Lille, three at Roubaix, two at Dunkirk and Tourcoing, and one each at Rosendael, Canbrai, and Joix-du-Nord, some of which are supported by the Municipality, some privately, and some by the Municipality and private means combined, and all are under the control of the Administrative Authority.

In Dieppe the nursery is a private one, subsidised by the town.

In Nantes there are two nurseries supported solely by private means, and four charitable institutions subsidised by the town.

Without exception they are successful, and have been of much service to the poor people, but, as is expected, they are not self-supporting. They are controlled by Regulations prescribed by the Decree Concerning Nurseries, issued by the President of the Republic, May 2, 1897, and based upon similar regulations decreed in 1862 . The Minister of the Interior and the Prefect are empowered to lay down minor conditions and regulations under an Order. The Ministerial Order of December 20, I897, is a document of

I These nurseries receive children from their birth up to the age of three years. Each establishment contains at least twenty-five to thirty beds, and is under medical supervision. The resources come to them from (I) Subscriptions from the members of a Society; (2) gifts ; (3) legacies; (4) contributions from the State, from the Department, from the City of Paris, and from the Society of Day Nurseries. The subscriptions of the City of Paris in 1903 amounted to 144,000 francs $(f 6,000)$; (5) Payments by mothers, who contributed about Id. or $2 \mathrm{~d}$. per day. 
much interest, entering fully into many important details. For example, that infants shall not be kept in the nurseries at night, that weaned infants shall be separated from unweaned; the necessary cubic capacity of rooms in the nursery; the heating arrangements; the suitability of cradles, beds, and articles of toilette; the absolute disallowance of the tube feeding-bottle; accommodation for feeding and the kind and quantity of food ; the management of sickness and protection from infection; and the keeping of a register. Elementary counsels to mothers and nurses are also issued.r In Dr. Moore's report there is an interesting account of the results of works of this kind in the Commune of Villiers le Duc.

\section{Germany.}

Dr. Moore states that in Elberfeld and Munich there are Day Nurseries (Krippen) supported by the town. In Schwerin, Darmstadt, Dusseldorf, Bremen, Leipsic, Breslau, Elberfeld, Munich, Berlin, Kiel, Cologne, and Hamburg there are Day Nurseries which are supported by charity but some of which also receive a grant from the town and State. In Frankfort the municipal authorities arrange for the children of poor parents who are obliged to work during the day to be taken care of by the neighbours, but there is a movement on foot, in which the municipality, howiever, are not concerned, to establish a Day Nursery.

The object of the nurseries is to look after the children of poor people who have to work outside the house during the day. The children remain in the nursery up to the age of about three years. There are also Waiting Schools and Children's Nursing Institutes in many of the towns for older children.

Without exception the nurseries have proved a great success, and it cannot be doubted that they have fulfilled

see Appendix, p. 346. 
their objects. They offer to the children a healthy adoption, food of a nutritious character, and the moral and physical development of the children is looked after. They do not appear to be a financial success, nor is such expected or aimed at, and they all require a considerable sum over and above that received by way of fees from the children to enable them to continue.

In Dusseldorf, in order to reduce infantile mortality, strong regulations have been made respecting the milk supply and other cognate matters. ${ }^{x}$ Special regulations also exist for looking after foster children, places where they are kept being liable to surprise visits by medical men, and, if neglect is found, the permission which is necessary for the adoption of foster children is withdrawn.

In Elberfeld the keeping of children by foster mothers is subject to police regulations. A print of regulations and recommendations, practically similar to the Dusseldorf regulations, is given in every case of birth, and arrangements are also made with the doctors by which the town undertakes the cost of first treatment in pressing cases. There are also arrangements in existence by which poor, suffering children are afforded holidays in the country for the good of their health. In Elberfeld there are also other kindred institutions-a Kinderheim conducted by a deaconess, and a Marienheim supported by the sisters of the Catholic communion. Dr. Moore is able to quote various regulations concerning the fitting-up and administration of Krippen in Elberfeld.

In Cologne there are also soup-kitchens for poor children, holiday colonies for sending poor, delicate children into the country for a short period, and milk stations. A copy of the recommendations for the nourishment and nursing of poor children in their first year is given in every case of birth.

I See Dr. Moore's Report, 1905, pp. 85-92. 
The advantages claimed for the crèche system may be summarised as follows : (1) The crèche is usually healthier and cleaner than the child's home ; the treatment is more enlightened, and the method of feeding better adapted to the child's tender age. (2) At the crèche the child is taught cleanliness and good habits, becomes stronger and healthier, and is given a better chance in life. (3) Crèches are under medical supervision, and the promptitude with which a case of sickness is treated often prevents more serious consequences. (4) The mother is required to bring the child clean; better methods of feeding are learned; and the cleanliness and discipline of the creche insensibly react to the advantage of the home.

Yet after all they are but a palliative method of prevention, and are not to be compared for a moment in value with education and training of the mother. The diminution in the proportion of women occupied in domestic service (from 14.2 to $12 \%$ per cent. at the last census), compulsory education, and the increase in the cultivation of amusement, and the love of ease and pleasure, have tended to lessen domesticity among the younger working women of the present day, and it is these conditions which would appear to necessitate the largest degree of constructive reform. No scheme of assisting maternity can ever have a wholesome effect which lessens the sense of responsibility or minimises the essential value of personal service. 


\section{$\mathrm{X}$ \\ PREVENTIVE METHODS: (II.) THE CHILD}

THE methods which concern more particularly the

1 child are those of birth-registration, protection, and artificial feeding.

(1) The first attempt to require by law the registration of births was in 1812, when an Act was passed for regulating and preserving parish and other registers of births, baptisms, marriages, and burials in England. The only registrations required by this Act were those of baptisms. In 1836 , however, an Act came into force for registering births, deaths, and marriages, and for the establishment of the necessary administrative machinery and the appointment of a Registrar-General. To the Guardians of the Union in each district was allocated the duty of arranging the registration districts and the appointment of registrars, \&c. As the Act of 1836 did not specify any time limit for the registration of births, it became necessary eventually to pass an amendment Act, namely, the Births and Deaths Registration Act of 1874 , by Section I of which it was enacted that in the case of every child born alive it shall be the duty of the parents, or in their default the occupier of the house in which the child was born, to give to the district registrar, within forty-two days of the birth, information and the necessary particulars for registration. Where this information has not been 
furnished within the specified period the registrar may, by notice in writing, require the necessary information within not less that seven days and not more than three months It is the duty of the registrar to inform himself as far as possible of every birth occurring within his district. Where a birth has not been registered within twelve months of its occurrence it cannot be registered except by consent of the Registrar-General, and the Superintendent Registrars are empowered by the Act to institute proceedings for failure to register. In the case of an illegitimate child no penalty attaches to the father for non-registration, but the mother is liable for neglect to register. The father may, however, have the child registered in his name if he so elects. No registration is required of still-born children, but before such can be buried a medical certificate, coroner's certificate, or parental declaration is required.

In practice it has been found that about two-thirds of the total births occurring in England and Wales are registered within the six weeks' limit of the Act of 1874 , whilst as we have seen about one-third of the total deaths of infants takes place in the first month. It is therefore evident that many births first come to the knowledge of the Sanitary Authority on the bills of mortality, which effectually precludes any preventive action.

In 1854 an Act was passed "to provide for the better registration of births, deaths, and marriages in Scotland," under which birth registration is required within twenty-one days, just half the allowed period in vogue in England.r This, of course, is a considerable improvement, but even so it is found that three weeks is an inconveniently long period for the Sanitary Authority to wait for information as to births. Accordingly, efforts have been made to

The French Code (Civil Art. 55) provides for registration within three days of birth. 
organise a system of earlier intimation. In Glasgow a remuneration of one shilling has been offered to any one intimating to the Medical Officer of Health the occurrence of a birth within forty-eight hours of the event. Dr. Chalmers reports, however, that this arrangement has not produced the desired effect, a failure which has been counteracted in part by a system of intimation (within forty-eight hours) from the Maternity Hospital of "outdoor" births attended by the staff. In various districts lady sanitary inspectors have periodical access to the registrar's lists, or midwives are furnishing early information. This last method has been most fully organised in London, where the Medical Officer of the County Council (Sir Shirley F. Murphy) has arranged to collect every week from the midwives a record of births attended by them and to distribute these lists to the various Borough Councils. In this way early intimation is obtained of a large number of births.

Lastly, in Huddersfield a voluntary system of payment of one shilling, as in Glasgow, for birth intimations within forty-eight hours, which has been adopted for some months, has developed into a clause in a local Act

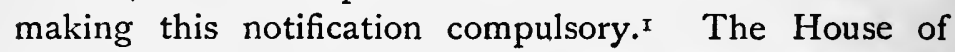
Commons has approved of the clause, which, it may be hoped, is thus destined to be the forerunner of new legislation requiring the early notification of births, without which the Sanitary Authority is considerably

The operative part of the clause reads as follows :-

"I. In the case of every child born within the borough after the commencement of this Act, it shall be the duty of the father of the child, if he is actually residing in the house where the birth takes place at the time of its occurrence, or in his absence of any person in attendance upon the mother at the time of the birth or within six hours thereafter, to send or give notice of the birth to the Medical Officer within forty-eight hours after such birth."

The fee payable for notification is one shilling. Penalty for failure to notify, twenty shillings. 
hampered in the exercise of preventive measures against early infant death. ${ }^{x}$

(2) The law provides for the protection of children and infants in three enactments-the Midwives Act of 1902, the Infant Life Protection Act, I897, and the Prevention of Cruelty to Children Act, 1904. A steady and uniform enforcement of these three statutes, with some minor amendments, is likely to result in immense improvement. We have not yet had time to experience to the full the enormous difference to the child-life of Great Britain which may yet result from this legislation. A few words as to the purpose of each Act may be added.

\section{(a) The Midwives Act.}

In addition to the performance of various routine work in connection with the registration of midwives, the following duties having direct import with regard to the public health are to be carried out by the Local Supervising Authority under Section 8 of the Act:-

I. The Authority is to exercise a general supervision over all midwives practising within its area, in accordance with rules drawn up by the Central Midwives Board in pursuance of Section 3 of the Act.

2. The Authority is to investigate charges of malpractice, negligence, or misconduct on the part of any midwife practising in its area, and, should a primâ facie case be established, to report the same to the Central Midwives Board.

3. The Authority is to suspend a midwife from practice,

2 The Registrar-General, in reviewing this question, writes in the Report just issued: "After serious consideration of the situation as it presents itself to me, I have come to the conclusion that whilst it would be unwise at present to disturb the existing organisation of birth registration, a welldevised system of early notification of births-legalised and worked in conjunction with the present registration system on the one hand, and with sanitary administration on the other-might, along with other motive forces, serve as a most effective and lasting barrier with which to stem the tide of infant mortality." (Sixty-seventh Ann. Rep. of Registrar-General, I904, p. xlix.) 
when necessary to do so, in accordance with the rules drawn up by the Central Midwives Board in pursuance of Section 3 of the Act.

The more important of the rules which have been drawn up by the Central Midwives Board, as cited above, are to the following effect:-

I. Whenever a midwife has been in attendance upon a patient suffering from puerperal fever, or from any other illness supposed to be infectious, she must disinfect herself, and all her instruments and other appliances, to the satisfaction of the Local Sanitary Authority, and must have her clothing thoroughly disinfected before going to another labour.

II. Formal notification must be made by the midwife to the Local Supervising Authority when any of the following occur :-

(a) When the mother or the child dies without having been seen by a Registered Medical Practitioner.

(b) When the child is deemed to be stillborn.

(c) When, owing to the occurrence of various complications of either the labour or of its aftercourse, as defined in the rules, it has been necessary for the midwife to "advise that a Registered Medical Practitioner be sent for."

III. The Local Supervising Authority must make arrangements to secure a proper inspection of every midwife's case-book, bag of instruments and appliances, \&c., and must, when thought necessary, make arrangements for an inspection of the midwife's place of residence, and for an investigation of her mode of practice.

IV. In carrying out certain rules for checking the spreading of puerperal infection by midwives, it will be the duty of the Local Supervising Authority to suspend from practice a midwife who contravenes the directions issued for the use of disinfectants and for the proper safeguards against the spread of infection laid down by the Central Midwives Board, and any other rules laid down by the Board. And in the exercise of that duty the Local Supervising Authority shall, after communicating their decision in writing to the midwife concerned, at once report any suspension (with the grounds thereof) to the Central Midwives Board. 
The avowed object of this Act was to secure the better training of midwives and to regulate their practice; and when it is remembered that there is a heavy loss of infant life within a few days after birth, it will be seen how great may be the saving of life through its means. Indeed, the midwife is often the first teacher of the mother as to infant management, and in various districts she is now, in practice, acting in this capacity and as an early certifier of births.

\section{(b) The Infant Life Protection Act, 1897.}

The first legislative enactment to protect nursechildren was the Infant Life Protection Act of 1872, which provided that a person could not receive for hire or reward more than one infant, or, in the case of twins, two infants, under the age of one year, for maintenance apart from their parents, for a longer period than twenty-four hours, except in a house which had been registered as a suitable place. And in I896 Lord Denbigh, on behalf of the London County Council, introduced a Bill in the House of Lords, which eventually passed unopposed through both Houses, and became the Infant Life Protection Act of 1897 . The chief provisions of this Act will be found in the Appendix (p. 350).

It is desirable that the Act should be extended to include every child received for hire or reward, and every child adopted for a lump sum, no matter what the amount; that nurse-children should remain under inspection until seven years of age; and the Local Authority should be empowered to remove an infant from the keeping of any person who is unfit to take care of it, by reason of character or otherwise, and to remove any child kept in a house or on premises unsuitable for the purpose. "Single" cases need inspection equally with those where more children than one are nursed, because infant deaths are 
largely caused by preventable diseases resulting from carelessness, ignorance and neglect, and nothing but regular inspection can remedy this. ${ }^{\mathrm{I}}$

\section{(c) The Prevention of Cruelty to Children Act, 1904.}

This Act only concerns infancy in a general way as a statute for the prevention of cruelty to all or any children. Section I enacts that if any person over the age of sixteen years, who has the care of any child under the age of sixteen years, wilfully assaults, ill-treats, neglects, abandons, or exposes such child, or causes or procures such child to be assaulted, ill-treated, neglected; abandoned, or exposed in a manner likely to cause such child unnecessary suffering, or injury to its health (including injury to or loss of sight, or hearing, or limb, or organ of the body, and any mental derangement), that person shall be guilty of a misdemeanour; and $(a)$ on conviction on indictment, shall be liable, at the discretion of the court, to a fine not exceeding $£ \mathrm{I} O 0$, or alternatively, or in default of payment of such fine, or in addition thereto, to imprisonment, with or without hard labour, for any term not exceeding two years ; and $(b)$ on summary conviction, shall be liable, at the discretion of the court, to a fine not exceeding $£ 25$, or alternatively, or in default of payment of such fine, or in addition thereto, to imprisonment, with or without hard labour, for any term not exceeding six months.

A person may be convicted of an offence under this section either on indictment or by a court of summary

I Much has been written on a relation which, it is believed by some, obtains between infant mortality and insurance. No doubt most dead infants have been insured, for the reason that most infants of the poor are habitually insured. There is but little evidence in support of the view that many infants are insured and then slowly but wilfully done to death. No doubt such events occur, but they do not contribute substantially to the death rate. 
jurisdiction notwithstanding the death of the child in respect of whom the offence is committed.

If it is proved that a person indicted under this section was directly or indirectly interested in any sum of money accruable or payable in the event of the death of the child, the court, in its discretion, may $(a)$ increase the amount of the fine, or $(b)$ sentence the person indicted to penal servitude for any term not exceeding five years.

\section{The Artificial Feeding of Infants.}

(3) Next to absolute protection comes infant feeding, and the great requirement is the breast-feeding of infants. ${ }^{\mathrm{x}}$ But this unfortunately is not always possible. A mother may be unable from one cause or another to furnish a natural supply of milk for her child. Some mothers may be unwilling to nurse their children, and others, though desiring to do so, may find it impracticable, owing to the fact that they may have to act as the bread-winner of a family and go out to work. But if all these cases be deducted from the total there yet remains in large communities a considerable number of mothers incapable of nursing their children. It is for such cases that Infants' Milk Depôts have been established, to supply a pure milk, suitably modified to make it as much like human milk as possible. It is clear that such a specialised milk-supply

- Abundant evidence has been furnished in previous chapters of the high mortality occurring among artificially-fed infants as compared with breast-fed. M. le Prof. Budin, of Paris, kindly allows me to reproduce his charts illustrating this special incidence in Paris. The matter could hardly be more clearly demonstrated, for the charts show not only the marked rise of diarrhœa mortality in the third quarter of the year, but the special mortality of the artificially fed as compared with the breast-fed. The decline in both, illustrated in the second chart (1899-1901), Dr. Budin believes to be due to the influence of the improved feeding of infants originating in the French milk depôts and consultations. 
does not meet the entire problem of infant mortality, the solution of which depends, on the whole, ultimately, not upon the State, nor yet upon this or that system of milk feeding, but, as we have seen, upon the intelligence, the devotion, and the maternal instinct of the mother. Nevertheless, it is true that a properly equipped and controlled Infants' Milk Depôt is part of the solution at the present time and under present conditions, and is a practical step in the right direction.

Infants' Milk Depôts are of French origin, and are generally speaking of two kinds-namely, the consultation de nourrissons and the goutte de lait. $\mathrm{x}$ In 1892 , Budin founded one of the former at the Charite Hospital in Paris, and in the same year Variot established another one in connection with the Belleville Dispensary. There are two types of consultations de nourrissons - the one is a kind of lying-in institution in which women are admitted for confinement free of charge, and the children born in the hospital are kept as out-patients under regular medical supervision for the first two years. Breast-feeding is encouraged, but where impracticable, sterilised milk is supplied in bottles containing sufficient for one meal only. The child is weighed and examined periodically. In the second type, the consultation is not attached to a hospital, but is otherwise similar. The goutte de lait (or drop of milk) is a sort of milk dispensary from which infants are fed, under medical supervision, upon sterilised milk, with or without modification. The first institution of this kind to exist separately was established at Fécamp in 1894 by Dr. Leon Dufour. Most of these Infants' Milk Depôts in France are conducted on a philanthropic basis, and are financed by voluntary subscriptions. At

I For particulars as to the history and equipment of Infants' Milk Depôts see Infantile Mortality and Infants' Milk Depôts, by G. F. McCleary, M.D., I905; also four. of Hygiene, vol. iv. 1904, pp. 329-368; and Practitioner, I905 (October). 
INFANT DEATHS from EPIDEMIC DIARRHCEA in PARIS 1898.

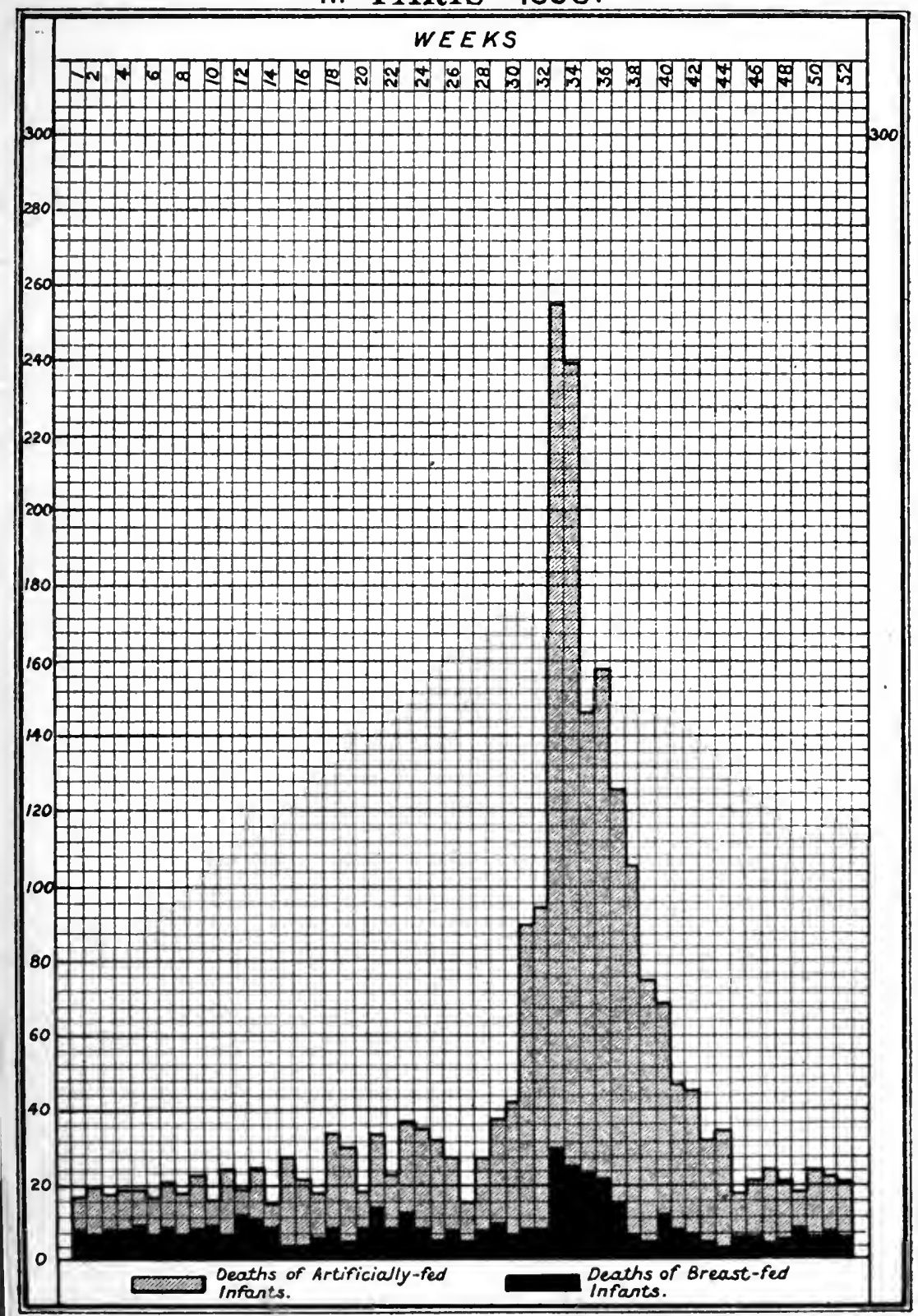



INFANT DEATHS from EPIDEMIC DIARRHCEA in PARIS 1899.1900\&1901

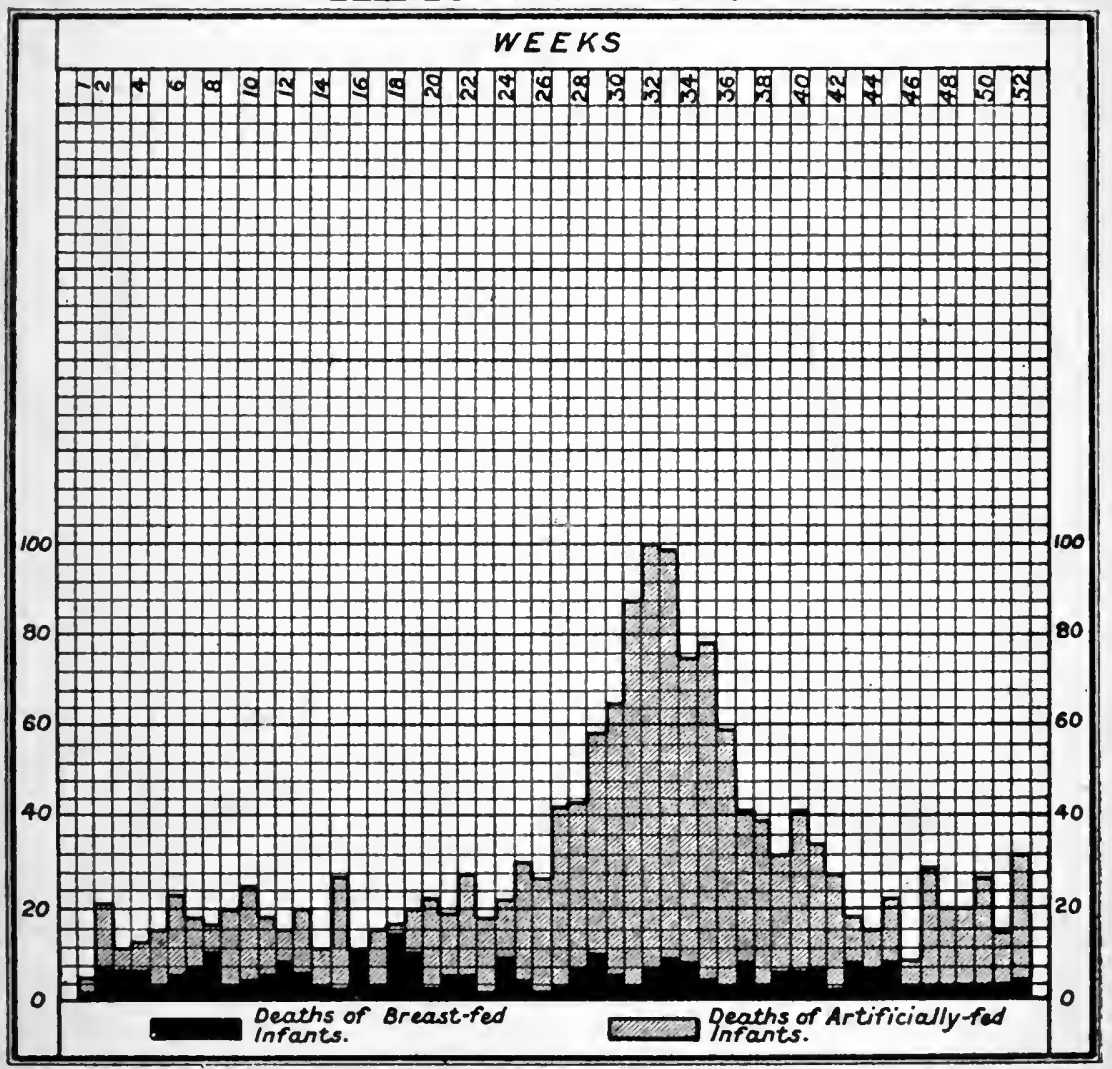



some of them arrangements are made by which food is supplied to weakly mothers who suckle their infants; at others mothers who breast-feed their children receive a douceur of 3 francs every fortnight when they bring their infant to be weighed. Again, some of the consultations serve as training schools for future mothers, being attended by jeunes filles who take a voluntary share in the management. Thus it will be seen that there is a variety of useful purposes which may be fulfilled by these institutions. There are now upwards of ninety gouttes de lait in France, and in other countries they are also being established.

In 1893 a somewhat similar movement was started by the Hon. Nathan Straus, who established a milk depôt in New York for the sale of milk for children under five years of age. The milk is cooled after yield and refrigerated during transport to the fourteen or more depôts now existing. At the laboratory it is run through a separator for purification from particulate matter and bottled. It is then pasteurised for twenty minutes at $167^{\circ} \mathrm{F}$. About 250,000 bottles of this milk are now issued monthly. Mr. Straus claims that this milk has been "the most important element" in the reduction of the number of deaths of children under five years of age in New York since 1893 . From $1891-95$ the average mortality among children of this age was, according to Mr. Straus, $90^{\circ} 6$ per 1,000 , and in the quinquennium 1900-4 it had fallen to $61^{\prime} 2$ per $\mathrm{I}, \infty 00$. The deaths of children from June to August have also greatly fallen in number, and a similar reduction has taken place in the Infant Asylum at Randall's Island, New York, where the milk has been supplied.I The methods of Mr. Straus have been adopted elsewhere also with good results.

' See Brit. Med. Four., 1905, vol, ii. pp. 644-646. 
The first Infants' Milk Depôt in England was opened in 1899 at St. Helens, in Lancashire, and since that date depôts have been established at Liverpool, I90I (the largest in this country), ${ }^{\mathrm{r}}$ Battersea, 1902, and in about a dozen other places. They have not all followed the French type, particularly in respect of the medical supervision of the children and the discriminating distribution of the milk. Indeed, there is a somewhat unsatisfactory variety of method and purpose adopted, which has no doubt somewhat hindered a steady advance such as has occurred in France. Further, in this country the chief depôts are carried on by the municipalities, and are larger and therefore more expensive as to plant than the ordinary French model. On the whole, however, satisfaction is generally expressed with the results up to

I Since its establishment early in I901 to end of 1905, upwards of 10,000 infants have been fed through the Liverpool Depôts.

The Medical Officer of Health of Liverpool (Dr. Hope) asks : "Can the municipality provide these means ? Ought it to do any more than attend carefully to general sanitation, to ensure that the milk shall be delivered pure and wholesome ; to send intelligent educated women to explain how the infant should be fed, and to teach the rudiments of domestic cleanliness? Obviously, if it chooses to incur the expense, it can do a vast deal more, for it can provide actually the most suitable food for the infants whose mothers cannot suckle them, and provide it in such a form as to abolish, or at all events minimise, all the risks of bacterial contamination -which is the most dangerous form of contamination-during transit or domestic storage.

"Without going into detail with regard to the nature of the food, it may be said that the aim is to prepare from cows' milk a mixture which shall imitate chemically and physically, as closely as possible, the milk of the mother at various periods of lactation, and in such a form as to enable it to be given to the infant as free from bacterial impurity as the mother's milk. . . . The fact is that this step, no less than the others which have been enumerated, is merely a sanitary measure ; it is merely an attempt to break one more link in the chain of destruction; it is not a trade any more than the supervision over the milk supply already referred to is a trade; it will make no more return in cash than the employment of female inspectors will, or the provision of hospitals, or of parks and gardens, of baths and playgrounds, of street scavenging, or of sewagefarms ; like all of these, it is merely a sanitary measure, and the outlay in this case, like the outlay in the rest, is justified not by the cash profits, but by the improvement in the health of that section of the public, viz., the infant section, which it is designed to benefit." (Report on Health of Liverpool, I904, pp. 155-6.) 
the present.r In addition to the ordinary infant milk depôt, other allied work having similar objects has been done in connection with hospitals, and also independently, as at the Infants' Hospital at Hampstead.

\section{The Work of an Infant Milk Depôt.}

I propose to take as a type of these Infant Milk Depôts that established in Finsbury, which possesses characteristics of an important nature. The commencement of a Social Workers' Association furnished the occasion for the commencement of the Finsbury Infant Milk Depôt, and the work entailed was undertaken by a voluntary committee of medical men, assisted by some lady visitors, the object being to establish a depôt on a small scale, under proper control and on satisfactory lines, for a few children, rather than to work a larger institution for a considerable number. The whole of the necessary funds were subscribed by a few friends of the enterprise. The principles by which the Medical Committee wished to be guided were: (a) Absolute control of the milk, and the avoidance of the serious fallacy of sterilising unclean milk; (b) medical supervision of the entire management of the depôt, and of the infants using the milk; (c) a discriminating and careful distribution of the milk only to infants who could not be breastfed; and (d) the systematic study of the effect of the milk on the children. ${ }^{2}$ The committee desired to make the method as individual as possible, and in no way to lessen the responsibility of the mother. It is evident that these are not easy principles to carry out, and many difficulties were encountered.

"See Special Rcport on "Infantile Milk Depôts," I905 (November), by Dr. Sidney Davies, of Woolwich.

- The writer may perhaps be allowed to admit that his early belief in the efficacy of Infants' Milk Depôts did not receive much encouragement from the simple fact that these four principles, among others, did not appear to be practised in the depôts of which he had knowledge. 
On the whole, however, the results have been satisfactory, owing to the fact that there is medical supervision, and that the milk is prepared, and, if necessary, sterilised on the farm.

Preparation of the Milk.-The first essential in the establishment of an Infants' Milk Depôt is a pure milk. It is idle to attempt to work on the basis of obtaining ordinary unclean milk and trusting to sterilisation for the removal of any unsatisfactory characters. It cannot be too clearly understood that sterilisation does not make bad milk good, or dirty milk clean. Nor is it sufficient merely to contract for a supply to the depôt from some dairyman of good standing. As far as possible, complete control from the very beginning is necessary to ensure purity. The depôt and the milk farm must in some way be directly connected with and under the control of those responsible for the working of the depôt. Great harm has been done to the whole cause of milk reform by duality of responsibility and by attempting to meet all difficulties by sterilisation. Milk is a favourable nidus for microbes. A pint of apparently good milk may contain millions. Most of them are fortunately harmless; but some are not, and all of them begin to produce in an hour or two toxicity or staleness in the milk. Sterilised milk may be free from living germs, but it is not on that account necessarily free from the toxicity produced in it before the organisms were killed by heat. If it was, in short, a dirty milk before sterilisation, it is also a dirty milk afterwards, although the actual microbes may have been killed. It is, then, necessary that milk should be absolutely pure before any modification is undertaken.

A second requirement is that any treatment of the milk -refrigeration, sterilisation, or modification-should be carried out immediately after milking and, if possible, at the farm. The treatment of a stale milk, or of a milk 
which has spent many hours on the railway, is not at all the same thing as its treatment when fresh and just drawn from the udder.

By the kind offices and co-operation of Mr. J. Carson, of Theydon Bois, the milk used at the Finsbury Depôt is obtained from his farm in Essex, and is modified according to the committee's prescription at the farm immediately after milking. Mr. Carson's farm consists of 82 acres near Epping, and is managed on scientific and business principles.

The dairy herd consists of about 70 thoroughbred Jersey cows, and is specially selected for milking purposes. As is well known, this breed of dairy cow yields a high quality milk, richer in cream than the milk of the ordinary shorthorn or their cross. It is also rich in colour and liberal in quantity. The average yield per cow at Crystalbrook Farm is about 600 to 700 gallons per annum, as compared with a general average of about 420 gallons per annum. ${ }^{x}$ Each cow in the herd is tested once a year with the tuberculin test, and any cow reacting to the test is at once eliminated from the herd. During the last six years, of all the milch cows tested at this farm only four have reacted, which gives a percentage of $0 \cdot 6 .{ }^{2}$ A number of animals leave, and others join, the herd every year, which is thus continually reinforced and refreshed. The quality and quantity of each cow's milk is tested monthly and recorded. The feeding of the cows is kept under strict control. No brewer's grains are used. In summer the cows feed on fresh grass, the grazing land being limed every other year; they also have linseed oil cake, and a small quantity of cotton-seed cake and bran. In winter they have hay, mangolds, crushed oats, maize, germ meal,

" "Blue Violet," one of the Crystalbrook herd, yielded 1,100 gallons of milk in 1904 .

2 In 1902 Geddes showed that Jersey cattle on the Island of Jersey gave a percentage of $0^{\circ} 3 \mathrm{I}$, whereas those tested on the mainland gave a much higher percentage of reaction. 
and linseed and cotton-seed cake. The cows are groomed daily. In the summer they are out day and night, and even in winter spend the day in the open air. They are milked twice daily ( 6 a.m. and 5 p.m.) in the byre adjoining the milk laboratory. No cow is milked for the depôt within a week of calving. The udders of the cows are cleaned before milking, and the milkers themselves are required to be clean in person and manner of milking. Clean white overalls are used, and all utensils, cans, and churns are kept scrupulously clean and regularly sterilised by steam.

The farm itself is well kept, and has an abundant water supply from the Herts and Essex Water Works Company, Ltd.I There are four cowsheds (for 28, 24, I2, and 4 cows respectively), built of brick and having tiled roofs. There is an abundant window space and means of ventilation. The floors are concreted and channelled. The manure is removed from the sheds at once, stacked 200 yards away, and, as soon as practicable, placed on the fields. The liquid refuse runs into a cemented tank, and from this is forced by windmill pump on to the arable land. The buildings and arrangements are very simple but the conditions obtaining reach a high standard of excellence.

These details have been mentioned as they have everything to do with the efficiency of the whole dairy farm. Poor cows giving a small yield of milk and kept amidst much insanitation and filth-and these are conditions prevailing all over England-not only result in poor, unclean milk, but are a poor investment. A large and rich yield of milk per cow is necessary in order to make a dairy farm pay. And the other matters named are each and all important in their way as leading to efficiency and a pure supply of

- The Medical Committee had a bacteriological examination made of the water as supplied at the farm, and found it of an exceptionally high standard of purity. 
milk. Generally speaking, however, Mr. Carson does nothing on his farm that could not be done on almost every dairy farm in the kingdom with care, attention to detail, and the training of the staff. His cowsheds are of the simplest construction, and there is no elaboration or unnecessary expense. Economy with cleanliness and efficiency in all these matters should be the guiding principle.

Immediately after milking the milk is removed and strained through a metal screen. It is then cooled over a Lawrence refrigerator in the open air under cover, and at once taken into the adjoining laboratory and separated in an ordinary Laval separator, which acts, of course, in part as a method of purifying the milk. The separated milk is then modified as described below, and poured by means of a mechanical automatic bottle-filler into bottles which have been previously sterilised at $212^{\circ} \mathrm{F}$. for 60 minutes. In winter the bottled milk is then pasteurised at $140^{\circ}$ or $150^{\circ} \mathrm{F}$. for 20 minutes, and in summer it is sterilised at 2 I $2^{\circ} \mathrm{F}$. for 20 minutes. In mid-winter for a period of some weeks no pasteurisation or heating of any kind is done. After pasteurisation the milk is cooled to $53^{\circ} \mathrm{F}$. by admitting cold water into the steriliser, and kept at that tempera'ure until the time has arrived for transmission by rail in cases (holding 100 bottles each) to the Distributing Depôt in Finsbury. The milk for the Infants' Depôt is milked in the evening, modified and bottled within a few minutes of leaving the udder, kept on ice or in cold water, and delivered in Finsbury the next day, where in the summer it is kept on ice till distribution.

Modification of the Milk. - The Medical Committee, with the assistance of Mr. J. Kear Colwell, F.I.C., Public Analyst, carefully considered the subject of standards of modification, and finally decided to commence with the three following degrees :- 
A.-One part separated milk, two parts water $+8 \mathrm{oz}$. cream +7 oz. milk sugar to the gallon.

B. -One part separated milk, one part water + I I oz. cream +5 oz. milk sugar to the gallon.

C.-Two parts separated milk, one part water + 12 oz. cream +5 oz. milk sugar to the gallon.

Various degrees of modification were made with the average milk supplied by Mr. Carson's herd, and the above were found on analysis to yield desirable milks, and approximately comparable to human milk:-

\begin{tabular}{lll|c|c|c|c}
\hline & & $\begin{array}{c}\text { Human } \\
\text { Milk. }\end{array}$ & $\begin{array}{c}\text { Modification } \\
\text { A. }\end{array}$ & $\begin{array}{c}\text { Modification } \\
\text { B. }\end{array}$ & $\begin{array}{c}\text { Modification } \\
\text { C. }\end{array}$ \\
\hline Total Solids & $\ldots$ & 12.50 & 9.53 & II.05 & 12.49 \\
Fat... & $\ldots$ & $\ldots$ & 3.70 & 2.51 & 3.28 & 3.86 \\
Proteids & $\ldots$ & $\ldots$ & 2.30 & 1.24 & I.91 & 2.48 \\
Lactose & $\ldots$ & $\ldots$ & 6.20 & 5.49 & 5.45 & 5.56 \\
Ash & $\ldots$ & $\ldots$ & 0.30 & 0.29 & 0.41 & 0.59 \\
\hline
\end{tabular}

These three modifications are used as follows :-

\begin{tabular}{c|cc|c|c|c}
\hline $\begin{array}{c}\text { Standard } \\
\text { of } \\
\text { Modification. }\end{array}$ & Age of Infant. & $\begin{array}{c}\text { No. of } \\
\text { Bottles per } \\
\text { Day. }\end{array}$ & $\begin{array}{c}\text { Amount per } \\
\text { Bottle } \\
\text { in Ounces. }\end{array}$ & $\begin{array}{c}\text { Amount per } \\
\text { Day } \\
\text { in Ounces. }\end{array}$ \\
\hline A & Under I month old $\ldots$ & 9 & 2 & I8 \\
I-2 months old & $\ldots$ & 9 & 3 & 27 \\
B & 3-3 months old & $\ldots$ & 8 & 4 & 32 \\
C & $6-6$ months old & $\ldots$ & 7 & 5 & 35 \\
6-9 months old & $\ldots$ & 6 & 6 & 36 \\
\hline
\end{tabular}


Variations in quantity are made from time to time, and the modification is not applied in any hard-and-fast manner, the particular milk for each child, whatever its age, being carefully considered after the first medical examination. Generally, however, it may be said that children receiving A modification consume from 6-10 oz. of pure milk daily, those receiving $B$ between 15 and $20 \mathrm{oz}$., and those receiving $\mathrm{C}$ from $20-30 \mathrm{oz}$. of pure milk daily.

Chemical and bacteriological examinations of the milk were made at intervals in order to check the process. The examinations made in London without any notice to the farm workers have shown a steady quality of milk approximating as nearly to the standard set out above as the natural variations in cows' milk will permit. From a bacteriological point of view, the milk has been found to be sterile, or, when pasteurised only, containing a few lactic acid organisms per cubic centimetre.

The Method of Working the Depot.-It has been intended that the depôt should be both a remedy and a school-a remedy by supplying suitable nourishment to infants debarred from natural mother's milk, and where necessary a school of infant management. It is not a milk shop where any person can obtain milk, and care has been taken in no way to injure the ordinary milk trade carried on in the borough. It is a specialised milk supply for special circumstances which cannot be met by the trade.

The daily stock of milk is sent up to Finsbury in sealed bottles packed in specially prepared cases. On arrival at the distributing centre it is placed in a cool room, and in summer in a refrigerator. The depôt, or distributing centre, consists of two rooms. One room is a waiting and dressing room, the other is the weighing room. In the latter room there is a refrigerator and shelves and cupboard for storing milk if necessary. There is also the weighing balance (a Walker-Gordon cradle balance), and 
record and register books. All unnecessary expense has been avoided. It is not so much upon apparatus as upon methods that a distributing centre depends for success.

Infants requiring the milk are introduced to the depôt by medical practitioners, hospitals, nurses, sanitary inspectors, birth registrars, and others. The parents or guardians must pay the necessary price of the milk in advance, and must be residents of Finsbury. The price charged is the ordinary market price of milk in the district -namely, 4d. per quart. On the Wednesday following the date of application the infant is brought to the depôt, medically examined by a member of the Medical Committee, and weighed. Particulars respecting the child are entered in the Record Book (see opposite), and a second page is devoted to fortnightly entries as to progress, increase or otherwise of weight, and general physical condition. It is obligatory that the child shall be brought once a fortnight to be weighed, and, if necessary, examined. The milk is only supplied on this condition. No medicine is given, and if medical advice is required the mother is instructed to consult a medical man or go to hospital. The depôt is not a "consultation de nourrissons" but a "goutte de lait." After medical examination the suitable degree of modification is ordered from the farm, and the milk delivered.

Measured bottles of varying size are used with a patent removable stopper, which comes clear away from the bottle. When required for use the bottle is placed in a jug of hot water to bring the temperature of the milk up to blood heat. The stopper is then removed and a clean teat placed on the bottle-from which the child can then be fed. Each day a thoroughly clean teat is issued in the place of the teat provided the day before, which is returned to the depôt, washed in warm boracic lotion, soaked all night in boracic lotion, and in the morning washed under the tap. 
Finsbury Milk Depôt.

Name.

Whether illegitimate

Whether insured or in benefit

Name of parents

Occupation

Address

\section{General Surroundings-}

Number of rooms occupied Rent

Sanitary conditions of house (light, ventilation, cleanliness of house, bedding, \&c., drainage, yard, dust-bins, sanitary accommodation)

Overcrowding

Wages of parents

No. of brothers and sisters living

or deceased, and their ages

Causes of deaths in family

\section{Condition of Child-}

General Health

Reported weight at birth Measurements-Height, \&c.

Weight at first attendance Weight at subsequent attendances

(entered with clinical notes on opposite page of Record Book)

Health of Mother (especially during and since pregnancy)-

\section{Foeding of Infant-}

Breast alone

Breast and artificial

Artificial alone

Reasons for artificial feeding

Age at weaning

The bottles are carried in wire baskets, and at the time 
of each day's delivery the empty bottles and unclean indiarubber teats are returned. Full instructions are given to the mother as follows:-

\section{Infants' Milk Depôt.}

I. All charges for a supply of Modified Milk are payable in advance :-

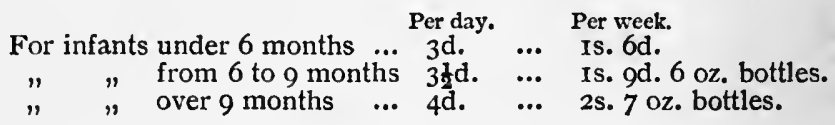

The depôt is opened from 12 to I p.m. on weekdays, and from I 2.30 to 1.30 p.m. on Sundays in the summer.

2. The milk will be supplied in bottles in a basket. Each bottle contains sufficient milk for one meal, the amount varying with the age of the child. Infants under two months receive nine bottles per day; older children receive fewer bottles, as they should be fed less frequently.

3. If children are sent for the milk, they must be warned not to tamper with the stoppers of the bottles. On no account must a bottle be opened until the infant is ready to be fed.

4. Teats can be bought for $2 \mathrm{~d}$. each. The teats must be kept scrupulously clean; after use they should be thoroughly washed in soda and hot water, then rinsed in cold water, and afterwards placed in a jar of clean cold water, where they should be kept until required for the next feed. The teat must be returned each day with the empty bottles.

5. Just before use each bottle should be placed unopened in a basin or jug of hot water for about five minutes, and warmed. The bottle should then be opened and the teat put on. The child must be fed at regular intervals, and fed from these bottles only. On no account should any other feeding bottle be used.

6. When all the milk in one bottle is not used, the remainder must not be warmed up again, but a fresh bottle opened for the next meal.

7. On no account should bread or other food be given with the milk. The milk will be found to be quite sufficient if given regularly. 
8. Immediately after use, the bottle should be well rinsed in cold water.

9. Full value will be charged for all bottles, baskets, stoppers, \&c., not returned to the depôt.

ro. The child must be brought once a fortnight to be weighed, on Wednesdays at $2.3^{\circ} \mathrm{p} . \mathrm{m}$.

Ir. The presence of infectious disease (including whooping cough, measles and chicken-pox) in a house must be at once notified at the depôt.

12. Names of applicants for the milk will be received at the depôt daily at $\mathbf{I} 2$ noon.

N.B. - The Milk must never be used in preference to mother's milk, which is the best of all foods for young infants.

A. Babies-from Birth up to the age of Three Months.

A baby should have its meals, from the first, as regularly as a sick person, whether it is breast-fed or bottle-fed. This is of great importance to the baby's health, and if carefully carried out does much to "free" the mother's time.

A baby under a fortnight old may be fed every two hours by day, and not oftener than every four hours at night. The baby should be awakened for food in the daytime, but not at night.

A baby a month old should not be fed oftener than every $2 \frac{1}{2}$ hours by day. Gradually extend the time between each feed, and by the time the child is three months old it should be fed only every three hours by day, and every five hours during the night if awake. Give the baby its last feed about 10 o'clock at night. Change it, and make it comfortable, and it will probably sleep until four o'clock in the morning.

Be sure the milk is not given too hot. Just before use, the bottle should be placed unopened in a basin or jug of hot water for about five minutes.

Give the food very slowly and train the child not to suck quickly.

\section{General Adrice.}

Never give the baby Tea, Coffee, or Cocoa. The longer a child is kept from their use the better. 
It is very important to wash out the baby's mouth night and morning. Take a piece of clean rag, fix it firmly round the finger, dip it into clean water, and thoroughly wash the roof and gums of the child's mouth. Then burn the rag. A fresh piece must be used each time.

You are strongly advised not to use a "comforter." Their use is often the cause of "thrush," and other diseases, and when the baby is constantly sucking them the digestive system gets no rest. This often causes wind and indigestion, and makes the baby cross and irritable.

A healthy baby should gain from four to six ounces in weight every week. On an average a baby should double its weight in the first five months. A knowledge of a baby's gain or loss in weight gives the readiest indication of its health. So be sure and bring your baby to $26_{4}$, Goswell Road, once a fortnight to be weighed.

\section{B. Babies-from Three to Six Months Old.}

A baby, four months old, should be fed every three hours by day and once in the night if it wakes, but if it is healthy and well it will probably sleep until about six in the morning, when it should be given its first feed. The next feed should be given about $9.3 \circ$, as the feeds should be given three hours after the last feed is finished. It will now be having about $31 \frac{1}{2}$ oz. or $1 \frac{1}{2}$ pints of milk per day.

\section{Babies-from Six Months to One Year Old.}

A baby, six months old, should be fed every three hours by day and once during the night if awake. The time between the feeds should be gradually extended, so that by the time the child is twelve months old it should be fed every four hours by day and not at all during the night.

[After the child is ten months old and has cut several teeth it may be given milk pudding at dinner-time in addition to its bottle, if medically advised. At eleven months old it may have rusks or a little toasted bread soaked in milk, and at twelve months old some breadcrumbs and gravy, but do not reduce the quantity of milk that it gets each day, and do not be in a hurry to 
leave off "bottles." A "weaned" baby often suffers from lack of nourishment.]

Each child fed on the depôt milk is visited in its own home once a week, and in some cases more frequently. In this way a direct personal influence is brought to bear on the mother, and homely advice is given and procautions taken as to the management of the infant. Sanitary conditions and their effect on the health of the child are noted. Moreover, it has been found in practice that printed instructions as to the way in which the milk is to be used are not properly understood by the mother apart from personal advice or actual demonstration. Preparation and bottling at the farm protect the milk from home contamination, but it is necessary that the infant should take the milk direct from the bottle in the proper way if such contamination is to be absolutely avoided. Good practice in this respect is obtained by personal visits. I attribute much of the success of the depôt to these personal visits and assistance. They have been of the greatest value to both mothers and infants. This part of the work has been done by Miss Frith, who is a certificated hospital nurse (St. Bartholomew's Hospital) and certified under the Midwives Act, 1902. She instructs the mothers as to points needing their attention, and visits each home to see that the instructions are being properly carried out. She keeps a visiting diary in which periodical notes respecting each child's progress are kept; she also keeps a register and account-book of payments for the milk.

It should be added that the children admitted to the depôt are only such as belong to Finsbury, and are introduced by lady sanitary inspectors, medical men, and neighbouring hospitals.

A Study of Results.-The depôt was opened on November 23, 1904, and up to April, 1906, 184 children 
had been entered on the books. Twenty per cent. of the children came from homes of one room only, and another 43 per cent. from two-roomed homes. So that not less than 63 per cent. lived in homes of two rooms or less, and very few indeed lived in homes of four rooms or more. It may be taken, therefore, that the children came as a rule from poor homes.

A second point of importance is that 75 per cent. of the children admitted were ill at the time of admission, many of them were very seriously ill, and some of them dying. It is obvious that healthy children would not usually be introduced by medical men, who sent fully 55 per cent. of the total number. But many of the others were ill, underfed and wasting, and the mothers sought the depôt on that account. Previous to admission 58 per cent. of the children had been fed on some form of cow's milk, and 42 per cent. on condensed milk or artificial foods. In a number of cases the child had had a little breast milk during the first few days of life.

The age and sex of the children admitted were as follows :-

\begin{tabular}{|c|c|c|c|c|c|c|c|c|c|c|c|c|c|}
\hline Infants. & \multicolumn{12}{|c|}{ Months. } & Totals. \\
\hline & 焉 & I-2 & $2-3$ & $3-4$ & $4-5$ & $5^{-6}$ & $6-7$ & $7-8$ & $8-9$ & 9-10 & |I0-II & II -12 & • \\
\hline Male $\quad .$. & II & $2 I$ & 18 & 17 & 14 & I 2 & 3 & 3 & 2 & 3 & I & I & 106 \\
\hline Female ... & 18 & 15 & I7 & 8 & 5 & 4 & 6 & - & 2 & I & - & 2 & 78 \\
\hline Totals & 29 & 36 & 35 & 25 & I9 & 16 & 9 & 3 & 4 & 4 & I & 3 & 184 \\
\hline
\end{tabular}

From this table it will be seen that 100 (or 54 per cent.) were admitted at or under three months of age, and this is a very important fact, for it directly affects the death 
rate, which is, as we have seen, much higher in the first few weeks of life. Fifteen of the parents applied but did not use the milk (unwilling to pay or conditions too strict, \&c.).

Before discussing some of the results of this milk-feeding in detail, it may be desirable to deal with two matters, namely, the general increase in weight, and the cause of death in the cases which ended fatally.

First, as to increase in weight. The importance of the weight of an infant as a criterion of its health and progress is well known. Indeed, the weight is often the only criterion as to whether the infant is improving in health or not. At birth the average weight is about 7 lbs.; at three months it may-be about 9 to I I lbs.; at six months about 13 to $15 \mathrm{lbs}$; ; at nine months about 16 to $17 \mathrm{lbs}$; and at twelve months 19 to 20 lbs. Dufour's standard has been used in the Finsbury Depôt, as in French depôts, and the charts appearing in the present volume are drawn to that scale. It is well known that the standard rise in weight in the early months of life is greater than subsequently, but roughly it may be said that throughout the twelve months of infancy the average increase is one pound a month ( 12 lbs. +7 lbs. at birth $=19$ lbs.). We have taken that as a standard, with the following result :-

Out of 169 infants who have used the milk, 118 have attended more than one month, and of these 95 (80.5 per cent.) have each gained on an average more than half a pound per month, and on a total average $16 \frac{1}{4}$ oz. per month, the remaining 23 (19.5 per cent.) have each gained on an average less than half a pound per month.

Secondly, as to the deaths. There were 13 cases of death out of the 169 infants. Three of these were children brought in a dying condition, and at special and urgent request were given a little of the milk for a few days before 
the fatal issue. Thirteen deaths yield an infant death rate per 1,000 births of $76^{\circ} 9$, but if these three exceptional cases be excluded the death rate is $59^{\prime} \mathrm{I}$ per $\mathrm{I}, 000$ births. I The Infant Milk Depôt in Liverpool, which is the largest in this country, has yielded an infant death rate of 89 per 1,000 births. The average age at commencement of the use of the milk at Liverpool has been four and a half months, whereas in Finsbury it has been three and a half months, and more than half the infants were admitted under the age of three months, and more than a quarter were under six weeks of age. The percentage of admissions of sickly children has been probably somewhat higher than at Liverpool.

From the records of the 13 deaths it will be found that all these infants were admitted to the depôt more or less seriously ill, three of them practically dying, and brought as a last resource. Seven out of the 13 deaths were due to epidemic diarrhœa, directly or indirectly.

It is now necessary to consider somewhat more closely the effect of the milk upon the infants at the depôt. For convenience they are divided into four classes, as follows :$A$. Infants who have shown steady improvement throughout.

$B$. Infants who, whilst taking the milk, suffered from epidemic diarrhœa and the results of the attack.

C. Infants brought to the depôt suffering from epidemic diarrhoa and who recovered on the milk.

$D$. Infants brought to the depôt suffering from grave constitutional disease, and for whom this milkfeeding has done little or nothing.

In 1905 the infant mortality rate for Finsbury was 148.6 , and for London I3I.I. The infant mortality rate of children at the depôt at Fécamp in 1894-5 was 121 , as compared with 240 for the town of Fécamp. In 1899 this had fallen to 70 , as compared with 228 in Fécamp. At St. Helens (1899-190I) the depôt-fed children had a death rate of 103 per 1,000 births, as compared with 173 in the town of St. Helens. 


\section{A. Infants who have shown steady improvement throughout.}

The following are six typical illustrations of thoroughly satisfactory cases :-

I. K. A. W., f., born October 3, 1904; began depôt milk November 25, 1904; aged seven weeks. Health of mother, fair, anæmic ; first child ; insured. Occupation of father, cabinet maker; 40s. per week. Sanitary conditions of house good. Three rooms; 6s. 6d. per week. Infant-reported weight at birth, about $7 \frac{1}{2}$ lbs. Weight on admission, $8 \frac{1}{2}$ lbs. Reason for admission-mother had no milk. Condition of infant-fair, thrush at time of admission; slight eczema. Weight increased from $8 \mathrm{lbs} .8$ ozs. to $25 \mathrm{lbs}$. in $\mathrm{r} 2$ months. Child did excellently throughout. Touch of diarrhœa in August lessened the steady rise for a month. (See Chart A.)

2. C. E. C., m., born September 15, I904; began depôt milk December 17; aged three months. Mother's health good; four other children, all living and healthy. Father, bookbinder, out of work. Family occupy two rooms; rent, 4s. 3d. ; sanitary conditions good. Infant-reported weight at birth, $7 \frac{1}{2} \mathrm{lbs}$. Had mother's milk for first fortnight, then cow's milk and barley water. On admission - weight $8 \frac{1}{2} \mathrm{lbs}$., wasted and some eczema. Increased from $8 \frac{1}{2} \mathrm{lbs}$. to $20 \mathrm{lbs}$. in 10 months. Reason why this child did not normally increase in weight during first three months of life, before admission to the depôt, was illness and operation. After admission child did well throughout. (See Chart A.)

3. A. H., f., born July 19, I904; began depôt milk December 2nd, then aged $4 \frac{1}{2}$ months. Health of mother fairly good; dyspeptic. Three other children, all living and healthy. Insured. Family occupy whole house; six living rooms and shop. Sanitary conditions good. Infant-premature; reported weight at birth 5-6 lbs. Had mother's milk for $3 \frac{1}{2}$ months, was then weaned, as she was not thriving. Had diarrhoea at time of weaning. General health fair, but much wasted and feeble. On admission weighed $8 \mathrm{lbs}$. instead of $12 \mathrm{lbs}$.; increased to $18 \mathrm{lbs}$. 2 ozs. in twelve months. Did excellently throughout. (See Chart A.) 
4. R. W., f., born July 25, I904; began depôt milk December I6th; aged nearly five months. Insured. Mother's health good; five other children, four living and healthy, one died (prematurity, lived only fifteen minutes). Father, carman, wages 20s. Family occupy three rooms, rent 5s. 3d. Sanitary conditions good. Infant-reported weight at birth, $6 \frac{1}{2} \mathrm{lbs}$; had mother's milk for one month, then mother had influenza and lost milk, after which the child had Nestlé's milk' and barley water. Wasted after weaning. On admission weighed ro lbs., and increased to $18 \mathrm{lbs}$. in seven months. Did well throughout, but had epidemic diarrhœa in the last month, which somewhat lessened the steady increase in weight.

5. F. R. H., f., born November 23, 1904; began depôt milk June I7, I905; aged nearly seven months : insured. Mother's health good. Has had one other child, which died of diarrhœea and sickness at five months of age. Father, engraver, piecework, makes up to $40 \mathrm{~s}$. ; one room, rent $5 \mathrm{~s}$. Infant-reported weight at birth, 8 lbs. Has always been subject to bronchitis. Had mother's milk for six weeks, and then Nestlé's milk in addition. On admission-weighed $\mathrm{I}_{3}$ lbs., and increased to $18 \mathrm{lbs}$. in

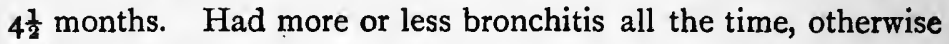
did very well.

6. E. L., f., born April 6, 1905; began depôt milk gth June; aged two months. Mother has been in hospital several times with gastric ulcer, and a year before the birth of the baby had severe hæmatemesis. Was aged 40 at the birth of this, the first child. Father, engine driver in a brewery, wages 30 . Occupy three rooms; rent $7 \mathrm{~s}$. 6d. Exceptionally clean and well kept. Infant-reported weight at birth, ro $\frac{1}{4}$ lbs. Had Nestlé's milk since birth. On admission-weighed I I lbs. and increased to 19 lbs. 12 ozs. by April 25th.

Respecting this group of cases, comment is needless. These six infants represent many others who have passed through the depôt, and have done well from the beginning. As a rule they have been put on the standard modification for their respective ages, and in comparatively few cases has it been necessary to put them back on to the weaker milks. 


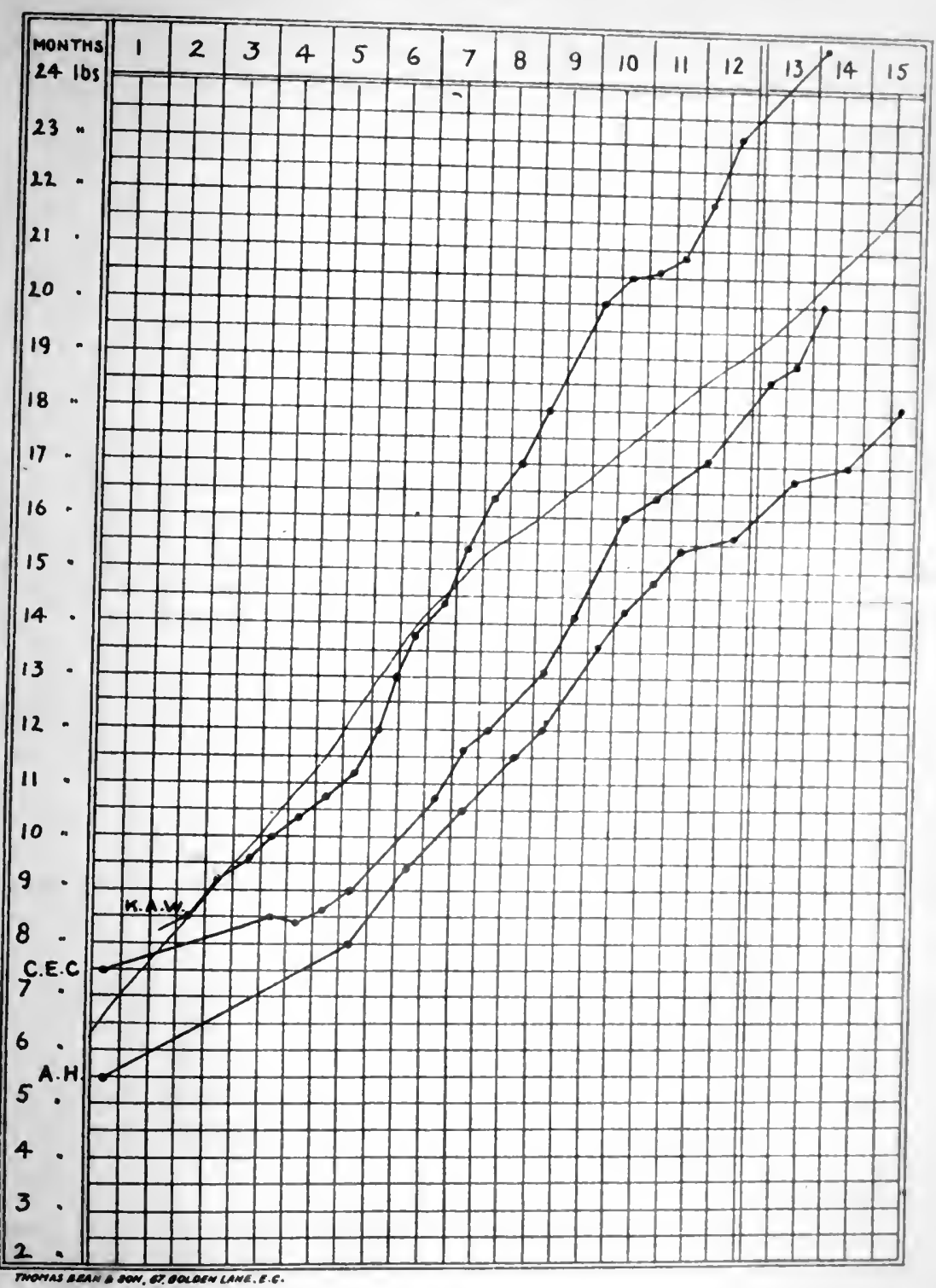

CHART A. CASES 1, 2, 3

The figures at the top are of months, divided into fortnights. The weight in pounds is stated in the column on the left. The fine black line is the standard increase of weight, the other lines indicate actual increase of weight in certain infants 



\section{B. The next group is constituted of Infants who whilst taking the milk suffered from epidemic diarrhaa, and the results of the attack.}

7. F. M. C., f., born November 26, 1904 ; began depôt milk February 28, 1905; aged three months. Mother has good health. Father died of phthisis when the baby was two weeks old; four other children living and healthy. The family of five live in one large room (one is in an Orphan Home), fairly clean and tidy; rent 4s. 6d. Not insured. Infant had had good health, no illness or diarrhœa ; reported weight at birth, $6 \frac{1}{2} \mathrm{lbs}$. Had mother's milk for a little over three weeks, then cow's milk and barley water. Condition on admission-fairly well nourished; no diarrhcea. Weight at first attendance, $9 \frac{3}{4} \mathrm{lbs}$. During the first eleven weeks that she had the milk she did well, gaining $2 \frac{3}{4} \mathrm{lbs}$. Then she gradually took less milk, and was occasionally sick, with short attacks of diarrhœa. She also began to waste. The diarrhoa was never continuous, but recurred repeatedly. The child was therefore put on a lower modification of milk, combined with medicinal treatment by a medical practitioner. During her illness the child was always very languid, and took hardly any milk, till, in September, she only weighed what she did at the start $\left(9 \frac{3}{4} \mathrm{lbs}\right.$.). She was still kept on very dilute milk. At last she began to improve, the diarrhoa and sickness ceased entirely, she took all the milk well, was bright and contented, and rapidly gained weight. Went off depôt February 2nd, weighing I5 lbs. 4 ozs. (See Chart B.)

8. E. S., f., born March 9, I905; began depôt milk July 1 5th ; aged four months. Health of mother, fair; has had six other children (one died at two years of diphtheria). Father, carman. The family of eight occupy two rooms ; rent $7 \mathrm{~s}$. ; fairly clean and well looked after. Infant not been ill but did not get on and increase in weight; reported weight at birth, $5 \frac{1}{2}$ lbs. On admission weighed 8 lbs. Io ozs. Had thrush. Mother's milk alone for seven weeks, then cow's milk and water in addition. Was entirely weaned at ro weeks, and then had cow's milk and barley water. Had an attack of epidemic diarrhoea in August, and took the depôt milk badly and lost weight $\left(\frac{1}{2} \mathrm{lb}\right.$.). The child was therefore placed on a lower modification ( $\frac{2}{3}$ water) and at once 



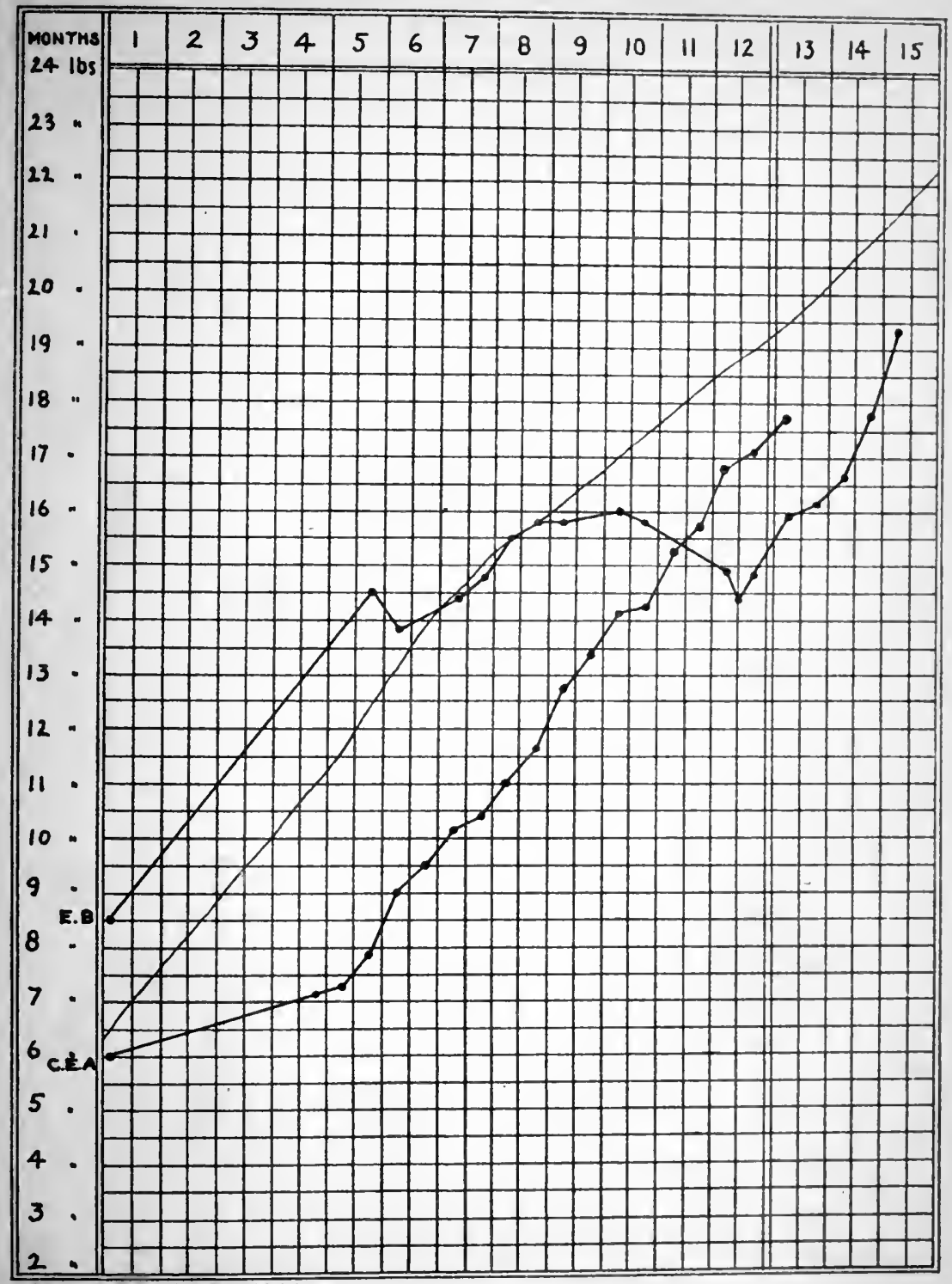

CHART C. CASES 9 \& 10

The figures at the top are of months, divided into fortnights. The weight in pounds is stated in the column on the left. The fine black line is the standard increase of weight, the other lines indicate actual increase of weight in certain infants 

From these results three conclusions may be drawn. First, the feeding of infants on modified and sterilised milk does not necessarily prevent them from having epidemic diarrhœa, particularly in the third quarter of the year.

Secondly, it is evident from a study of these cases that epidemic diarrhoea reduces the strength and weight of the infant even though it be fed on pure, properly modified milk.

Thirdly, children properly fed on pure milk suffer from epidemic diarrhœa less than children fed in other artificial ways. During the third quarter of 1905 we had 57 children on the depôt, 16 of them suffered from epidemic diarrhœa (28 per cent.). They were in no way a selected set of children-indeed, if anything they were much below the average of Finsbury children, for they were nearly all brought to the depôt already ill. How does this 28 per cent. compare with the Borough as a whole? We have no means of knowing exactly how many cases of the disease occurred in the Borough, as it is not notifiable. But we may obtain some guidance in the following way. In the whole Borough there were in the same third quarter of 1905,702 births and 65 deaths from epidemic diarrhœa. It may be safely assumed that each death indicates at least five cases of the disease, which would give 325 cases of the disease in the Borough (or 46.2 per cent.). Further, the general fatality is less in the children properly fed on artificial lines than it is in improperly fed children. This fact would be enormously emphasised if it were possible to draw out the Borough infant death rate in two forms, namely, a death rate of breast-fed children and a death rate of artificially-fed children. But it is impracticable to state this accurately in figures. How great the difference between the death rates of the artificially-fed children at the depot and the artificially-fed children outside in the Borough would be is, however, clear when one remembers 
that out of the 146 children dying in the Borough, 115 were artificially fed. ${ }^{2}$ It is perfectly clear, therefore, that the high Borough infant death rate is mostly due to deaths of infants artificially fed. No one can study these figures and the clinical history of these depôt-fed children without being satisfied (a) that such children suffer much less from epidemic diarrhœa than other artificially-fed children, and $(b)$ that they have a much lower fatality, even when they are attacked. And yet nearly all the depôt children are of the poorest classes. All of them are artificially fed. All were living at home, and subject to precisely the same external conditions of life as the other children. All the conditions indeed were the same for both classes, except that the depott-fed children were receiving pure milk and proper supervision.

C. The third group consists of infants brought to the depott suffering from Epidemic Diarrhoa and who recovered on the Milk.

II. E. B., born I6th January, I905; began depôt milk I2th August; aged 7 months. Not insured. Mother cook in P.H. Baby boarded out with a family of four persons who occupy four rooms ; rent $8 \mathrm{~s}$. Clean and well cared for. Infant-reported at birth to have been small; weakly; always constipated. Had been fed on cow's milk and barley water since birth. Condition on admission: Had had epidemic diarrhœea for a month, pulled down and thin, skin hanging loose, wasted, discharge from right ear. Weight at first attendance, $12 \frac{3}{4} \mathrm{lbs}$. (standard weight at seven months is $15 \frac{1}{2} \mathrm{lbs}$.). Started on a dilute milk ( $\frac{1}{2}$ water), suitable for three months' child. Has gone steadily ahead with the exception of one week, when she was admitted to hospital for mastoid abscess, during which time she lost $\mathrm{I}_{2}^{\frac{1}{2}} \mathrm{lbs}$. Weight on November 22nd, $17 \frac{3}{4}$ lbs. "Weight gained in fifteen weeks, 5 lbs.

2 Out of the 146 dead infants, 63 died of epidemic diarrhœa in Finsbury in the third quarter of 1905 , and of these 63 we were able to ascertain the method of feeding in 54 instances. Out of the 54 only 9 were breast-fed, 45 , or 83 per cent., being artificially fed. 
Left depôt very well and contented, sleeps well ; no diarrhoea or sickness. (See Chart D.)

12. W. G. H. S., m., born 3oth May, 1905; began depot milk I 7 th September; aged $3 \frac{1}{2}$ months. Health of mother only fair; first child. Father in Post Office Telegraphs; wages 25s. Mother in rubber works; wages 145 . Grandmother tends child during day. Occupy two rooms, rent $7 \mathrm{~s}$. $6 \mathrm{~d}$.; clean and well looked after. Infant-not weighed at birth; been under medical care since six weeks' old ; chronic colic since birth. Breast-fed for about four or five weeks, then Mellin's food, beef tea, barley water, and cow's milk. Condition on admission-diarrhea and sickness, colic, bronchitis, and wasting; seriously ill. Started on very dilute milk ( $\frac{2}{3}$ water). Weight at first attendance, $9 \frac{1}{2} \mathrm{lbs}$.; weight on Nov. 8th, $12 \frac{1}{2}$ lbs. ; weight gained in seven weeks, 3 lbs. Is now fat and well; very contented and sleeps well; no diarrhoea or sickness; quite recovered. Left depôt weighing $18 \frac{1}{2}$ lbs. (See Chart D.)

I3. E. L. T., f., born 22 nd July, r 905 ; began depôt milk gth September; aged seven weeks. Not insured. Mother's health good; has had four other children; two dead (aged eight months and eleven weeks, both from epidemic diarrhœea). Father potman in public-house; wages 145.-25s.; unsatisfactory person and drinks. The family of five have two rooms, but only occupy one, the other being unused; furniture pawned; fairly clean; rent 6s. 3 d. Infant-weight at birth stated to have been $7 \mathrm{lbs}$., and on tenth day $9 \mathrm{lbs}$. Had some mother's milk for first few days, then cow's milk and barley water. Condition on admissionseriously ill ; enlarged abdomen, diarrhœa, and sickness; wasting. Started on small quantities of very dilute milk ( $\frac{2}{3}$ water). Milk strengthened after seven weeks. Weight at first attendance, $9 \frac{3}{4} \mathrm{lbs}$; on 15 th November, $12.3 \mathrm{lbs}$; gain in ten weeks, $2 \frac{3}{4} \mathrm{lbs}$. No diarrhœea or sickness; contented and sleeps well ; quite recovered. Still on depôt: weight 16 lbs. 13 ozs. (See Chart D.)

These three typical cases, and those numbered $7,8,9$, and ro, illustrate an elementary point of importance which must not be overlooked respecting the effect of a Milk Depôt upon epidemic diarrhoea. It appears to be com- 
monly supposed that the use of sterilised milk is suitable treatment for an infant suffering from diarrhœea. That is not so. In acute epidemic diarrhœa milk should, as a rule, be stopped. The child should be fed for 24 hours on boiled water or weak barley water, and even when milk is again commenced it must be greatly diluted and low in percentage of casein. We have adopted this treatment in cases of acute diarrhœa. The child has been starved for a few hours in order to remove remnants of its last food and then fed on small quantities of a very dilute milk (two-thirds boiled water) which also contains only half the amount of casein present in ordinary human milk. The beneficial results of this feeding have appeared repeatedly, and may be seen also in the cases quoted. An infant Milk Depôt is an institution that requires careful watching and controlling. It is not making the best of such a depôt to distribute the milk indiscriminately, not only to any infant whether it can be breast-fed or not, but to any artificially-fed child, and particularly to infants suffering from epidemic diarrhœa.

D.-The last group is composed of those infants brought to the depot suffering from grave constitutional disease, and for whom milk-feeding has done little or nothing.

r4. E. L. W., f., born 6th December, r904; began depôt milk 18th February, 1905; aged ten weeks. Health of mother poor, underfed; six previous children; two dead (one died of whoopingcough, one of bronchitis). Sanitary condition of house fair. Family of seven live in two rooms, which are rather unclean. Occupation of father, picture-frame gilder, piece work, poor wages. Mother puts bristles in tooth brushes at home. Infant -weight at birth stated to have been 5 lbs.; always weakly and ailing. Insurance agent would not insure it. Condition on admission-emaciated, poorly nourished, weakly, and seriously ill. Weight at first attendance, $6 \mathrm{lbs}$. 4 ozs. (ro weeks). Been 


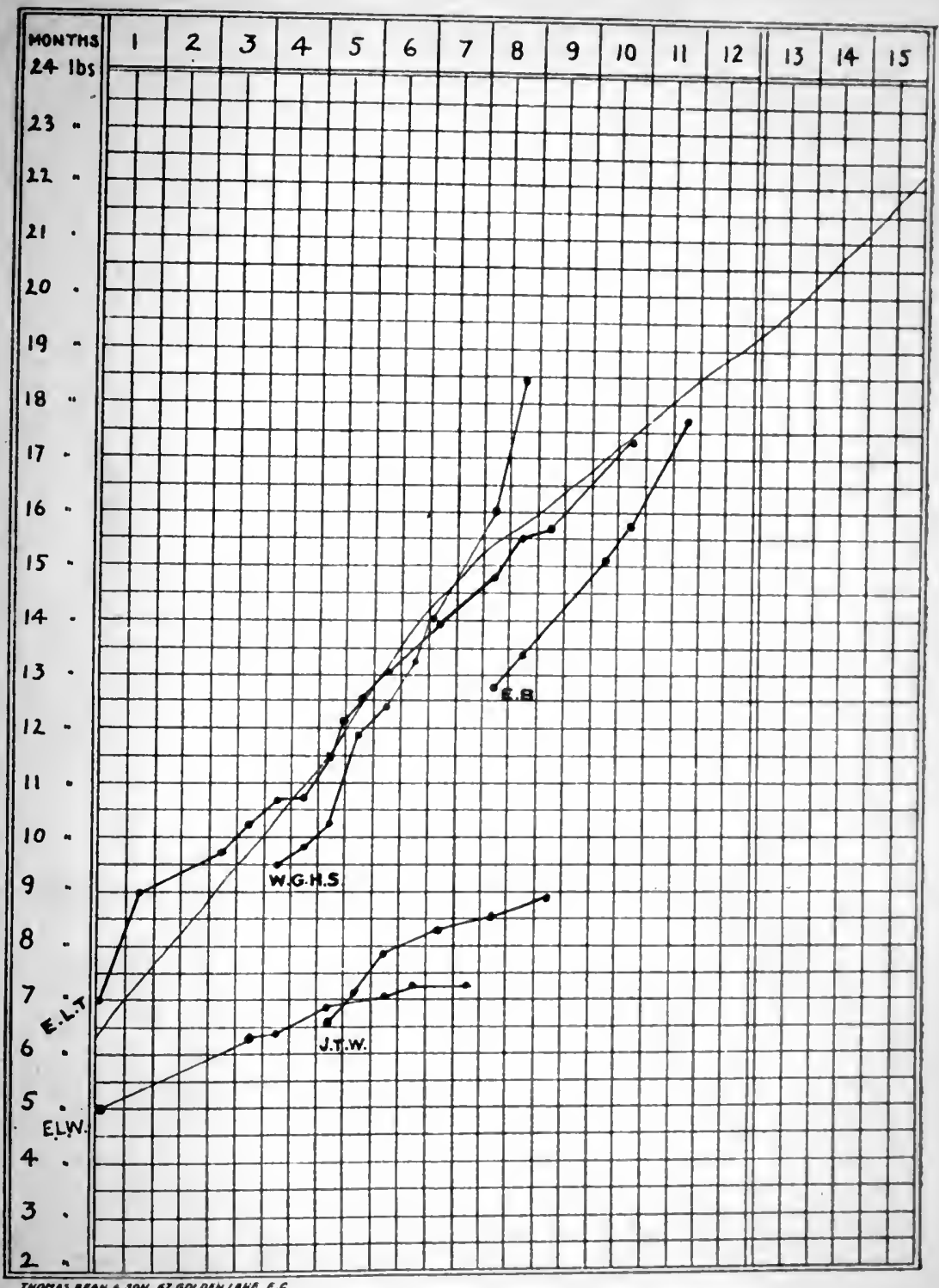

CHART D. CASES 11, 12, 13, $14 \& 16$

The figures at the top are of months, divided into fortnights. The weight in pounds is stated in, the che the black line is the standard increase of weighe, the other indicate actual increase of weight in certain infants 

fed on cow's milk since birth. On dep6t milk from February 18 th till its death, July 3 Ist, gained only 17 ozs. in the four months during which it was weighed (standard gain for four months 75 ozs.); took milk well throughout till last fortnight. During the latter half of July had diarrhoea and sickness, and only took a small quantity of milk. Died July 3 Ist ; weight unknown. Certified cause of death was infantile enteritis, but also suffered from generalised tuberculosis. (See Chart D.)

15. J. T. W., born 22nd February, 1905; began depôt milk 8th July ; aged $4 \frac{1}{2}$ months. Insured. Health of mother poor; ill all through pregnancy; instrumental labour. Has had five other children, four living and well and one dead (at $7 \frac{1}{2}$ months of malnutrition). Father is a clothes salesman. The family of seven occupy two rooms; rent 6s. 6d. ; bedding, \&c., dirty, but children fairly clean and well loóked after. Sanitary conditions fair. Infant not weighed at birth; very small, about $5^{\frac{1}{2}} \mathrm{lbs}$. Has an imperfectly formed throat with a large double uvula; always regurgitates food through nose, and has much difficulty in swallowing. Has cried incessantly since birth. On admission weight $6 \frac{1}{2} \mathrm{lbs}$. (standard at same age, $12 \mathrm{lbs}$.) Child emaciated with an aged appearance; skin shrivelled; seriously ill. Improved somewhat on the milk, especially at first, then during October had three abscesses-two on right thigh, and one on left side of chest. Depôt milk discontinued November $\mathbf{3}^{\text {th }}$, as the mother was not satisfied with the child's progress; weight 8 lbs. 14 ozs. (standard weight $16 \frac{3}{4}$ lbs.) (See Chart D.)

These two cases represent a remnant of infants brought to the depôt suffering from grave constitutional disease which neither breast milk, artificial milk, nor any other food could permanently alleviate. In such cases the depôt, of course, failed to be of any real value, although it may somewhat have prolonged the short life of the infant. Summary of Conclusions.-The Finsbury Infant Milk Depôt seems to illustrate some of (I) the essential principles upon which such work should be carried on, which may now be named:- 
(a) Direct control of the milk at the farm;

(b) Treatment of the milk, whatever it may be, immediately after its yield, and before the contained micro-organisms have had time to multiply or secrete their products ; $^{\mathrm{T}}$

(c) Medical supervision of the depôt and of the infants using the milk.

(d) A discriminating and careful distribution of the milk only to children who cannot be breast-fed, and the use of a suitable modification for each child;

(e) The systematic study of the effect of the milk on each child, accompanied by medical examination and periodical weighing;

$(f)$ The adoption of a policy of attempting to increase rather than decrease the sense of responsibility of the mother.

(2) The milk used in the depôt under consideration is prepared under exceptionally good conditions, but not such as cannot be adopted by other dairy farms. Not the least valuable part of the work which has been done seems to be the practical demonstration which it furnishes in model dairying, which could, and should, be more widely practised in this country.

(3) As far as can be judged, the depôt saved the lives of some children and strengthened the physical condition and constitution of others. Eighty-one per cent. of the children who consumed the milk for a period of not less than a month gained the standard average weight of one pound per month. Whilst it is admitted that an Infants' Milk Depôt is only a palliative method of preventive medicine, these results show that under certain circumstances it may be of substantial value in the reduction of infant death rates among a certain class.

I The importance of this matter is not sufficiently recognised by dairyfarmers generally. 
(4) There is evidence to show that the depôt has served as an important training school of infant management. Its value in this respect, as well as in respect of nourishing and saving life, would appear to depend in large measure upon the personal assistance and advice of a skilled nurse in the homes of the children.

(5) The history of the first year of this experimental depôt, particularly the clinical record, confirms the view that infants, even when properly and well fed on artificial lines, may still suffer from one of the most preventable and fatal of children's diseases-epidemic diarrhoea. It would therefore appear that, however much this disease may be spread by milk-and undoubtedly such is the case - it may also be communicated to infants in other ways. Uncleanliness in the home, and particularly the common use of articles known as "comforters" and other similar appliances which readily collect dust and dirt, may contribute largely to this result, especially in the summer months. The clinical records of depôt-fed infants suffering from this disease further seem to indicate that with careful dieting the disease may often be prevented or cured, and death averted. No doubt there are points in the working of this experimental depôt which are open to criticism; but, on the whole, the results show an exceptional measure of success, and such as justify the establishment of similar depôts elsewhere. It is in view of the fact that this depôt serves as a practical experiment in milk reform, and has been established on what seem to be, generally speaking, desirable lines, that so much space has been devoted to an account of it. 


\section{CHAPTER XI}

PREVENTIVE METHODS:(III.) THE ENVIRONMENT

F INALLY, a brief chapter must be added on the $F$ preventive methods to be adopted for the improvement of the external sanitary conditions surrounding both mother and infant. The more essential matters are improved sanitation in the factory and in the home, urban cleanliness, and the control of the milk supply.

"Progress in health in factory and workshop life," said Miss Anderson, H.M. Principal Lady Inspector of Factories at the Home Office, "is mainly a question of raising the ordinary general hygiene." $x$ Supervision of dangerous trades and the prohibition of women working immediately before and after confinement are, of course, of great value, but in the long run cleanliness, sufficient ventilation and light, freedom from dust and from extremes of temperature, adequate and suitable provision of sanitary accommodation, reasonable hours of labour, and more effort to apply the worker to the work for which she is most fitted, are of chief importance. Most of these desiderata are provided for in the Factory and Workshop Act, 1901, which, compared with early regulations at the beginning of last century, may be looked upon as one of the workers' great charters of freedom. Although no doubt

× Rep. of Interdepart. Com. on Physical Deterioration, I904, vol. ii. p. 66, Q. 15 I8. 
as time passes amendments are necessary, the principal need at the present time is a steady and uniform enforcement of the powers which Local Authorities possess in this and kindred enactments. The same may be said of the Public Health and Housing Acts. Many of their provisions remain a dead letter, owing to the supineness and vested interest which still exists in many local government bodies. Dampness, overcrowding, an absence of storage cupboards for food, ill-ventilation, and uncleanliness, are common features of much of the dismal tenement property of towns and even of cottages in the country, where the nation is attempting with only partial success to rear its children. The remedy of these matters lies in the direct line of health reform.

Secondly, there is urban cleanliness. "For the reduction of the mortality from diarrhoea," writes Dr. Scurfield "(which is one of the chief causes of the infantile mortality) and enteric fever we must look to measures which will bring about greater cleanliness in and around the houses. In particular we must push on with-(x) the abolition of the privy-middens and the provision of water-closets and frequently emptied dust-bins; (2) the reconstruction of defective drains and sewers; (3) the better paving of streets and yards. Under this heading I wish to point out the need for dealing with the sink wastes in the case of back-to-back houses, the contents of which are discharged on the footpaths, and frequently have to run a long distance down the street gutter before they reach a street gulley. The common and not unnatural practice of the residents in such cases of throwing their slops out on to the street surface gives rise to an abominable smell, which is, of course, worse in hot weather." I To reduce dust and infective filth to a minimum these three matters need attention, and without

× Rep. on Health of Sheffield, 1904, p. 17. 
that reduction milk and other food will continue to be contaminated and infantile diarrhœa will result. But there is a fourth requirement, namely, effectual scavenging and cleansing of streets. Dr. Spottiswoode Cameron has shown the beneficial effect of such cleansing on the diarrhœal death rate in Leeds, $x$ and in other districts increased flushing of streets in the dusty weeks of August and the more rapid and effectual removal of refuse has apparently led to a similar reduction in the infant death rate from diarrhœa. We have already seen how the incidence of this disease declines in a wet summer, and Tyndall showed many years ago how organisms and particulate matter adhere to wet surfaces. Depending upon these simple facts, it would be well if local authorities and the community could co-operate together to secure a much higher standard of municipal cleanliness and the substitution of wet scavenging for dry.

\section{Control of the Milk Supply.}

Thirdly, there is needed increased control of the milk supply. We have seen that infant mortality, and particularly fatal diarrhœa, chiefly affects infants fed on condensed milk and cow's milk, and only in the smallest degree those who are breast-fed. We have seen also how this fatality occurs mainly in the second and third trimesters of the first year of life, at the time of weaning, and that it falls in a less marked degree, or is quite absent, in children fed on pure milk. The more the problem of infant diarrhoa, as it occurs in the middle of the first year, is examined the more will stale, polluted milk, as consumed in towns, come under suspicion as one of the chief causes. "Contrast the suitability of this milk," writes Dr. Hope, "as an infant's food, after a longer or

× Public Health, October, 1900, pp. 33-36. 
shorter period of storage, with the breast milk of the mother. The breast milk of the mother is beyond any doubt peculiarly adapted, both chemically and physically, to the special requirements of her particular offspring, and changes as the needs of the infant change. It is freshproduced, in fact, as it is required ; it is adequately mixed ; the temperature is exactly what it ought to be ; but, above all, it has never been exposed to the air; no atmospheric impurities have reached it, as it passes direct from the gland to the stomach of the infant, and is consequently bacteriologically pure." $\mathrm{x}$

There are, however, two other reasons necessitating reform of the milk supply-the prevention of milk-borne epidemics, ${ }^{2}$ and the desirability of increased consumption. The former has but little relation to infant mortality. The latter, on the other hand, is of considerable importance in this connection. It was recently estimated that the average consumption of milk per capita is 42 gallons annually. This figure is arrived at approximately on the total yield of four millions of milch cows. In $1892 \mathrm{Mr}$. R. H. Rew stated, however, that the annual consumption per capita in London was 11.5 gallons (0.25 pint per day), and in the country generally 19.7 gallons ( 0.43 pint per day). 3 In a careful estimate made in Finsbury in 1903-4 I calculated that the annual consumption per head was about 10 gallons (0.21 pint per day), but among the very poor not more than one-tenth of a pint per diem. 4 Returns of this nature vary not only in correspondence with poverty and social position, but also in relation to the consumption of condensed milk, which in some places has shown a marked increase. An average of one-tenth of a pint is

- Rep. on Health of Lizcrpool, 1904, p. 154 .

- Bacteriology of Milk (Swithinbank and Newman), 1903, pp. 259-391.

3 fourn. of Roy. Statistical Soc., 1892, pp. 265-267.

4 Brit. Med. Four13., 1904, ii. p. 425. 
not sufficient. Milk is the ideal food for children, and there can be no doubt at all that an enormous increase of its consumption by children would directly tend to improve the physique of the rising generation. Not a little of such physical deterioration as exists among working-class children is due to living in urban communities, with all that it entails, and not receiving sufficient milk nourishment.

To improve and increase the milk trade is, then, a requirement of national concern, and is a strong reason why great efforts should be made to control the supply. It is a significant fact that the total dairy produce imported annually into Great Britain is valued at upwards of $£ 30,000,000$. The importation of condensed milk has exactly doubled during the last ten years, 18941903 (from four million to eight million imperial gallons), and during the same period an import trade in fresh milk has arisen amounting now to about 200,000 gallons a year. This may be but a cloud the size of a man's hand, but unless the British dairy trade wakes up the cloud may cover the sky. The control of the milk supply is therefore not only a method of preventive medicine, but a national requirement.

There are three broad principles which may be submitted as governing the question. First, in a general way some reform should come from the consumer. What the public demand the trade will supply. If the public insists on a pure whole milk obtained by cleanly methods from healthy, clean cows, there is no doubt the supply can be provided. Secondly, some reform should come from the trade. This should be from inside rather than outside, from the dairyman rather than from the Act of Parliament. The milk trade would do well to learn the vast importance of co-operation in the development of what should be a great national industry. A perusal of the 
conditions and regulations of the dairy companies in Denmark, America, and Great Britain serves to illustrate what can be done in this respect, and their enterprise has largely led the way in milk reform. Thirdly, there is the sphere of the Legislature, which should take, I contend, a large view of the question, making the aim to control by development rather than by restraint, by encouraging rather than hindering the trade, whilst at the same time insisting upon a pure milk rather than adopting counsels of perfection in respect of cowsheds. What is needed in this country is not so much more legislation in respect of milk as a direct and uniform application and enforcement of the legislation which now exists. ${ }^{r}$

Now, whilst these general principles seem to indicate the path of advance, there are some details of importance. The requirement is a pure milk supply - that is, a clean whole milk, unadulterated and unsophisticated, and without preservation, derived from healthy cows living under clean and sanitary conditions, and protected from contamination (dust and dirt) and infection (agents and products of disease). The details of control involve milk production, conveyance, and distribution.

(a) Milk Production.-The importance of commencing the control of milk at the beginning can scarcely be overestimated. If the cow be diseased or unclean nothing can correct the unsatisfactory character of the milk. Milking herds, their breeding and management, call for more attention than they have yet received in this country.

From an administrative point of view it is important to emphasise the need for regular, frequent, and systematic veterinary inspection of all cows used for dairy purposes (for the detection of vesicular eruptions of the udder and teats, the elimination of diseased cows, tuberculin test, \&c.).

Bacteriology of Milk, 1903, Pp. 452-543 (for needed amendinents see pp. $47 \mathrm{I}-472$ and p. 543). 
It is noteworthy to witness the improvement in dairy cattle (as, for instance, in the London cowsheds) where inspection is properly carried out. Two further points have relation to general sanitation of cowsheds and to milking and the after-treatment of milk. It is evident what the intention of the Legislature was in introducing the Dairies, Cowsheds, and Milkshops Orders (1885, 1886, and 1899), and in inserting various Regulations as to cubic space, \&c., though it is not clear why the Regulations are made permissive or the Order allowed to remain so much a dead letter as it is. The really essential matters are not exact limits of cubic capacity, but thorough cleanliness and sanitation, coupled with a decent water supply, conditions which do not as a rule obtain. A model dairy does not require a large outlay of capital, but it requires a keen intelligence and unremitting care in its management. It is not expensive structural alterations which are needed, nor elaborate cowsheds, nor special water supplies laid on at great expense, but it is thorough cleanliness. A polluted water readily leads to a polluted milk, and is frequently at the bottom of unclean dairying, even as insufficient light in the byre leads to uncleanliness. One of the first steps towards reform of milk production is reform of rural water supplies, and the direction in which such improvement is required is not so much in the provision of new supplies as in the protection from surface contamination of the supplies which exist.

In the second place, there is the method of milking. The greatest possible care and cleanliness should be observed in every detail connected with the work of milking. The hind-quarters and udder of the cow should be kept clean. In autumn, before the cows are housed, the long hair on the tail, udder, and hind-quarters should be clipped, and the cow also regularly groomed. The practice of milking in the field during summer is 
strongly recommended. The passing of the female milker is to be regretted, for now it happens that frequently odd men about the farm are employed as milkers amongst their other functions. They are often ill-trained, and unclean in person and manipulation. Yet the milker should be clean in all respects. He should, of course, be free from infectious disease of any kind, including tuberculosis.

In respect to treatment of milk after milking, the Danes recognise in a manner and to an extent at present unknown generally in Great Britain that the destruction and inhibition of bacterial activity in milk is the basis of all successful dairying. They, recognise the multitudinous opportunities which milk has of becoming polluted from the time it leaves the udder of the cow to the time it reaches the consumer's mouth, and that milk is a highly favourable medium, and, therefore, the bacteria which gain access multiply at an enormous rate. In consequence of this knowledge the Danes adopt three simple rules. First, prevent organisms gaining access by cleanly methods of dairying; secondly, strain thoroughly; thirdly, inhibit by refrigeration the growth of such organisms as may have by accident gained access to the milk. Clean milking, careful straining, immediate cooling, are the cardinal principles of the dairy creed. Whatever treatment milk is to receive it should receive at once. One of the greatest mistakes is to suppose that milk may be treated after it has stood or travelled for ten or twelve hours. Refrigeration or sterilisation is then too late to gain the highest advantage. A pure milk from the outset is vastly better than a milk subsequently sterilised. Many of the so-called "sterilised" milks now on the market are open to grave criticism, partly because they are frequently not sterile, and partly because they are dirty milks. Sterilisation does not purify a dirty milk. It cannot be too clearly 
understood that what is required is a pure milk from the beginning, and all through the dairying process.

(b) Milk Conveyance.-For town supplies the question of railway transit is of importance. As a rule, most of the milk conveyed on the English railways is carried in special milk-trains. Some of it, in small quantities, is conveyed in vans attached to passenger trains, and a small amount by the ordinary goods trains. Generally speaking, the heavy milk traffic passes at night-time. Rates are low, and probably the gross revenue of all the railway companies for carrying milk to London is under half a million. Viewed from the railway standpoint, therefore, the traffic is not worth exceptional consideration. There is lack of co-operation and organisation in the trade, which is necessary to make the trade a good customer to the railways. Viewed from the dairyman's standpoint, there are grievances against some of the railway companies, which may be summarised by saying that the trade requires (though frequently it is ignorant of the requirement): (a) quick transit; (b) sealed churns; and (c) milksheds at loading stations. These conditions are provided in other countries, and they ought to be provided in England. Railway transit in Great Britain is alleged to be bad rather than slow, porterage at the stations is frequently left to the trade, milk is sometimes packed with other articles such as fish, watercress, and general goods, and frequently is kept at such a temperature throughout the journey that it either arrives sour or readily sours. The existence of these conditions has led to all sorts of suggestions as to enforcing railway companies by law to do this, that, and the other, which is surely unreasonable. The railway companies in America and in Denmark have had to meet a demand from the trade, not an Act from the Legislature; and they have met it. Reform of railway transit of milk must spring from an 
organised trade able to be a good customer. Then the companies will become their servants. They cannot give an efficient and express service for a few churns or an odd wagon here and there, which would necessarily be costly, whilst at the same time the milk rates are low. What is required is co-operation on the part of farmers and milkproducers of a district for the carrying on not of a casual business from many centres, but a well-organised trade from a few centres, and by efficient dairying to raise the quantity and quality of milk per district. Railway companies will respond when there is business, and when they respond may they remember the three cardinal principles of efficient transit of milk: (I) Cleanliness and absence of dust contamination of the milk; (2) shortness of time of transit, every hour lost being detrimental to a living fluid like milk; and (3) lowness of temperature.

(c) Milk Sale and Distribution.-In New York milk is sold from 12,000 stores, or an average of one store to every 286 persons. In London the average works out at about one milkshop to every 500 persons. These milkshops are of two kinds : (a) Dairies or shops selling dairy produce only, and $(b)$ general shops selling milk in addition to a variety of articles, often including spices, herrings, soap, firewood, paraffin oil, blacking, and many articles creating a dusty atmosphere. It is probably correct to say that the former, the dairies, constitute less than 20 per cent. of all the milk-selling premises, taking London as a whole. This state of affairs gravely complicates the effort to obtain a pure milk supply. But unfortunately there is no direct power conferred on the local authorities, who are responsible for registration of milkshops, of refusing to grant registration to unsuitable shops. Clause 6 of the Dairy Order of 1885 enacts that every local authority shall keep a correct register of all milk sellers and purveyors in their district, and they shall register every such person who 
applies. It would be desirable that the Local Authority should have direct power of refusing registration to unsuitable persons or premises. In the meantime it is important that local authorities should raise the standard of sanitation and cleanliness required in milkshops under Clauses 8 to 13 (including Regulations) of the Public Health (London) Act, I89I, Section 28, and thus compel the general salesman, who only sells insignificant quantities of milk, to discard the sale of milk or bring his shop into line with the dairies in standard of sanitation and cleanliness. In relation to this matter of sanitation in milkshops, it should also be understood that milk becomes contaminated in milkshops because it is not sufficiently protected. It is placed in a counter-pan so constructed as to expose a large surface of milk to dust contamination. Constant dipping, flies, and dust from the shop and street serve in a remarkable degree to contaminate the milk. Probably the time is approaching for a more general adoption of bottled milk.

A perusal of Bulletin 46, issued by the Bureau of Animal Industry at Washington, shows how far America is in advance of Great Britain in respect of the control of the milk supply, particularly in the following respects: (a) The increasing use of bottled fresh milk; (b) the diminution in the practice of pasteurisation, the Americans having learned that pure milk is preferable to pasteurised milk; (c) the enforcement of the dairy laws; (d) the beneficial results of thorough examination and inspection $;^{r}$ and $(e)$ the value of the careful collection

I At the same time as instituting measures of bacteriological examination and inspection, the Sale of Food and Drugs Act should continue to be pressed into the work of protecting milk. Irregular sampling, Sunday sampling, and more frequent sampling are required. Adulteration of milk is changing in process rather than becoming less. Mixing of separated and whole milk, and of condensed and cow's milk, is now probably more common than the grosser method of simply adding water to increase volume. It is becoming increasingly desirable to obtain some legislation on the lines of the Departmental Committee's Report on Preservatives, rgor. 
of facts respecting milk. It is not too much to say that America has gained a march upon us even in the matter of reports. A record like the American report' if made in this country would lead to such an inquiry into the methods of the milk trade as would of itself exert a most beneficial effect throughout the country. The public needs more information, more knowledge of the exact condition of things, and it would very speedily demand reform.

It must further be mentioned in connection with milk distribution that home contamination requires attention. The poor have no pantries, and the milk is stored in dirty vessels exposed to dust and other uncleanness. Education on domestic hygiene in elementary schools and teaching the importance of the use of milk by lady inspectors and health visitors would assist in securing progress in the right direction.

"Milk Supply of Two Hundred Cities and Towns (U.S. Dep. of Agriculture), r903, Bull. 46, pp. 1 18-123. 


\section{APPENDICES}

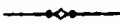

APPENDIX 1 .

INFANT MORTALITY IN VARIOUS COUNTRIES, Ig04.

(Sixty-Seventh Rep. of Reg.-Gen., r904, p. xliv.)

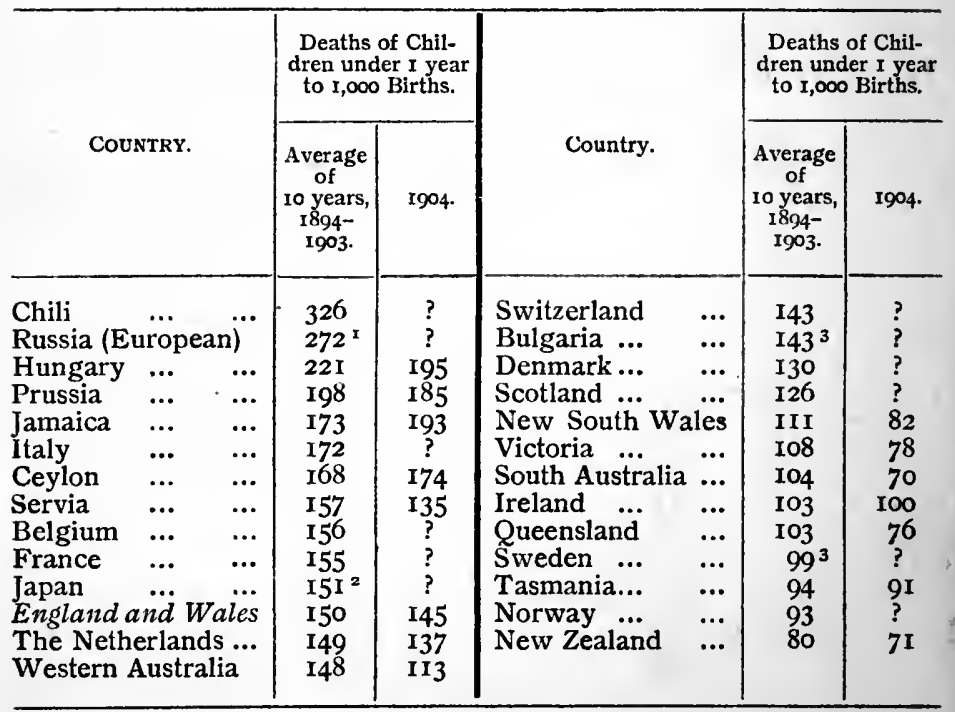

Iverage for 1o years, $1890-99$.

2 Average for 10 years, 1892-1901.

3 Average for 1o years, 1893-1902. 


\section{APPENDICES}

APPENDIX II.

ENGLAND AND WALES.

Infantile MORTALITY From SEveral CaUSES in Registration
COUNTIES, 1903 .

(Sixty-sixth Report of Registrar-General, 1903, p. cliv.)

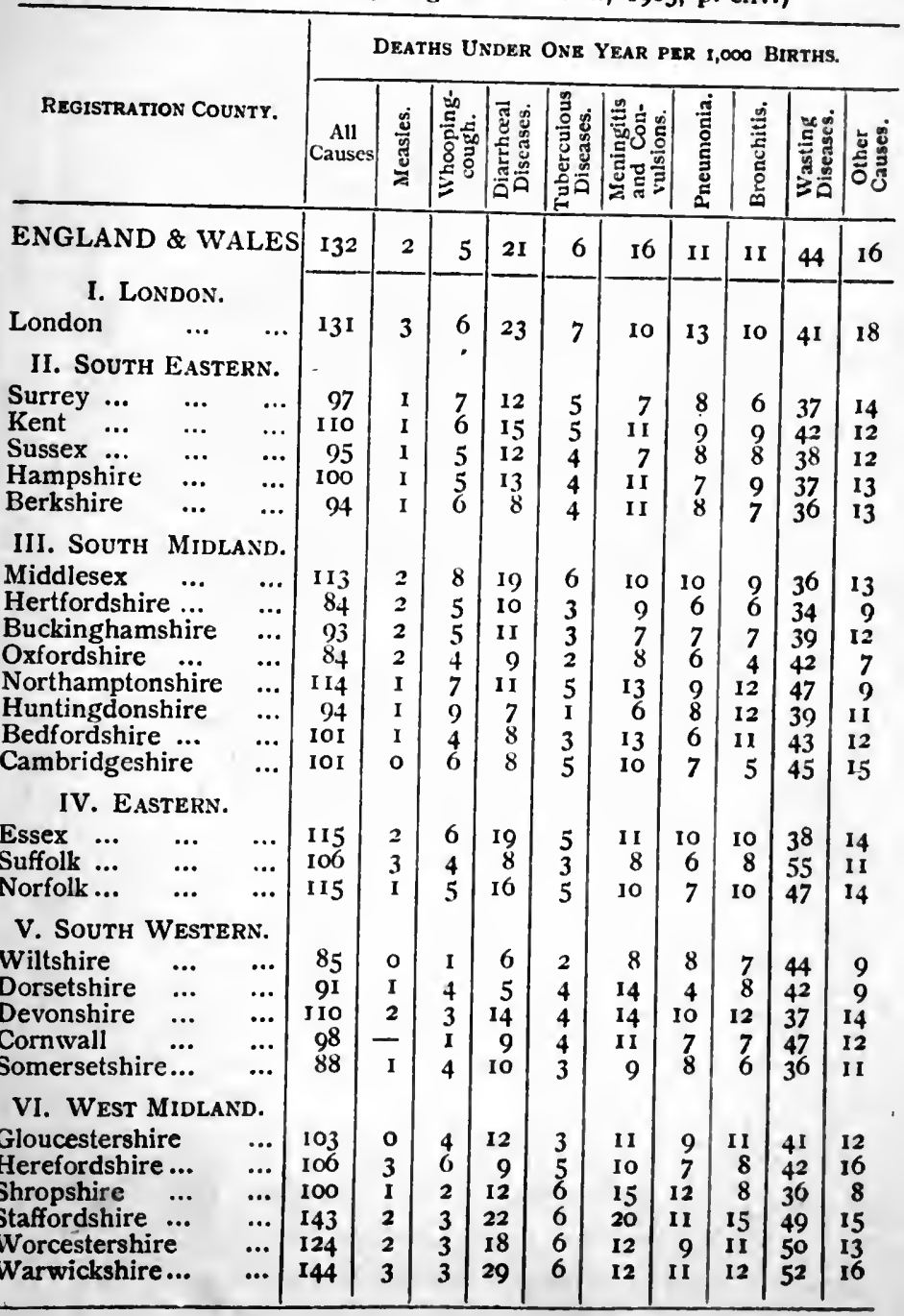


APPENDIX II. (continued).

\begin{tabular}{|c|c|c|c|c|c|c|c|c|c|c|c|}
\hline \multirow{2}{*}{\multicolumn{2}{|c|}{ REGISTRATION COUNTY. }} & \multicolumn{10}{|c|}{ DEATHS UNDER ONE YEAR PER $\mathrm{r}, 000$ BIRTHS. } \\
\hline & & All & 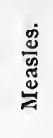 & 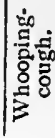 & 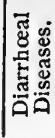 & 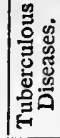 & 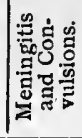 & 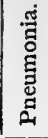 & 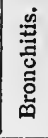 & 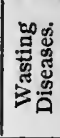 & 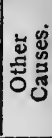 \\
\hline \multicolumn{2}{|c|}{$\begin{array}{l}\text { ENGLAND \& WALES } \\
\text { (continued)- }\end{array}$} & & & & & & & & & & \\
\hline \multicolumn{2}{|c|}{$\begin{array}{l}\text { VII. NoRTH MIDLAND. } \\
\text { Leicestershire ... }\end{array}$} & & & & & & & & & & \\
\hline Leicestershire ... & & 134 & 2 & 2 & 23 & 8 & I9 & 7 & 15 & 47 & II \\
\hline Rutlandshire $\ldots$ & ... & I03 & - & I7 & 7 & Io & 12 & Io & 7 & $3^{8}$ & 2 \\
\hline Lincolnshire ... & ... & I27 & I & 7 & I7 & 5 & 22 & 8 & I I & 45 & I I \\
\hline Nottinghamshire & ... & I5I & 3 & 6 & 24 & 7 & I7 & I6 & II & 53 & I4 \\
\hline Derbyshire $\quad$... & ... & I30 & 2 & 5 & I7 & & $2 I$ & Io & I2 & 43 & 12 \\
\hline \multicolumn{2}{|c|}{ VIII. NORTH WESTERN. } & & & & & & & & & & \\
\hline Cheshire $\quad \ldots$ & $\ldots$ & I34 & 2 & 7 & 25 & 7 & I6 & Io & II & $4 I$ & 15 \\
\hline Lancashire $\quad \ldots$ & $\cdots$ & I 54 & 3 & 6 & 28 & 7 & I9 & I4 & I4 & 47 & 16 \\
\hline \multicolumn{2}{|l|}{ IX. YoRKSHIRE. } & 150 & 3 & 6 & 24 & 7 & $2 \mathrm{I}$ & I5 & I4 & $4^{6}$ & I4 \\
\hline \multicolumn{2}{|c|}{$\begin{array}{l}\text { West Riding } \ldots \text {... } \\
\text { East Riding (with York) }\end{array}$} & I 49 & 3 & 3 & $3 I$ & 5 & 20 & II & I4 & 46 & I6 \\
\hline \multicolumn{2}{|c|}{ North Riding ... } & I 44 & 2 & 4 & 23 & 6 & 20 & I4 & ro & 49 & I6 \\
\hline \multicolumn{2}{|l|}{ X. NORTHERn. } & & & & & & & & & & \\
\hline Durham $\quad \ldots$ & & 156 & 2 & 3 & 22 & 8 & 24 & I3 & I6 & 55 & I3 \\
\hline Northumberland & ... & 152 & $\mathbf{I}$ & 3 & 26 & 7 & 22 & I4 & $\mathbf{I 3}$ & 50 & I6 \\
\hline Cumberland $\quad .$. & ... & 129 & 2 & 4 & 20 & 5 & I4 & I0 & I4 & 48 & 12 \\
\hline Westmoreland & ... & 98 & 3 & Io & 6 & I & I3 & 5 & 8 & 38 & I4 \\
\hline \multicolumn{12}{|l|}{ XI. Welsh. } \\
\hline Monmouthshire & $\cdot \ldots$ & I3I & 3 & 6 & I7 & 4 & 25 & I2 & I0 & 43 & II \\
\hline \multicolumn{6}{|l|}{ South Wales- } & 6 & 32 & I4 & Io & 40 & \\
\hline Carmarthenshire & $\cdots$ & I35 & 4 & 3 & I3 & 3 & 44 & 12 & 7 & 37 & 12 \\
\hline Pembrokeshire & $\ldots$ & I I 4 & 4 & I & I I & 5 & 24 & 8 & 8 & 40 & 13 \\
\hline Cardiganshire & $\cdots$ & II 2 & 2 & 4 & I2 & 2 & 32 & 8 & 6 & 32 & I4 \\
\hline Brecknockshire & $\cdots$ & I 18 & $\mathbf{I}$ & 5 & II & 2 & 23 & 7 & 8 & 46 & I4 \\
\hline Radnorshire... & ... & 87 & 4 & 4 & Io & 2 & 4 & 8 & 6 & 35 & I4 \\
\hline \multicolumn{12}{|l|}{ North Wales- } \\
\hline Montgomeryshire & ... & 93 & - & 4 & 8 & I & 20 & 8 & 7 & $3 \mathrm{I}$ & I4 \\
\hline Flintshire $\ldots$ & $\cdots$ & 84 & - & 2 & Io & - & I9 & 5 & 8 & 28 & I2 \\
\hline Denbighshire & $\cdots$ & 142 & 0 & 5 & I7 & 5 & 35 & II & 18 & 34 & I7 \\
\hline Merionethshire & ... & I4I & 4 & 5 & $2 \mathrm{I}$ & 6 & 36 & II & 6 & 35 & I7 \\
\hline Carnarvonshire & ... & I29 & 2 & 5 & I2 & 4 & 33 & I0 & IO & 40 & I3 \\
\hline Anglesey ... & $\cdots$ & I2I & - & 2 & I9 & 5 & 36 & 4 & 9 & 33 & 13 \\
\hline
\end{tabular}

Since the above table was printed the RegistrarGeneral's Report for 1904 has been issued. The returns are of a precisely similar character, except that the rates throughout are slightly higher (average 145 instead of 132). 


\section{APPENDICES}

\section{APPENDIX III.}

\section{ENGLAND AND WALES.}

Birth Rates, ETc., in Counties, I894-I903 AND igo4.

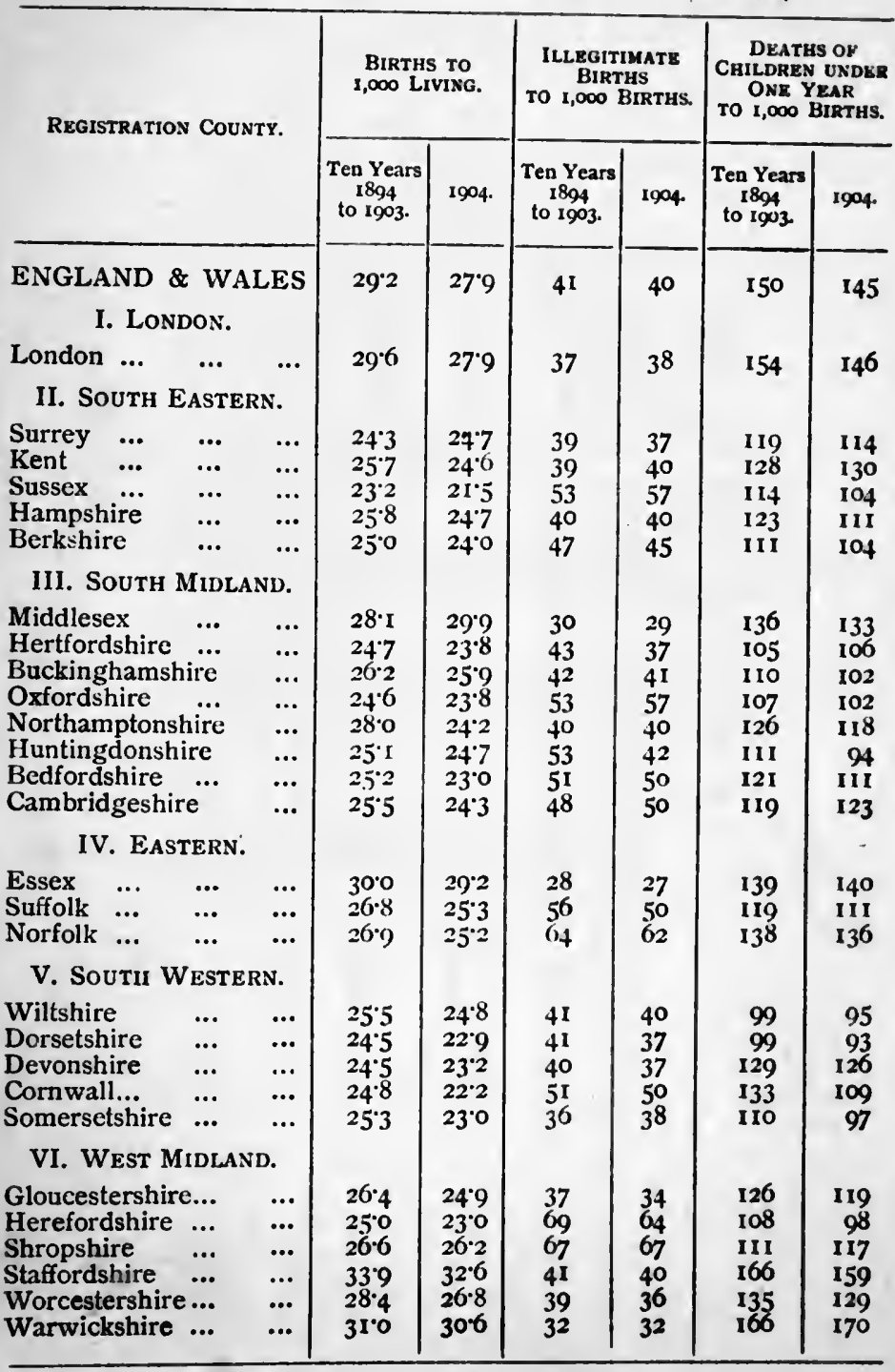


APPENDIX III. (continued).

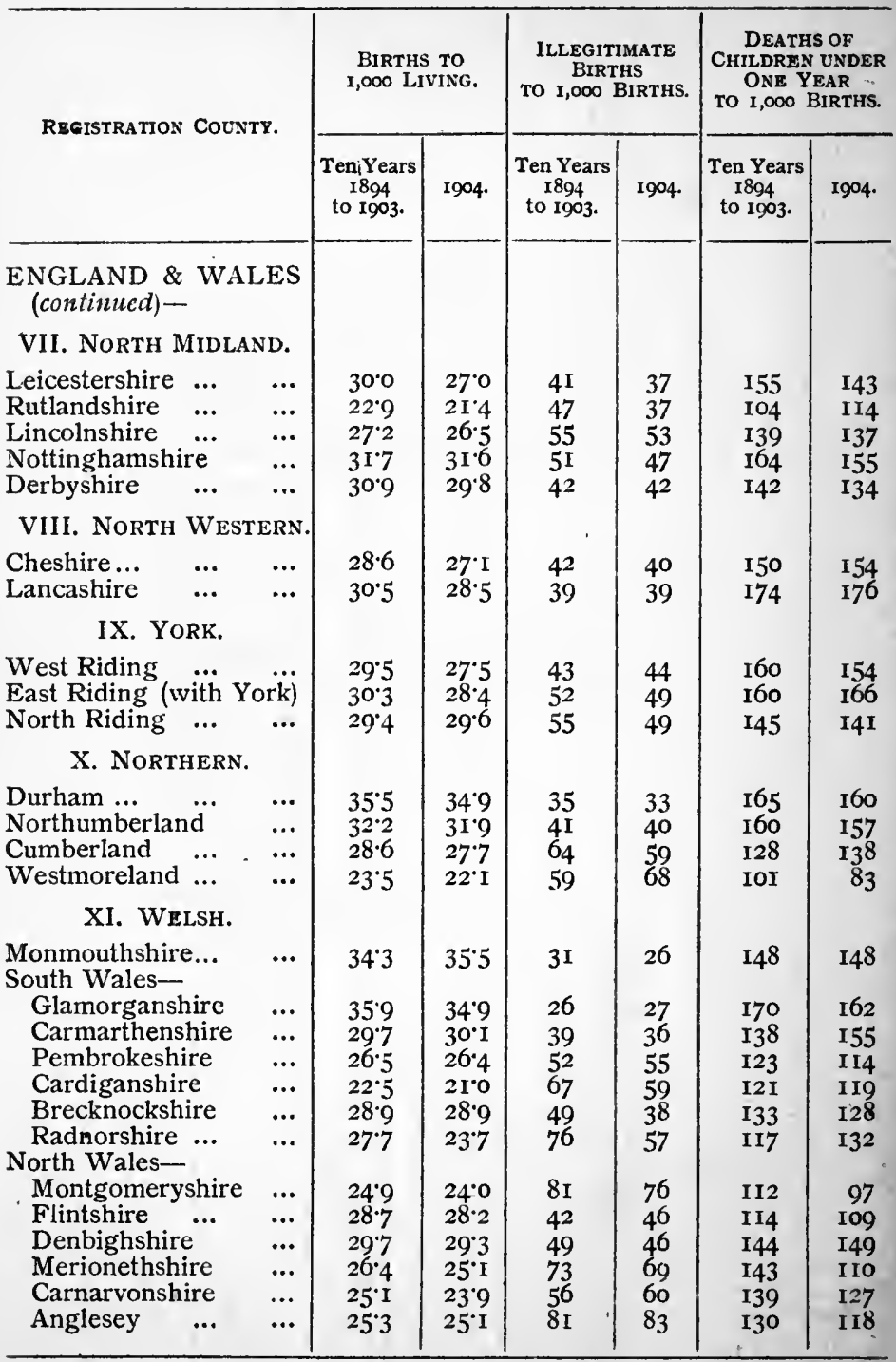




\section{APPENDIX IV.}

\section{INFANT DEATHS DISTRIBUTED IN THREE - MONTH PERIODS IN ENGLISH COUNTIES, 1903.}

Percentages of Infant Deaths on Total Infant Deaths.

(Constructed from Sixty-sixth Report of Registrar-General, 1903, pp. 126-137.)

\begin{tabular}{|c|c|c|c|c|c|c|c|}
\hline \multicolumn{5}{|c|}{ County. } & \multirow{2}{*}{$\frac{0-3 \text { Months. }}{5^{1} 4}$} & \multirow{2}{*}{$\frac{3-6 \text { Months. }}{19^{\circ} 9}$} & 6-12 Months. \\
\hline ENGLAND & AND W & WALES & $\cdots$ & $\cdots$ & & & $28 \cdot 7$ \\
\hline London & $\ldots$ & $\cdots$ & $\cdots$ & $\cdots$ & $50^{\circ} 0$ & $20 \cdot I$ & 29.9 \\
\hline Surrey & $\ldots$ & $\ldots$ & $\ldots$ & $\ldots$ & 577 & I8. I & $24 \%$ \\
\hline Kent ... & $\ldots$ & $\cdots$ & $\ldots$ & ... & 547 & $17 \cdot 8$ & $27 \cdot 5$ \\
\hline Sussex & $\ldots$ & $\cdots$ & $\cdots$ & $\ldots$ & $55 \cdot 3$ & $17 \cdot 1$ & 27.6 \\
\hline Hampshire & $e \ldots$ & $\cdots$ & $\ldots$ & $\ldots$ & $55^{\circ}$ & $17 \cdot 2$ & $27 \cdot 6$ \\
\hline Berkshire & $\cdots$ & $\cdots$ & $\cdots$ & $\ldots$ & $56 \cdot 0$ & $17 \cdot 2$ & $26 \cdot 8$ \\
\hline Middlesex & $\ldots$ & $\cdots$ & $\cdots$ & $\cdots$ & $52 \cdot 0$ & $19 \cdot 8$ & $28 \cdot 2$ \\
\hline Hertfordsh & hire & $\ldots$ & $\cdots$ & $\ldots$ & $58 \cdot 8$ & 13.3 & 27.9 \\
\hline Buckinghar & amshire & e ... & $\ldots$ & ... & 59.5 & 13.6 & $26 \%$ \\
\hline Oxford & $\cdots$ & $\ldots$ & $\ldots$ & ... & 60.9 & 12.5 & $26 \cdot 6$ \\
\hline Northampt & ton & $\cdots$ & $\cdots$ & $\cdots$ & 567 & $17 \cdot 4$ & $25^{\circ} 9$ \\
\hline Huntingdor & & $\cdots$ & $\cdots$ & $\cdots$ & $57^{\circ} 0$ & $15^{\circ}$ & $27 \cdot 1$ \\
\hline Bedford & $\cdots$ & $\cdots$ & ... & $\ldots$ & 637 & $14 \cdot 6$ & 217 \\
\hline Cambridge & e... & ... & $\cdots$ & ... & $55 \cdot 3$ & 18.5 & $26 \cdot 2$ \\
\hline Essex & $\ldots$ & ... & ... & $\ldots$ & $5 I \cdot 8$ & $19^{\circ} 1$ & 29.1 \\
\hline Suffolk & $\ldots$ & $\cdots$ & $\cdots$ & $\cdots$ & $58 \cdot 8$ & $16 \cdot 3$ & 249 \\
\hline Norfolk & ... & $\cdots$ & $\cdots$ & $\cdots$ & 540 & $19 \cdot 7$ & $26 \cdot 3$ \\
\hline Wiltshire & $\ldots$ & $\ldots$ & $\cdots$ & $\ldots$ & $62 \cdot 1$ & $15^{\circ} 9$ & $220^{\circ}-1-1$ \\
\hline Dorset & ... & ... & $\ldots$ & $\ldots$ & $60 \% 9$ & $15 \cdot 8$ & $23 \cdot 3$ \\
\hline Devon & $\ldots$ & $\cdots$ & $\ldots$ & $\ldots$ & $53 \cdot 6$ & 187 & 277 \\
\hline Cornivall & $\ldots$ & $\cdots$ & $\ldots$ & $\ldots$ & 62.9 & $14 \cdot 6$ & $22 \cdot 5$ \\
\hline Somerset & ... & $\cdots$ & $\cdots$ & $\ldots$ & 577 & $17 \cdot 2$ & $25^{\circ} 1$ \\
\hline Gloucester & $\ldots$ & $\cdots$ & $\ldots$ & $\ldots$ & 56.9 & 204 & 227 \\
\hline Hereford & $\ldots$ & $\ldots$ & $\ldots$ & $\ldots$ & $59 \cdot 6$ & $17 \% 9$ & $22^{\circ} 5$ \\
\hline Shropshire & $\ldots$ & $\ldots$ & ... & $\ldots$ & 584 & 19.4 & $22 \cdot 2$ \\
\hline Stafford & $\ldots$ & $\ldots$ & $\ldots$ & $\ldots$ & $51 \cdot 0$ & $2 i \cdot 3$ & $27 \%$ \\
\hline Worcester & $\ldots$ & $\ldots$ & $\ldots$ & $\ldots$ & $54^{\circ} \mathrm{I}$ & 20.5 & $25^{\circ} 4$ \\
\hline Warwick & ... & $\ldots$ & ... & $\ldots$ & $5 \mathrm{I} \cdot 5$ & $20 \cdot 6$ & $27^{\circ} 9$ \\
\hline Leicester & $\ldots$ & ... & $\ldots$ & $\ldots$ & $49 \cdot 5$ & $21 \cdot 3$ & $29 \cdot 2$ \\
\hline Rutland & $\ldots$ & $\ldots$ & $\ldots$ & $\ldots$ & $55^{\circ} 8$ & $13 \cdot 9$ & $30 \div 3$ \\
\hline Lincoln & $\ldots$ & ... & ... & $\cdots$ & $51 \cdot 5$ & $19 \cdot 3$ & $29^{\circ} 2$ \\
\hline Nottingham & & $\ldots$ & $\ldots$ & $\ldots$ & $50 \cdot 6$ & $2 \mathrm{I} \cdot 2$ & $28 \cdot 2$ \\
\hline Derby & ... & $\ldots$ & $\ldots$ & $\ldots$ & $52 \cdot 8$ & 184 & $28 \cdot 8$ \\
\hline Cheshire & $\ldots$ & ... & $\ldots$ & $\cdots$ & $49 \cdot 8$ & 210 & 29.2 \\
\hline Lancashire & ... & $\ldots$ & $\ldots$ & $\ldots$ & $47^{\circ} 6$ & $2 I \cdot 1$ & $31 \cdot 3$ \\
\hline West Ridin & & ... & $\ldots$ & ... & $49 \cdot 8$ & $20: 2$ & $30^{\circ} 0$ \\
\hline East Riding & & $\ldots$ & $\ldots$ & $\ldots$ & $49 \cdot 1$ & $21 \cdot 3$ & $29 \cdot 6$ \\
\hline North Ridi & ing & $\ldots$ & $\ldots$ & $\ldots$ & $52 \cdot 8$ & $18 \cdot 5$ & 287 \\
\hline Durham & $\ldots$ & ... & $\cdots$ & $\ldots$ & $51 \cdot 5$ & $20 \cdot 2$ & $28 \cdot 3$ \\
\hline Northumbe & erland & $\ldots$ & $\ldots$ & $\ldots$ & $51 \cdot 5$ & 204 & $28 \cdot 1$ \\
\hline Cumberlan & & $\ldots$ & $\ldots$ & $\ldots$ & $54 \cdot 1$ & $18 \cdot I$ & $27^{\circ} 8$ \\
\hline Westmorel & land & $\ldots$ & $\ldots$ & $\ldots$ & $60 \%$ & $17^{\cdot 8}$ & $22 \cdot 2$ \\
\hline Monmouths & ishire & ... & $\ldots$ & $\cdots$ & $52 \cdot 2$ & 194 & $28 \cdot 4$ \\
\hline South Wale & & ... & $\ldots$ & $\cdots$ & $50 \cdot 8$ & 204 & $28 \cdot 8$ \\
\hline North Wale & & $\cdots$ & $\cdots$ & $\cdots$ & 544 & 20.8 & $24^{8} 8$ \\
\hline
\end{tabular}


APPENDIX V.

CAUSES OF DEATH IN INFANCY, I903.

ENGLAND AND WaLes.

\begin{tabular}{|c|c|c|c|c|c|c|c|c|}
\hline \multirow{2}{*}{ DISEASES. } & \multicolumn{4}{|c|}{ Males. } & \multicolumn{4}{|c|}{ Females. } \\
\hline & $0-3$ & $3-6$ & $6-12$ & Total. & $0-3$ & $3-6$ & $6-12$ & Total. \\
\hline 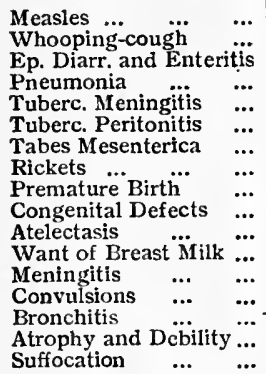 & $\begin{array}{r}30 \\
433 \\
1,856 \\
1,235 \\
72 \\
139 \\
172 \\
41 \\
10,664 \\
1,971 \\
750 \\
243 \\
170 \\
4,845 \\
2,156 \\
6,922 \\
621\end{array}$ & $\begin{array}{r}89 \\
578 \\
2,465 \\
I, 446 \\
223 \\
243 \\
262 \\
85 \\
108 \\
188 \\
122 \\
293 \\
293 \\
1,563 \\
1,631 \\
1,554 \\
236\end{array}$ & $\begin{array}{r}1,042 \\
\mathbf{1}, 310 \\
\mathbf{2 , 7} 788 \\
\mathbf{3 , 2 9 8} \\
\mathbf{5 2 5} \\
\mathbf{2 8 5} \\
339 \\
269 \\
29 \\
\mathbf{1 7 2} \\
-49 \\
49 \\
673 \\
\mathbf{1}, 251 \\
2,280 \\
888 \\
68\end{array}$ & $\begin{array}{r}1,161 \\
2,321 \\
7,109 \\
5,979 \\
820 \\
667 \\
773 \\
395 \\
10,801 \\
2,331 \\
750 \\
414 \\
1,136 \\
7,666 \\
6,067 \\
9,364 \\
925\end{array}$ & $\begin{array}{r}19 \\
473 \\
1,395 \\
922 \\
56 \\
75 \\
120 \\
9 \\
8,137 \\
1,526 \\
562 \\
166 \\
128 \\
3,394 \\
1,601 \\
5,194 \\
584\end{array}$ & $\begin{array}{r}73 \\
580 \\
2,017 \\
1,082 \\
182 \\
160 \\
211 \\
45 \\
119 \\
163 \\
81 \\
81 \\
266 \\
1,226 \\
1,186 \\
1,270 \\
221\end{array}$ & $\begin{array}{r}888 \\
1,399 \\
2,440 \\
2,766 \\
465 \\
250 \\
264 \\
175 \\
20 \\
123 \\
-76 \\
56 \\
492 \\
997 \\
\mathbf{r} 938 \\
760 \\
66\end{array}$ & $\begin{array}{r}980 \\
2,452 \\
5,852 \\
4,770 \\
703 \\
485 \\
595 \\
229 \\
8,276 \\
1,812 \\
562 \\
303 \\
886 \\
5,617 \\
4,725 \\
7,224 \\
871\end{array}$ \\
\hline All other causes & 4,226 & $2,74 \mathrm{I}$ & 4,077 & 11,044 & 3,152 & $2,13^{8}$ & 3,363 & 8,653 \\
\hline Total, all causes & 36,546 & 13,827 & 19,350 & 69,723 & 27,513 & 11,020 & 16,462 & 54,995 \\
\hline
\end{tabular}




\section{APPENDIX VI.}

CAUSES OF DEATH IN INFANCY, I903.

LONDON.

\begin{tabular}{|c|c|c|c|c|c|c|c|c|}
\hline \multirow{2}{*}{ Diseases. } & \multicolumn{4}{|c|}{ MaLES. } & \multicolumn{4}{|c|}{ Fearales. } \\
\hline & $0-3$ & $3-6$ & $6-12$ & Total. & $0-3$ & $3-6$ & $6-12$ & Total. \\
\hline Measles ... $\quad \ldots$ & Io & 24 & 229 & 263 & 7 & 19 & I70 & 196 \\
\hline $\begin{array}{l}\text { Whooping-cough } \\
\text { Ep.Diarrhoea) }\end{array}$ & 47 & 68 & 224 & 339 & 53 & 83 & 260 & 396 \\
\hline $\begin{array}{l}\text { Ep. Diarrhœa } \\
\text { and Enteritis }\end{array}$ & 288 & 426 & 485 & I, 199 & 238 & 342 & 426 & I,006 \\
\hline Pneumonia $\quad .$. & I96 & 214 & 494 & 904 & I74 & i 76 & 422 & 772 \\
\hline $\left.\begin{array}{l}T \text { ubercul ous } \\
\text { Meningitis }\end{array}\right\}$ & 14 & 47 & 98 & I59 & I4 & 28 & 92 & 134 \\
\hline $\begin{array}{l}\text { Tubercu lo us } \\
\text { Peritonitis }\end{array}$ & 27 & 29 & 26 & 82 & 13 & 18 & 30 & $6 \mathrm{I}$ \\
\hline $\begin{array}{l}\text { Tabes Mesenterica } \\
\text { Rickets }\end{array}$ & 39 & $\begin{array}{l}29 \\
16\end{array}$ & $\begin{array}{l}39 \\
52\end{array}$ & $\begin{array}{r}\text { I07 } \\
79\end{array}$ & 25 & 28 & 29 & \\
\hline Premature Birth & 1,386 & $\begin{array}{l}10 \\
17\end{array}$ & $\begin{array}{r}52 \\
4\end{array}$ & $\begin{array}{r}79 \\
1,407\end{array}$ & $1, \overline{076}$ & $\begin{array}{r}7 \\
16\end{array}$ & $\begin{array}{r}33 \\
6\end{array}$ & $\begin{array}{r}40 \\
1,098\end{array}$ \\
\hline $\left.\begin{array}{c}\text { Congen it a l } \\
\text { Defects }\end{array}\right\}$ & 300 & 32 & 22 & 354 & 215 & 25 & 14 & 254 \\
\hline Atelectasis $\quad \ldots$ & I2I & - & - & I2I & 93 & 一 & - & 93 \\
\hline $\begin{array}{c}\text { Want of Breast } \\
\text { Milk ... }\end{array}$ & 46 & 22 & I3 & $8 I$ & 26 & 18 & 12 & 56 \\
\hline $\begin{array}{ll}\text { Meningitis } & \ldots \\
\text { Convulsions } & \ldots\end{array}$ & 27 & $\begin{array}{r}43 \\
106\end{array}$ & $\begin{array}{l}97 \\
70\end{array}$ & 167 & I7 & 43 & 80 & 140 \\
\hline $\begin{array}{ll}\text { Convulsions } & \ldots \\
\text { Bronchitis } & \ldots\end{array}$ & $\begin{array}{l}397 \\
290\end{array}$ & $\begin{array}{l}106 \\
184\end{array}$ & $\begin{array}{r}79 \\
249\end{array}$ & $\begin{array}{l}582 \\
723\end{array}$ & $\begin{array}{l}305 \\
217\end{array}$ & $\begin{array}{r}80 \\
139\end{array}$ & $\begin{array}{r}71 \\
706\end{array}$ & $45^{6}$ \\
\hline Atrophy and De- & & 190 & IIO & I.075 & 635 & 150 & 190 & $55^{2}$ \\
\hline $\begin{array}{c}\text { bility ... } \\
\text { Suffocation }\end{array}$ & 775 & 71 & 110 & $\begin{array}{r}1,0 / 5 \\
206\end{array}$ & 035 & $\begin{aligned} 58 \\
150\end{aligned}$ & 90 & 875 \\
\hline … & & & & & & 30 & 27 & 207 \\
\hline All other causes & 641 & $4 \mathrm{I} 3$ & 523 & $I, 577$ & 486 & 307 & 437 & 1,230 \\
\hline Total, all causes & $4,8 \mathrm{I} 8$ & $I, 93 I$ & 2,766 & 9,515 & 3,776 & 1,537 & 2,395 & 7,708 \\
\hline
\end{tabular}




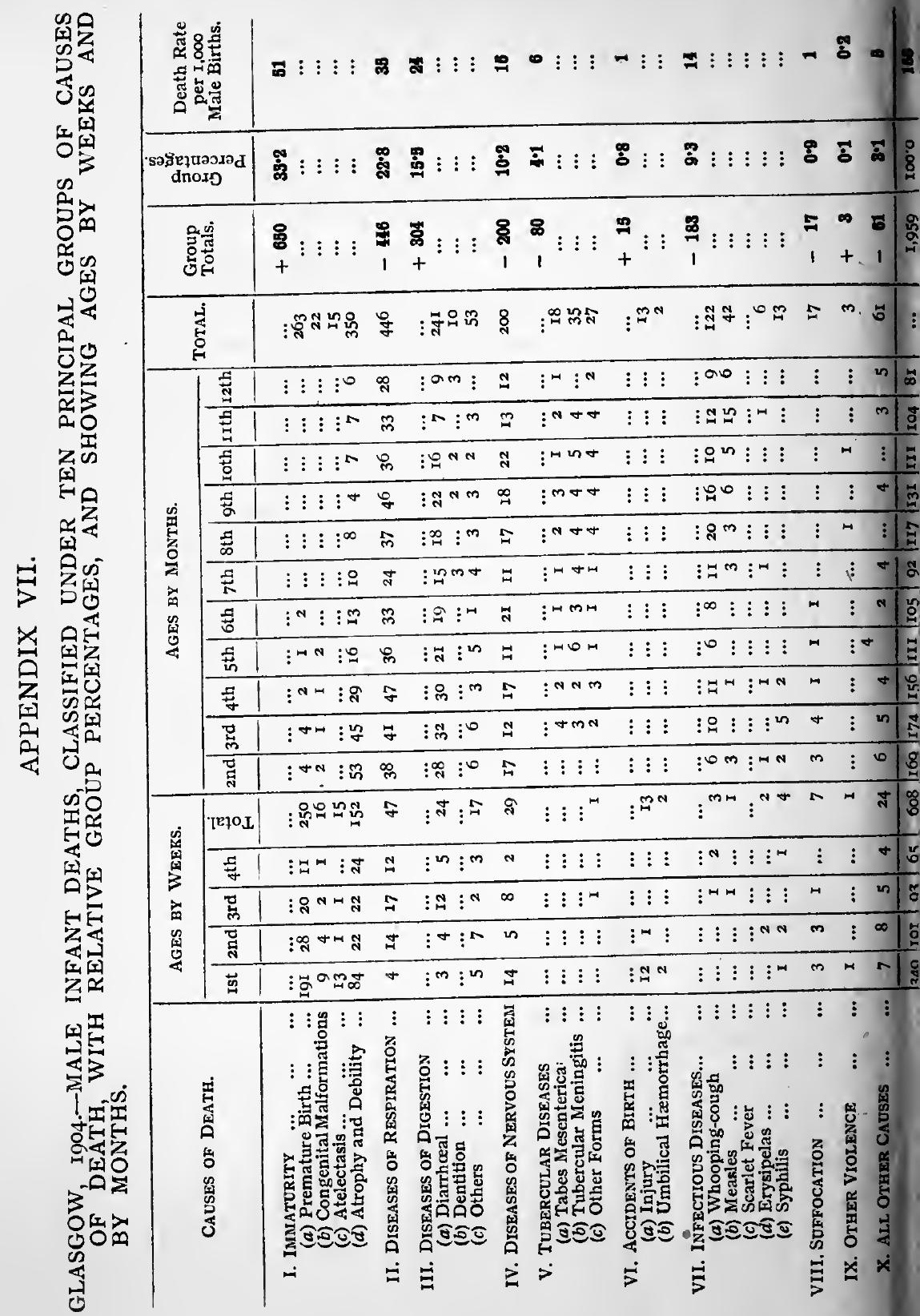




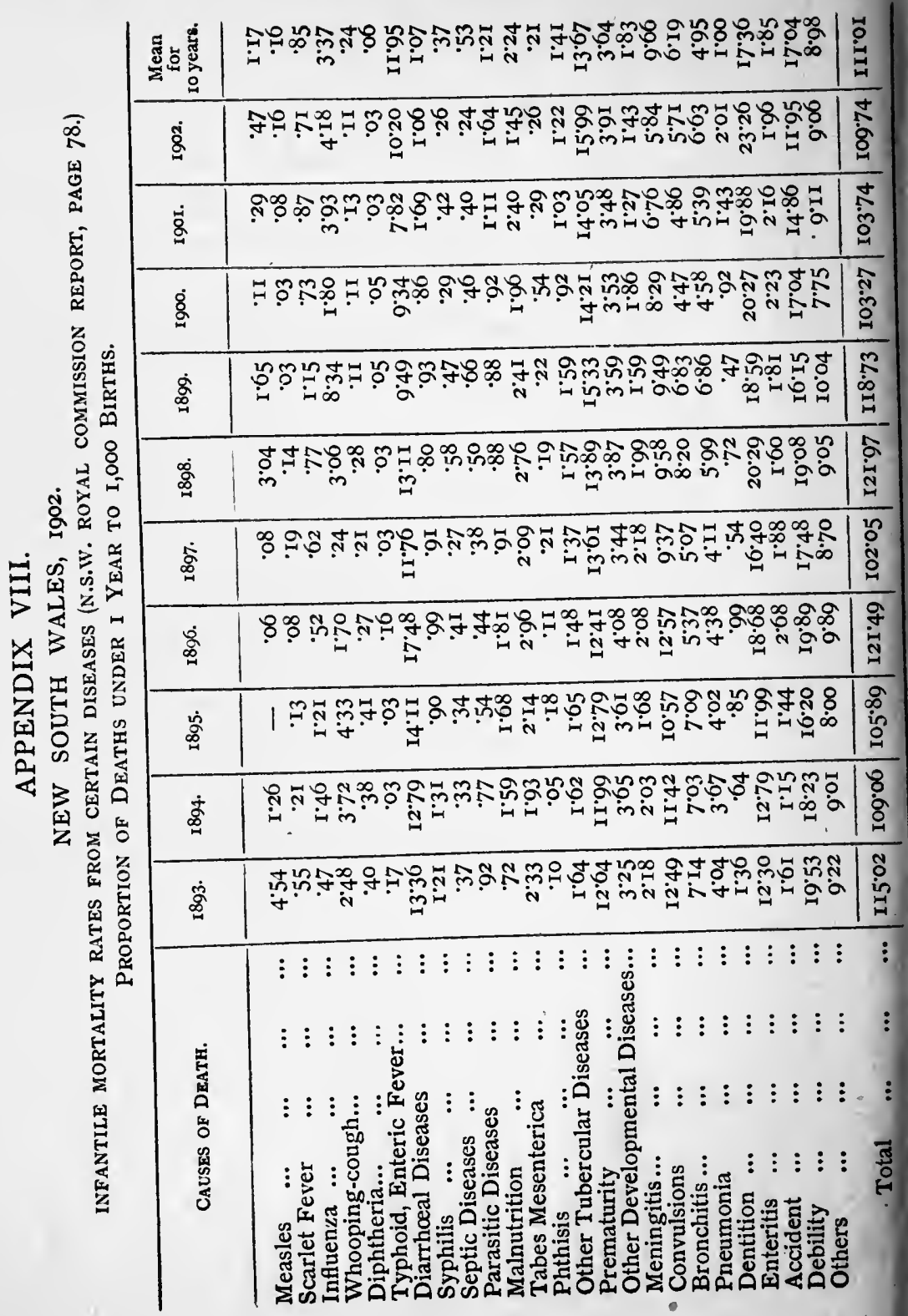




\section{APPENDIX IX.}

INFANT MORTALITY IN LEEDS FOR EACH QUARTER OF FIFTEEN YEARS (1890-I904), AND FOR EACH OF THOSE YEARS THE AMOUNT PER CENT. ABOVE OR BELOW THE AVERAGE OF THE WHOLE PERIOD. (DR. SPOTTISWOOdE CAMERON, Annual Report on Health of Leeds, I904, pp. 2 I AND 22.)

\begin{tabular}{|c|c|c|c|c|c|c|c|c|c|c|}
\hline & \multicolumn{2}{|c|}{ I. } & \multicolumn{2}{|c|}{ II. } & \multicolumn{2}{|c|}{ III. } & \multicolumn{2}{|c|}{ IV. } & \multicolumn{2}{|c|}{ YEAR. } \\
\hline & $\begin{array}{c}\text { Deaths } \\
\text { per } \\
\text { I,O00 } \\
\text { Births. }\end{array}$ & $\begin{array}{c}\% \\
\text { above+ } \\
\text { below- }\end{array}$ & $\begin{array}{c}\text { Deaths } \\
\text { per } \\
1,000 \\
\text { Births. }\end{array}$ & $\begin{array}{c}\% \\
\text { above }+ \\
\text { below }-\end{array}$ & $\begin{array}{c}\text { Deaths } \\
\text { per } \\
\text { I,000 } \\
\text { Births. }\end{array}$ & $\begin{array}{c}\% \\
\text { above+ } \\
\text { below- }\end{array}$ & $\begin{array}{c}\text { Deaths } \\
\text { per } \\
\text { I,000 } \\
\text { Births. }\end{array}$ & $\begin{array}{c}\% \\
\text { abovet } \\
\text { below- }\end{array}$ & $\begin{array}{c}\text { Deaths } \\
\text { per } \\
\text { I,000 } \\
\text { Births. }\end{array}$ & $\begin{array}{c}\% \\
\text { abovet } \\
\text { below- }\end{array}$ \\
\hline I 890 & 152 & $-I_{4}$ & 143 & -19 & 217 & +23 & 178 & +1 & 173 & -2 \\
\hline I89I & 156 & - II & I73 & -2 & 205 & +17 & I75 & $-I$ & I77 & $+I$ \\
\hline 1892 & I59 & -10 & 139 & $-2 I$ & 209 & +19 & 166 & -6 & I68 & -5 \\
\hline 1893 & I75 & $-I$ & 167 & -5 & 310 & +76 & I7 I & -3 & 206 & +17 \\
\hline 1894 & 138 & -22 & I3I & -26 & I84 & +5 & 173 & -2 & 156 & - II \\
\hline 1895 & 163 & -7 & I33 & -24 & 296 & +68 & 176 & $\pm_{0}$ & I9I & +9 \\
\hline 1896 & I55 & -12 & 164 & -7 & 207 & +18 & 146 & -17 & 169 & -4 \\
\hline 1897 & I4I & -20 & 118 & -33 & 319 & $+8 \mathrm{I}$ & 187 & +6 & 190 & +8 \\
\hline I898 & 145 & -18 & 140 & $-2 I$ & 286 & +63 & 160 & -9 & 183 & +4 \\
\hline 1899 & I4I & -20 & 128 & -27 & 262 & +49 & 156 & $-I I$ & 172 & -2 \\
\hline I900 & I73 & -2 & 160 & -9 & $24 \mathrm{I}$ & +37 & 157 & $-I I$ & 183 & +4 \\
\hline I9OI & I43 & -19 & I27 & -28 & 320 & +82 & 164 & -7 & I 88 & +7 \\
\hline 1902 & I52 & $-I 4$ & 142 & -19 & 172 & -2 & 172 & -2 & 160 & -9 \\
\hline 1903 & I3I & -26 & II 6 & -34 & I77 & $+I$ & 190 & +8 & I53 & -13 \\
\hline 1904 & 160 & -9 & 147 & -17 & 238 & +35 & $15^{8}$ & -10 & I76 & \\
\hline
\end{tabular}


APPENDIX IX. (continued).

MEAN TEMPERATURE ( ${ }^{\circ}$ F.) FOR EACH QUARTER AND FOR EACH YEAR FROM I890 TO I904 INCLUSIVE.

\begin{tabular}{|c|c|c|c|c|c|}
\hline & I. & II. & III. & IV. & YEAR. \\
\hline $\begin{array}{l}I 890 \\
I 891 \\
1892 \\
I 893 \\
I 894\end{array}$ & $\begin{array}{l}42 \cdot 9 \\
40 \cdot 2 \\
40 \cdot 1 \\
42 \cdot 3 \\
42 \cdot 6\end{array}$ & $\begin{array}{l}55^{\circ} \mathrm{O} \\
55^{\circ} \mathrm{O} \\
54^{\circ} 6 \\
59^{\circ} \mathrm{I} \\
55^{\circ} \mathrm{I}\end{array}$ & $\begin{array}{l}6 I \cdot 6 \\
6 I \cdot 3 \\
59 \cdot 7 \\
63 \cdot 9 \\
6 I \cdot 0\end{array}$ & $\begin{array}{l}43 \cdot 5 \\
43 \cdot 8 \\
42 \cdot 3 \\
46 \cdot 3 \\
47 \cdot 5\end{array}$ & $\begin{array}{l}50 \cdot 6 \\
50 \cdot 1 \\
49 \cdot 2 \\
52 \cdot 9 \\
51 \cdot 6\end{array}$ \\
\hline $\begin{array}{l}1895 \\
1896 \\
1897 \\
1898 \\
1899\end{array}$ & $\begin{array}{l}36 \cdot 8 \\
44^{\circ} \cdot 1 \\
4 I \cdot 7 \\
44^{\cdot} \cdot 1 \\
4^{2} \cdot 6\end{array}$ & $\begin{array}{l}57 \cdot 9 \\
58 \cdot 5 \\
56 \cdot 0 \\
55 \cdot 3 \\
56 \cdot 5\end{array}$ & $\begin{array}{l}64 \cdot 0 \\
61 \cdot 3 \\
63 \cdot 4 \\
64 \cdot 3 \\
64 \cdot 5\end{array}$ & $\begin{array}{l}44^{\circ} 9 \\
42^{\circ} 9 \\
47^{\circ} 3 \\
49^{\circ} \mathrm{I} \\
45^{\circ} 9\end{array}$ & $\begin{array}{l}50 \cdot 4 \\
51 \cdot 9 \\
52 \cdot 1 \\
52 \cdot 2 \\
52 \cdot 4\end{array}$ \\
\hline $\begin{array}{l}\text { I900 } \\
\text { I901 } \\
\text { I902 } \\
\text { I903 } \\
1904\end{array}$ & $\begin{array}{l}40 \cdot I \\
40 \cdot I \\
42 \cdot 6 \\
45 \cdot 5 \\
4 I \cdot 4\end{array}$ & $\begin{array}{l}55^{\circ} 9 \\
5^{8} \cdot 0 \\
54^{\circ} 0 \\
55^{\circ} \cdot 8 \\
56.4\end{array}$ & $\begin{array}{l}64 \cdot 0 \\
66 \cdot 0 \\
60 \cdot 9 \\
61 \cdot 4 \\
63 \cdot 5\end{array}$ & $\begin{array}{l}48^{\circ} \cdot 9 \\
45 \cdot 3 \\
47^{\circ} 2 \\
45^{\circ} 6 \\
46^{\circ} \cdot 2\end{array}$ & $\begin{array}{l}52 \cdot 2 \\
52 \cdot 4 \\
5 I \cdot I \\
52 \cdot I \\
5 I \cdot 9\end{array}$ \\
\hline Means & $4 I \cdot 8$ & $56 \cdot 2$ & $62 \cdot 7$ & $45^{\cdot 8}$ & $5 I \cdot 6$ \\
\hline
\end{tabular}

RAINFALL-INCHES.

\begin{tabular}{|c|c|c|c|c|c|}
\hline & I. & II. & III. & IV. & YEAR. \\
\hline $\begin{array}{l}1890 \\
1891 \\
1892 \\
1893 \\
1894\end{array}$ & $\begin{array}{l}5 \cdot 65 \\
2 \cdot 36 \\
4 \cdot 27 \\
4 \cdot 32 \\
8 \cdot 78\end{array}$ & $\begin{array}{l}4 \cdot 86 \\
4 \cdot 88 \\
8 \cdot 02 \\
2 \cdot 96 \\
6 \cdot 70\end{array}$ & $\begin{array}{l}8 \cdot 71 \\
7 \cdot 08 \\
5 \cdot 99 \\
8 \cdot 21 \\
5 \cdot 69\end{array}$ & $\begin{array}{c}3 \cdot 5^{6} \\
10^{\circ} \cdot 32 \\
9 \cdot 00 \\
6 \cdot 34 \\
6 \cdot 81\end{array}$ & $\begin{array}{l}22 \cdot 62 \\
24 \cdot 64 \\
27 \cdot 28 \\
21 \cdot 83 \\
27 \cdot 98\end{array}$ \\
\hline $\begin{array}{l}1895 \\
1896 \\
1897 \\
1898 \\
1899\end{array}$ & $\begin{array}{l}6 \cdot 27 \\
4 \cdot 48 \\
7 \cdot 67 \\
2 \cdot 83 \\
5 \cdot 67\end{array}$ & $\begin{array}{l}4 \cdot 86 \\
5 \cdot 32 \\
5 \cdot 68 \\
7 \cdot 05 \\
6 \cdot 11\end{array}$ & $\begin{array}{c}10.00 \\
6.24^{x} \\
5.72 \\
4.19 \\
6.03\end{array}$ & $\begin{array}{l}8 \cdot 79 \\
8 \cdot 72 \\
6 \cdot 04 \\
7 \cdot 47 \\
5 \cdot 59\end{array}$ & $\begin{array}{l}29^{\circ} 92 \\
24^{\circ} 76^{1} \\
25^{\circ} 11 \\
21.54 \\
23^{\circ} \cdot 4^{\circ}\end{array}$ \\
\hline $\begin{array}{l}1900 \\
1901 \\
1902 \\
1903 \\
1904\end{array}$ & $\begin{array}{r}8.36 \\
5.03 \\
3.15 \\
6.62 \\
7.05\end{array}$ & $\begin{array}{l}4 \cdot 88 \\
3 \cdot 84 \\
5 \cdot 68 \\
5 \cdot 93 \\
4 \cdot 40\end{array}$ & $\begin{array}{l}9 \cdot 17 \\
3 \cdot 25 \\
6 \cdot 17 \\
7 \cdot 86 \\
5 \cdot 65\end{array}$ & $\begin{array}{l}8 \cdot 14 \\
8 \cdot 93 \\
5 \cdot 95^{\prime} \\
8 \cdot 83 \\
3 \cdot 44\end{array}$ & $\begin{array}{l}30.55 \\
2 I^{\circ} 05 \\
2 I^{\circ} 0 I^{2} \\
29.24 \\
20.54\end{array}$ \\
\hline Means & $5 \cdot 50$ & $5 \cdot 4 I$ & $6 \cdot 66$ & $7 \cdot 20$ & $24^{\circ} 76$ \\
\hline
\end{tabular}

I The fourth quarter of 1890 , and third of 1896 , and the fourth of 1902 contained 14 weeks. The total rainfall for the quarter has been corrected by deducting a fourteenth part ; and a fifty-third part of the total has been deducted from the amount for the year for the same periods. 


\section{APPENDIX $\mathrm{X}$.}

ANNUAL DEATH RATES FROM ALCOHOLISM IN ENGLAND AND WALES PER MILLION LIVING, 1875-I904.

(From Registrar-General's Reports.)

\begin{tabular}{|c|c|c|c|c|}
\hline & Males. & $\begin{array}{l}\text { Average for } \\
\text { Five Years. }\end{array}$ & Females. & $\begin{array}{l}\text { Average for } \\
\text { Five Years. }\end{array}$ \\
\hline $\begin{array}{l}1875 \\
1876 \\
1877 \\
1878 \\
1879\end{array}$ & $\begin{array}{l}73 \\
69 \\
71 \\
64 \\
49\end{array}$ & 65 & $\begin{array}{l}24 \\
24 \\
23 \\
26 \\
26\end{array}$ & 25 \\
\hline $\begin{array}{l}1880 \\
1881 \\
1882 \\
1883 \\
1884\end{array}$ & $\begin{array}{l}50 \\
64 \\
69 \\
68 \\
64\end{array}$ & 63 & $\begin{array}{l}23 \\
29 \\
33 \\
29 \\
30\end{array}$ & 29 \\
\hline $\begin{array}{l}1885 \\
1886 \\
1887 \\
1888 \\
1889\end{array}$ & $\begin{array}{l}68 \\
66 \\
68 \\
68 \\
72\end{array}$ & 68 & $\begin{array}{l}32 \\
36 \\
37 \\
35 \\
39 \\
\end{array}$ & 36 \\
\hline $\begin{array}{l}1890 \\
1891 \\
1892 \\
1893 \\
1894\end{array}$ & $\begin{array}{l}94 \\
94 \\
86 \\
93 \\
76\end{array}$ & 89 & $\begin{array}{l}50 \\
49 \\
49 \\
55 \\
47 \\
\end{array}$ & 50 \\
\hline $\begin{array}{l}\text { I } 895 \\
\text { I } 896 \\
1897 \\
\text { I } 898 \\
\text { I } 899\end{array}$ & $\begin{array}{r}84 \\
91 \\
97 \\
98 \\
113\end{array}$ & $\begin{array}{l}97 \\
.\end{array}$ & $\begin{array}{l}51 \\
52 \\
58 \\
59 \\
69\end{array}$ & $5^{8}$ \\
\hline $\begin{array}{l}\text { I900 } \\
\text { I901 } \\
\text { I902 } \\
\text { I903 } \\
\text { I904 }\end{array}$ & $\begin{array}{r}132 \\
113 \\
105 \\
91 \\
85\end{array}$ & 105 & $\begin{array}{l}95 \\
80 \\
65 \\
62 \\
55\end{array}$ & 71 \\
\hline
\end{tabular}




\section{APPENDIX XI.}

MORTALITY AMONG LEGITIMATE AND ILLEGITIMATE INFANTS, RESPECTIVELY, IN THE YEAR I9O2.

Average Rates of Death from Various Causes, UNDER ONE Year, PER I,000 BirThs (a) in LONDON aND (b) IN THE SAME RURAL Codnties as IN TABLE ON P. 52.

(Report of Interdepartmental Committee on Physical Deterioration, 1904, p. 134).

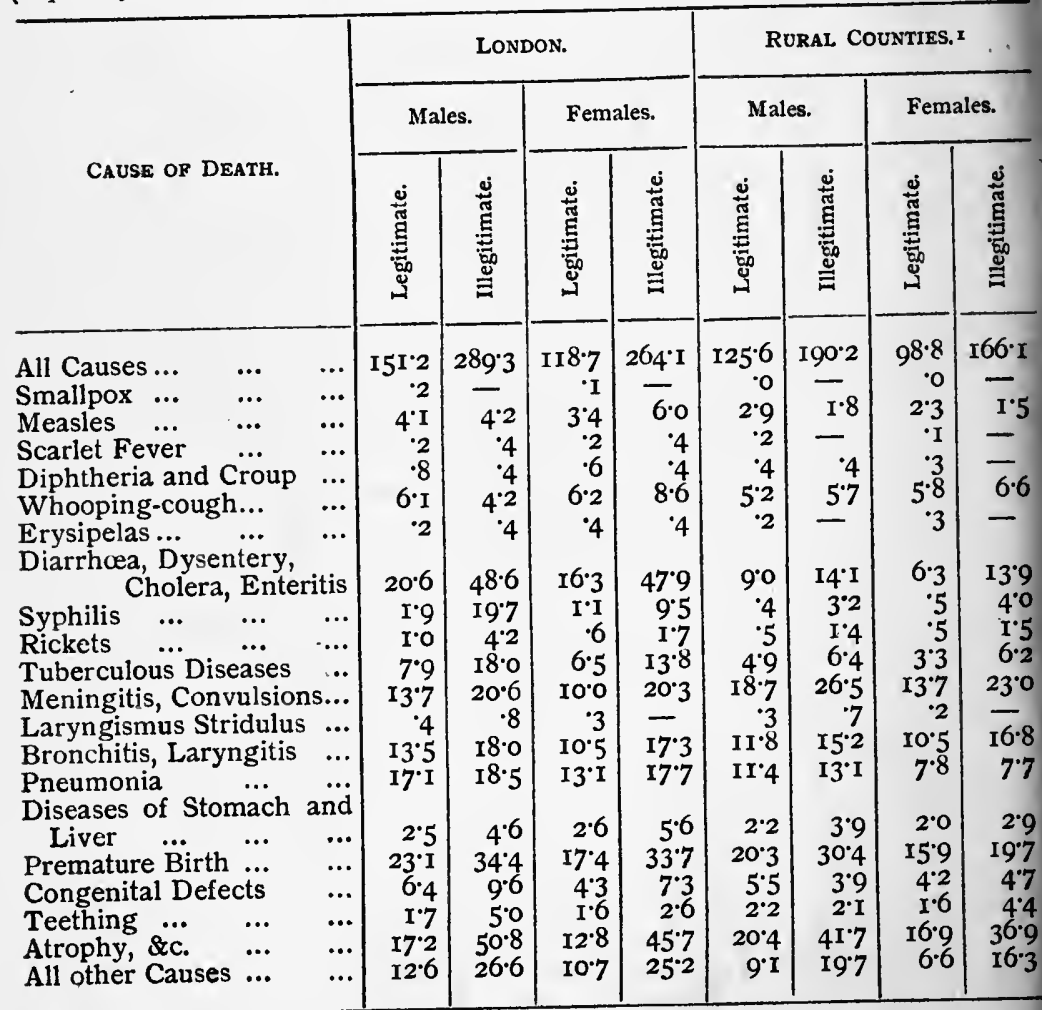

Note.- -0 indicates that the deaths were too few to give a rate of 05 per 1,000 .

- Rural Counties. Buckingham, Cambridge, Cornwall, Hereford, Huntingdon, Lincoln, North Wales, Norfolk, Oxford, Rutland, Salop, Somerset, South Wales (less Glamorgan), Suffolk, Westmoreland, Wilts.

Estimated Population in $1902: 4,279,175$. 


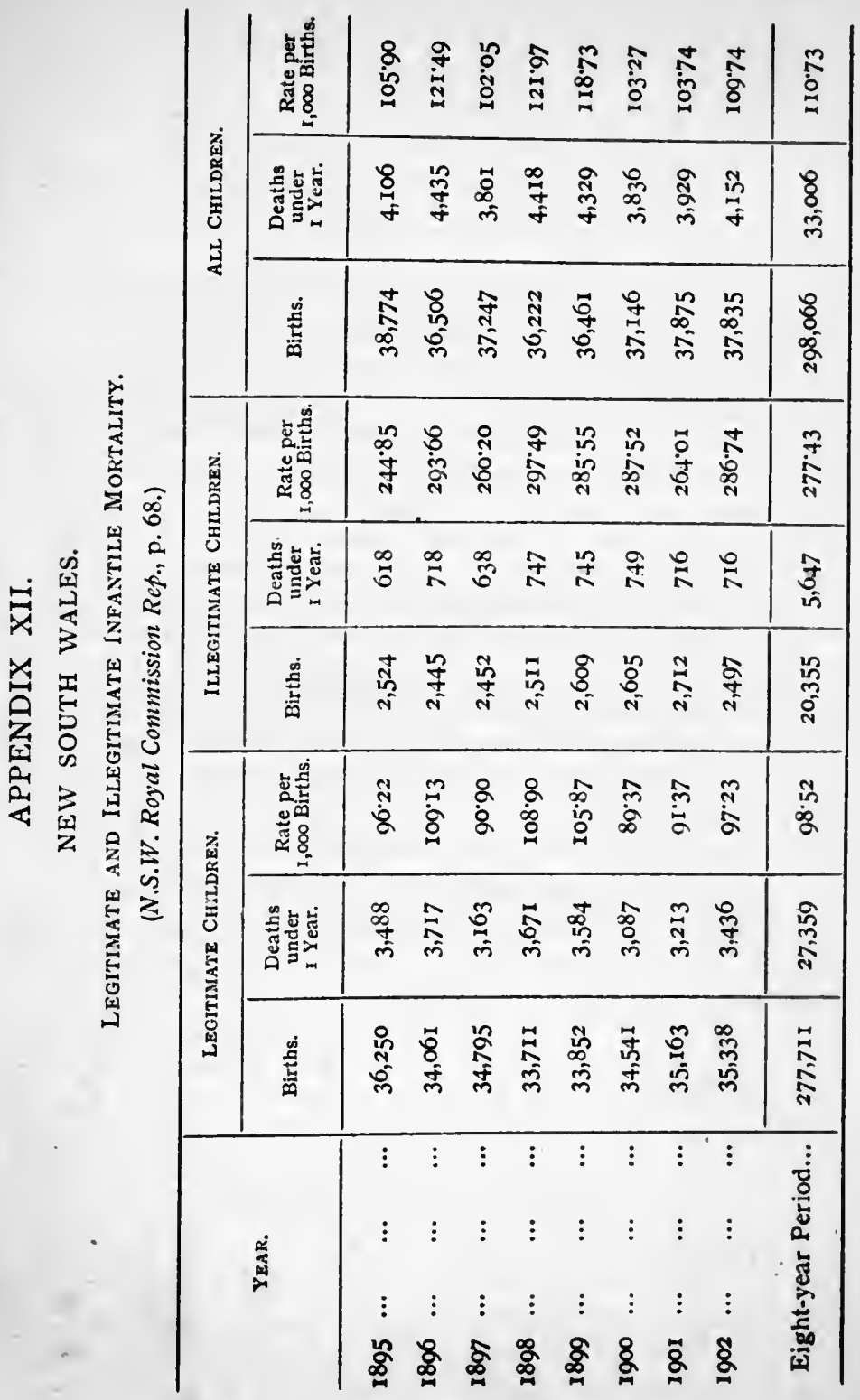




\section{APPENDIX XIII.}

The Metropolitan JBorougb of Jinsburp.

\section{THE \\ CARE AND FEEDING OF INFANTS. \\ I \\ FEEDING.}

Thousands of infants die every year from improper feeding.

If the mother has plenty of breast milk, the infant should not have any other food until it is gradually weaned during the 8th or 9th month. During the first 2 months it should not be suckled oftener than every 2 hours, and after the $3^{\text {rd }}$ month not oftener than every 3 hours. Regularity in feeding is most important. Do not feed between meals "just to keep the baby quiet."

During the suckling period the mother requires good plain wholesome food, including milk or milk puddings. Beer or other stimulants are not desirable unless ordered by the doctor.

If the mother has not sufficient milk, it should be supplemented with cow's milk and water, or barley water, made as below.

If the mother cannot suckle her child, it should be fed with cow's milk and water, or barley water, with a little sugar added (as below). Skimmed milk should not be used. It is best to boil the milk, especially in summer.

During the first fortnight.-Boil together $\frac{1}{4}$ pint of fresh milk, $\frac{1}{2}$ pint of water, and a small tablespoonful of sugar, and keep in a clean corked bottle or covered jug. Three tablespoonfuls of this should be given every 2 hours.

Between 2 weeks and 2 months.-Boil together $\frac{1}{2}$ pint milk, $\frac{3}{4}$ pint of water, and a tablespoonful of sugar Five tablespoonfuls should be given every 2 hours.

During the 3 rd and 4 th months. - Boil together $\frac{3}{4}$ pint milk, $\frac{3}{4}$ pint water, and a tablespoonful of sugar. Eight tablespoonfuls to be given every $2 \frac{1}{2}$ or 3 hours. 
During 5th to oth months. - Boil together I pint of milk (5th month), $1 \frac{1}{\text { pint }}$ (6th month), $1 \frac{1}{2}$ pint of milk (7th to 9th month), with $\frac{3}{4}$ pint water, and a tablespoonful of sugar. Io to 12 tablespoonfuls to be given every 3 hours.

Use a boat-shaped feeding bottle, with a rubber teat and no tube. After each feed the bottle and teat should be well washed in hot water and soda, and kept in clean water. Never keep food over in the bottle for the next meal.

At 9 months old the milk may be thickened with one or two tablespoonfuls of cornflour, and some broth or beef tea may be given. At ro months old the child may have bread and milk, bread and butter, and cornflour or porridge, but not meat.

Children require plenty of milk until the age of 3 years, as they cannot digest the same food as grown-up persons. After 18 months they may have fresh fish, gravy and bread crumbs, eggs, \&c., once a day. Do not give them beer, spirits, wine, cheese, pickles, pastry, fruits, nuts, or sweets.

Do not give them teething powders, sleeping draughts, or soothing syrups.

\section{II.}

\section{GENERAL REQUIREMENTS.}

Keep infants warm with flannel underclothing, and take them out during the day, whenever it is fine, but not at night.

Fresh air and sunlight are nearly as important as food.

If they can be kept sufficiently warm they should sleep in cots or cradles, rather than in bed with parents; a clean box, such as an orange box, or a clothes basket will do, if a cradle is not readily obtainable. Many babies are overlaid every year from sleeping with their parents. water.

Wash them all over at least once a day with soap and warm

Rooms should be kept very clean and well ventilated, and the windows open at the top.

Public Health Department,

Finsbury Town Hall,

Rosebery Avenue, E.C. 1905. 


\section{APPENDIX XIV.}

\section{ELEMENTARY COUNSELS TO MOTHERS AND NURSES. ${ }^{-}$}

(Edited and completed by the Commission on the Hygiene of Infancy of the Academy of Medicine, Paris.)

\section{Natural Freding.}

r. The breast-feeding of the new-born infant by the mother, or, in her default, by a wet-nurse under the eyes of the family, is the method of nourishment which gives the most happy results, and diminishes to the utmost the chances of the infant dying.

2. Milk must constitute the principal nourishment of the infant during its first year at least, that is to say, until the appearance of the first 10 or 12 teeth. It is dangerous to give a solid nourishment to the infant during the first month. It must not be forgotten that it is premature feeding which makes the most victims among young infants.

3. During the two days following birth, and while waiting for the milk to come into the breasts of the mother, or the arrival of the wet-nurse, the infant may be fed with warm, slightly sweetened, water.

4. From the time that it takes the breast the infant should be fed every two hours, and less frequently during the night. The number of meals, however, should be apportioned to its needs, its appetite, and its strength.

5. An infant should never be awakened to give it the breast unless it should be very weak, or that its sleep is prolonged for more than three hours during the day, or five or six hours during the night.

6. It is very dangerous for the mother, or the nurse, to allow the infant to sleep in their bed, and the doctor should prohibit this absolutely.

7. In case of pregnancy every mother, or nurse, must gradually cease to nurse the child so as not to endanger its health.

× From Dr. Moore's Special Report on Infant Mortality in Huddersfield, 1905, in which will be found further instructions of a similar nature. 


\section{Mixed Feeding.}

8. In case of the mother not having enough milk, or of her ill-health, one may, after two or three months, or even earlier in certain circumstances, alternate the meals two or three times in the twenty-four hours with artificial foods according to the following rules.

\section{Artificial Feeding.}

9. If the mother cannot feed the child and if a wet-nurse cannot be procured, the infant must be nourished with the milk of an animal (ass, cow, or goat). From the second day after birth one gives, it may be, the milk of an ass, it may be when this cannot be obtained, goat's or cow's milk, with water added. This milk should be taken when it is possible from that first drawn, and from an animal recently delivered.

ro. The dilution of the milk of the cow, or the goat, must be made with pure boiled water, and not with infusions or decoctions. Except in the case of illness (see further on) this dilution must be made, and given, in the following proportions.

I I. During the first week, half milk and half water, two or three tablespoonfuls every two hours, thenceforward until the end of the second month, two-thirds milk and one-third water, four or five tablespoonfuls every two hours according to the tolerance of the stomach. From the commencement of the second month the dilution of the milk may be reduced to one-fourth, and the dose of the liquid increased to a half-glass about every two hours. At the third and following months one glassful should be given every three hours. It is not until the end of the third month that the milk should be given pure.

12. The quantity of diluted or pure milk varies also according to the appetite, the digestion, and the state of health or sickness of the infant, and also according to the strength and purity of the milk.

13. The quantity of cow's or goat's milk required for the feeding of the child for 24 hours must be sterilised daily after having been diluted. This sterilisation should be practised regularly by the person in charge of the infant.

14. Whatever may be the vessel used for boiling the milk, it 
must not be of tin or lead, and if the feeding-bottle is used it should not be stopped with vulcanised rubber. A tube feedingbottle is fatal, and must be absolutely prohibited. The same feeding-bottle must never be used for several infants.

r 5. These different vessels must never contain more than the quantity of milk necessary for a single repast, and the residue must be thrown out, as it may be soured.

r6. The vessels also shall be cleaned with care every time that they are used, and maintained in a state of extreme cleanliness. In the intervals between feeding, the bottle must be kept in boiled water. If these indispensable precautions are not taken, the milk newly placed in the vessels will become altered and will soon cause those accidents - colics and diarrhoas - which are the principal cause of the mortality of infants.

I7. It is for the same reason that one must avoid the use of "comforters" of whatever nature, such as one too frequently has the habit of leaving between the lips of children to calm them.

18. It must be remembered that artificial feeding considerably augments the chances of sickness and death when it is not practised in the family with minute care and by experienced persons.

19. Artificial feeding, already dangerous in itself, becomes more so as the result of crowding when it is carried on in the same place and with a large number of children.

20. Towards the seventh month one may add to sterilised milk either the yolks of eggs, baked flour of wheat, starch, oats, or tapioca, first of all made into clear stews, and always well cooked, and later on one may replace the milk by weak beef tea.

2r. Speaking generally the various compositions recommended by commercial undertakings to replace milk should be abstained from.

\section{WEANING.}

22. Weaning may be effected at the end of the ninth month, and even earlier if circumstances render it necessary; for example, when the milk of the mother or the wet-nurse becomes insufficient. But when the conditions of breast feeding remain satisfactory, it is preferable not to wean the infant until after the tenth month, or even after the first year. 
23. All solid food should be excluded from the practice of weaning until dentition is more or less advanced. It should not be carried out when the child is feverish nor during teething, nor during any illness of the child. During the interval of calm which separates the appearance of teeth, weaning may be commenced.

24. Weaning should be effected by degrees.

25. When weaning is accomplished the nourishment should be rendered more substantial little by little, by adding bread soaked in the juice of meat, or purées of farinaceous vegetables; but meat should not be given until the appearance of the first back teeth. Also cakes, all sorts of sweets, wines, and liquors should be kept out of the foods of infants.

26. Weaning only requires for the mother, or the nurse, a little attention at the moment when they cease completely to give the breast ; a few purgatives, and diuretic and acidulated drinks.

\section{Hygiene and Clothing.}

27. As soon as the child is born the midwife should especially wash the eyes with warm boiled waier. The child should be reared in a room as well aired as possible, and sufficiently warmed in winter.

28. No child should be taken out until the fifteenth day, except the external temperature should be very mild and dry. It is not to be forgotten that it is by the respiration of a too cold, or too sharp, air that the infant contracts bronchitis.

29. The toilette of the infant should be made every morning before it is put to the breast, or given food. The toilette consists of a bath or washing of the body (above all of the genital organs), and the seat (which must always be kept very clean), washing the head, and changing the linen. The binder must be retained for the first month.

30. The "maillot complet" must be absolutely rejected; that is to say, the garment which envelops and binds together with the aid of bands, \&c., the four limbs and body, because the more liberty the infant has in its movements, the more it becomes robust and well formed. Reject also every bandage which includes the head. 
3I. The child must always be clothed more or less warmly according to the country which it inhabits and to the seasons, but it must always be preserved with care from cold and from excessive heat either out of doors or indoors.

32. The child should not be allowed to walk too soon. It should be allowed to pull itself about on the floor with its own strength, and to lift itself up. The use of go-carts should be rejected.

33. The indispositions of children, such as cough, colics, diarrhœa, and vomiting, should never be neglected. A doctor should be called in from the onset.

34. It is indispensable to have the child vaccinated in the first three months, or even earlier in the presence of an epidemic of small-pox. Vaccination is the only certain preservative against this malady.

\section{APPENDIX XV.}

\section{INFANT LIFE PROTECTION ACT, 1897.}

The chief provisions of this Act are as follows :-

I. Any person retaining or receiving for hire or reward more than one infant under the age of five years for the purpose of nursing or maintaining such infants apart from their parents for a longer period than forty-eight hours, shall give notice thereof to the Local Authority. Such notice shall state the name, age, and sex of such infants, the name of the person receiving them, and the dwelling within which they are being kept, and the name and address of the person or persons from whom the infants have been received. If any such infant is removed from the care of the person who has received the infant for the purpose aforesaid, such person shall forthwith give to the Local Authority notice of the removal.

2. An inspector or other person duly appointed shall from time to time inspect any infants referred to in any notice given under this Act, and the premises in which they are retained or received, in order to satisfy himself as to the proper maintenance of such infants, or to give any necessary advice or directions as to such maintenance. 
3. It shall be the duty of the Local Authority to fix the number of infants under the age of five years which may be retained or received in any dwelling in respect of which notice has been received under the Act.

4. Any person retaining or receiving an infant under the age of two years on consideration of a sum of money not exceeding twenty pounds paid down, and without any agreement for further payment, as value for the care and bringing up of the said infant until it is reclaimed or of an age to provide for itself, shall within forty-eight hours from the time of receiving such infant give notice of the fact to the Local Authority.

5. Should any infant, in respect of which notice is required to be given under the Act, $(a)$ be kept in any house or premises which are so unfit or so overcrowded as to endanger its health; or $(b)$ be retained or received by.any person who, by reason of negligence, ignorance, or other cause, is so unfit to have its care and maintenance as to endanger its health, any inspector or other person appointed for the purpose of this Act may apply to the Local Authority for an order in writing, directing him to remove such infant to a workhouse or place of safety, until it can be restored to its relatives or guardians or be otherwise lawfully disposed of.

6. In case of the death of any infant respecting whom notice is required under the Act, the person having the care of such infant shall, within twenty-four hours of such death, cause notice thereof to be given to the coroner of the district within which the body of such infant lies.

7. Every person guilty of an offence under the Act shall be liable to a penalty not exceeding five pounds, or to imprisonment for not more than six months, as a court of summary jurisdiction may award. 


\section{INDEX}

AGE incidence of infant mortality, 9-I5

Alcoholism, maternal, 72-77

" among women, 2032 II

$" \quad$ arrests for, 204

" death rates of, 205, 34I

Anderson (Miss) on factory employment of women, 9I, 125

$n$ on importance of general hygiene, 3 I6

Ante-natal conditions, $6 \mathrm{I}-89$

$$
\begin{array}{ll}
\quad \text { infections, } 67 \\
\quad \text { toxœmias, } 69
\end{array}
$$

Appendices I.-XV., 328-35I

Artificial feeding of infants, 22I, 285

Aschong on infant feeding in Sweden, 232

Ashby on causes of infant mortality and maternal physique, 86-87

Atrophy as cause of death, 46, 5I

Australian Commonwealth, 7, 8, 9

Austria, infant mortality of, 6

" infant feeding in, 235

BALLANTYNE on ante-natal conditions, 63-66

Ballard on causes of diarrhœa, I40, I43-I45, 149-150

Bedfordshire, infant mortality in, 32-35
Bedford and Luton compared, 34 Belgium, infant mortality in, 6

Berg on infant feeding in Sweden, 232

Birmingham, housing and social conditions in I90-I96

" infant feeding in, 254

Birth rate, decline of, $3,4,5,215$

" and illegitimacy, 2II216

Blackburn, infant mortality at, 105

" meteorology at, I57

" infant feeding at, 253

Bolton, infant mortality at, I05

" meteorology at, 159

Booker on cause of diarrhcea, I46

Booth on effect of social conditions, $186-188$

" on alcoholism among women, 206-209

Brighton, meteorology at, $\mathrm{I}_{5} 6$

" infant feeding at, 249 252

Budin and Tarnier on prematurity, 79-80

Budin on diarrhœa in Paris, 285

" on infant milk depôts, 286

Burnley, infant mortality at, I05

Bury, infant mortality at, 105

CARBONIC acid gas in atmosphere, I27-128 
Carson on management of a dairy farm, 291

Causes of infant mortality, 43-60 $"$ of weaning, 249

Chalmers on causes of infant death, 58

" on meteorology of Glasgow, 160

Chili, infant mortality in, 6

Clinical record of a milk depôt, 30r-315

Colchester, infant feeding at, 253

Collett (Miss) on occupation of women, 100

$" \quad$ on poverty and infant mortality, 106, 107

Comforters, use of, 247

Condensed milk, injuriousness of, 239-253

Control of the milk supply, 318327

Convulsions as cause of death, 48

Cotton famine and infant mortality, 227

Coullett's restaurants, 26I

Crèches, 27 1-277

Creighton on infant mortality before nineteenth century, 43

Croydon, meteorology of, 157 infant feeding at, 253

Cunningham on physical standards, 86

Deane(Miss) on lead poisoning, 7 I Delépine on causes of diarrhœa, 147, 171-172

Denmark, infant mortality in, 6,7 Density of population, effect of, 26-29

Derby, infant feeding at, 237-24r

Diachylon, 81

Diarrhoea, epidemic, of infants, $48,53,139-176$

" pathology and clinical characters of, 139

" cause of, 144

A A
Diarrhœa bacteriology of, 145

" conditions favourable to, 149

" meteorology in relation to, 153

in back-to-back houses, 175

in Paris, 285

Distribution of infant mortality, 20-42

Domestic and social conditions, 177-220

Dorset, infant mortality in, 254

Dundee, effect of factory system in, $\mathrm{II}_{4}-\mathrm{II}_{7}$

EAMES on health of Kearsley, $132-$ 133

England and Wales, infant mortality of, 3, r3, 2r

English counties, infant mortality of, 20-29

Epidemic diarrhœea, 48, 53, 139I 76

Escherich on causation of diarrhœa, 145

FARR on life expectation, 180 Fatal diseases of infancy, 43-60 Fatigue and infant mortality, 112 Feeding of infants, $22 \mathrm{I}$

Finsbury, infant feeding in, 242249

" prematurity in, 46

" infant milk depôt, 289$3 \mathrm{r}_{5}$

Flies and diarrhœe, 168

Food and diarrhœa, 170

France, infant mortality in, $6,7,12$

$" \quad$ infant feeding in, 234

" milk depôts in, 286

GERMANY, infant mortality in, 6 Glasgow, infant mortality in, 13 Glibert on employment of women, II 4 
RaNSOM on diachylon, $8 \mathrm{I}$

Registrar-General on birth rate, 4-5

$"$ on age incidence of mortality, I3

" on urban and rural districts, 38

on suffocation in bed, 2 Io

Reid on infant mortality in the Potteries, 108

Robb on occupation of women at Paisley, II7

Robertson on urbanisation and infant mortality, 175

" on social conditions and infant mortality, I90-I96

") on infant feeding at Birmingham, 254

Roopa on infant mortality in Russia, 236

Ross on infant feeding in Lewis, 23I

Rowntree on poverty and infant mortality at York, I89 " on infant feeding at York, 254

Rural and urban district mortality, 38-42

Russia, infant mortality in, 6, 236

SALFORD, infant feeding at, 254

Sandilands on infant feeding, 243

Sanitary conveniences in workshops, I29-I3I

Saxony, infant mortality in, 7 , II 8-120,

Scotland, infant mortality in, 29-3I infant feeding in, 229-23I

Shadwell on infant mortality in Saxony and Westphalia, II8

on alcoholism, 209

Shawe on alcoholism and infant mortality, 74

Simon on sanitary state of English people, 92-97
Sinclair on maternal physique, 89

Spain, infant mortality in, 6

Squire (Miss) on illegal employment of women, 124

Stark on infant feeding in Scotland, 229

Stockport, infant feeding at, 253

Straus on pasteurised milk, 287

Suffocation of infants in bed, 2 ro2 I I

Sullivan on alcoholism, 72

Sweden, infant mortality in, 7,8

Switzerland, infant mortality in, 6

Sydney, infant mortality of, 9

Sykes on age incidence of death, I2

Syphilis, 67-69

TARNIER and Budin on prematurity, 79

Tatham on illegitimacy and infant mortality, 15-213

n on causes of infant mortality, 45,53

Temperature of soil and diarrhoa, $153-170$

Time-cribbing, 12I

Tropics, infant mortality in, 7,8

URBAN and rural districts compared, 38, 52

Urbanisation, effect on infant mortality, 31, 178-203

$" \quad$ effect on epidemic diarrhoa, 173-176 increase of, 179

WEANing, causes of, 249

Wellington, infant mortality of, 9

Westphalia, infant mortality in, II9

Wiglesworth on alcoholism and infant mortality, 76

Wiltshire, infant mortality of, 35

YoRK, poverty and infant mortality at, $\mathbf{1 8 9}$

" infant feeding at, 254

UNWIN BROTHERS, LIMITED, PRINTERS, WOKING AND LONDON. 



